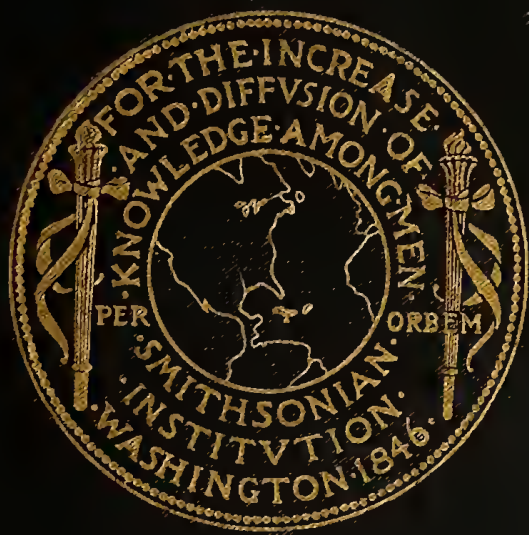

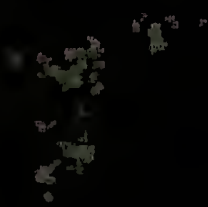

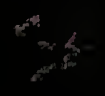









\title{
OSTEOLOGY OF THE CARNIVOROUS DINOSAURIA IN THE UNITED STATES NATIONAL MUSEUM, WITH SPECIAL REFERENCE TO THE GENERA ANTRODEMUS (ALLOSAURUS) AND CERATOSAURUS
}

\author{
BY \\ CHARLES WHITNEY GILMORE \\ Associate Curator, Division of Paleontology \\ United States National Museum
}

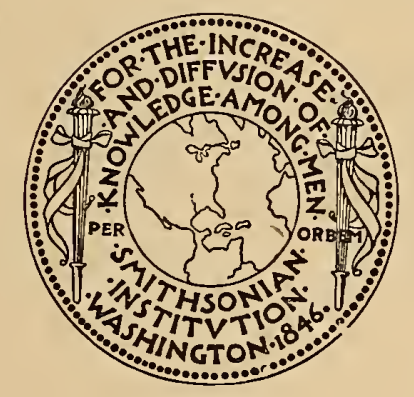

WASHINGTON

GOVERNMENT PRINTING OFFICE 1920 
BULLETIN OF THE UNITED STATES National MUSEUM. 


\section{ADVERTISEMENT.}

The scientific publications of the Uniter States National Museum consists of two series, the Proceedings and the Bulletins.

The Proceedings, the first volume of which was issued in 1878, are intended primarily as a medium for the publication of original, and usually brief, papers based on the collections of the National Museum, presenting newly-acquired facts in zoology, geology, and anthropology, including descriptions of new forms of animals, and revisions of limited groups. One or two volumes are issued annually and distributed to libraries and scientific organizations. A limited number of copies of each paper, in pamphlet form, is distributed to specialists and others interested in the different subjects as soon as printed. The date of publication is printed on each paper, and these dates are also recorded in the tables of contents of the volumes.

The Bulletins, the first of which was issued in 1875 , consist of a series of separate publications comprising chiefiy monographs of large zoological groups and other general systematic treatises (occasionally in several volumes), faunal works, reports of expeditions, and catalogues of type-specimens, special collections, etc. The majority of the volumes are octavos, but a quarto size has been adopted in a few instances in which large plates were regarded as indispensable.

Since 1902 a series of octavo volumes containing papers relating to the botanical collections of the Museum, and known as the Contributions from the National Herbarium, has been published as bulletins.

The present work forms No. 110 of the Bulletin series.

Williair DEC. Ravenel, Administrative Assistant to the Secretary, In charge of the United States National Museum.

Washington, D. C., June 20, 1920. 

TABLE OF CONTENTS.

Introduction.

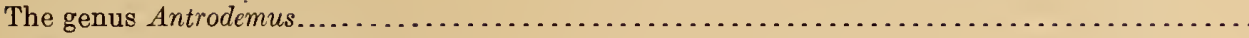

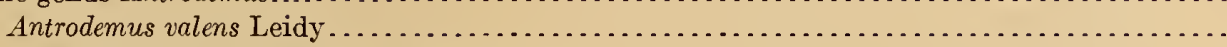

Osteology of Antrodemus. . . . . . . . . . . . . . . . . . . . . . . . . . . . . . . . .

Summary of Antrodemus specimens. . . . . . . . . . . . . . . . . . . . . . . .

Skull.

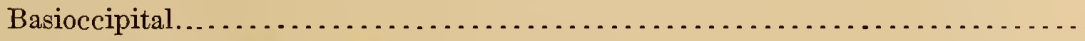

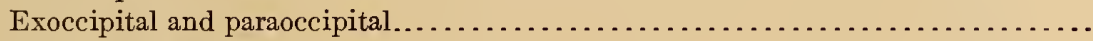

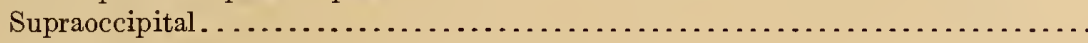

Alisphenoid.

Basisphenoid.

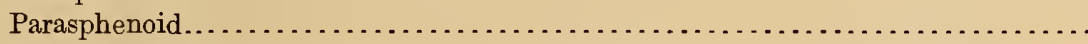

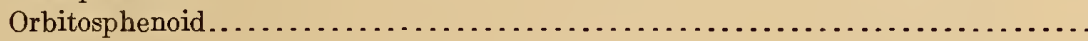

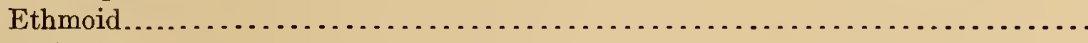

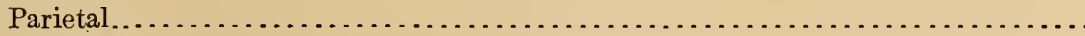

Frontals.

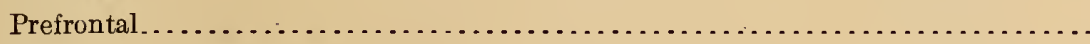

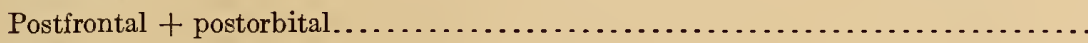

Proötic.

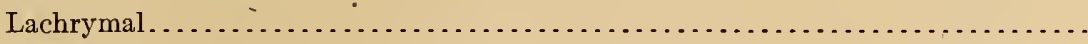

Nasals.

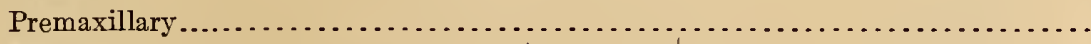

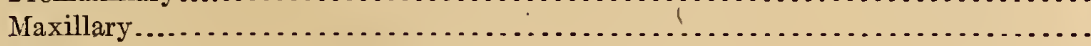

Jugal.

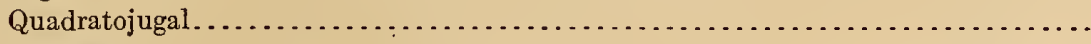

Quadrate...

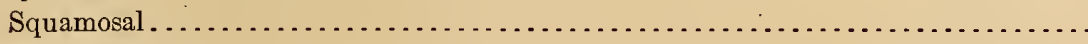

Ectopterygoid.

Pterygoid.

Comparative measurements of Antrodemus and Ceratosaurus skulls...........

Lower jaw.

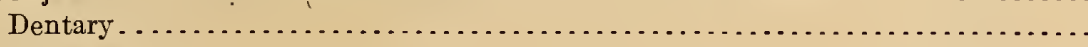

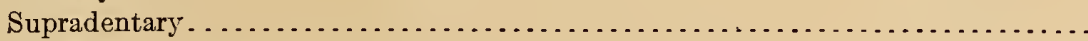

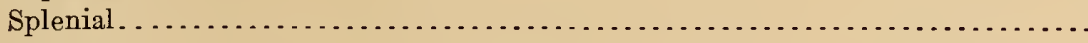

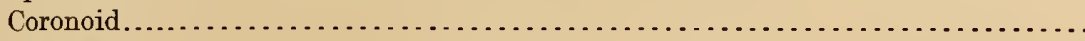

Angular

Surangular.

Articular

External openings in the skull

Lateral temporal fenestra.

Orbital opening.

First antiorbital fenestra

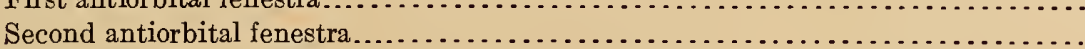

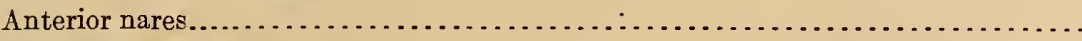

Supratemporal fossa...

Teeth. 
The genus Antrodemus-Continued.

Osteology Antrodemus-Continued.

Page.

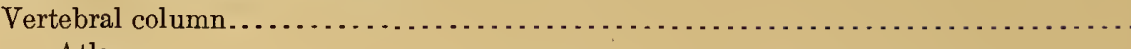

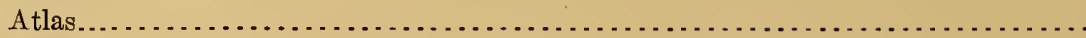

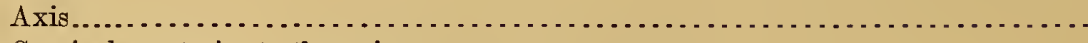

Cervicals posterior to the axis. . . . .

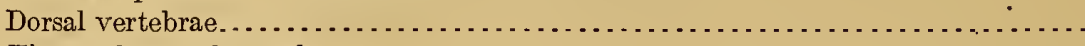

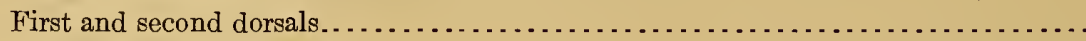

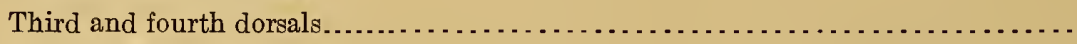

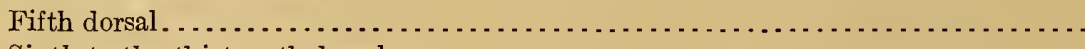

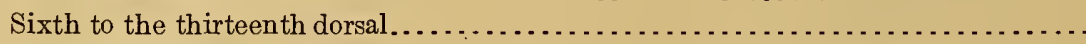

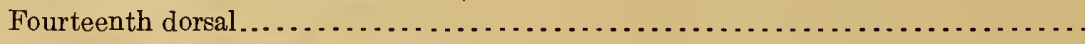

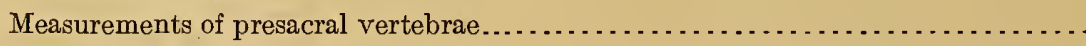

Sacral vertebrae.

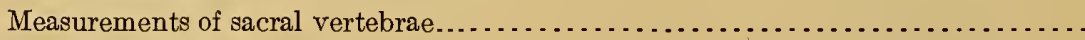

Caudal vertebrae. . . . . . . . . . . . . . . . . . . . . . . . . . . . . . . . . . .

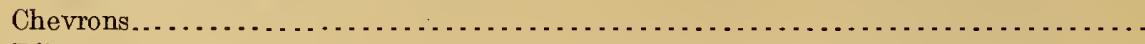

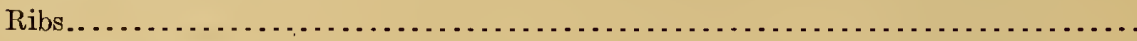

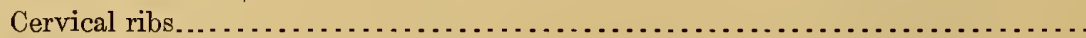

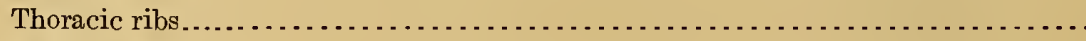

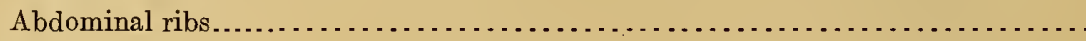

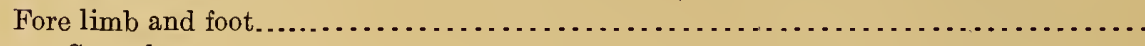

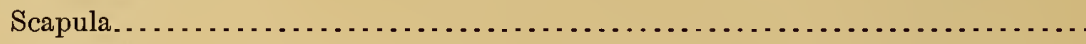

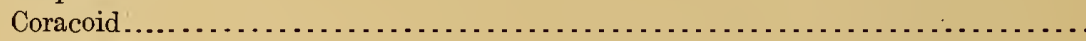

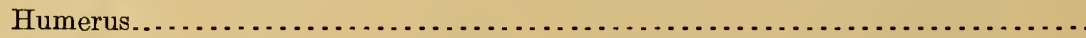

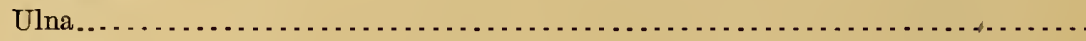

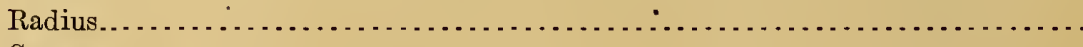

Carpus... . . . . . . . . .

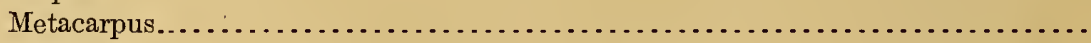

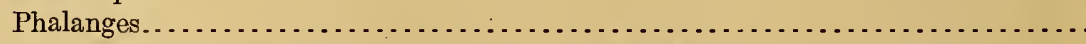

Phalangial formulae of various Theropod Dinosauria $\ldots \ldots \ldots \ldots \ldots \ldots . . .6 \ldots$

Pelvis.

Ilium. .

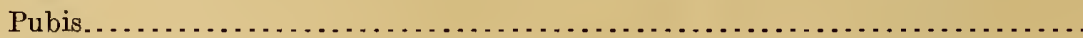

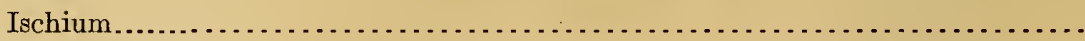

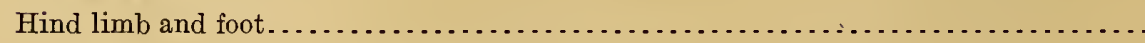

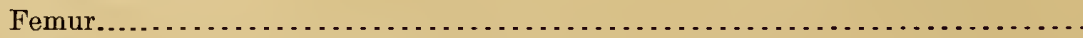

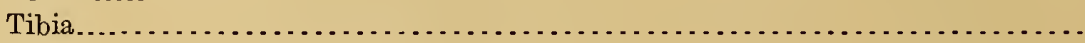

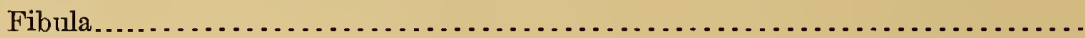

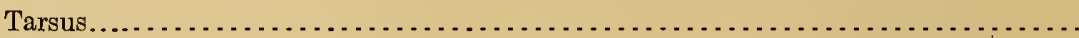

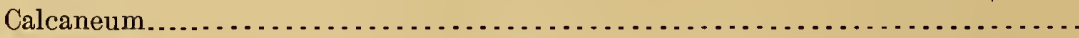

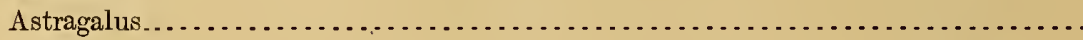

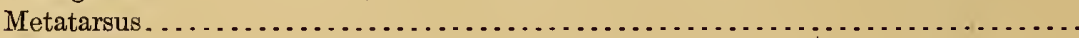

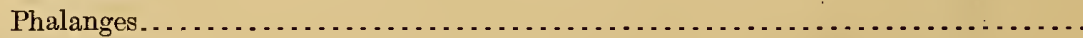

Family Ceratosauridae.

Family characters........

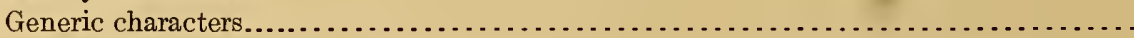

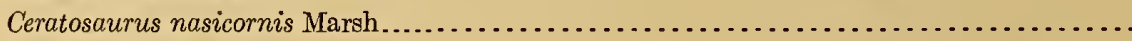

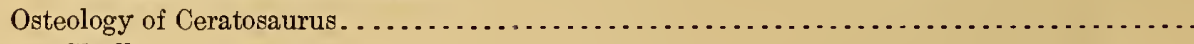

Skull

Basioccipital

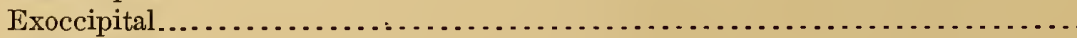

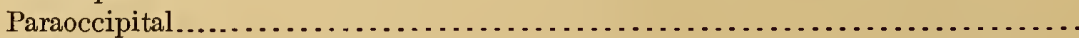

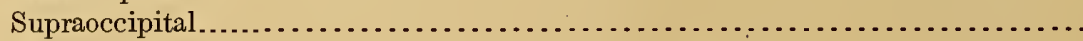

Alisphenoid.

31

32

34

36

37

37

39

39 
Family Ceratosauridae--Continued.

Osteology of Ceratosaurus-Continued.

Skull-Continued.

Page.

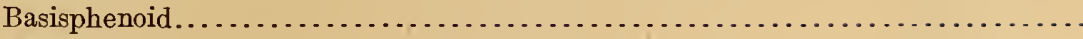

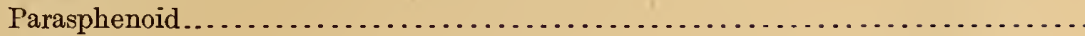

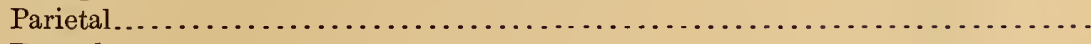

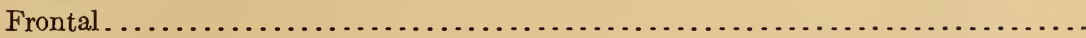

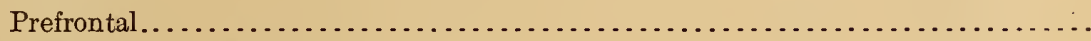

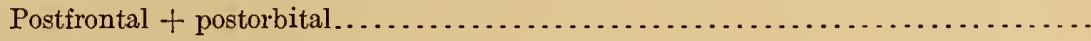

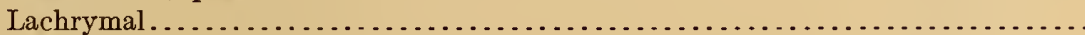

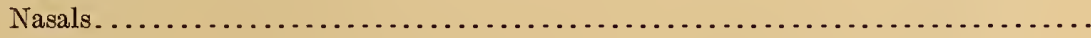

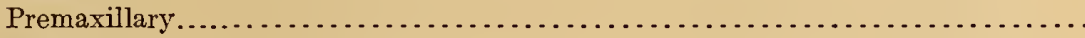

Maxillary

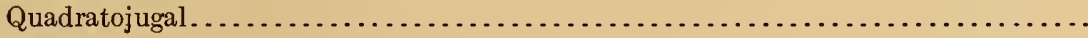

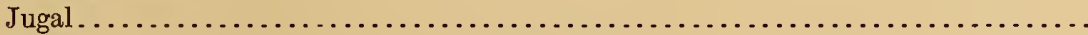

Quadrate.

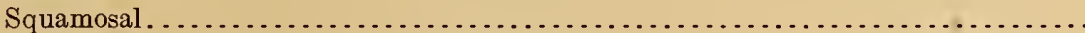

Palate...

Comparative measurements of Ceratosaurus and Antrodemus skulls...........

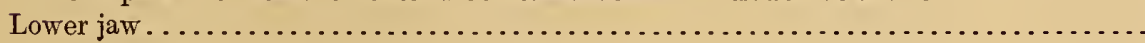

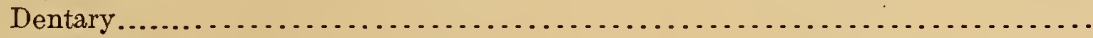

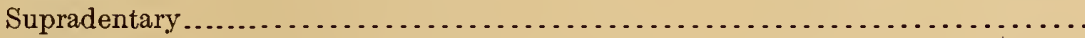

Angular...

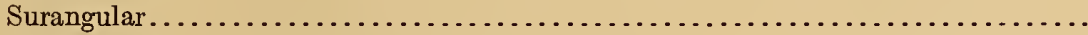

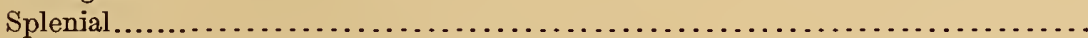

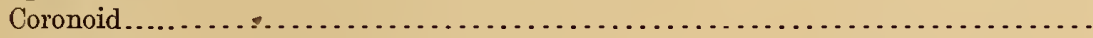

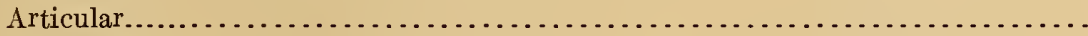

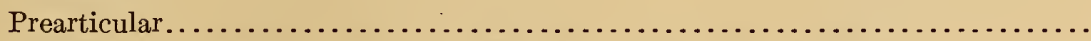

Comparative measurements of Ceratosaurus and Antrodemus lower jaws.......... Hyoid.

Teeth.

Brain

Vertebral column

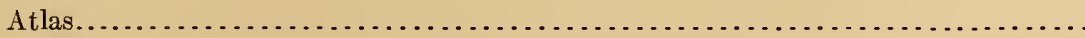

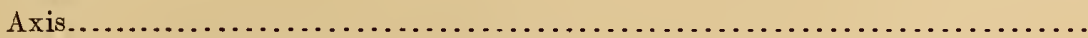

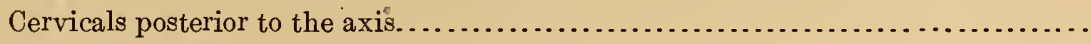

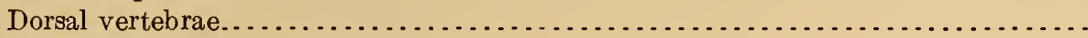

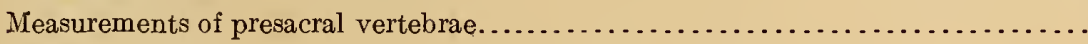

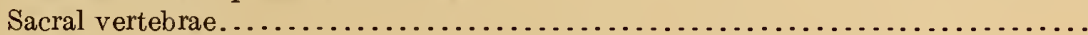

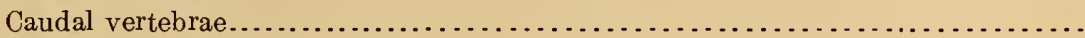

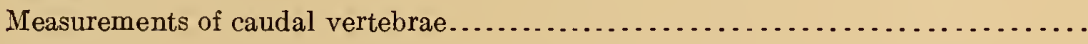

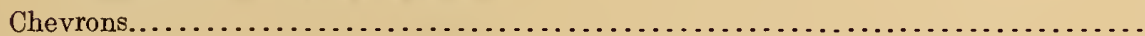

Ribs.

Thoracic ribs..

Abdominal ribs.

Shoulder girdle.

Scapula.

Fore limb and foot.

Ulna...

Radius.

Forefoot

Carpus.

Metacarpus.

Phalanges.
80

80

80

81

81

81

81

82

82

83

83

83

84

84

84

88

88

88

89

89

90

90

90

90

90

91

92

92

93

93

94

95

95

96

97

97

98

100

100

101

101

102

102

102

103

103

103

104

104

104

105 
Family C'eratosauridae-Continued.

Osteology of Ceratosaurus-Continued. Page.

Pelvis.

Ilium....

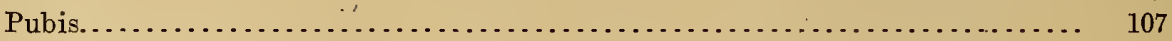

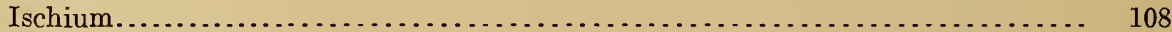

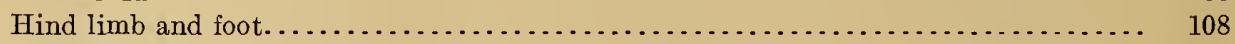

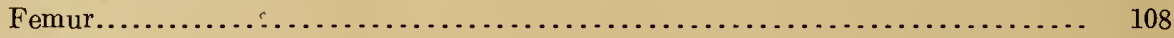

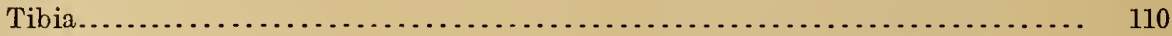

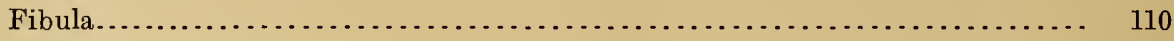

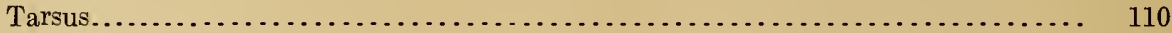

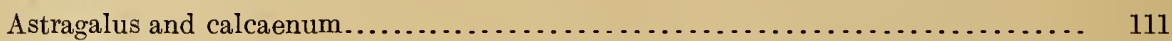

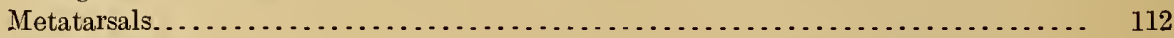

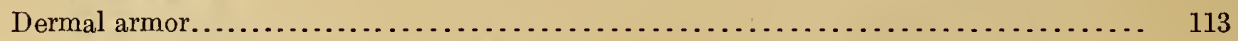

Mounted skeleton of Ceratosaurus nasicornis Marsh . . . . . . . . . . . . . . . . . . . . . . . 114

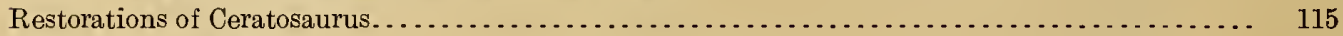

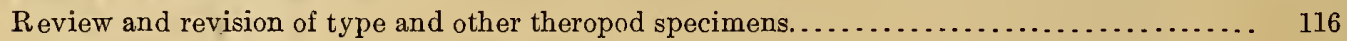

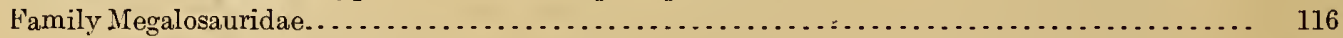

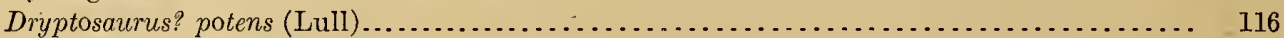

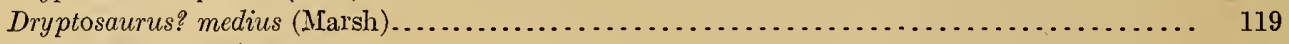

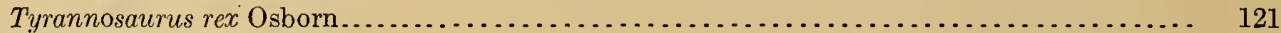

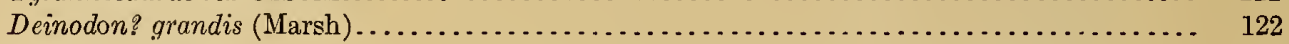

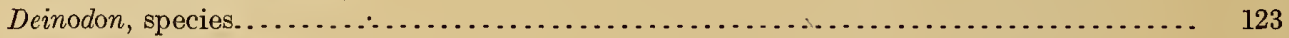

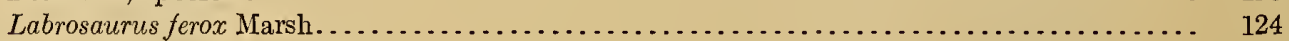

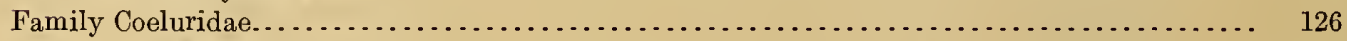

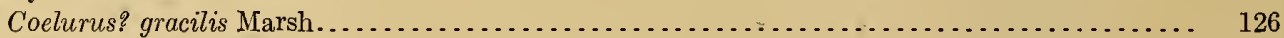

Coelurus fragilis Marsh. . . . . . . . . . . . . . . . . . . . . . . . . . . . . . . . . . . . . 127

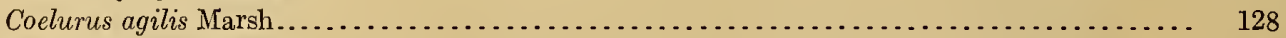

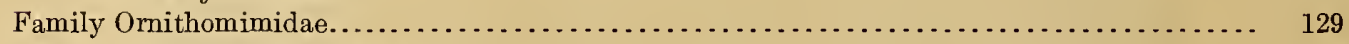

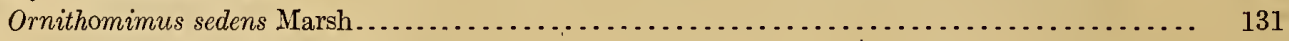

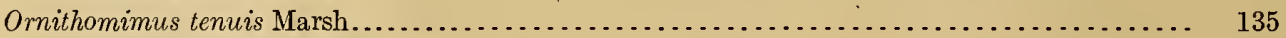

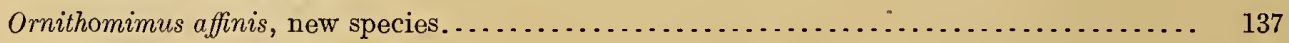

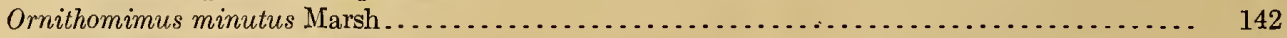

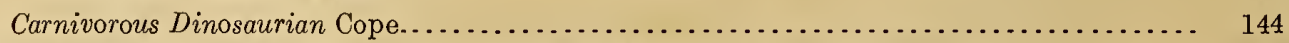

Observations on the progressive structural modifications of the Theropod skeleton.......... 144

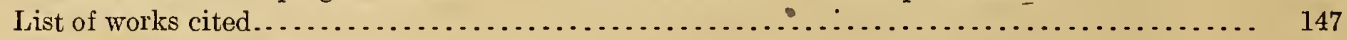

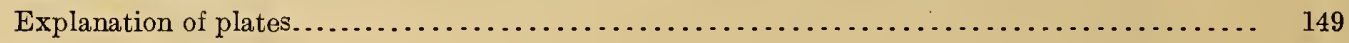

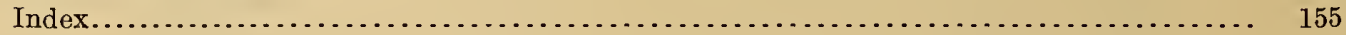




\section{LIST OF ILLUSTRATIONS.}

PLATES.

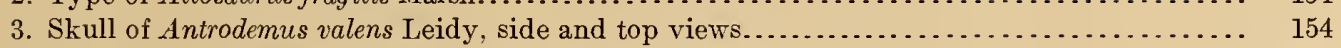

4. Skull of Antrodemus valens Leidy, side and top views. . . . . . . . . . . . . . . . . . . . 154

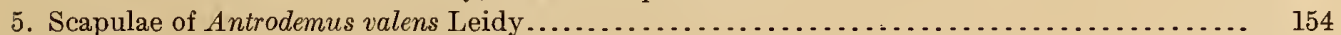

6. Humerus of Antrodemus valens Leidy . . . . . . . . . . . . . . . . . . . . . . . . . . . 154

7. Radius, ulna, fore and hind feet of Antrodemus valcns Leidy . . . . . . . . . . . . . . . . . 154

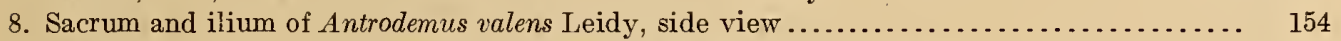

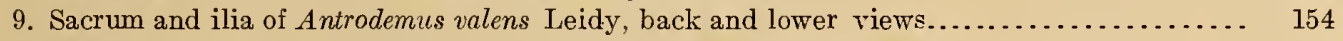

10. Sacrum and ilia of Antrodemus valens Leidy, front and side views.................. 154

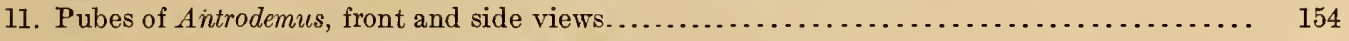

12. Ischia of Antrodemus valens Leidy, all aspects. . . . . . . . . . . . . . . . . . . . . . 154

13. Hind limbs, pelvis and sacrum of Antrodemus valens Leidy, lateral view............... 154

14. Femur of Antrodemus valens Leidy, all aspects. . . . . . . . . . . . . . . . . . . . . . . 154

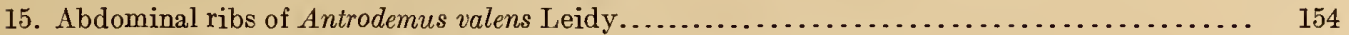

16. Articulated skeleton and restoration of Antrodemus valens Leidy................... 154

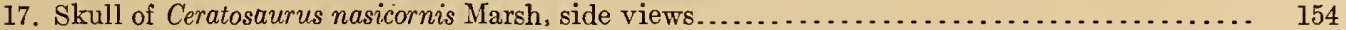

18. Skull of Ceratosaurus nasicornis Marsh, side and top views...................... 154

19. Atlas and axis of Ceratosaurus nasicornis Marsh, all aspects....................... 154

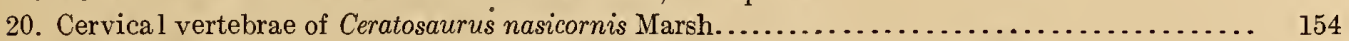

21. Sacrum and pelvis of Ceratosaurus nasicornis Marsh, ventral and front views............ 154

22. Caudal vertebrae of Ceratosaurus nasicornis Marsh, side and ventral views...............

23. Sacrum and pelvis of Ceratosaurus nasicornis Marsh. side view.................... 154

24. Metatarsals of Ceratosaurus nasicornis Marsh, front, sides, and top................... 154

25. Metatarsals of Ceratosaurus nasicornis Marsh, back and end views................. 154

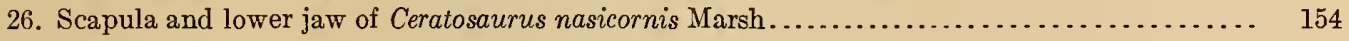

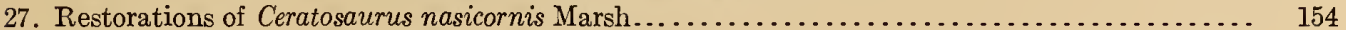

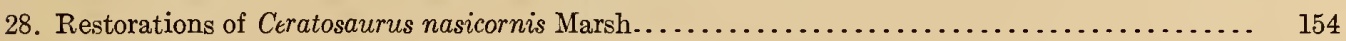

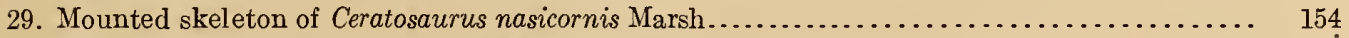

30. Skeleton of Ceratosaurus nasicornis Marsh . . . . . . . . . . . . . . . . . . . . . . . . . . . 154

31. Restoration of Ceratosaurus nasicornis Marsh . . . . . . . . . . . . . . . . . . . . . . . . . 154

32. Caudal vertebrae of Dryptosaurus? potens (Lull) and Antrodemus valens Leidy .............. 154

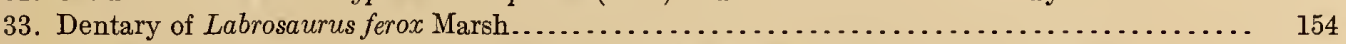

34. Bones of Dryptosaurus? medius (Marsh), Coelurus agilis and Coelurus fragilis Marsh.........

35. Pelvis and caudals of Ornithomimus sedens Marsh; Skeleton of Ornithomimus altus Lambe... 154

36. Brain of Ceratosaurus nasicornis Marsh; unguals of Coelurus? gracilis Marsh and unidentified dinosaur

TEXT FIGURES.

1. Skull of Antrodemus valens Leidy, side view . . . . . . . . . . . . . . . . . . . . . .

2. Skull and lower jaw of Tyrannosaurus rex Osborn, side view. . . . . . . . . . . . . . . . .

3. Skull and lower jaw of Antrodemus valens Leidy, side view . . . . . . . . . . . . . . . . . .

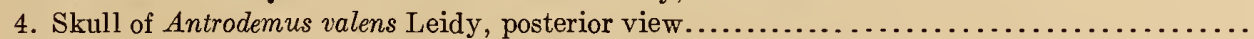

5. Skull of Antrodemus valens Leidy, superior view . . . . . . . . . . . . . . . . . . . . . .

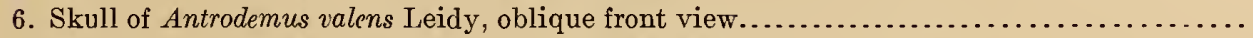

7. Left prefrontal of Antrodemus valens, Leidy, lateral and internal views. 
8. Left lachrumal of Antrodemus valens $\dot{L}$ Page.

9. Left nasal of Antrodemus valens Leidy, lateral and ventral views.......................... 18

10. Right premaxillary of Antrodemus valens Leidy, lateral and internal views. ............ 19

11. Right premaxillary of Antrodemus, species ? anterior, lateral and internal views......... 20

12. Left maxillary of Antrodemus valens Leidy, internal view...................... 21

13. Right jugal, quadratojugal, and quadrate of Antrodemus valens Leidy, internal view........ 23

14. Right ectopterygoid of Antrodemus valens Leidy, superior view.................... 24

15. Posterior end of right ramus of Antrodemus valens Leidy, lateral, internal, and superior views. 27

16. Brain case of Antrodemus valens Leidy, oblique side view........................ 29

17. Atlas and axis of Antrodemus valens Leidy, lateral, anterior, and ventral views............ 33

18. Articulated cervical vertebrae of Antrodemus valens Leidy, lateral view............... 34

19. Fourth cervical vertebra of Antrodemus valens leidy, anterior view ................. 35

20. Ninth cervical vertebra of Antrodemus valens Leidy, anterior view...................... 36

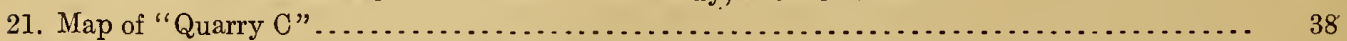

22. Third dorsal vertebra of Antrodemus valens Leidy, lateral view..................... 39

23. Fourth dorsal vertebra of Antrodemus valens Leidy, lateral and anterior views . . . . . . . . 40

24. Sixth dorsal vertebra of Antrodemus valens Leidy, lateral view..................... 40

25. Ninth dorsal vertebra of Antrodemus valens Leidy, lateral and anterior views.............. 41

26. Tenth dorsal vertebra of $A$ trodemus valens Leidy, lateral view...................... 42

27. Fourteenth dorsal vertebra of Antrodemus valens Leidy, lateral and anterior views......... 44

28. Sixth caudal vertebra of Antrodemus valens Leidy, lateral view. . . . . . . . . . . . . . . . 46

29. Median caudal vertebra of Antrodemus valens Leidy, lateral view................... 47

30. Caudal vertebra from distal part of the tail of Antrodemus valens Leidy, lateral view....... 47

31. Series of five distal caudal vertebrae of Antrodemus valens Leidy, lateral view............. 48

32. Anterior chevron of Antrodemus valens Leidy, lateral and posterior views.............. 49

33. Right cervical rib of third cervical vertebra of Antrodemus valens Leidy, two internal views. 49

34. Right cervical rib of eigth cervical vertebra of Antrodemus valens Leidy, internal view..... 50

35. First thoracic rib of Antrodemus valens Leidy, internal view. . . . . . . . . . . . . . . 51

36. Right thoracic ribs of Antrodemus valens Leidy anterior view...................... 52

37. Double abdominal rib of Antrodemus valens Leidy, ventral views . . . . . . . . . . . . . 53

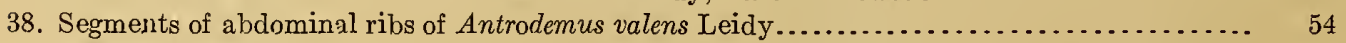

39. Transverse section of abdominal basket of Antrodemus valens Leidy................... 55

40. Right fore limb and foot of Antrodemus valens Leidy, lateral view ................... 57

41. Right humerus of Antrodemus valens Leidy, anterior and posterior views............... 59

42. Left ulna of Antrodemus valens Leidy, posterior view . . . . . . . . . . . . . . . . . . . . . 60

43. Right radius of Antrodemus valens Leidy, internal view . . . . . . . . . . . . . . . . 61

44. Carpal bones of right foot of Antrodemus valens Leidy, distal view .................. 61

45. Digits of right fore foot of Antrodemus valens Leidy, lateral view .................... 62

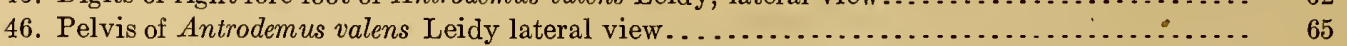

47: Right pubis of Antrodemus valens Leidy, lateral and distal views................... 67

48. Left tibia, fibula, astragalus, and calcaneum of Antrodemus valens Leidy, anterior, lateral and

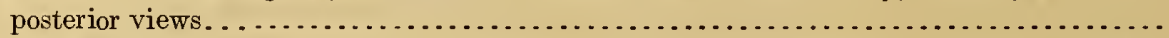

49. Left tibia, fibula, astragalus, and calcaneum of Antrodemus valens Leidy, proximal and distal

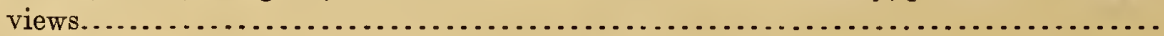

50. Left astragalus of Antrodemus valens Leidy, anterior, dorsal and lateral views.............

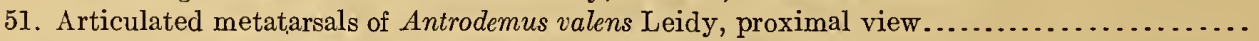

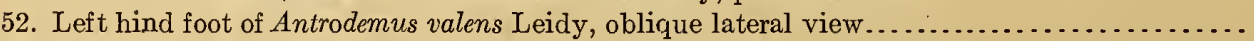

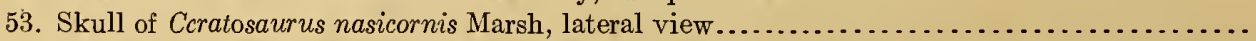

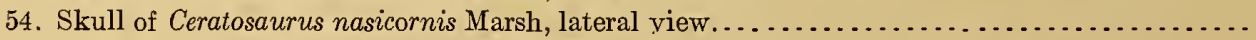

55. Left ramus Ceratosaurus nasicornis Marsh, internal view ....................................

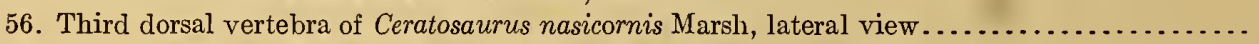

57. Fifth caudal vertebra with chevron of Ceratosaurus nasicornis Marsh, lateral view............

58. Left fore limb and foot of Ceratosaurus nàsicornis Marsh, lateral view. . . . . . . . . . . . . . .

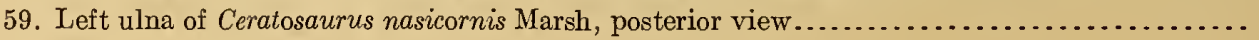


60. Left radius, ulna and foot of Ceratosaurus nasicornis Marsh, anterior view. . . .......... 104

61. Left radius of Ceratosaurus nasicornis Marsh, posterior view ...................... 105

62. Left fore foot of Ceratosaurus nasicornis Marsh, anterior view . . . . . . . . . . . . . . . 105

63. Pelvis of Ceratosaurus nasicornis Marsh, lateral view............................ 107

64. Right femur of Ceratosaurus nasicornics Marsh, front, inside and back views. ............ 109

65. Right tibia, fibula, astragalus and calcaneum of Ceratosaurus nasicornis Marsh, front, side and back views...................................................... 111

66. Anterior caudal vertebra of Dryptosaurus? potens (Lull) ...................... 117

67. Sacrum and ilia of Ornithomimus sedens Marsh, inferior view ...................... 132

68. First caudal vertebra of Ornithomimus sedens Marsh, side and front views. . . ............ 134

69. Caudal vertebrae of Ornithomimus sedens Marsh, side and front views. . . . . . . . . . . .... 134

70. Metatarsal of Ornithomimus tenuis Marsh, all views............................ 136

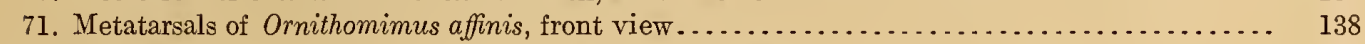

72. Metatarsal of Ornithomimus affinis, back and side views......................... 139

73. Proximal phalanx of Ornithomimus affinis, front and side views......................... 139

74. Second phalanx of Ornithomimus affinis, front and side views. . . . . . . . . . . . . . 140

75. Second phalanx of Ornithomimus affinis, front view............................ 140

76. Ungual phalanx of Ornithomimus affinis, top and side views....................... 141

77. Caudal vertebra of Ornithomimus affinis, top and side views...................... 141

78. Sacral vertebral centrum Ornithomimus affinis, dorsal and lateral views ............... 142

79. Metatarsal of Ornithomimus minutus Marsh............................... 143 



\title{
OSTEOLOGY OF THE CARNIVOROUS DINOSAURIA IN THE UNITED STATES NATIONAL MUSEUM, WITH SPECIAL REFERENCE TO THE GENERA ANTRODEMUS (ALLOSAURUS) AND CERATOSAURUS.
}

\author{
By Chäles Whitney Grlmore, \\ Associate Curator, Division of Paleontology, United States National Museum.
}

\section{INTRODUCTION.}

In the present paper it is proposed to discuss all of the Theropodous dinosaur specimens contained in the collections of the United States National Museum. The material at hand includes the remains of many individuals, several of which are represented by a considerable part of the skeleton; there are also quite a large number of separate bones. Of the associated skeletons the type of Ceratosaurus nasicornis Marsh is worthy of special mention, for it comprises parts of almost the entire skeleton, and was to a considerable extent found articulated. Although this specimen was found more than 30 years ago it is still the most perfect example of the genus yet discovered. A specimen of Antrodemus Leidy originally described and figured as Allosaurus fragilis consisting of the skull and lower jaws, presacral vertebrae, complete sacrum, and 30 or more caudal vertebrae, pelvis, ribs, and all four limbs and feet, is of interest as being the individual of which Marsh published illustrations of the articulated hind limb and pelvis (as fig. 2, pl. 11), in Dinosaurs of North America. A second specimen, No. 8367, U.S.N.M., may also be mentioned not only on account of there being a considerable part of the skeleton but also because of the remarkably fine state of preservation of the bones.

The considerable number of type specimens, even though many are fragmentary, add much to the importance of this collection of carnivorous dinosaur remains in the United States National Museum. These are: Ceratosaurus nasicornis Marsh, Allosaurus medius Marsh, Labrosaurus ferox Marsh, Antrodemus valens Leidy, Creosaurus potens Lull, Coelurus gracitis Marsh, Ornithomimus sedens Marsh, and $O$. tenuis Marsh. The type specimens of Ornithomimus minutus Marsh and $O$. grandis Marsh should be in these collections, but I have been unable to positively identify them. Several of these types have been only too briefly described, and a number of them have never been figured. All of these are here illustrated, redescribed, and the information concerning them brought up to date. This procedure it is hoped will make them more fully available to future students of the Theropoda.

One of the interesting discoveries resulting from this work was the recognition of an Ornithomimid dinosaur among the materials from the Arundel formation of Maryland, here made the type of the new species Ornithomimus affinis. It records the first occurrence of a member of this family east of the Mississippi River, and also its first occurrence in a formation older than Upper Cretaceous. 
These specimens were secured almost entirely through transfer from the United States Geological Survey, having been collected by field parties working under the direction of the late Prof. Othniel Charles Marsh. When received at the National Museum in 1898 and 1899 only a small part of the carnivore material was in condition for study. The preparation of this material was begun in 1911 and has continued, barring interruptions, up to the close of the year 1918. Practically all of the known Theropod specimens in the collection have been prepared and are now available for study and exhibition purposes.

This preparatory work has been done by Messrs. N. H. Boss, G. B. Giles, John M. Barrett, and Louis Goldberg, and they are to be highly commended for the efficiency and skill displayed in extracting these delicate fossils from a most refractory matrix.

Many of the wash drawings which are here reproduced through the courtesy of the United States Geological Survey were made by the late Mr. Frederick Berger and were prepared under the direction of the late Prof. O. C. Marsh. The later drawings are nearly all the work of Mr. Rudolph Weber. The photographs were made by the late Mr. T. W. Smillie, and his successor, Mr. L. M. Beeson, both of the United State National Museum.

I wish to acknowledge here my indebtedness to Dr. George P. Merrill, head curator of geology, United States National Museum, for the confidence expressed by his unfailing support of all things pertaining to the preparation of this paper, which extended over such a long period of time. I also wish to thank my colleagues, Mr. J. W. Gidley and Dr. O. P. Hay, for invaluable advice on numerous occasions; and especially do I appreciate the generosity of Mr. Walter Granger, of the American Museum of Natural History, in supplying me with data and photographs of Antrodemus specimens in advance of the appearance of his article on the same subject.

\section{THE GENUS ANTRODEMUS LEIDY.}

In $1870^{1}$ Prof. Joseph Leidy described the posterior half of a caudal centrum to which he gave the name Poicilopleuron ${ }^{2}$ valens, and at the same time proposed the generic name Antrodemus in the event of more adequate material showing characters that would distinguish it generically from the European saurian Poicilopleuron.

Three years later, 1873, Leidy republished with a few emendations his original description, ${ }^{3}$ illustrated by three views of the type specimen. He recognized the dinosaurian nature of the animal as well as its Theropod affinities. The text of this paper was under the caption Poicilopleuron valens, but in the explanation of the plate illustrations they were correctly designated as Antrodemus.

In $1890^{4}$ Zittel referred the genus to the family Megalosauridae.

In $1901^{5}$ Hay referred to this genus all of the described species of the genus Labrosaurus, but in a later article ${ }^{6}$ shows that no sufficient reason existed for dis placing Marsh's generic name in favor of Antrodemus.

1 Proc. Acad. Nat. Sci. Phila., 1870, p. 3 .

${ }^{2}$ In the literature it is also found spelled Poikilopleuron and Poekilopleuron.

3 Extinct Vert. Fauna West. Terr., 1878, pp. 267-279, pl. 15, figs. 16-18.

4 Handbuch der Palaeontologie, 1890, pt. 1, vol. 3, p. 722.

6 Bull. No. 179, U.S. Geol. Survey, 1901, p. 489.

6 Proc. U.S. Nat. Mus., 1908, vol. 35, p. 353. 
During the half century that has elapsed since Antrodemus was established, it will be observed from the above review, but little attention has been given this genus, due, no doubt, to the scanty materials on which it was founded.

Recently I have made a very careful comparison of the type specimen of Antrodemus valens with the anterior caudal vertebrae of No. 8367 U.S.N.M., a specimen previously identified as Allosaurus fragilis Marsh, and such close resemblances were found as to indicate their generic identity.

In plate 1 , figures 1 to 6 , is shown, in three aspects, comparative views of the genotype of Antrodemus with a caudal of corresponding size of the above specimen. Their close resemblance down to the minutest details is clearly indicated. Their comparative measurements are as follows:

Greatest vertical diameter of posterior end of centrum .....................

Greatest transverse diameter of same.....................................

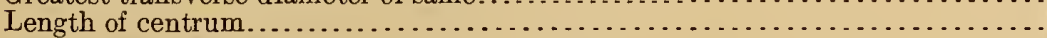

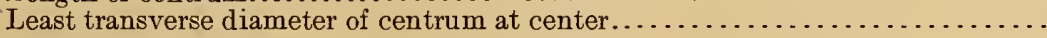

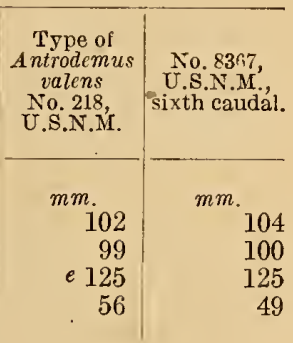

$e$ Estimated.

The medullary cavities within the body of the centrum are larger in the genotype than in No. 8367, but this may be due to a slight difference in the position of the point where the cross section was taken. At most it is only a difference of degree and certainly does not indicate any important structural modification.

Unfortunately direct comparison can not be made with the genotype of Allosaurus, inasmuch as no anterior caudals are preserved with that specimen. The so-called caudal mentioned in Marsh's original description, below, turns out to be the damaged centrum of a dorsal vertebra. See plate 2, fig. 2.

The original description ${ }^{1}$ of Allosaurus fragilis Marsh consists of the following:

This genus may be distinguished from any known Dinosaurs by the vertebrae which are peculiarly modified to insure lightness. Although apparently not pneumatic, they have the weight of the centra greatly reduced by deep excavations in the sides. Some of them have the centra hourglass in form, the middle part being so diminished as to greatly reduce the strength. The vertebrae preserved are biconcave, with shallow cavities. The feet bones referred to this species are very slender. A Iumbar vertebra has its centrum $105 \mathrm{~mm}$. in length, and $89 \mathrm{~mm}$. in least transverse diameter. An anterior caudal, $85 \mathrm{~mm}$. long, has its centrum so much constricted that its least transverse diameter is $38 \mathrm{~mm}$., while its anterior face is $90 \mathrm{~mm}$. in transverse diameter.

The animal indicated by the remains preserved was from 15 to 20 feet in length. All the known specimens are from the upper Jurassic of Colorado.

The type of Allosaurus fragilis Marsh is in the Peabody Museum of Yale University, and in a recent letter Professor Lull informs me it is from "Garden Park," near Canon City, Fremont County, Colorado, collected by B. F. Mudge in 1877. It bears the catalogue number 1930 of the Yale Museum. The type material is 
from the same locality as specimen No. 4734 to be described here, and possibly from the same quarry. The fore and hind limbs (No. 4734 and 4735 U.S.N.M.) figured so widely by Marsh do not pertain to the type specimen, although such reference ${ }^{1}$ has been made regarding them.

In compliance with my request Prof. R. S. Lull, of the Yale University Museum, very kindly forwarded plaster copies of all of the bones comprising the type specimen of Allosaurus fragitis Marsh. They consist of a well-preserved tooth, two dorsal centra and the proximal phalanx of digit III of the right hind foot. The vertebral centra are considerably damaged (figs. 2 and 3, pl. 2), reproduced here from a photograph made of the casts, and both pertain to the posterior dorsal region, notwithstanding Marsh's earlier determination that the smaller one of the two belonged to the caudal series. These casts have been carefully compared with the homologous parts of a very complete skeleton, No. 4734, U.S.N.M., from the same locality as the type, a specimen which Marsh had previously identified as Allosaurus fragitis, and of which he published an illustration of the articulated pelvis, hind limb and foot ${ }^{2}$ (pl.13). A considerable part of the tail of this specimen is missing, and it can not, therefore, be directly compared with the genotype of Antrodemus. Compared with No. 8367, U.S.N.M., consisting of a well-preserved though not a complete backbone and other skeletal parts, shows these two specimens as unquestionably belonging to the same genus, and this latter specimen is the link in the chain that enables me for the first time to correctly determine the true affinities of the caudal centrum on which the genus Antrodemus is founded. That all of these specimens belong to the same genus there now seems to be but little doubt.

The fragmentary nature of the type specimens of Antrodemus and Allosaurus renders the proper disposition of these genera a most perplexing problem. In this connection the following nomenclatural propositions present themselves:

1. Regard Allosaurus fragitis to be a synonym of Antrodemus valens, because of the very close resemblances pointed out in the preceding paragraphs.

2. Regard the type of Antrodemus valens as an indeterminate specimen, and continue the use of Allosaurus fragitis, characterizing it on the splendidly preserved topotype No. 4734, U.S.N.M., to which Marsh has applied his name, a name that has become well established both in this country and abroad.

3. Regard both the types of Allosaurus fragitis and Antrodemus valens as being indeterminate and create a new genus and species based on an adequate specimen.

On account of the close resemblances, down almost to the minutest details, between the type of Antrodemus valens, fragmentary though it is, and the corresponding bone in an adequate specimen shown to be the same as the topotype of Allosaurus fragilis, the first proposition set forth above seems to me the logical one to adopt in the present case.

It is anticipated that some paleontologists will contend that there is no justification for superseding the long-established and well-known name Allosaurus by the earlier and little known Antrodemus, and that it would be better to either disregard the law of priority, or else consider the type of Antrodemus as being an

\footnotetext{
I Hay, O. P., Proc. U. S. Nat. Mus., vol. 35, 1903, p. 355. 
indeterminate specimen. Were Allosaurus established on a good and sufficient specimen there might be some reason in maintaining the genus as suggested, but since it also is based on meager materials, that are hardly more diagnostic than the genotype of Antrodemus, it would seem therefore, that the law of priority should prevail.

I do not feel that the characterization of the genus Allosaurus on the topotype would any more firmly establish it, than if that same specimen were used to define the genus Antrodemus which clearly has priority. The matter of retaining a name because it has become well fixed in the literature has no weight in nomenclatural procedure so long as it can be shown that an already existing name has precedence.

In view of the fact that such evidence as there is, indicates that in all probability all of these specimens pertain to a common genus, it would seem inexpedient to apply the third proposition to the present problem. Later, with the acquisition of new materials if it is found that two genera have been confused in these fragmentary types, it will then be time enough to adopt the third proposition.

At this time I propose to consider all of these specimens previously identified as Allosaurus fragitis as pertaining to Antrodemus valens Leidy, and from them have derived the characters which I consider diagnostic of the genus as given below:

Generic characters: Premaxillaries with 5 teeth; maxillaries with 15 to 17 teeth; dentary with 15 to 16 teeth; 9 cervical vertebrae, opisthocoelus; 14 dorsal vertebræ, amphicoelus; 5 sacrals; distal caudals with clongated prezygophyses; pelvis not coossified; pubis with notch funtioning as pubic foramen; 3 digits in manus, first provided with robust curved ungual; third digit reduced; 4 digits in pes, first (hallux) reduced; dermal ossifications not known; abdominal ribs present.

\section{ANTRODEMUS VALENS Leidy, 1870}

Plates 1-16.

Poicilopleuron (Antrodemus) valens LEIDy, Proc. Acad. Nat. Sci. Phila., 1870, p. 3; Extinct Vert. Fauna West Terr. 1873, pp. 267-279, (Poicilopleuron) pl. 15, figs. 16-18, (Antrodemus).-MerriLl, G. P., Bull. No. 53, U. S. Nat. Mus., pt. 2, 1907, p. 76.-ZITTEL, K. A., Handbuch der Palaeontologie, pt. 1, vol. 3,1890 , p. 722 .

Antrodemus valens, HAY, O. P., Bïbliog. and Cat. Foss. Vert. N. Amer. Bull. No. 179, U. S. Geol. Survey, 1901, pp. 489, 490.-Nopcsa, F. Baron, Földtani Közlony, vol. 31, 1901, p. 199.-HAy, O. P., Proc. U. S. Nat. Mus., vol. 35, 1908, p. 353.-Huene, F. von, Geol. und Paleont. Abhand. Sup. vol. 50, 1907-1908, pp. 326, 334.-Ziтtel, K. A., Grundzuge der Paleontologie, pt. 2, 1911, pp. 280, 282.Моoк, C. C., Annals New York Acad. Scí., vol. 27, 1916, p. 142, (as Antrodesmus valens.)

Allosaurus fragilis MARSH, O. C., Amer. Jour. Sci., ser. 3, vol. 14, 1877, pp. 515; Amer. Journ. Sci., ser. 3, vol. 27, 1884, pp. 335-337, pls. 11, fig. 2, pl. 12, fig. 2; Sixteenth Ann. Rept. U. S. Geol. Surv., pt. 1, 1896, p. 163, pl. 10, fig. 2; pl. 11, fig. 2; pl. 13, fig. 5 (as Labrosaurus fragilis); Mong. U. S. Geol. Surv., vol. 27, 1897, p. 505, fig. 61; Amer. Journ. Sci., ser. 4, vol. 7, 1899, p. 232, fig. 3.LYDEKKeR, R. Cat. Foss. Reptilia and Amphibia in British Museum, pt. 1, 1888, p. 154, fig. 25.Zittel, K. A., Handbuch der Palaeontologie, Abt. 1, vol. 3, 1887-1890, p. 726, fig. 628 (as Allosaurus agilis).-Hutchinson, H. N., Extinct Monsters, 1893, p. 84, text fig. 16.-Hay, O. P., Bull. No. 179, U. S. Geol. Survey, 1901, p. 489.-NopcsA, F. Baron, Földtani Közlony, vol. 31, 1901, p. 199.Williston, S. W. Amer. Journ. Sci., ser. 4, vol. 11, 1901, p. 1]1.-ZItTel, K. A., Text-book of Paleontology, Eng. ed., vol. 2, 1902, pp. 229-230, fig. 330 (as Allosaurus agilis).-OsBorN, H. F., Bull. Amer. Mus. Nat. Hist., vol. 19, 1903, pp. 697-701, figs. 1, 2; Century Magazine, vol. 68, 1904, pp. 680-694.-Beasley, W. A., Sci. American, vol. 97, 1907, pp. 446-447, 3 text figs.-Huene, F. von, Geol. und Palaeont Abhand. Sup., vol. 1, 1907-1908, pp. 326, 327, 334.-HAY, O. P., Proc. U. S. $144035^{\circ}-20-2$ 
Nat. Mus., vol. 35, 1908, pp. 353-356.-Hutchinson, H. N., Extinct Monsters and Creatures of other days, 1911, new ed., p. 140, pl. 15, fig. 44.-JAEKAL, Otto, Die Wirbeltiere, 1911, p. 160, fig. 176, (as Allosaurus agilis).-ZitтeL, K. A., Grundzuge der Palaeontologie, vol. 2, 1911, pp. 282, fig. 427, (as Allosaurus agilis).-Os BonN, H. F., Memoirs Amer. Mus. Nat. History, vol. 1, pt. 1, 1912, text figs. 9, 10, 11, 26, and 27 (as Allosaurus agilis).-GREGORY, W. K., Journ., Morph. vol. 24, 1913, p. 11, fig. 8 (as Allosaurus agilis).-Grimore, C. W., Bull. 89, U. S. Nat. Mus., 1914, p. 4; Proc. U. S. Nat. Mus. vol. 49, 1915, pp. 501-513, text figs. 1-7.-Mоor, C. C., Annals New York Acad. Sci., vol. 27, 1916, p. 141.-Lambe, L. M., Memoir 100, Geol. Surv. Canada, 1917, p. 56, figs. 32, 37.

Allosaurus KING, C., U. S. Geol. Explor. 40th Par., 1878, p. 346.-Cope, E. D., Amer. Nat., 1885, Jan. p. 67.--Osborn, H. F., Bull. Amer. Mus. Nat. Hist., vol. 22, 1906, pp. 283-294, figs. 2 and 6 A.Matthew, W. D., Journ. Amer. Mus. Nat. Hist., vol. 8, 1908, pp. 3-5, pl. 1; Dinosaurs, Hand book Series, No. 5, Amer. Mus. Nat. Hist., 1915, pp. 36-46, figs. 8, 9, 10, 11, 12.

Genotype.-Cat. No. 218, U.S.N.M. Consists of the posterior half of a caudal centrum (probably the sixth) from the anterior fourth of the tail. Collected by Dr. F. V. Hayden, 1869.

Type-locality.-Middle Park, Grand County, Colorado.

Horizon.-Morrison, Jurassic.

The original description is as follows:

A specimen, consisting of less than the half of a vertebral body, was submitted to my examination by Professor Hayden, who obtained it last summer during his geological survey. It is from Middle Park, Colorado, and Professor Hayden thinks was derived from a cretaceous formation. Similar specimens were reported to be not unfrequent, and were known under the appellative of "petrified horse hoofs." The fossil indicates an elongated form of caudal vertebra of some large saurian. Much constricted toward the middle, such specimens would be most liable to break in this position, and the halves from their form might readily be taken, by the inexperienced in such matters, for what they are called.

The vertebral body in its entire condition would resemble in form those of Megalosaurus, but in form and other characters bears a near resemblance to those of Poicilopleuron Bucklandi. This is an extinct reptile from the oolitic formation of Caen, in Normandy, described by Deslonchamps; and remains apparently of the same animal from the Wealden of Tilgate, England, have also been described by Professor Owen:

Poicilopeluron has generally been viewed as a crocodilian reptile with biconcave vertebrae, but probably pertains to the dinosaurs. The $P$. Bucklandi is estimated by Deslonchamps to have been about 25 feet long. The Colorado fossil indicates a much larger animal, having been more than onethird greater.

One of the most remarkable characters of the Poicilopleuron is the presence of a large medullary cavity within the bodies of the vertebrae, parallelled among living animals, so far as I know, only in the caudal vertebrae of the ox. The same character is presented by the Colorado fossil. In the former animal the cavity appears simple or unobstructed by osseous trabeculae. In the Colorado fossil, as seen in the broken surface of the specimen, the medullary cavity occupies the lower two-thirds of the interior of the body and is crossed by a few trabeculae. The sides of the cavity converging below are constituted by a layer two lines thick and as compact as the walls of the medullary cavity in the limb bones of most ordinary mammals. The upper third of the interior of the body is occupied by the ordinary spongy substance which becomes more compacted, ascending into the interior of the neural arch. The cavernous structure of the Colorado fossil is occupied with crystalline calcite.

The estimated length of the vertebral body is 6 inches or more [estimate too great by at least an inch]. The sides are much narrowed toward the middle, and they are concavely depressed just below the sutural conjunction of the neural arch. A narrow groove occupies the lower border of the body, as is indicated to be the case in the Tilgate specimens. The posterior articular surface of the body is moderately depressed, but its lower fourth curves forward, producing a thick, convex ledge for the accommodation of a chevron. The bread th of the articular surface is scarcely 4 inches and its depth is about the same measurement.

The species represented by the fossil may be named Poicilopleuron valens. Should the division of the medullary cavity of the vertebral body into smaller recesses by trabeculae be significant of other 
characters indicating the Colorado saurian to be distinct from Poicilopleuron, it might be named Antrodemus.

In the original description given above the type-specimen is most accurately described, and needs no further elucidation at this time.

\section{OSTEOLOGY OF ANTRODEMUS.}

In the pages that follow I have attempted to give, for the first time, a detailed description of the complete osteology of Antrodemus (Allosaurus) valens (Leidy). This work is based almost entirely upon material preserved in the paleontological collections of the United States National Museum, and primarily upon specimen No. 4734, U.S.N.M., known also by the collector's designation as "Sk. 7." I have selected this specimen on account of the well-preserved condition of the bones and from the fact that it consists of the greater part of the skeleton of a single individual. Reference will occasionally be made to other individuals when important structural differences are displayed, and bones not present in this skeleton will be described from other specimens.

\section{SUMMARY OF ANTRODEMUS MATERIALS.}

The specimens in the United States National Museum now identified as Antrodemus valens Leidy are as follows:

1. No. 4734, U.S.N.M. "Sk. 7." Nearly complete skeleton from "Quarry No. 1," Canon City, Fremont County, Colorado. Collected by M. P. Felch, 1883-4.

2. No. 8367, U.S.N.M. Consists of 9 cervicals, 10 dorsals, 2 sacral and 7 caudal vertebrae. Cervical and dorsal ribs, 6 chevron, pubes, ischia, and portions of ilium. From "Quarry C," Albany County, Wyoming. Collected by Fred Brown, 1886.

3. No. 2323, U.S.N.M. (juvenile), consists of 8 cervical centra, 11 dorsal centra, 2 sacral centra, numerous neural processes of both cervical and dorsal vertebrae, right ilium, 2 ischia, right femur, parts of many ribs, from "Quarry 9," Como, Albany County, Wyoming. Collected by Fred Brown, 1888.

4. No. 8423 , U.S.N.M. "Sk. 5 " consists of 2 maxillae, 5 dorsal centra, 5 coossified sacral vertebrae, 3 caudal centra, parts of ilia, 2 ischia (broken), 2 pubes (broken), 2 femora, left hind foot, few bones of fore foot. "From Quarry No. 1," Canon City, Fremont County, Colorado. Collected by M. P. Felch, 1884.

5. No. 8335, U.S.N.ML. Consists of right maxillary with teeth and dentary of same side, from "Quarry No. 1." Canon City, Fremont County, Colorado. Collected by M. P. Felch, 1884.

6. No. 218, U.S.N.M. Type of Antrodemus valens, Leidy, consists of distal half of anterior caudal centrum, from Middle Park, Grand County, Colorado. Collected by Dr. F. V. Hayden, 1869.

7. No. 8405 , U.S.N.M. Consists of 5 coossified sacral centra, lateral metatarsal, phalanges of fore and hind feet, from "Quarry D." Como, Albany County, Wyoming. Collected by Fred Brown, 1884.

8. No. 7336, U.S.N.M. Consists of left astragalus, from "Quarry No. 1," Canon City, Fremont County, Colorado. Collected by M. P. Felch, 1886.

9. No. 8302, U.S.N.M. C Jnsists of ungual of digit III, fore foot from "Quarry 9," Como, Albany County, Wyoming. Collected by Ed. Kennedy, 1884

10. 8257, U.S.N.M. Consists of ungual digit II, right fore foot, from near Canon City, Fremont County, Colorado. Collected by M. P. Felch, 1883.

SKULL.

Plates 3-4.

A complete articulated skull of Antrodemus (Allosaurus) is unknown, though several more or less perfect but disarticulated skulls have been found, but none 
more perfect than the cranium to be described; and its importance is greatly enhanced on account of its forming a part of so perfect a skeleton as the present individual.

The occipital segment was largely articulated (as shown in fig. 4) when found, but the other parts were detached though not far separated in the matrix. The skull has been skillfully articulated by Mr. N. H. Boss, as shown in plate 3. The missing portions have been restored by him, so that it now gives a very close approximation to its original shape and proportions. In some few instances, because of

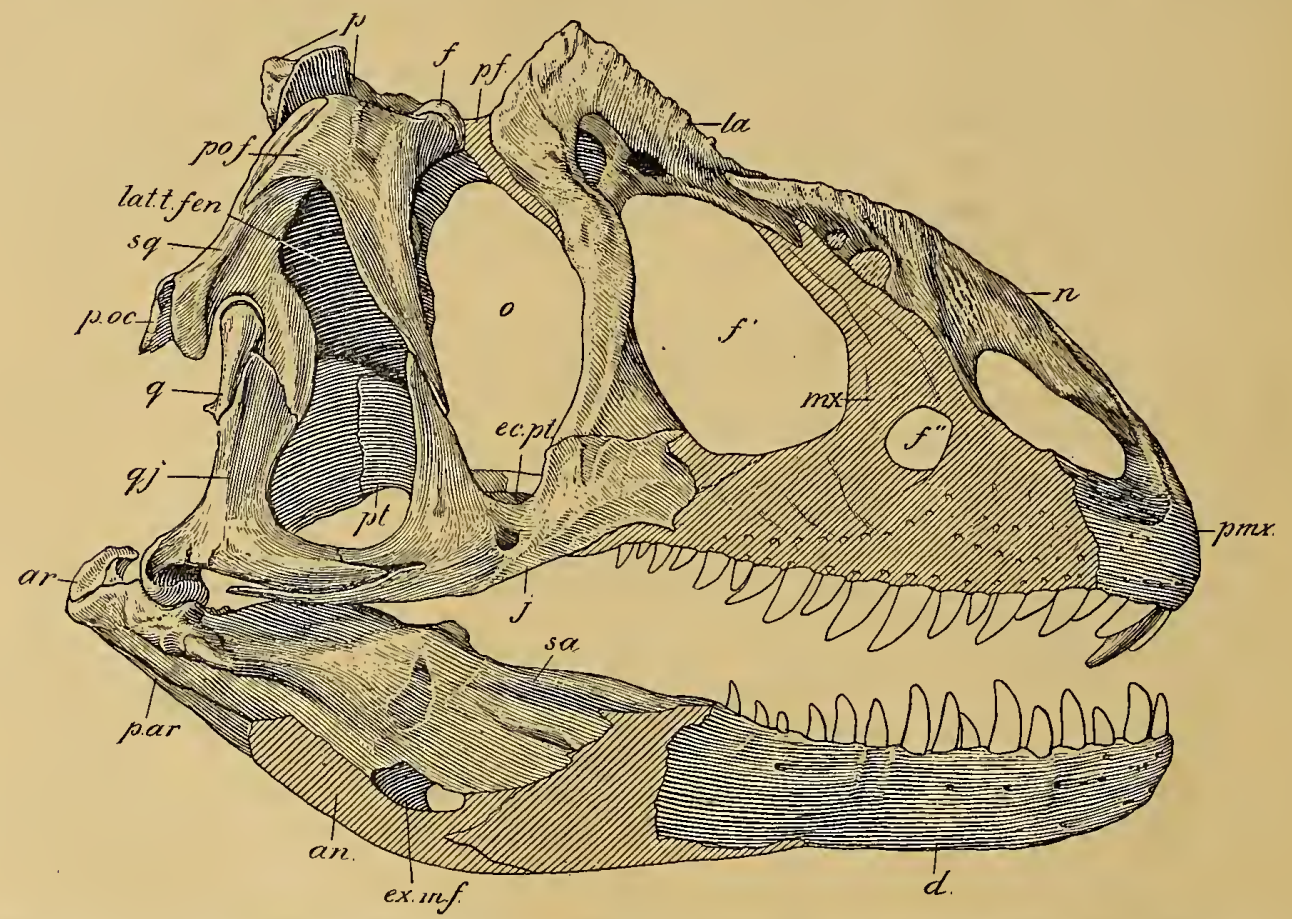

Fig. 1.-SkUll of ANTRodemus Valens Leidy. Side view. CAT. No. 4734, U.S.N.M. $\frac{1}{6}$ Natural Size, an, ANgular; ar, ARTICULAR; $d$, DENTARY; $e c . p t$, ECTOPTERYGOID; $e x . m . f$, EXTERNAL MANDIBULAR FORAMEN; $f$.FRONTAL; $f^{\prime}$, FIRST ANTIORBITAL FENESTRA; $f^{\prime \prime}$, SECOND ANTIORBITAL FENESTRA; $j$, JUGAL; $l a$, LACHRYMAL; lat.t. fen, LATERAL TEM PORAL YENESTRA; $m x$, MAXILLARY; $n$, NASAL; 0 , ORBIT; $p$, PARIETAL; $p . a r$, PREARTICULAR; $p f$, PREFRONTAL; $p m x$, PREMAXILLARY; $p . o c$, PARAOCCIPITAf; po.f, POSTFRONTAL+POSTORBITAL; $p$, PTERYGOID; $q$, QUADRATE; $q j$, QUADRATOJUGAL; $s a$, SURANGULAR; $s q$, SQUAMOSAL.

The dentary pertains to SPEcimen Cat. No. 8335, U.S.N.M. SEe P. 25.

distortion by crushing, it was necessary to compromise in regard to the exact articulation of the elements, but in the main they joined up very accurately.

The important parts missing may be enumerated as follows: left premaxillary, right maxillary, right prefrontal, left jugal, left quadrate, and quadratojugal. Of the palatal region the left pterygoid and all bones forward of the ectopterygoids are missing. The lower jaw is represented by the posterior half of the right ramus, which lacks the coronoid, splenial, and the greater portion of the angular. The dentary of a second individual No. 8335, U.S.N.M. of about the same size and proportions was used in restoring the jaw as now exhibited, and as shown in figure 1 and also in plate 4 , fig. 2. 
In 1903 Osborn ${ }^{1}$ described and figured cranial material, identified as pertaining to the genus Creosaurus, but subsequently ${ }^{2}$ referred by him to Allosaurus. (See fig. 3.) There are two skulls in the American Museum of Natural History, New York, from the famous "Bone Cabin Quarry," in Wyoming, both of which are considerably larger that the specimen now before me, as is shown by the table of comparative measurements given below.

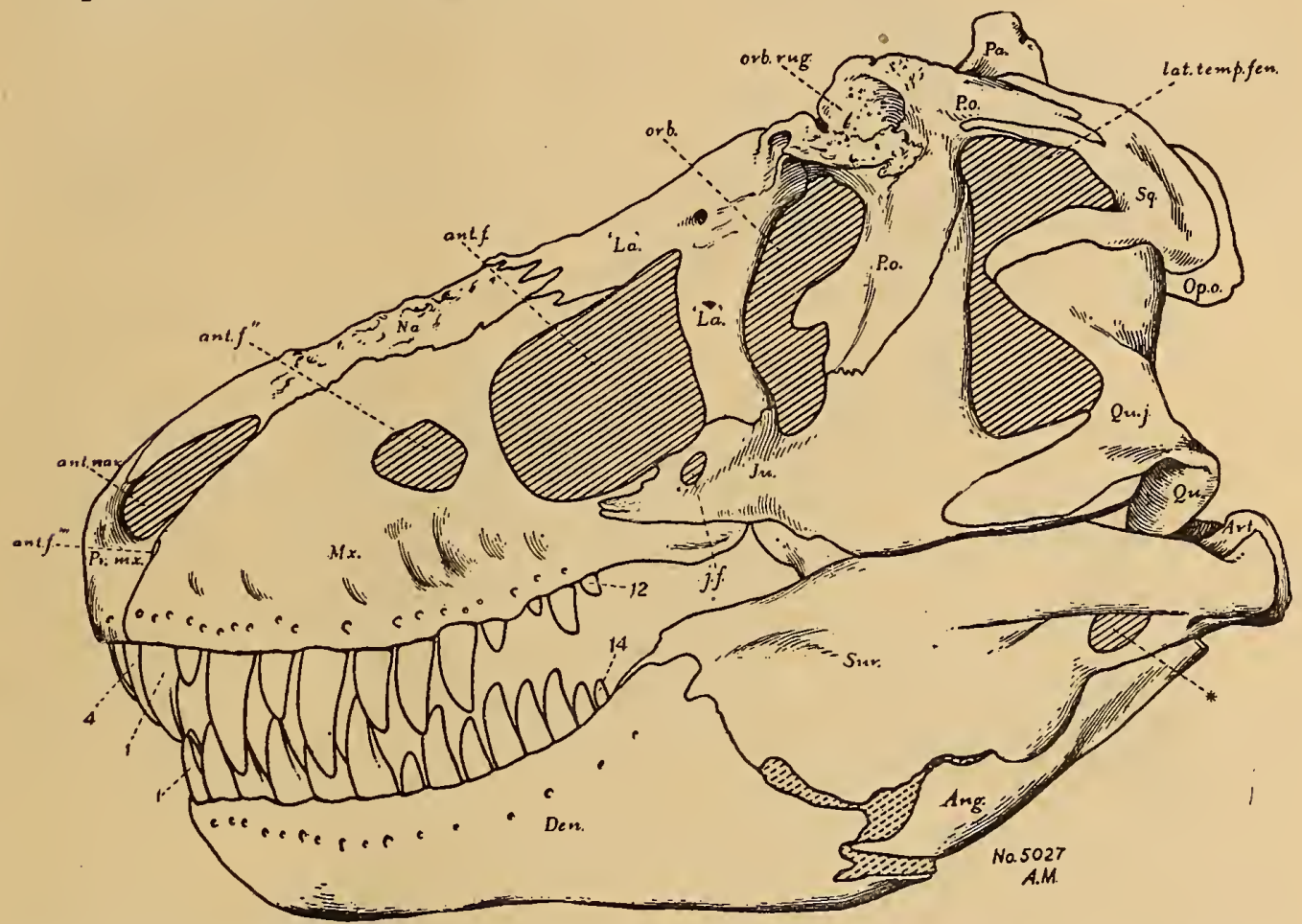

Fig. 2,-SKUll AND LoWER JAW OF TYRANNOSAURUS REX OSBORN. No. 5027, A.M.N.H. $\frac{1}{6}$ NAT. Size, ang, ANGULAR; ant.f; ant. $f^{\prime \prime}$; ant. $f_{, \prime \prime}$ ANTJORBITAL FENESTRAE; ant.nar, ANTERIOR NARES; art, ARTICULAR; den, DENTARY; $j . f$, JUGAL FORAMEN; $j u$, JUGAL; la, LACHRYMAL; lat.temp.fen, LATERAL TEMPORAL FENESTRA; mx, MAXILLARY; na, NASAL; orb, ORBIT; orb.rug, ORBITAL RUGOSITY; op.o, PARAOCCIPITAL; $p a$, PARIETAL; $p .0$, POSTORBITAL+POSTFrontaL; $p r . m x$, PremaXILLARY; $q u$, QUADRATE; $q u . j$, QUAdRATOJUgal; sq, SQUamosal; sur, SURANGUlar; * Foramen. (AFTer Osborn.)

Comparative measurements of Antrodemus crania.

\begin{tabular}{|c|c|c|c|}
\hline & $\begin{array}{l}\text { U.S.N.M. } \\
\text { No. } 4734 .\end{array}$ & $\begin{array}{l}\text { A.M.N.H. } \\
\text { No. } 600 \text {. }\end{array}$ & $\begin{array}{l}\text { A.M.N.H. } \\
\text { No. } 666 \text {. }\end{array}$ \\
\hline Length, occipital condyle to end of premaxillary.. & $m m_{605}$ & $\begin{array}{l}m m_{810} \\
\end{array}$ & $m m .885$ \\
\hline 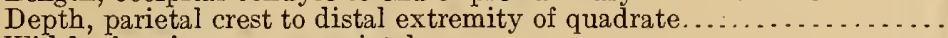 & 355 & 415 & 430 \\
\hline Width of occiput across parietals. . . . . . . . . . . . . . . . . . & 153 & $\ldots$. & 230 \\
\hline 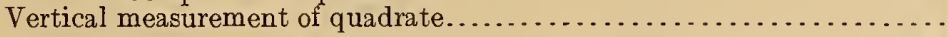 & 190 & 205 & 235 \\
\hline
\end{tabular}

1 Osborn, F. F. The Skull of Creosaurus, Bull. Amer. Mus. Nat. Hist., vol. 19, 1903, pp. 697-701, figs. 1 and 2.

${ }^{2}$ Crania of Tyrannosaurus and Allosaurus, Memoirs Amer. Mus. of Nat. Hist., vol. 1, new ser. pt. 1, 1912, pp. 27,29, figs. $26,27$. 
Viewed from the side the structure of the skull of Antrodemus valens is light and open. The posterior portion is deep dorsoventrally and moderately expanded transversely. The facial portion is somewhat elongate, and tapers to the muzzel. In all of the above respects this skull closely resembles that of Ceratosaurus nasicornis, but when more closely compared they show many differences as will be pointed out later. From the side view one special feature is the four large openings on the side of the skull. These openings are all characteristic of the Theropodous dinosaurs, though in the several known genera they differ much in size, shape and position. Another prominent feature is the high horn-like elevation of the lachrymal bones extending well above the median dorsal surface of the skull. The sharp upper surfaces of these elevations are rugose and furrowed with grooves, which in life evidently were covered with chitinous skin.

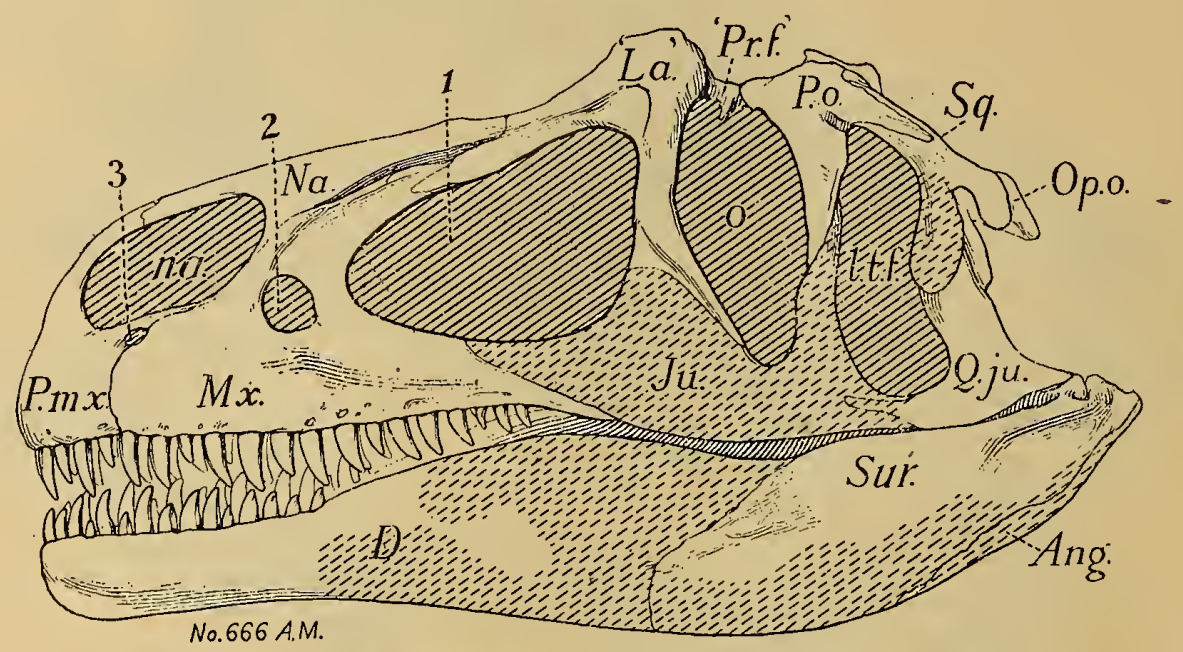

FIG. 3.-SKULL AND LOWER JAW OF ANTRODEMUS VALENS LEIDY. No. 666, A.M.N.H. $\frac{1}{8}$ NAT SIZE. ang, ANGULAR; $d$., DENTARY; $j u$, JUGAL; la, LACHRYMAL; $l t . f$, LATERAL TEMPORAL FENESTRA; $m x$, MAXILLARY; na, NASAL; $n . a$, ANTERIOR NARES; 0 , ORBTT; op.o, PARAOCCIPITAL; P.mx, PREMAXILLARY; $p .0$, POSTORBitAL COMPLEX; $p r . f$, POSTFRONTAL; $q . j u$, QUADRATOJUGAL; $s q$, SQUAMOSAL; sur, sURANGULAR; $1,2,3$, ANTORBITAL FENESTRAE. (AFTER OsbORN.)

Viewed from above the skull is triangular in outline, wide behind and tapering to a bluntly rounded nose as shown in plate 4 , figure 1 . The sides are slopingthat is, from above downward-the bottom of the skull being wider than the upper portion.

Basioccipital (boc.).--The basioccipital is composed of the convexly rounded occipital condyle, and a long, narrow but heary inferior process that joins latterly with the descending branches of the exoccipitals or opisthotic elements. The exoccipitals in this specimen contribute quite extensively to the formation of the occipital condyle, see figure 4, although Osborn ${ }^{1}$ has written in describing the occipital region of Creosaurus (afterward regarded as Allosaurus, now Antrodemus). "The basioccipital alone enters into the prominently convex condyle." The smooth articulating surface continues well forward on the lateral and ventral surfaces of the occipital condyle. This would appear to indicate a great mobility of the head in

1 Bull. Amer. Mus. Nat. Hist., vol. 19, 1903, p. 700. 
all directions, such as would be naturally expected in an animal of carnivorous habits. The condyle as in nearly all dinosaurs is inclined ventrally in relation to the longer horizontal axis of the skull. The median superior surface of the basioccipital contributes to the inferior boundary of the foramen magnum, much as in Camptosaurus but to a slightly less degree.

The ventral process extends downward some 57 millimeters below the occipital condyle. It is comparatively narrow and articulates laterally with the ventral processes of the exoccipitals, as well as the posteriorly directed plates of the basisphenoid. The median posterior and ventral surfaces are deeply concave thus separating the subspatulate basioccipital processes, see figure 4.

Exoccipital (ex.oc.) and paraoccipital $(p . o c$.$) .- The exoccipitals$

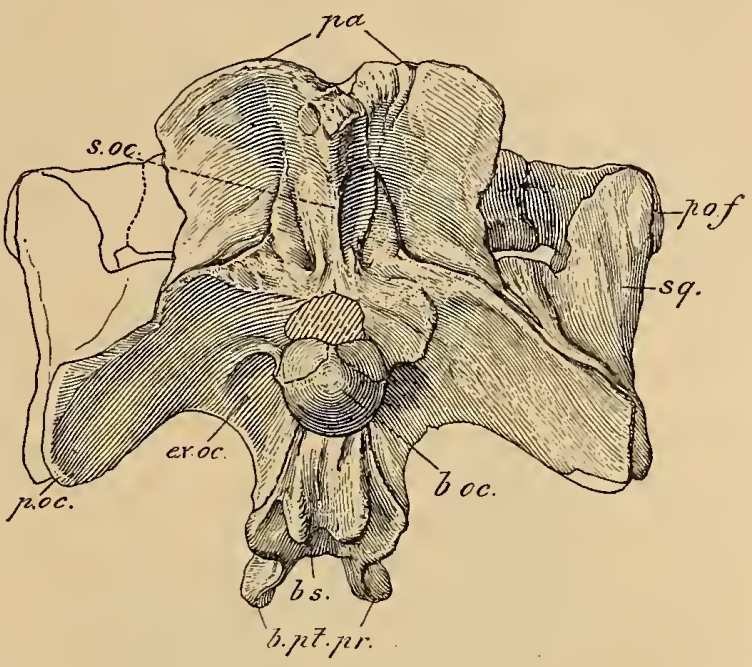

Fig. 4.-Skull of ANtrodem Valens Liedy. Posterior view. No. 4734, U.S.N.M. I NAT. SIZE. $b . o c$, BASIOCCIPITAL; $b . s$, BASISPHENOID; b. $p t$. $p r$, BASISIPTERYGOID PROCESSES OF THE BASISPHENOID; $e x . o c$, eXocCIPITAL; $p a$, PARIETAL; $p$. oc, PARAOCCIPITAL PROCESS; $p$. POSTFRONTAL; $s$. oc, SUPRAOCCIPITAL; $s q$, SQUAMOSAL. seen from behind extend outward from the basioccipital in two broad wing-like plates with which the paraoccipitals are coalesced. It can not be determined from the

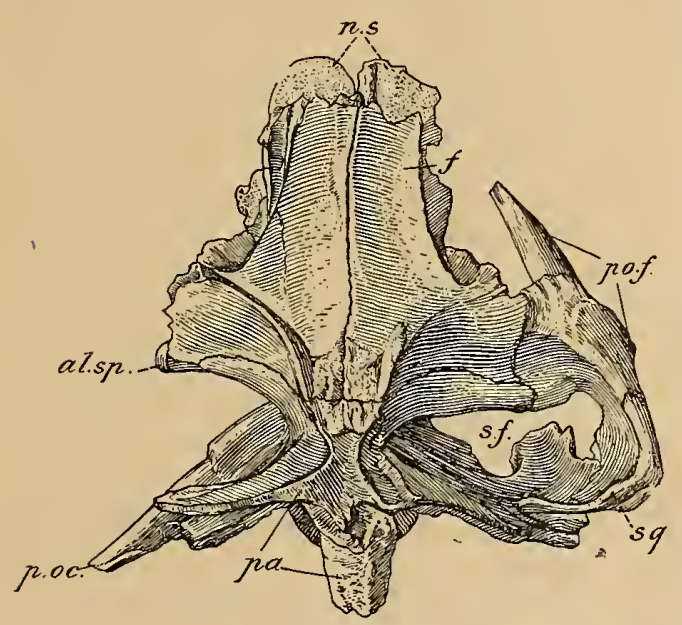

Fig. 5.-Skull of ANTrodemus valens Leidy. No. 4734, U.S. N.M. $\frac{1}{4}$ NAI. SIZE. SUPERIOR VIEW. al. $s p$, ALISPHENOID; $f$, FRONTAL; $n . s$, SUTURAL SURFACE FOR NASAL BONES; $p a$, PARIETAL; $p$. oc, PARAOCCIPITAL PROCESS; po.f, POSTTRONTAL; s. $f$, SUPRATEMPORAL FOSSA; $s q$, SQUAMOSAL. present specimen whether they meet on the median line above the foramen magnum or not, but I am inclined to believe that the supraoccipital is not interposed between them. The paraoccipital processes extend outward, backward, and downward at an angle of $45^{\circ}$ to the central surface terminating at a line $40 \mathrm{~mm}$. posterior to the rear of the occipital condyle. The upper and lower borders of these processes gradually approach one another toward their outer extremities which are obliquely truncated. Dorsally the exoccipitals and paraoccipitals unite in order from the center outwards with supraoccipitals, parietals and squamosals, the latter being applied more to the, upper anterior face of the paraoccipital than to the dorsal border. On the anterior

median surface these coalesced bones unite by a long lapping suture with the prootics (fig. 6). The elongated aperture between the paraoccipital and squamosal in 
the posterior view of the skull of Antrodemus as published by Osborn ${ }^{1}$ is not apparent in the present specimen, the space being filled by the slender outwardly directed process from the parietal, as shown in figure 4.

There are deep, vertically elongated depressions lateral to and on either side of the basioccipital and exoccipital bones into which foramina for the IX, XI, and XII cranial nerves make their exit. (See fig. 16, B.)

Supraoccipital (s.oc.).-The supraoccipital in Antrodemus is relatively reduced in size. It is a comparatively narrow, vertical elongated bone that unites by suture with the overhanging parietal, and is not a cartilaginous union as in many of the Predentate dinosaurs. Its lateral borders appear to unite exclusively with the exoccipitals, the latter sending upward narrow, tapering processes that are interposed between the parietal and supraoccipital bones. The ventral extent of the supraoccipital can not be determined from this specimen as the sutures around this end have become coalesced and obliterated, but I am inclined to believe that when a specimen is found in which the occipital elements can be entirely differentiated the supraoccipital will be excluded from the superior median boundary of the foramen magnum as it is in the Sauropoda by the median junction of the exoccipitals above that opening as correctly figured by Osborn. On the upper posterior surface a sharp median ridge is developed that joins a similar ridge on the overlaying parietal. . Below the ridge the bone contracts transversely, the median surface being longitudinally depressed. On either side of this contracted part of the bone the lateral surface turns abruptly forward and with the exoccipitals forms a vertically elongated depression (fig. 4). Across the upper half the supraoccipital has a transverse width of $38 \mathrm{~mm}$; ; below the carina it contracts to $18 \mathrm{~mm}$. in width.

Alisphenoid (al. sp.).- The alisphenoid in Antrodemus, as in other Theropodous dinosaurs, is large when compared with the very much smaller elements in the Predentate and Sauropodous dinosaur skulls. It consists of an inferior and superior branch, the latter turning outward at right angles to the former. Superiorly it unites with the frontal and parietal, posteriorly with the prootics. The outer end of the transverse process is rugosely roughened sub-oval in outline and is received in a pit on the lower side of the postfrontal postorbital complex, a condition that prevails in all known dinosaurian crania. The ventral process expands into a thin but broad cimeter-like process, that laps along the sides of the basisphenoid. On the posterior side, at a point about midway between the upper and lower extremities, the bone is notched by the foramen ovale through which the trigeminal or fifth nerve makes its exit from the brain. Internally it joins by lapping suture the orbitosphenoid between which are the exits for the II and III cranial nerves. The upper inner surfaces of the alisphenoids form the walls of that part of the brain case which lodges the cerebral hemispheres. The alisphenoids do not meet the exoccipitals, as Osborn ${ }^{2}$ has stated they do in Tyrannosaurus, a statement which I think is to be questioned even in that genus. Such a relationship would be most unusual, and entirely different from any reptile, living or extinct, with which I am acquainterl. 
Basisphenoid (b. s.).-The basisphenoid in Antrodemus has a most unusual ventral development, its lower border extending below the level of the basioccipital processes. This part of the basioccipital consists of two lateral plates of bone, broad antero-posteriorly that diverge from one another in a downward direction. Between these plates on the inner posterior sides the basioccipital processes are received, and the posterior borders unite by suture with the ventral extension of the paraoccipital processes. Thirty millimeters posterior to their anterior margins a transverse bridge connects the two lateral plates and completes the boundaries of a very deep rectangular, wedge-shafed cavity.which extends upward to a point above the level of the lower extension of the alisphenoids shown in a lateral view (fig. 6). This cavity probably leads up to the foramen for the median Eustachian canal, as in the crocodile and alligator. The structure of this part of the basisphenoid is quite different from that of Tyrannosaurus which apparently has a longitudinal bridge with a cavity on either side.

In front of the bridge mentioned above the lateral plates thin, terminating in a relatively acute edge and on the upper half, meeting at the median line. On the lower half they turn gently outward away from the center, their lower anterior border developing vertically, elongated, oval basipterygoid processes for articulation with the pterygoids ( $b ., p t ., p r$., figs. 4 and 6). Superiorly the basisphenoid unites with the prootics and alisphenoids, the latter sending down long flattened processes that lap along the median part of the

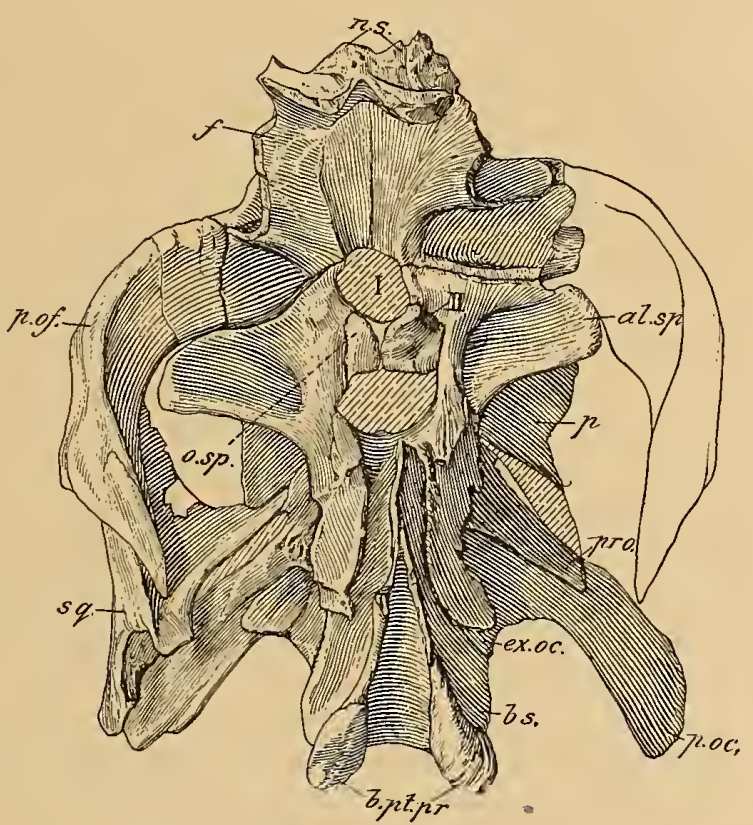

FIG. 6.-SKULL OF ANTRODEMUS YALENS LEIDY VIEWED FROM IN FRONT AND BELOW. NO. 4737 , U.S.N.M. $\frac{1}{4}$ NAT. SLZE. als $p$, ALISPHENOII); b. $p t$. $p r$, BASTPTERYGOID PROCESSES OF THE BASISPHENOID; $b s$, BASISPHENOID; ex. oc, EXOCCIPITAL; $f$, FRONTAL; $n$. $s$, SUTCRE FOR NASAL BONES; $0 . s p$, ORBITOSPHENOID; $p$, PARIETAL; $p$. oc, PARAOCCIPITAL. PROCESS; $p$. of, POSTFRONTAL; pro, PROOTIC; sq, SQUAMOSAL; I, II, FORAMINA FOR EXIT OF CRANIAL NERVES ONE AND TWO. plate-like ventral extension.

Parasphenoid (p.sp.).-The parasphenoid is missing in this specimen though doubtless it continues out from the anterior upper border of the basisphenoid as in Tyrannosaurus. It is present in the American Museum srecimen, as shown in figure 16.

Orbitosphenoid (o. $s p$.).-The orbitosphenoids are two curved plate-like bones lying between and in front of the alisphenoids, united by suture on the midline, and forming that part of the brain case which underlies the olfactory lobes. These bones, as Gregory ${ }^{1}$ has pointed out, may in part also represent the presphenoids, but for convenience in referring to them are here designated orbitosphenoids. 
These elements unite laterally with the alisphenoids, but in this specimen the point of union is almost wholly obliterated, though it appears to pass through the foramina for the exit of the third and fourth cranial nerves as shown in figure 6 . The opening for the exit of the second or optic nerve is immediately below and posterior to the orbitosphenoids, and is very large in this specimen as it is also in the skull figured by Osborn. ${ }^{1}$

In Tyrannosaurus the exit is divided by a filiment of bone and it appears most probable that this partition is missing in the present specimens.

Ethmoid (e.).-The ethmoid is missing in specimen, No. 4734, U.S.N.M., though the sutural anterior borders of the orbitosphenoids and alisphenoids show where it joins when present.

Parietal (pa.).- Viewed from above the parietal presents an antero-posterior crest, and a transverse supraoccipital crest. The latter extends outward at right angles to the central axis of the bone as two thin vertically expanded, wing-like plates much as in Tyrannosaurus and especially as in Ceratosaurus nasicornis. They rise above the level of the median superior surface of the parietal so that when seen from the rear there is a broad concave notch between them at the center (fig. 4). The superior surface of the parietal in front of the transverse portion is shallowly concave transversely and has a least diameter between the supratemporal fossa of $18 \mathrm{~mm}$. The upper surface of the anterior end is markedly rugose and transversely expanded and appears to be joined to the frontals by a nearly straight transverse suture. Only the lateral sutures between the parietals and frontals are clearly seen in this specimen, those on the superior surface being very indistinct. At the lateral sutures the parietal has a transverse diameter of $37 \mathrm{~mm}$. The lateral borders of the superior surface are raised presenting an acute edge that turns outward and upward into the more obtuse free borders of the vertical transverse plates (fig. 5).

The median lateral surfaces drop abruptly downward from the superior surface and form a considerable part of the inner boundary of the supratemporal fossae. The parietals do not meet the postfrontals as in most Predentate and Sauropodous dinosaurs, but are excluded from them by the lateral expansions of the frontals. Ventrally, within the supratemporal fossa the parietals meet the superior borders of of the alisphenoids and prootics for a short distance. Posteriorly the lower borders of the transverse portion rests upon the top of the paraoccipital processes, and for a short distance only an internal branch of the squamosal (fig. 4). The lower outer part of the plate is produced outward and backward as a long slender tapering process, that passes to the back of the inner squamosal process and to the front of the paraoccipital process resting in a groove between the two, as shown in figure 4 . Posterior to the transverse crest the parietals are continued backward as a heavy, overhanging, bluntly pointed projection, much as in Ceratosaurus. In Tyrannosaurus of the Upper Cretaceous, there is no posterior projection of the parietal. The upper surface of this portion is rugosely roughened. It overhangs the supraoccipital with which it is firmly coalesced. The parietal, however, is excluded from a lateral contact with the supraoccipital by the interposition of slender, upwardly

\footnotetext{
1 Mem. Amer. Mus. Nat. Hist., vol. 1, pt. 1, p. 16, fig. 9.
} 
directed processes from the exoccipitals as shown in figure 4. The greatest length of the parietals is about $101 \mathrm{~mm}$.; the greatest width between ends of the transverse plates is $155 \mathrm{~mm}$.

Frontals $(f$.$) .- The frontals are relatively short, wide, and heavy, paired bones.$ Viewed from above they are roughly triangular in outline with the anterior apices truncated, as in Ceratosaurus and Tyrannosaurus, they have a great transverse expansion on their posterior half, attaining a combined width of $180 \mathrm{~mm}$. between the fronto-postfrontal sutures. These lateral expansions unite ventrally with the alisphenoids and prootics, and laterally with the postfrontals. Their superior surfaces look backward and upward and form the greater part of the anterior boundary of the supratemporal fossae.

With the exception of a small rugose area on the median superior surface of the frontal near the fronto-parietal suture, the remaining surfaces are smooth and flat, except the anterior ends, each of which is shallowly concave transversely and thus forming a slight longitudinal ridge at their median junction. Beginning at either end of the transverse fronto-parietal suture the superior surface is separated from the lateral surface by sharp raised ridges that diverge as they continue forward but subside before reaching the notch between the postfrontals and prefrontals. Above the orbits on the ventral surface the frontals are concave antero-posteriorly. They are almost entirely excluded from the upper external boundary of the orbit, by the postfrontal and prefrontal bones. There is a deep, but narrow notch, between those bones and their lower borders appear to have been in contact along the lower part of the notch. In front of this notch the frontal bone is much thickened, with a deep angular pit for the reception of a posteriorly directed projecting spur on the prefrontal. Anterior to this pit the frontals send outward and forward a rounded tapering process that extends free and appears to have been received between the upper and lower branches of the $U$-shaped prefrontal. The upper process of the latter bone appears to lap along the anterior side of the frontal terminating in front of the fronto-nasal suture as shown in plate 4, figure 1. Anteriorly the frontals join the nasals by a toothed transverse suture. An underlying projecting shelf underlaps the posterior ends of the nasals as shown in figures 5 and 6 . The frontals have a greatest length along their midline of about $145 \mathrm{~mm}$.

Prefrontal $(p f$.$) . - A small irregular U-shaped bone found detached but in close$ proximity to the other portions of the skull is here identified as the left prefrontal. Although not exactly fitting the sutures of the frontal (due in all probability to slight crushing) the presence of an angularly rounded protuberance (fig. 7), for the lateral pit on the frontal and an obtusely rounded orbital border together with the general agreement of the more important surfaces and articulations, renders it almost impossible of mistaken identification. Viewed from the side when articulated the prefrontal is $U$-shaped, the opening being forward. The limbs of this bone are formed by two flattened, tapering processes (fig. 7), the upper being shorter and less expanded latterly than the lower, which extends downward and forward, being received in a groove on the internal posterior side of the lower branch of the lachrymal. The upper process continues forward, being interposed between the frontal, nasal, and lachrymal, as shown in figure 1, plate 4. On the external side at the junction of the two branches described above there is a concave articular surface 
which meets the posterior border of the lachrymal. The rounded spur-like projection of the frontal was received between the branches on the internal side of the bone. Its heavy vertically rounded posterior border forms the anterior boundary of the narrow but deep notch above the orbit.

So far as I am aware the prefrontal bone has not before been recognized in the Theropodous dinosaur skull except in Tyrannosaurus, where it is much more reduced and occupies a more central position, barely reaching the nasals.

Postfrontal + postorbital (po.f.). - The right postfrontal remained firmly attached to the posterior portion of the skull, the left was found detached, so that the two bones give a very accurate conception of its form and relationships. It is a triradiate bone, with one short heavy process that extends inward and articulates with the frontal by a deep interlocking suture; a second slender, tapering, posteriorly directed process that is received in a deep lateral groove on the anterior extension of the squamosal, these forming the upper temporal bar; the third, the longer one of the three, also a tapering process, extends downward and joins by a lapping suture the superior process of the jugal, thus forming the postorbital bar which separates the orbit from the infratemporal opening. This process, as in many of the Preden-

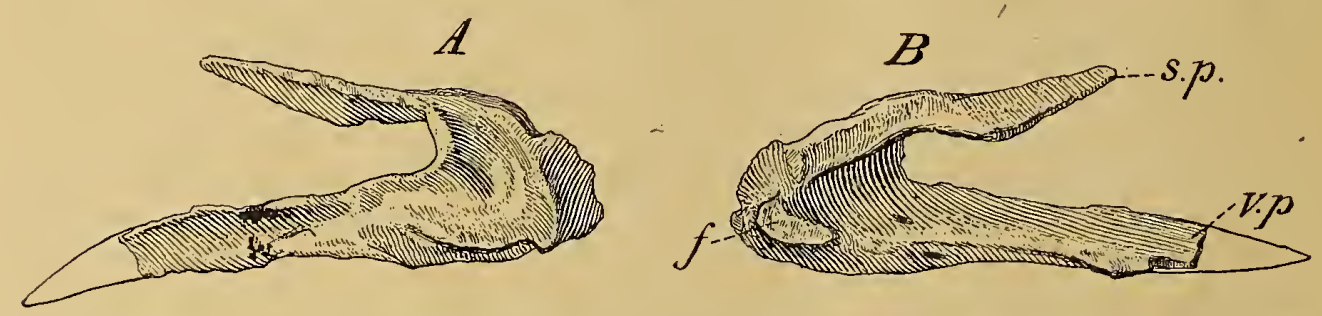

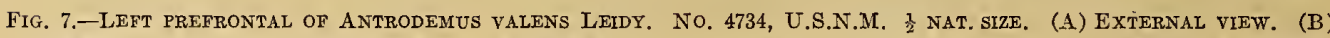
INTERNAL VIEW. $f$, PROTUBERANCE ON POSTERIOR END WHICH ENTERS A PIT ON SIDE OF FRONTAL; $s, p$, SUPERIOR PROCESS; $v$. $p$, VENTRAL PROCESS.

tate dinosauria, is trihedral in cross section. From the superior border to the end of the inferior branch it measures $190 \mathrm{~mm}$. in length. The greatest antero-posterior diameter is $160 \mathrm{~mm}$. Its principal features are well shown in plate 4, figures 1 and 2 .

The bone here identified as the postfrontal is called by some authorities the postorbital and by others the postfrontal. It undoubtedly represents a complex of the two bones as recognized by Osborn, for on the median internal side posterior to and below the sutural surface that meets the frontal is an elongated, cupped articular depression that receives the outer end of the alisphenoid as in all known dinosaurian crania. 'In those skulls in which the postfrontal and postorbital bones are found as distinct elements, this cupped depression for the reception of the outer end of the alisphenoid is always in the postorbital bone. It would appear therefore that the suture separating these bones, here coalesced, must be above this cup-like depression.

Proötic (pro.).-The proötic is wedged in between the parietal and occipital segments, and widely exposed externally. It bounds the auditory fenestra superiorly and also the foramen ovale. Osborn has shown that it also contributes to the boundary of the foramen for the exit of the seventh or facial nerve, but usually in dinosaurian crania this foramen passes directly through the proötic bone. On the 
posterior end it sends out a vertically expanded branch that extends backward and outward and laps along the median anterior surface of the opisthotic (fig. 6). The proötic is bounded superiorly by the parietal, anteriorly by the alisphenoid (orbitosphenoid of Osborn) and inferiorly by the basisphenoid.

Lachrymal (la.).-The elements bounding the orbits anteriorly and uniting with the jugals and maxillaries below, and with the nasals and frontals above are here designated as the lachrymals. Osborn in his description of the Tyrannosaurus skull ${ }^{1}$ following Gaupp, called the same bones the adlachrymals, but which correspond to the lachrymals of most authors. Since the appearance of that work, Gregory ${ }^{2}$ has conclusively shown that paleontological evidence does not support Gaupp's views and reaches the conclusion that "the prefrontal of reptiles is not homologous with the lachrymal of mammals."
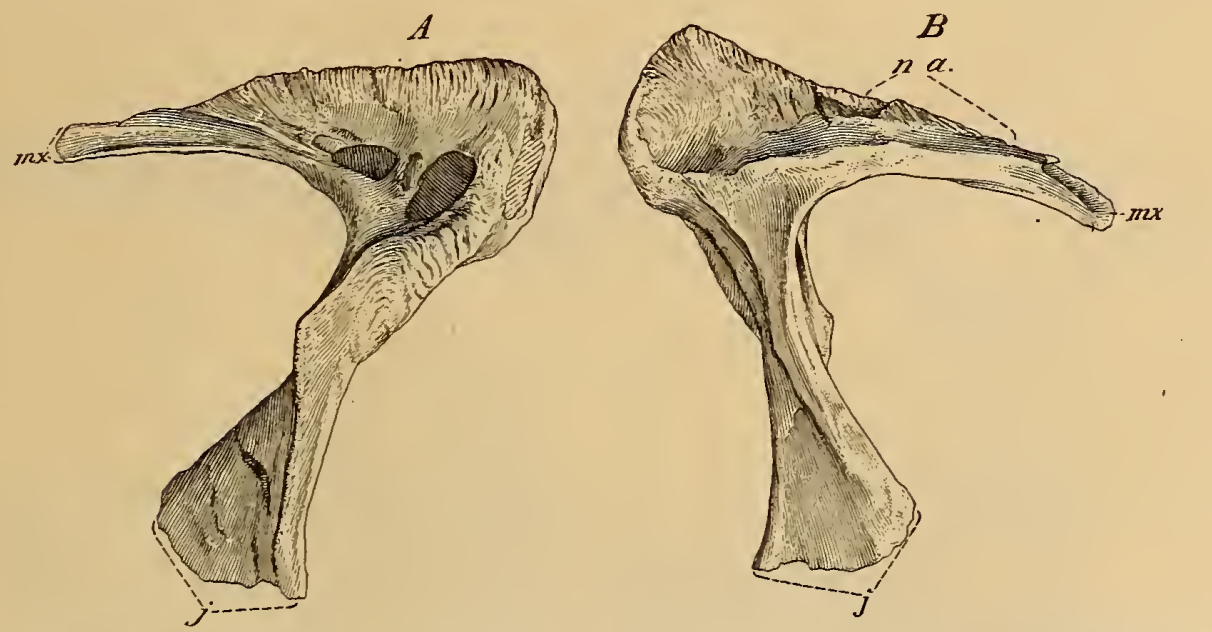

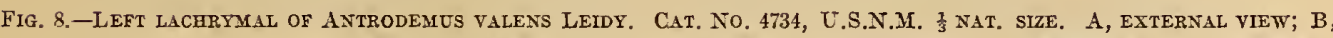
NNTERNAL VIEW, $j$, END THAT ARTICULATES WITH THE JUGAL; $m x$, PROCESS THAT UNITES WITH SUPERIOR AND POSTERIORLY DIRECTED PROCESS OF MAXILLARY; na, BORDER THAT MEETS THE NASALS.

The lachrymal in Antrodemus is an unusually robust element, the superior border of which forms a sharp, elongated (antero-posteriorly) elevation on the lateral median borders of the articulated skull. It may have supported, as first suggested by Osborn, "something in the nature of a low dermal horn."

The roughened surfaces of this portion of the lachrymal (fig. 8) are all indicative of the above conclusion.

On the external side (fig. 8, A), below the area described above, the bone is excavated, and still further lightened by deep connecting chambers within the heavier part of the bone. The entrance to this chambered region is by two oval openings, the larger one being posterior.

There is a slender tapering process which extends forward from the hornlike part of the prefrontal which meets the superior process from the maxillary, being

$1 \mathrm{Mem}$. Amer. Mus. Nat. Hist., vol. 1, new ser., pt. 1, 1912, p. 7.

2 Journ. Morphol., vol. 24, March, 1913, pp. 3-4; Proc. Paleontol. Soc., vol. 24, June, 1913, pp. 241-242.

${ }^{3}$ Bull. Amer. Mus. Nat. Hist., vol. 19, 1903, p. 701. 
united on the inside by a loose suture with the nasals and posteriorly with the prefrontals.

A moderately wide inferior process with an expanded distal extremity descends. to meet the jugal and maxillary.

The greatest height of the lachrymal of the right side is $254 \mathrm{~mm}$.; greatest length antero-posteriorly is $194 \mathrm{~mm}$. Both elements of specimen No. 4734, U.S.N.M., are present, though found disarticulated.

Nasals (n.).-The nasals in Antrodemus are narrow, elongate, bones. In specimen No. 4734, U.S.N.M., measuring $360 \mathrm{~mm}$. in length. Viewed from above, they gradually increase in width posteriorly. Both nasal bones were found disarticulated with this specimen, and though slightly distorted by pressure are otherwise perfectly preserved.
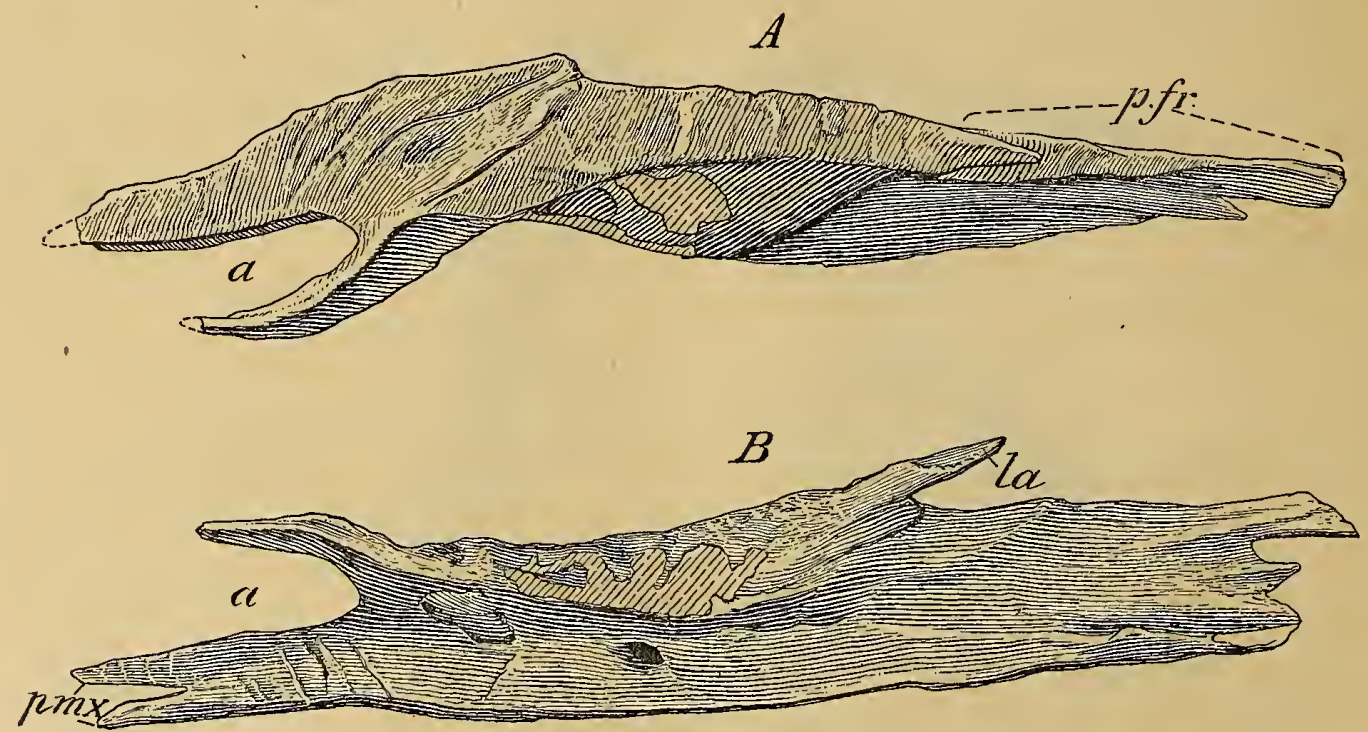

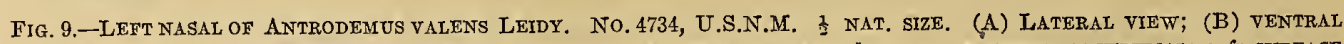
VIEW; $a$, NASAL CONTRIBUTION TO THE BOUNDARY OF THE ANTERIOR NARES; $l a$, SURFACE JOINING LACHRYMAL; $p . f r$, SURFACE JOINING PREFRONTAL; $p m x$, NOTCH RECEIVING PREMAXILLARY PROCESS.

They unite along their whole length on the midline by a deep vertical suture, the opposing surfaces of which are comparatively smooth.

Posteriorly the nasals are thin dorso-ventrally, but thicken anteriorly, reaching their maximum diameter just posterior to the border of the external nares. On the ventral side of the posterior end, where they overlap the forward ends of the frontals, these bones are longitudinally grooved with intervening ridges. (See B, fig. 9.)

On the external side at a point about one-third the total length of the bone from the posterior end is a slender spurlike process (fig. 9, la) that extends backward and slightly outward from the border and in the articulated skull passed on the outside of the anterior branch of the lachrymal as shown in figure 1. The external surface forward of this spur drops abruptly downward at right angles to the superior surface, presenting a sharp, raised edge where the two surfaces meet.

The narrow anterior end is bifurcated dorso-ventrally, the superior process from the premaxillary being received in a cleft in the dorsal prolongation (fig. 9). 
Viewed from the side this end is ovally emarginated, thus forming the nasal contribution to the boundaries of the external narial opening.

On the median ventral side the bone is traversed longitudinally by a shallow groove that marks the union of the nasal with the underlying maxillary. At the center and external to this groove the nasal overhangs the external surface of the maxillary, instead of rounding evenly into it as in most dinosaurian skulls. On the underside of this overhanging portion is one large opening, flanked by two smaller ones, that lead into connecting chambers within the heavier part of the bone. As observed in several of the larger elements of the skull, these chambers are evidently a provision of nature for getting the maximum strength from a minimum weight of bone, a feature that goes well with the light and open structure of the skull.
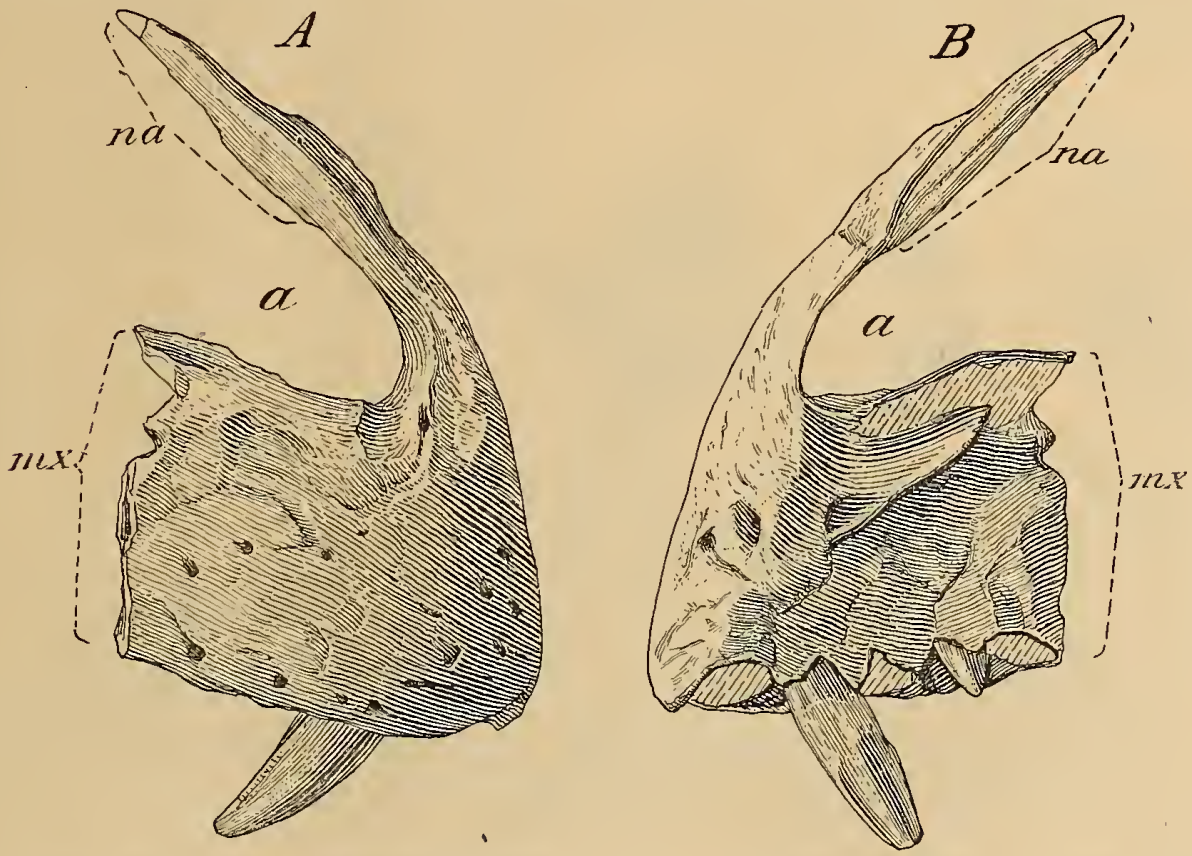

Fig. 10.-Right PREmaXillary of ANtrodemus valens Leidy. No. 4734, U.S.N.M. $\frac{1}{3}$ NAT. Size. (A) LATERAL view; (B) INTERNAL VIEW; $a$, ANTERIOR NARIAL OPENING; $m x$, END JOINING MAXILLARY; $n a$, EXTENT OF UNION WITH THE NASALS.

The sharp superior external edge, with the roughened central external margin of the nasal, is suggestive of having had a chitinous covering.

When articulated the median superior surfaces of the nasal region is decidedly dished transversely.

At the center the nasal has a transverse diameter of $56 \mathrm{~mm}$.; near the posterior end, $45 \mathrm{~mm}$.; near the anterior end, $15 \mathrm{~mm}$.

Premaxillary (pmx.).-The premaxillary is a heavy rectangular bone, with a long, slender, tapering process that projects upward and backward from the superior border anteriorly and forms part of the superior boundary of the external nasal opening. It unites above the nares with the nasals by a long lapping sutural contact. The anterior end presents a flattened surface, oblique to the longer axis of the bone, for union with the premaxillary of the opposite side (fig. 10). On the internal side 
immediately below the narial border is a deep longitudinal groove for the reception of a slender anterior process from the maxillary, otherwise the union of these two bones is by a straight vertical suture that is strengthened by a vertical median ridge on the posterior end of the premaxillary which fits into a corresponding depression on the anterior end of the maxillary. In Antrodemus the premaxillary carries five teeth, all of which, judging from the size of the aveoli and the two teeth preserved in this specimen, are of good size (fig. 10). The second aveolus contains a large worn tooth about to be shed and in the fourth aveolus is a germ tooth the point of which is just beginning to emerge below the dental parapet. Between the five aveolae are four well defined interdental rugosae. A careful comparison of this specimen with the right premaxillary figured by Marsh (on plate 12, fig. 1) Dinosaurs of North America (reproduced here as figure 11), as Creosaurus atrox fails to disclose any important differences, and since Lull has recently written me that this

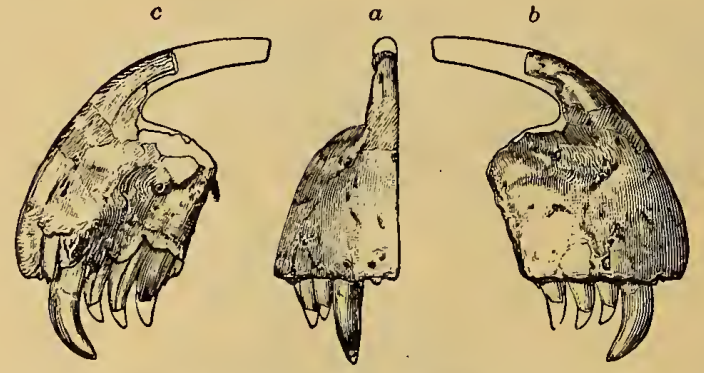

Fig.11.-Right premaxillary of Antrodemus, SP. Yale muSEUM. 1 NAT. SIZE. IDENTIFIED AND DESCRIBED BY MARSH as Creosaurus atrox. $a$, VIEWED FROM FRONT SIDE; $b$, VIEWED FROM SIDE; $c$, VIEWED FROM INTERNAL SIDE. (AFTER MARSH.) bone "may or may not" belong to the type material, I am inclined to regard it as pertaining to the genus Antrodemus, and probably also to the present species, though it pertains to a somewhat smaller individual than the premaxillary described above. The premaxillary of Antrodemus is relatively longer than in Ceratosaurus, which carries only three teeth. It may be distinguished from Tyrannosaurus and Coelurus (Ornitholestes) by the presence of four teeth in the premaxillaries of that genus. The greatest diameter anteroposteriorly of the premaxillary of No. 4734 is $105 \mathrm{~mm}$; its greatest depth from dental to nasal border is $83 \mathrm{~mm}$.

Maxillary $(m$.$) .- The left maxillary of No. 4734$ is almost entire and in a beautiful state of preservation. The functional teeth, with the exception of the ninth from the front, have all been lost. This maxillary contains alveoli for 17 teeth, and Osborn ${ }^{1}$ has observed in Antrodemus (Allosaurus), specimens studied by him, that "the maxillaries contain alveoli for from 16 to 18 teeth."

The type of Ceratosaurus nasicornis has 16 teeth in the maxillary though Marsh says 15 teeth.

Viewed laterally the maxillary is roughly triangular in outline, heavy in front and slender hehind. Dorsally it sends upward and backward a heavy tapering process that articulates with the nasal and lachrymal. The base of this process is perforated by the second antiorbital fenestra. This fenestra is absent in Ceratosaurus, but is present in Tyrannosaurus.

The anterior end of the maxillary is abruptly truncated and unites with the premaxillary by an open suture. This end has a transverse thickness of $27 \mathrm{~mm}$. 
In front of the superior process the concave upper border contributes to the boundary of the narial opening and to a considerably greater degree than in Ceratosaurus.

Posterior to the base of the ascending process the maxillary narrows rapidly in width to the obtusely pointed posterior end, which underlaps and unites by squamous suture with the anterior end of the jugal.

Viewed from the side the dental border is slightly sinuous. The lower external surface is perforated by a considerable number of foramina. The larger foramina appear to arrange themselves in two rows, an upper curved row that in going forward ascends one-third the height of the bone, and a lower row that parallels the alveolar border (fig. 2, pl. 4). Between these rows, and irregularly placed, are numerous smaller foramina, and forward of the curved row, which stops beneath the second antiorbital fenestra, scattered foramina are observed nearly to the top of this portion of the maxillary.

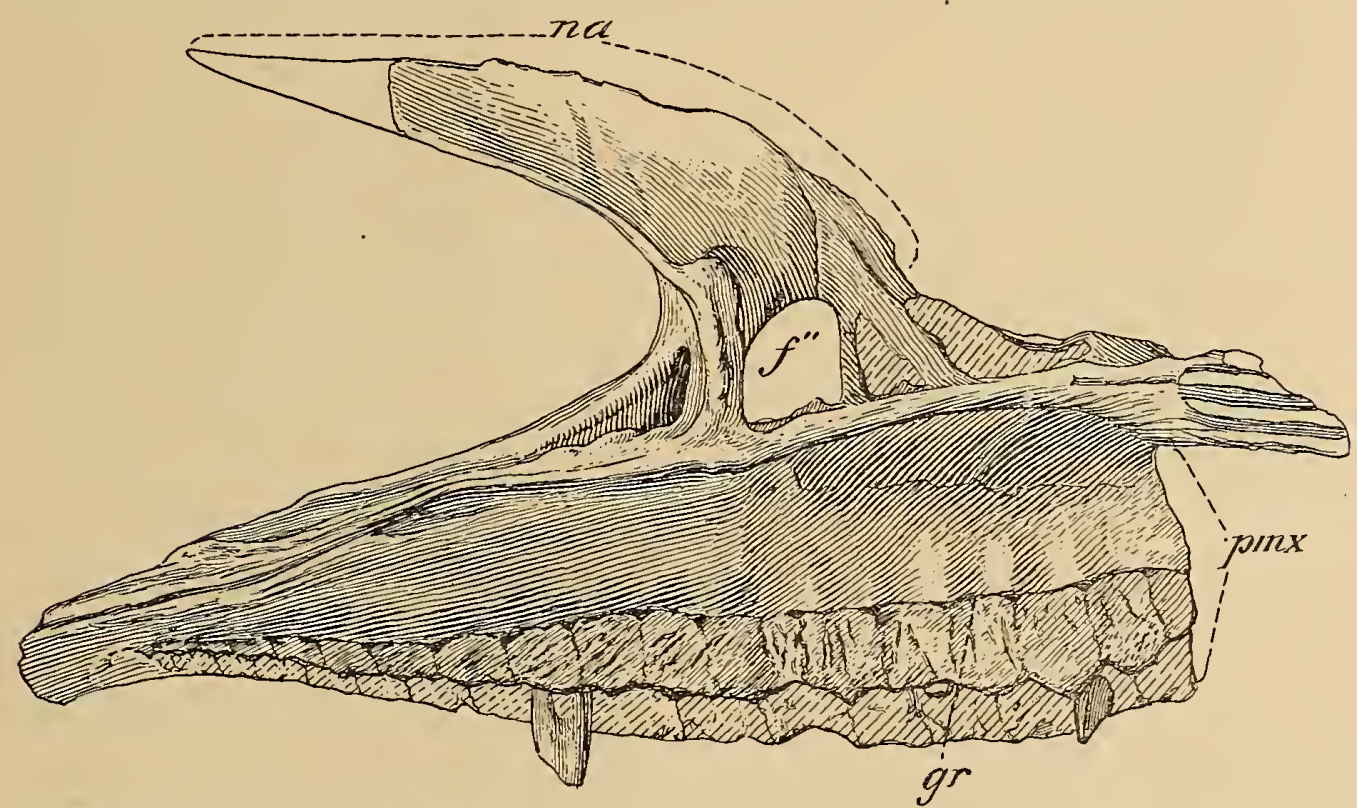

FIG. 12.-Left Maxillary of ANTROdemus valens LeIDY. No. 4734, U.S.N.M. INTERNal view. $\frac{2}{3}$ Nat. SIZE. f", SECOND ANTIORBITAL FENESTRA; $g r$, GROOVES FOR BLOOD VESSELS; $n a$, EXTENT OF UNION WITH NASAL BONE; $p m x$, END JOINING PREMIXILLARY.

The general form and appearance of the maxillary when detached from the surrounding elements is well shown in figure 12.

On the internal side (fig. 12) some $25 \mathrm{~mm}$., superior to the aveolar border on the anterior end and approaching withing $5 \mathrm{~mm}$. at the posterior end, is a row of small dental foramina. These foramina are at the bases of the interdental plates and are connected by nutrient grooves ( $g r$, fig. 12). The interdental plates hare their internal surfaces considerably roughened, and they shorten dorso-ventrally from the front toward the back. On the upper border of the internal side, on the anterior half of the maxillary, a strong shelf of bone projects inward, the anterior end of this shelf projecting some distance in front of the maxillo-premaxillary $144035-20-3$ 
suture. The inner side of this process is longitudinally grooved for articulation with the process on the opposite maxillary.

On the inner side of the ascending process and between the antiorbital fenestrae this process develops an inward extension that stands at right angles to the longer diameter of the process. It is perforated just above its junction with the body of the maxillary by an elliptical foramen apparently establishing a connection between the antiorbital fenestra.

On the superior border of the posterior branch the surface is roughly striated antero-posteriorly, evidently indicating the point of union with the palatines.

The greatest length of the maxillary is $360 \mathrm{~mm}$. . Osborn in the paper previously cited gives the length in the American Museum specimen as $460 \mathrm{~mm}$., but this is evidently a mistake as the illustrations accompanying that article show it to be about $378 \mathrm{~mm}$., which represents an adult specimen.

The series of alveoli measure $292 \mathrm{~mm}$. in length. These decrease in size from front to back, and are separated from one another by exceedingly thin bony partitions.

Jugal (j.).-The jugal is an exceedingly thin (transversely) triradiate bone (fig. 13), its median portion forming the lower boundary of the orbit. The anterior end is greatly expanded dorso-ventrally and laps along the outer sides of the lachrymal and maxillary. The tapering superior process joins by squamous union with the descending process from the postorbital complex, the two forming the postorbital bar which separates the orbit and lateral temporal fossa. Its manner of articulation with the quadratojugal is described under that heading and need not be repeated here. The jugal in Antrodemus is relatively longer than in Tyrannosaurus, and is heavier than the same bone in Ceratosaurus. The right jugal in No. 4734 has a greatest length of about $295 \mathrm{~mm}$. and a greatest height at the center of $144 \mathrm{~mm}$.

Quadratojugal ( $q j$.$) . - The quadratojugal joins the quadrate by a vertical suture$ along its inner posterior side, the median portion of the border being free forms the outer boundary of the quadrate foramen. This bone sends upward a moderately broad superior plate that joins, externally, by squamous suture, with a descending process from the squamosals as shown in figure 2 on plate 4. This quadratojugal of Antrodemus may at once be distinguished from the same bone of Tyrannosaurus by its narrower superior plate and its more rounded proximal extremity as compared with the broadly expanded and squarely truncated end in the latter genus. This plate is, however, somewhat shorter and also broader antero-posteriorly, than in Ceratosaurus.

The transversally flattened inferior process is directed forward and forms the great part of the lower boundary of the lateral temporal fossa. This bar is lapped along the ventral internal side by a slender tapering posteriorly directed triangular process of the jugal. Shown in figure 2 on plate 4, as being depressed slightly out of position. The forward end of the inferior bar of the quadratojugal divides into two spurs between which is received a portion of the upper posteriorly directed process of the jugal, these form a strong union. of the bones at this point. The flattened internal spur, (fig. 13), extends somewhat further forward than the external spur (figs. 1 and 2 on pl. 4). The greatest length antero-posteriorly of the inferior 
part of the quadratojugal is $143 \mathrm{~mm}$. the greatest diameter dorso-ventrally is $135 \mathrm{~mm}$.

Quadrate (q.).-The quadrate from the right side of skull No. 4734, U.S.N.M., is perfectly preserved and since it was found detached from the posterior part of the skull I am able to describe this element in detail. This bone is relatively short having a greatest length dorso-ventrally of $192 \mathrm{~mm}$., with an irregularly rounded articular proximal end for articulation with the squamosal. The distal end is widely expanded transversely with a smooth articulating surface that is bisected diagonally by a broad concave depression that divides this end in to two elongate, obtusely rounded articular surfaces that fit closely in to the cotyloid depressions of the lower mandible. The articulating surfaces of this end of the quadrate extend well up on the anterior and posterior aspects, being separated from the nonarticular part of these surfaces by a low but well defined undulating ridge.

Externally the quadrate is suturally united with the quadratojugal. The suture between the two bones beginning $31 \mathrm{~mm}$. below the upper extremity is visible from a lateral aspect but just above the quadrate foramen it passes to the posterior view. As in Ceratosaurus and Tyrannosaurus the external boundary of the quadrate foramen is formed by the inner surface of the quadratojugal. The posterior view presents a deep depression that slopes forward in all directions toward the quadrate foramen. A widely rounded groove runs diagonally downward from the inner surface of the quadrate to the

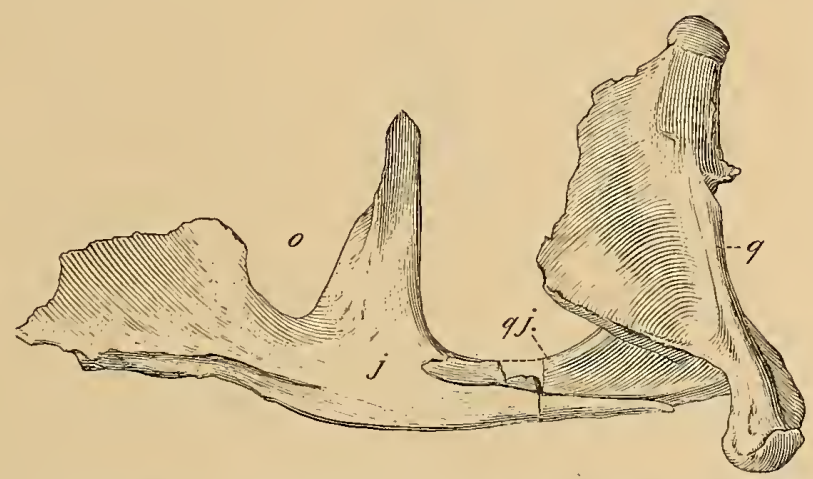

Fig. 13.-Right JUGAL, QUADRATOJUGAL, AND QUADRATE, OF ANTRONEMUS VALENS LEIDY. NO. 4734, U.S.N.M. $\frac{1}{4}$ NAT. SIZE. VIEWED FROM THE INTERNAL SWE. $j$, JUGAL; $o$, LOWER BOUNDARY OF THE ORBIT; $q j$, QUADRATOJUGAL; $q$, QUADRATE. quadrate foramen. Imme-

diately above this groove on the median posterior side a pointed spurlike projection extends posteriorly. On the anterior inner side the quadrate sends anteriorly a thin trianguilar sheet of bone that meets the pterygoids in the articulated skull by squamous suture. The lower border of this forward projection turns inward at right angles forming a narrow shelf that extends back and joins with the heavier shaft of the quadrate. The greatest transverse width of the distal end is $89 \mathrm{~mm}$., the greatest diameter of the proximal end is $27 \mathrm{~mm}$.

Squamosal (sq.).-The right squamosal of skull No. 4734, U.S.N.M., was found articulated, the left one being detached. These elements show the squamosal to be an irregular-shaped element, with a deep, cupped surface on the lower posterior side for the reception of the upper articular end of the quadrate. Forward of this articulation a wide but thin process descends to meet the quadratojugal, its lower end uniting by squamous union on the inner side of the upper end of the quadratojugal. Posterior to the quadrate articulation the squamosal contracts to an obtusely pointed process external to which a heavy descending process is directed 
downward behind the head of the quadrate as in Ceratosaurus. An anteriorly directed process meets the postfrontal, the latter being received in a deep elongated groove on the external face.

Posteriorly it rests upon the front upper border of the paraoccipital process. Continuing inward it meets the base of the transverse portion of the parietal with which it is suturally united. The longer axis of the squamosal in the articulated skull is inclined somewhat forward from the vertical as shown in plate 4 , figure 2. Its greatest vertical extent is $175 \mathrm{~mm}$.

Ectopterygoid (ec. pt.).- - In this specimen we are fortunate in having both ectopterygoid bones present in a good state of preservation, though found disarticulated. Through the kindness of Messrs. Walter Granger and Barnum Brown,

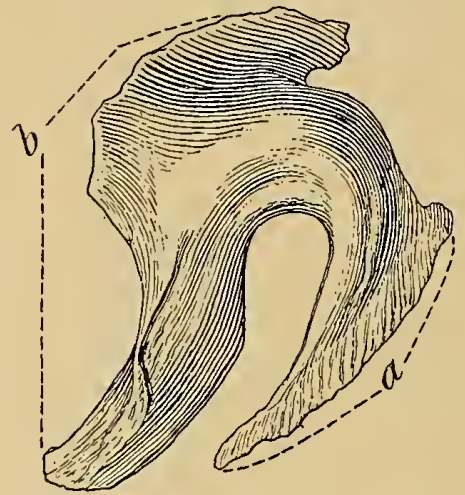

Fig. 14.- Right ectopterygoid of ANtroDEMUS VALENS LEIDY. NO. 4734, U.S.N.M. VIEWED FROM ABOVE, $\frac{1}{3}$ NAT, SIZE. $a$, BORDER LAPPING ALONG INNER SWE OF JUGAL; $b$, SIDE WHICH JOINS THE PTERYGOID of the American Museum of Natural History, New York, these bones were carefully compared with the articulated elements in Theropod skulls of that institution, so that their proper position in the palate as now articulated is to be relied upon as being accurate.

The ectopterygoid in Antrodemus is an irregularly U-shaped bone formed by two posteriorly directed branches, the more slender of which laps along the inner side of the jugal. The larger one is directed downward and backward extending well below the border of the jugal, as in Sphenodon. Along its posterior side it is lapped by a descending branch of the pterygoid, which in Ceratosaurus extends to the lower end of this process, and following that evidence it has been so restored in the Antrodemus skull. On the anterior internal side this bone develops a thin, curved, wing-like process that overlaps a convex extension of the pterygoid, as indicated in figure 14.

Pterygoid $(p t$.).-The pterygoids are represented by a considerable part of the central portion of the right element. The left is missing. A thin, vertical process extends backward and outward from its articulation with the basisphenoid processes and unites with the inner and forwardly directed plate-like extension of the quadrate (fig. 1). A horizontal process extending forward and outward from the same point of attachment underlaps the ectopterygoid and sends downward and backward a slender process that reaches the full length of a similar ventral process of the ectopterygoid.

The relations of the pterygoids to the other bones of the palate in Antrodemus are unknown at this time. 
Comparative measurements of Antrodemus and Ceratosaurus skulls.

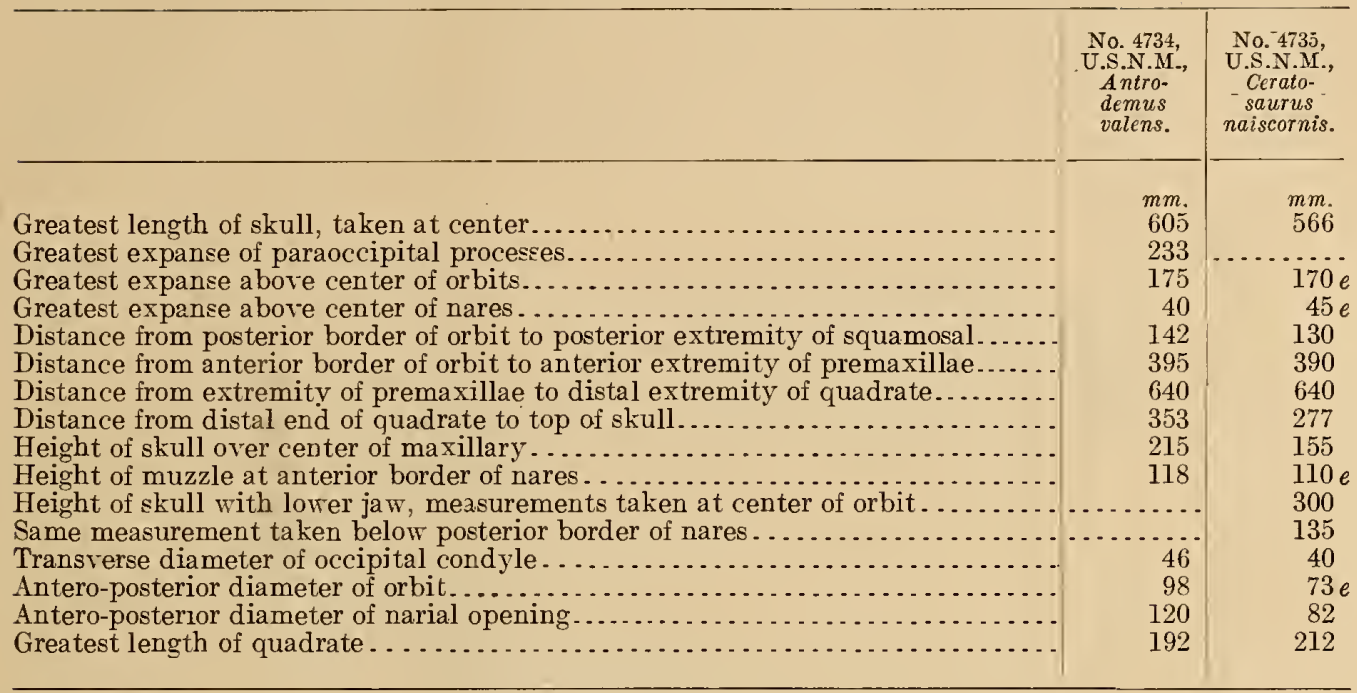

$e=$ Estimated

LOWER JAW.

Plates 3-4.

With the skull of No. 4734, U.S.N.M., only the posterior half of the right ramus is present. In this portion the articular, surangular, and prearticular are clearly determinable as shown in figure 15. A dentary from the same side belonging to specimen No. 8335, U.S.N.M., a slightly larger individual, has been introduced in the restoration of the lower mandible of No. 4734, U.S.N.M. The above-mentioned bones constitute all of the Antrodemus jaw material in the collections of the United States National Museum. As now restored the right ramus has a greatest length of $680 \mathrm{~mm}$.

Dentary (d.).-The dentary of specimen No. 8335, U.S.N.M., on which the present description is based, contains alveoli for 15 teeth, whereas Osborn ${ }^{1}$ has observed 16 alveoli in a dentary studied by him. These teeth occupy a space 297 $\mathrm{mm}$. long. On the internal side the alveolar septa expand into interdental "rugosae," similar to those found in Tyrannosaurus and other carnivorous dinosaurs. Transversely the dentary is much compressed, with a slightly thickened and rounded inferior border. Vertically this bone remains about the same depth $(65 \mathrm{~mm}$.) until toward the posterior end of the dental series it gradually increases in this diameter. The union with the opposite jaw was probably membraneous, there being no indication of a symphysial surface. The anterior end of the dentary is more angularly truncated than in Ceratosaurus, which presents a more rounded end. The posterior end of this dentary is missing, so that its exact manner of articulation with the surangular, angular, and splenial can not be determined. The principal features of this bone are well shown in figure 15. 
Supradentary (s. d.).-The supradentary is missing from this specimen No. 8335, U.S.N.M. That such an element was present is obvious after a comparison with the more perfect ramus of Ceratosaurus nasicornis. The bone mentioned by Osborn ${ }^{1}$ as the "presplenial" in his preliminary description of the Antrodemus (Creosaurus) jaw is in all probability the supradentary plate. He says: "If this is truly the presplenial it appears to extend as far forward as the symphysis." This is the condition in Ceratosaurus (fig. 55 d. p.).

Splenial (s.).-The complete splenial bone is apparently unknown in Antrodemus. It is missing in all of the specimens before me, but from the little available evidence it appears to have been a thin, triangular-shaped bone, that overlapped the inner side of the dentary, extending anteriorly for about half its length.

Coronoid (c.).-The coronoid is also missing from the specimens before me. Osborn in the article cited above says: "The suture between the coronoid and angular is faintly determinable posteriorly, the coronoid being depressed." Evidently the suture mentioned was that between the coronoid and the surangular. In the restoration of the ramus the coronoid was restored to fill the small triangular space between the prearticular and surangular as in Tyrannosaurus. ${ }^{2}$

Angular (an.).-The complete angular in Antrodemus is unknown. In figure 2, on plate 4, this bone has been restored after that element in Ceratosaurus. Its posterior extent appears to be indicated on the external side of the surangular and prearticular by a smoother surface and this peculiarity guided us somewhat in restoring this bone.

Surangular (sur. and sa.).-With specimen No. 4734, U.S.N.M., was found the nearly complete posterior portion of the right ramus in a beautiful state of preservation.

For the first time a complete surangular, articular, and prearticular are now known of Antrodemus. Unfortunately several of the sutures have become obliterated through coossification and the exact extent of certain parts of these bones can not be absolutely determined.

This specimen shows the surangular to have a very extensive exposure on the external side, which forms the entire upper border of the posterior half of the jaw. It is a relatively long bone, as in Ceratosaurus, and overlaps the posterior end of the dentary by a long squamous union. The bone is thin with the exception of the dorsal portion which turns inward at nearly right angles to the lateral surfaces and is somewhat thickened. Anteriorly, this inner extension has a longitudinal groove for the articulation with the upper posterior part of the dentary (C, fig. 15). Posteriorly, it articulates with the articular, and with that bone forms the outer part of the cotylus for articulation with the quadrate. It continues backward along the outer side of the articular but stops slightly forward of its posterior extremity. Ventrally it is suturally united with the angular and prearticular as indicated in figure 15.

On the median ventral border it is deeply notched by the external mandibular foramen, shown in figure $15(\mathrm{~A}) \mathrm{ex} . \mathrm{f}$.

The small posterior foramen observed in the surangular of Tyrannosaurus rex Osborn and Gorgosaurus libratus Lambe is not present in Antrodemus, though on the 
median anterior surface it is pierced by a small foramen that passes through the bone in a diagonal direction toward the front. The external surface is broadly concave dorso-ventrally and the inner is concave in the same diameter. The ventral anterior border is concave from the mandibular foramen upward and forward meeting the horizontal process that extends forward from the upper anterior surface to lap along the dentary.
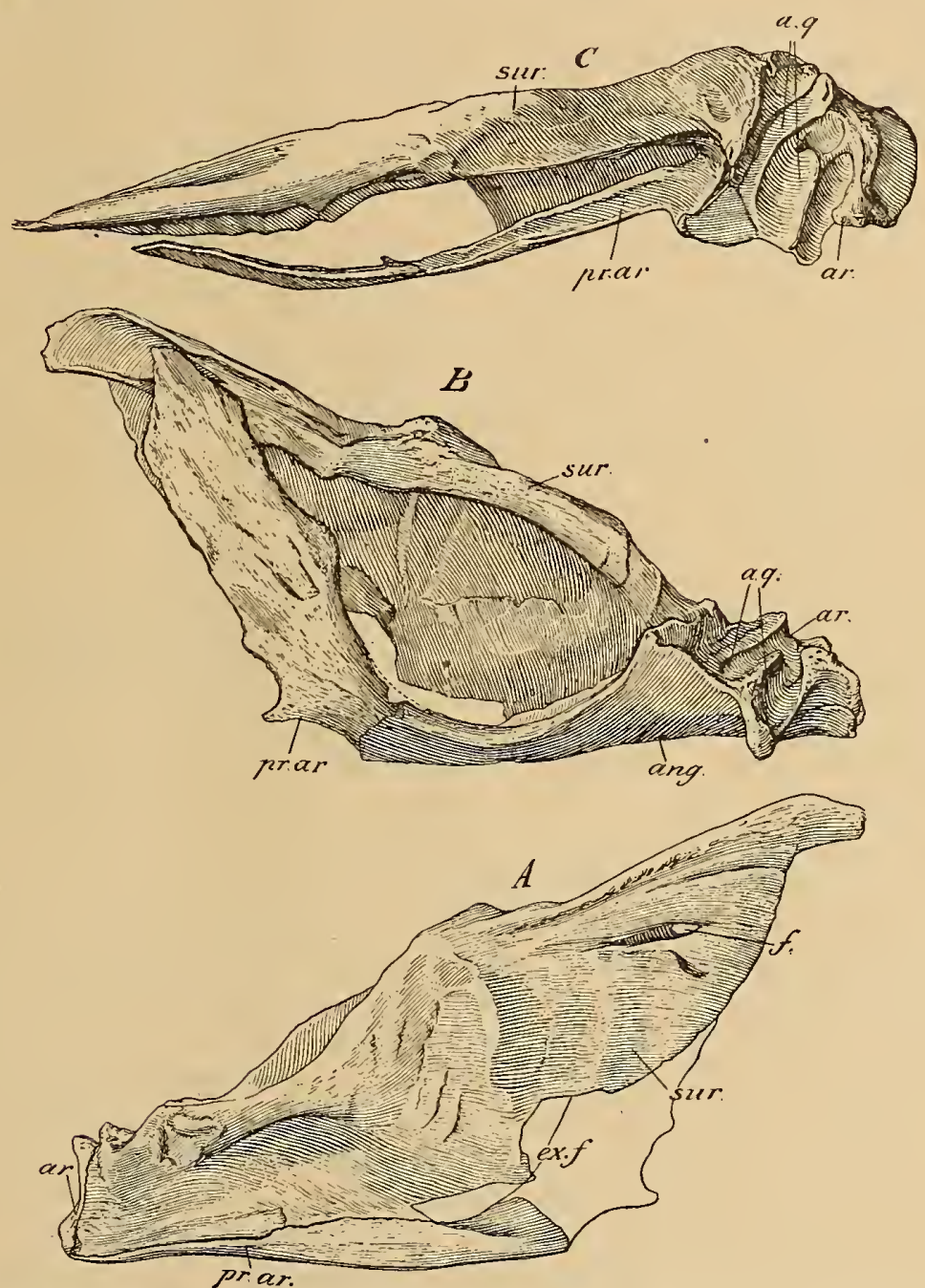

Fig. 15.-Postebior end of right ramus of Antrodemus valens Leidy. Cat. No. 4734, U.S.N.M. AlL $\frac{1}{z}$ Nat. Stze. $A$, EXTERNAL VIEW; $B$, INTERNAL VIEW; $C$, SUPERIOR VIEW; $a$ g, ANGULAR; a.q, SURFACES FOR ARTICULATION WITH QUADRATE; ar, ARTICULAR; ex.f, EXTERNAL MANDIBULAR FORAMEN; $f$, FORAMEN; pr.ar, PREARTICULAR; sur, sURANGULAR.

Articular (ar.).-The articular is an irregular bone wider than long, and constitutes the greater part of the posterior portion of the ramus. The cotylus of the articular has its greatest extent, transverse, deeply bifossate, these fossae being separated by an oblique ridge. The close articulation of the quadrate with these 
depressions apparently indicates a strictly upward and downward movement of the jaws. The articular forms more than one-half of the cotylus the anterior outer portion being in the surangular. Posterior to the cotylus on the inner side, there is an exceptionally deep transverse notch (fig. 15., C).

A high thin transverse ridge separates this notch from the broad, oblique, dorso-ventrally compressed posterior end of the articular which forms the most posterior portion of the ramus. The articular is overlapped along its outer side by the surangular, and on the ventral outer third by the prearticular.

Prearticular ( $p$. ar. and pr. ar.).--The prearticular is well shown in figure 15. It is a long curved element that extends forward from the articular and forms the lower posterior boundary of the ramus, externally it turns up and joins the inferior border of the surangular as shown in $A$ in figure 15. Unfortunately, on account of the coalesence of the suture with the articular the exact line of demarcation between these two elements can not be determined. The forward prolongation at about the center of the external mandibular foramen turns strongly upward terminating in a pointed end at the top of the-surangular. This part of the bone is relatively thin transversely but considerably expanded antero-posteriorly as shown in figure 15, B. It is almost identical in shape and position with the prearticular of Tyrannosaurus as figured by Osborn. ${ }^{1}$

EXTERNAL OPENINGS IN THE SKULL.

Viewed from the side, the openings in the skull of Antrodemus, beginning posteriorly, are the lateral temporal fenestra, the orbito-infraorbital opening, the first antiorbital fenestra, the second antiorbital fenestra and the anterior nares. I can find no evidence of a third antiorbital fenestra in specimen No. 4734, U.S.N.M., such as is present in Tyrannosaurus and which Osborn has observed ${ }^{2}$ in two skulls of Antrodemus in the collections of the American Museum of Natural History. Viewed dorsally the supratemporal fossae on either side of the brain case are the only openings of importance. No pineal opening present.

Lateral temporal fenestra (lat. t. fen.).-The lateral temporal fenestra is a vertically elongated opening, narrower above than below. This fenestra is bounded above by the postemporal bar formed by the united processes of the squamosal and postorbital bones; anteriorly by the postorbital bar formed by the union of the processes of the postorbital and jugal; ventrally by the quadratojugal and squamosal. The greatest vertical extent is $200 \mathrm{~mm}$; the greatest diameter anteroposteriorly is $80 \mathrm{~mm}$. whereas the same measurement in Ceratosaurus is $120 \mathrm{~mm}$.

Orbital opening $(o$.$) .- - Like the temporal fenestra the orbital opening is verti-$ cally elongated, widest antero-posteriorly at the middle, but narrowing at both top and bottom. There is no partial separation of the infraorbital portion as in Tyrannosaurus. Dorsally the upper boundary is formed by the postorbital-postfrontal complex, frontal, and prefrontal; anteriorly by the prefrontal and jugal; ventrally by the jugal, and posteriorly by the descending and ascending branches of the postorbital and jugal resfectively. At the top a deep but narrow notch carries the border in to the frontal.

${ }_{1}^{1}$ Memoir Amer. Mus. Nat. Hist., new ser., vol. 1, pt. 1, 1912, p. 22, fig. 18.

${ }^{2}$ Idem, p. 28, figs. 26, 27. 
First antiorbital fenestra $\left(f^{\prime}\right)$.- The first antiorbital fenestra is of large size, being relatively larger than in either Tyrannosaurus or Ceratosaurus and by far the largest vacuity in the skull. Its upper boundary is formed by the lachrymal and maxillary, anteriorly by the maxillary, ventrally by the maxillary and jugal, and posteriorly by the descending branch of the lachrymal.

Second antiorbital fenestra $\left(f^{\prime \prime}\right)$.- This opening which is small, subcircular in outline lies wholly within the maxillary.

Anterior nares (ex.nar.).-The external narial opening is elongate, oval in form and is bounded above by the nasal and premaxillary bones; anteriorly by the premaxillary; below by premaxillary and maxillary and posteriorly by the nasal and maxillary. In this specimen it has a length antero-posteriorly of $118 \mathrm{~mm}$.; a depth at the center of about $40 \mathrm{~mm}$.
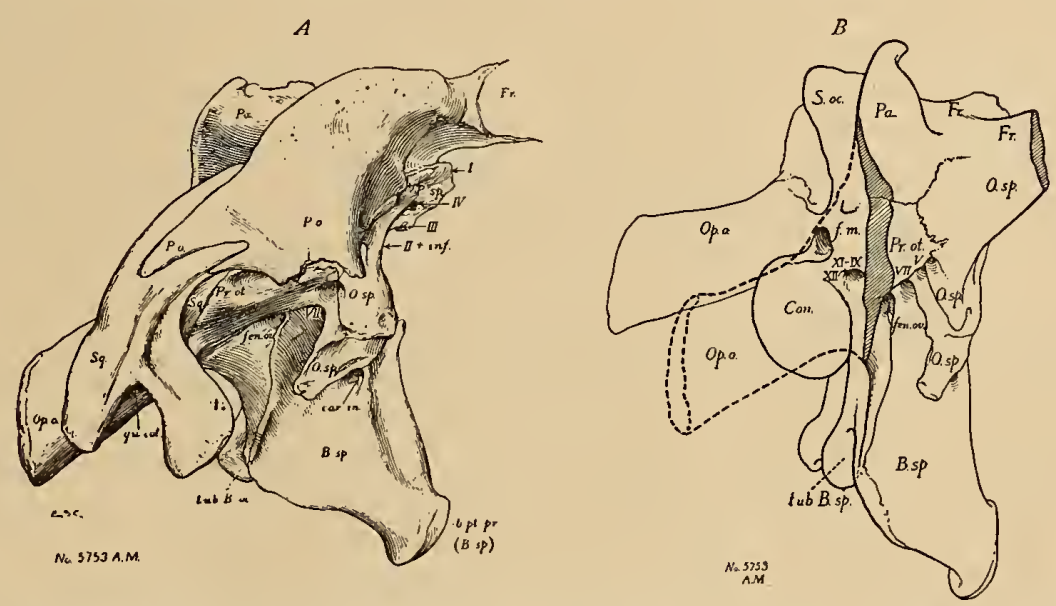

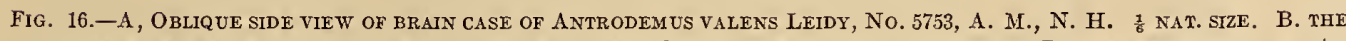
SAME WITH POSTFRONTAL AND SQUAMOSAL REMOVED; b.pt.pr, BASIPTEYGOID PROCESSES; B.sp, BASISPHENOID; car. in, CAROTID INTERNUS; con, OCCIPITAL CONDYLE; $f . m$, FORAMEN MAGNUM; fen.or, FENESTRA ovaLIS; Fr, FRONTAL; op. 0 PAROCCIPITAL; $0 . s p$, ALISPHENOID; $P a$, PARIETAL; Po, POSTORBITAL COMPLEX; Pr.ot, PROotic; P.sp, PRESPHENOID; $q u . c o t$, COTYLUS FOR QUADRATE; S.oc, SUPRAOCCIPITAL; $s q$, SQUAMOSAL; $t u b . B . o c$, TUBEROSITY OF BASIOCCIPITAL; $t u b$. $B . s p$, TUBEROSITY OF BASISPH ENOID; I, II, III, IV, V, VII, IX, XI, XII, FORAMINA FOR EXIT OF CRANIAL NERVES. PARAOCCIPITAI REPRESENTED AS TRANSPARENT IN ORDER TO SHOW FORAMINA. BOTH FIGURES (AFTER OSBORN).

Supratemporal fossa (s.t.f.).-The supratemporal fossae are of large size, especially when compared with those of Ceratosaurus nasicornis. Although these vacuities are considerably larger than as represented in Marsh's restoration of the top view of the skull of that animal. This fossa in Antrodemus is bounded anteriorly by the frontals, alisphenoid, and postorbitals; externally by the postorbital and squamosal above, below by the proötic and exoccipital; internally by the parietal, proötic and alisphenoid.

TEETH.

The dental formula of Antrodemus valens Leidy as shown by a study of several individuals :

Upper jaw: premaxillary, 5; maxillary, 15 to 17 ; total, 20 to 22 .

Lower jaw: Dentary, 15. 
All of the premaxillae studied agree in having a constant number of five teeth, which is two more than in Ceratosaurus, and one more than in Gorgosaurus and Tyrannosaurus respectively. In the maxilla, however, the number appears to be variable. All of those in the United States National Museum collections have alveoli for 17 teeth, but a specimen (No. 666) in the American Museum of Natural History, New York City, has only 15. One of the progressive specializations in this group of carnivorous dinosaurs along with the reduction of the fore limb and foot, appears to be a progressive decrease in the total number of teeth in the dental series, as for example Antrodemus from the Morrison formation has 20 to 22 teeth in the upper series and 15 in the lower; Gorgosaurus from the Belly River formation, 18 teeth in the upper and 14 in the lower series; and Tyrannosaurus from the Lance formation has 16 teeth in the upper series and 13 to 14 in the lower.

The premaxillary teeth are represented in specimen No. 4734, U.S.N.M., by the second and fourth of the right side. The second is a large worn tooth about to be shed, (fig. 10); the fourth a germ tooth, the point just emerging below the parapet of the alveolus. The second is a heavy strong tooth with little lateral compression that curves backward, being excellently adapted for use as a tearing instrument. It is probably equalled if not exceeded in size by the first of the series. Judging from the size of the alveoli the others progressively decrease in size toward the back.

The general features of the premaxillary teeth of Antrodemus are best displayed in specimen No. 1890 Yale University Museum, shown here in figure 11. This specimen was figured by Marsh as pertaining to Creosaurus atrox, but I am of the opinion, as expressed on page 20, that in all probability it belongs to the genus Antrodemus.

Material for study of the maxillary teeth is found in three specimens. No. 8423, U.S.N.M., has the second, third, fourth, and fifth teeth almost perfectly preserved in the right maxillary; No. 8335, U.S.N.M. has portions of the first, second, fourth, sixth, seventh, eighth (young), ninth, tenth (entire), eleventh, twelf th, and thirteenth (young); in the right maxillary; No. 4734, U.S.N.M., has the basal portion of the ninth tooth in the left maxillary. In addition there are in the collection a great number of detached teeth, but these are of little value, since at this time there is no way to distinguish upper from lower, and the location of loose teeth in the series is a very uncertain undertaking.

Apparently all of the teeth of Antrodemus have serrate edges. The edges are minutely serrated as in Ceratosaurus, there being about 10 denticulations in a length of $5 \mathrm{~mm}$. The teeth of the above genera appear to be indistinguishable. These serrations are on both front and back borders, but the posterior continues to the base of the tooth, whereas the anterior ends somewhat above it.

From the front toward the back of the series the outer surfaces of the teeth are gradually reduced, the inner expanded, until on the ninth or tenth tooth the two surfaces are subequal.

The anterior teeth are large, the fourth protruding $57 \mathrm{~mm}$. below the parapet of the alveolus. They continue robust back to the ninth, but posterior to that tooth they decrease rapidly in size, the seventeenth, judging from the alveolus being relatively of diminutive size. All of the maxillary teeth are latterly com- 
pressed with a backward curvature, especially of the upper anterior border. The upper portion tapers to an obtuse point. In section this part of the teeth is lenticular.

The great irregularity in size of the teeth is due to the loss of functional teeth and their subsequent replacement by young teeth which appear in various stages of growth. These changes apparently went on throughout the life of the individual.

Some of the teeth show signs of wear on the inner sides near their tips, but this abrasion is only found on the fully erupted ones. Many of the detached teeth in the collection are thus worn, probably from abrasion caused by the rubbing of the points of the upper and lower series.

VERTEBRAL COLUMN.

The vertebral formula in Antrodemus valens Leidy as largely determined from specimen No. 4734, U.S.N.M., is as follows: C, 9 ; D, 14; S, 5 ; C, $45 \pm$.

The precise number of vertebrae in the tail yet remains to be determined. Since the type of Ceratosaurus nasicornis shows 50 vertebrae it appears fair to assume that Antrodemus had an equal number. An articulated presacral series in the American Museum of Natural History, New York City, No. 666, verifies the present specimen in showing that there are 23 vertebrae in front of the sacrum.

A second specimen in the United States National Museum collection, No. 8367 , has 18 presacral vertebrae present, nearly all in an excellent state of preservation. The descriptions of the vertebrae to follow are largely based upon these two specimens.

The vertebral formula of Antrodemus as compared with other Theropodous dinosaurs is as follows.

\begin{tabular}{|c|c|c|c|c|c|c|}
\hline & Antrodemus. & Ceratosaurus. & $\begin{array}{l}\text { Gorgosau- } \\
\text { rus. }\end{array}$ & $\begin{array}{l}\text { Tyranno- } \\
\text { saurus. }\end{array}$ & $\begin{array}{l}\text { Ornitholes- } \\
\text { tes. }\end{array}$ & $\begin{array}{l}\text { Ornithomi- } \\
\text { mus. }\end{array}$ \\
\hline 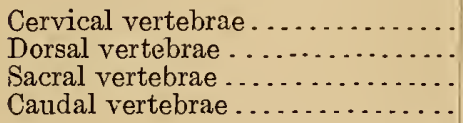 & $\begin{array}{r}9 \\
14 \\
5 \\
45 \pm\end{array}$ & $\begin{array}{r}? 9 \\
? 14 \\
5 \\
52\end{array}$ & $\begin{array}{r}? 9 \\
? 14 \\
5 \\
36 \pm\end{array}$ & $\begin{array}{r}10-9 \\
13-14 \\
5 \\
? 53\end{array}$ & $\begin{array}{r}19 ? \\
? 13 \\
4 \\
? 39-44\end{array}$ & $\begin{array}{r}10 \\
13 \\
5 \\
\quad \ldots \ldots\end{array}$ \\
\hline
\end{tabular}

Atlas (a. in.).-In specimen No. 4734, U.S.N.M., we are fortunate in having found the atlas and axis nearly in position in relation to one another, and the manner of their articulation is clearly shown in figure 17. Viewed latterly, when articulated with the hypocentrum of the axis, the cupped anterior surface of the intercentrum looks upward and forward at an angle of $45^{\circ}$ to the longer diameter of the axis.

The intercentrum of Antrodemus may be distinguished from that of Ceratosaurus by its shorter diameter antero-posteriorly, the more nearly parallel anterior and posterior borders when viewed from the side, and the greater width of the concave surface on the superior side. There are other slight differences noted, but doubtless these would vary with the individual. The chief features of this bone are clearly shown in figure 17 . The greatest length is $28 \mathrm{~mm}$.; greatest width is $66 \mathrm{~mm}$.

Only the neuropophysis of the left side is preserved with this specimen, and it lacks portions of the anterior and posterior processes. It differs from the neurapophysis of Ceratosaurus, however, in the less transverse expansion of the articular 
end of the pedicle, the greater expansion of this end antero-posteriorly, and especially in the anterior position of the posterior zygapophyses. As in the latter genus the vertical concave surface of the pedicle contributes to the formation of the cup for the condyle of the skull. Above the antero-posterior constriction the neurapophysis widens into a thin mesially directed plate, the superior surface of which looks more upward than outward. The anterior portion is directed inward and in conjunction with the process of the opposite side forms the covering for the neural arch through which the spinal cord passes from the foramen magnum. The posterior extension is largely missing in this specimen, but doubtless it will be found to extend backward as a long tapering process as in Ceratosaurus (fig. 4, rl. 19).

The posterior zygapophysis on account of its anterior position is not visible from a lateral view as it is in Ceratosaurus. This difference in position may be clearly seen by comparing figure 17 and figure 4, plate 19.

The odontoid is free in the present individual, though it becomes fused later in life, as indicated by the rugose nature of the posterior articular surface, and as shown in specimen No. 8367, U.S.N.M. (fig. 18, o), which has the odontoid firmly fused with the axis. It is wider than long (54 m.m. wide and $32 \mathrm{~mm}$. long); the upper surface slightly concave from side to side; viewed from the front the anterior protuberance that rests in the superior concave surface of the intercentrum is reniform in outline.

On the median anterior end there is a subcircular depression whose surfaces conform closely with the general concave cup of the other articulated elements of the atlas. Its posterior ventral border rests upon the superior surface of the axis hypocentrum.

Axis $(a x$.$) .- The axis, although having suffered slight distortion, is neverthe-$ less most perfectly preserved. The centrum is planoconcave, with rounded ventral surface without keel (fig. 17, C). In transverse diameter the ends are expanded, the median lateral sides much pinched in, with a small elongated opening toward the anterior end. The neural arch is comparatively low and heavy, being surmounted by a long, strongly developed median crest that rises rapidly toward the back. The posterior portion flares into a transversely expanded, overhanging spine. There are deep notches between the sides of this spine and the posteriorly projecting zygapophyses, which distinguishes at once the axis of Antrodemus from that of Ceratosaurus with its little differentiated posterior zygapophyses. The posterior zygapophyses almost entirely overhang the end of the centrum. Inferiorly they present very large subcircular articular faces that look almost directly downward. Between them a deep cavity extends forward into the arch above the neural canal. Obtuse roughened protuberances extend backward and upward from the top of each zygapophysial process slightly overhanging the underlying articular surfaces.

The anterior zygapophyses are rather weakly developed, consisting of rather thin pointed projections that extend forward and outward from the neural arch, considerably below the level of the anterior part of the median crest. They overhang slightly the anterior end of the centrum. The anterior end of the median crest is notched bēneath and ends forward as a heavy obtuse projection, that over- 
hangs the notch between the prezygapophyses. This projection in the axis of No. 8367, U.S.N.M., is rugose. Anterior and posterior horizontal lamina from the post and prezygapophyses, respectively, meet at the center of the neural arch and continue outward and downward to form the rather weak diapophyses (A. fig. 17), which extends well below the level of the neuro-central suture.

The pleuropophyses are well-developed articular cups on the anterior borders of the centrum and high in position. In this specimen the axis hypocentrum remains firmly joined to the front of the centrum, but their union remains clearly defined. In aged individuals it doubtless becomes firmly coalesced, as it has in Ceratosaurus (fig. 6, pl. 19). Osborn ${ }^{1}$ finds this element present as a distinct element in Tyrannosaurus. It is also known to be present in the Sauropod and Predentate groups of dinosauria, but often becomes so completely coalesced as to lose its identity.
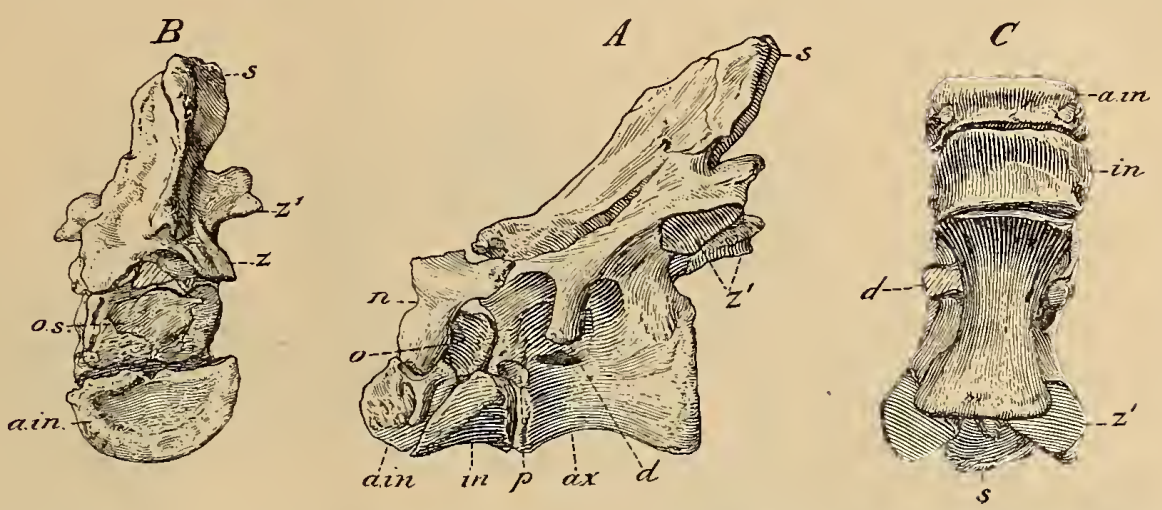

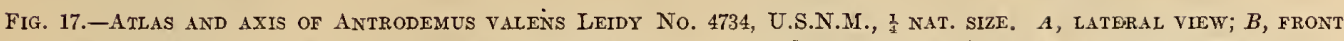
VIEW; $C$, VENTRAL VIEW; $a$. in, ATLAS INTERCENTRUM; $a x$, AXIS; $d$., DLAPOPHYSIS; $i n$, INTERCENTRUM BETWEEN ATLAS AND AXIS; $n$, NEURAPOPHYSIS OF ATLAS; $o$, ODONTOID; $0 . s$, SUTURAL SURFACE FOR ODONTOID; $p$, PARAPOPHYSIS; $s$, NEURAL SPINE; $z$, ANTERIOR ZYGAPOPHYSIS; $z^{\prime}$, POSTERIOR ZYGAPOPHYSIS.

The hypocentrum is a wide block-like bone that joins the anterior end of the axis centrum by a plain articular end. Viewed from the front the upper transverse border with which the odontoid articulates is straight; the lower border is broadly rounded from side to side. The anterior face is concave from above downward and lip-like, where it underlaps the articular end of the atlas intercentrum. The ventral surface is shallowly concave antero-posteriorly and broadly convex transversely. It has a greatest transverse width of $64 \mathrm{~mm}$. and a greatest antero-posterior diameter of $34 \mathrm{~mm}$. In specimen No. 8367, U.S.N.M., this bone measures $79 \mathrm{~mm}$. in width and $41 \mathrm{~mm}$. antero-posteriorly.

The axis of Autrodemus may be distinguished from the homologous element in Ceratosaurus by, (1) the absence of a keel on the ventral surface of the centrum; (2) the presence of deep notches between the spine and postzygapophyses; (3) by the stronger development of the diapophyses. 


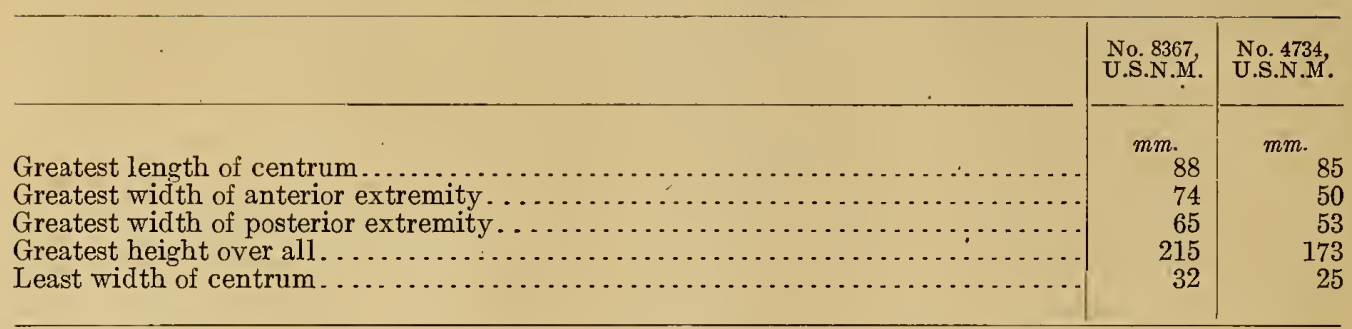

Cervicals posterior to the axis.-All of the cervicals posterior to the atlas and axis were found disarticulated, but. the complete series was recovered and in an excellent state of preservation.

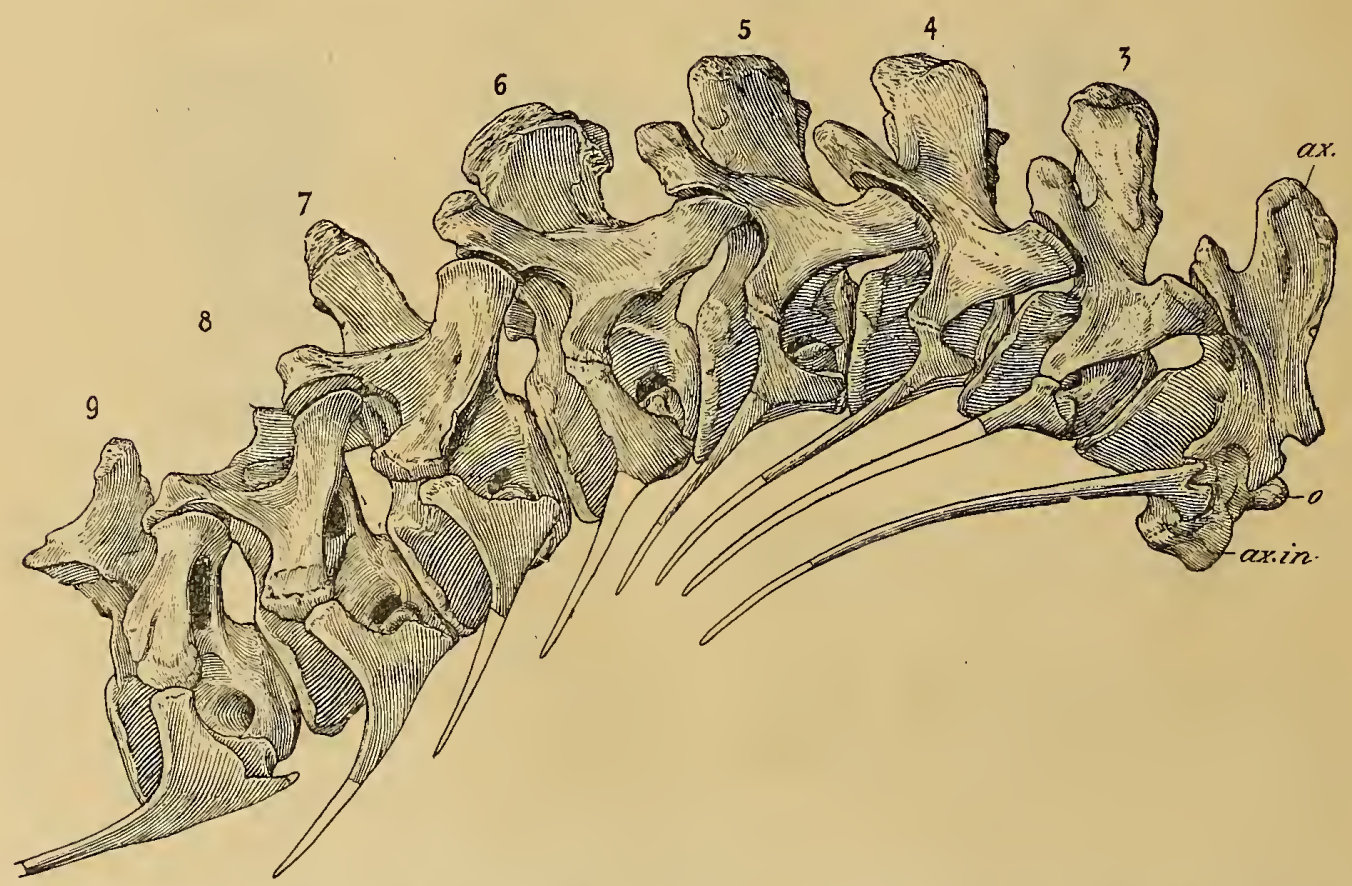

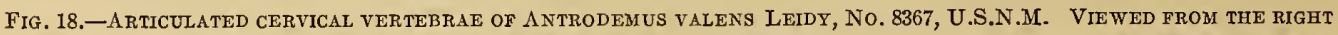
SIDE 1 NAT. SIZE. $a x$, AXIS; $a x$. in, AXIS INTERCENTRUM; 0 , ODONTOID; $3,4,5,6,7,8,9$, CERVICAL VERTEBRAE THREE TO NINE RESPECTIVELY.

In all, counting back from the skull there were nine vertebræ and these probably represent the entire cervical series as corroborated by specimen No. 8367, U.S.N.M., shown in figure 18. The remaining 14 presacrals were found articulated. This specimen therefore is in perfect accord with No. 666 of the American Museum of Natural History, New York, which has 23 vertebrae in the complete presacral series.

The third cervical may be distinguished by the sharp longitudinal keel on the ventral side of the centrum, all others including the atlas and axis, having this portion of the centrum smoothly rounded. 
Posterior to the third all of the other cervicals are strongly opisthocoelus. The centra gradually increase in size posteriorly. Viewed from the side (fig. 18) it will be observed that both the anterior and posterior ends of the centra are cut off obliquely to the longer axis of the bone. On the ventral side of the cervicals posterior to the third the posterior border takes a decided scoop downward; but this feature becomes less and less as the base of the neck is approached.

With the exception of the atlas, all of the cervical vertebrae are strongly cupped on the posterior end of each centrum. On the anterior end there is an almost equally well-developed ball, which is terminated by a rounded, blunt apex that is usually somewhat above the middle. The cervicals in Ceratosaurus differ in having the ball flattened.

When these vertebrae are articulated the ball does not reach the full depth of the cup, but shows that there was a considerable thickness of cartilage between.

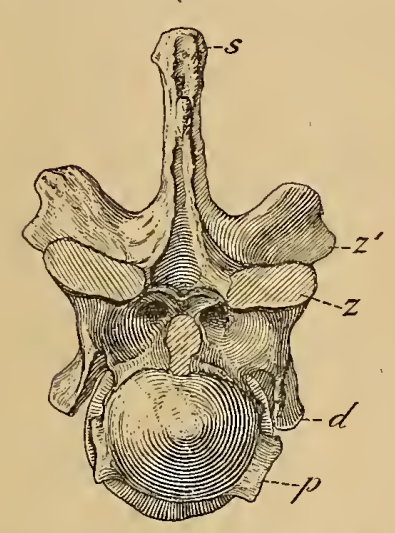

FIG. 19.-FOURTH CERVICAL VERTEBRA OF ANTRODEMUS VALENS LEIDY CAT. No. 4734, U.S.N.M. $\frac{7}{2}$ NAT. SIZE. VIEWED FROM FRONT, $d$, DIAPOPHYSIS; $p$, PARAPOPHYSIS; $s$, NEURAL SPINE; $z$, ANTERIOR ZYGAPOPHYSIS; $z^{\prime}$, POSTERIOR ZYGAPOPHYSIS.
There is a narrow articular border at the base of the ball, as in Ceratosaurus, that marks to some extent the depth of its insertion into the cup.

Below the neuro-central sutures the sides of the centra are deeply pinched in, especially toward the front above the capitular facets, at which point there are oval pits, some of which appear to lead into chambers within the centra, these persist as far back as the twelfth vertebra from the skull, in No. 8367. All of the cervicals are highly pneumatic.

The capitular facets, posterior to those on the axis, are large, placed low down on the side, at the base of the articular ball-like end. In the anterior members of the neck these facets are on stout, heary buttresses that project straight out from the centrum (fig. 19). Continuing posteriorly the buttresses gradually increase in size and length, and become inclined more and more ventrally as the dorsals are approached.

In the ninth, one-half of the articulation for the rib is below the level of the median ventral surface of the centrum, whereas in the third vertebra it is wholly above.

The neurapophyses in all of the cervicals have an extensive attachment to the centrum, spreading out conspicuously at the ends.

Well-developed diapophyses are present on all vertebrae posterior to the atlas. These are short and comparatively thin dorso-ventrally, but gradually lengthen and become more robust posteriorly. In the anterior cervicals they extend downward, quite close to the side of the centra, but gradually assume a more horizontal position posteriorly until on the ninth vertebra they extend outward at nearly right angles. All are lightened by cavities along the under side, and are supported by thin oblique laminae that extend upward from the anterior and posterior pedicles.

The articular ends are but little expanded, and the articular surface for the rib looks downward and outward. 
The neural canal is relatively small throughout the cervical series. The preand post-zygapophyses are wide apart and have large, flattened articular surfaces. The pre- and post-zygapophyses gradually draw nearer to one another anteroposteriorly. In other words, the zygapophyses of the ninth cervical, though a much larger vertebra than the third, are as near together antero-posteriorly as in the latter.

The neural spines of the anterior cervicals are high, quadrangular, plate-like processes, with slightly expanded extremities. These become narrower anteroposteriorly and wider transversely, so that on the eighth and ninth cervicals the spines are about equal in both diameters, and somewhat shorter than those of the anterior portion of the neck. The anterior and posterior surfaces of the two latter are rugosely roughened.

In the anterior half of the neck there are angular cone-shaped pits on the anterior side at the base of the spines between the zygapophyses which become

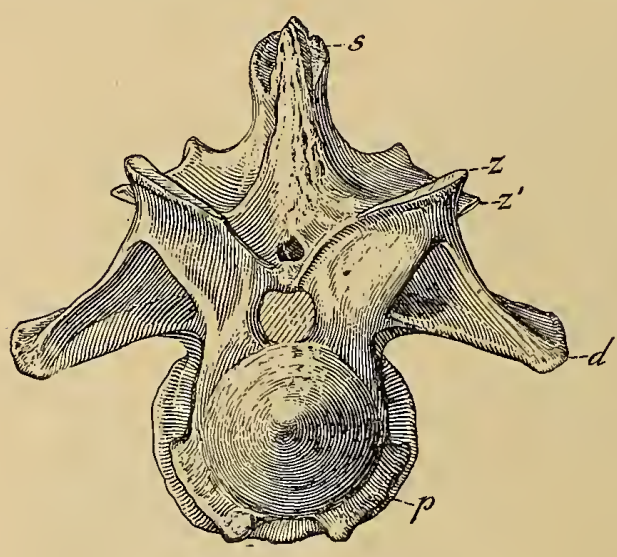

Fig. 20.--Ninth CERVical vertebra of ANTrodemus VALENS LEIDY. No.4734, U.S.N.M. $\frac{1}{4}$ NAT. SIZE. VIEWED FROM FRONT. $d$, DIAPOPHYSIS; $p$, PARAPOPHYSIS; $s$, NEU. RAL SPINE; $z$, ANTERIOR ZYGAPOPHYSIS; $z^{\prime}$, POSTERIOR ZYGAPOPHYSIS,

greatest development of this spur coincides with the change from the wide to the narrow spinous processes.

Dorsal vertebrae.-Specimen No. 4734, U.S.N.M., has an articulated series of 14 dorsal vertebrae, but since many of these lack protions of their neural processes, the detailed description of these vertebrae is largely based on the excellent supplementary naterial furnished by the somewhat larger individual catalogued as No. 8367, U.S.N.M. This specimen has 10 dorsals present, all in a splendid state of preservation. These are found more or less disarticulated, (fig. 21), but the manner in which the zygapophyses articulate indicate that seven of them represent a continuous series coinmencing with the sixth dorsal and continuing posteriorly. The first, second, fifth, and twelfth dorsals appear to be the ones that are missing. The third and fourth were found articulated with one another. 
First and second dorsals (Nos. 10 and 11).--In Antrodemus the point of change from cervical to the dorsal series appears to be distinctly indicated. The features which indicate where this change occurs are; a sudden shortening of the vertebral centra; the transfer of the parapophyses from a low to a higher position on the side of the centrum; a rapid increase in the height of the neural spines; an increase in length of the transverse processes and their elevation to a plane above the horizontal; the increased width of the space between the diapophyses and parapophyses and the passing of the opisthocoelus centra to the amphiplatyan type. In Tyrannosaurus Osborn" designates these vertebra as "cervico-dorsals, thus considering them transitional in character, which they are to a greater degree than in Antrodemus. The first dorsal of No. 4734, U.S.N.M., lacks the anterior end of the centrum and the upper portion of the right side of the neural arch. The posterior ventral surface of the centrum, when compared with the preceding vertebra, is angularly rounded as contrasted with the broad and evenly rounded centrum of the last cervical. Also the median portion of the centrum in the first dorsal is more pinched together.

The remaining remnant of the right diapophysis indicates that it must have reached a horizontal position whereas those anterior were all deflected below that level.

The second dorsal (No.4734, U.S.N.M.) consists of the complete centrum, but lacks niost of the neural arch. The anterior end is convex, but much less hemispherical than found in the cervical region. The parapophysis is large and its upper edge reaches the neurocentral suture. The median ventral portion is much pinched together transversely forming a decided ventral keel which widens out toward the front.

Third and fourth dorsals (Nos. 12 and 13).-These vertebrae of No. 8367, U.S.N.M., were found articulated. The centrum is greatly abbreviated as compared with the longer ninth cervical, the third having a slightly cupped posterior face and a nearly flat anterior face. In this individual the third dorsal may be distinguished from all others in the column by the sharp ventral keel on the centrum, which develops at its anterior end an expanded triangular face that projects downward below the anterior rim of the centrum and looks forward and downward. The surface of this face stops $23 \mathrm{~mm}$. posterior to the vertical plane of the anterior end of the centrum, from which it is distinctly separated by a shallow transverse groove (fig. 22). The sides of the centrum are moderately compressed, with a small pit that leads into the body of the centrum posterior to the center of the parapophysis. This is the last appearance of these lateral pits, which are found throughout the cervical region. In No. 4734 the third dorsal also bears the last pit.

The pleuropophysis is large, elliptical in outline, the longer diameter being vertical, the upper end extending slightly over the side of the pedestal of the neural arch. The neural arch is relatively low and incloses a neural canal of good size. Anteriorposteriorly the arch above its base is considerably shorter than the centrum. The long traverse processes extend outward and upward from the sides of the neural arch, slightly above the horizontal. The articular end presents a roughened, beveled 


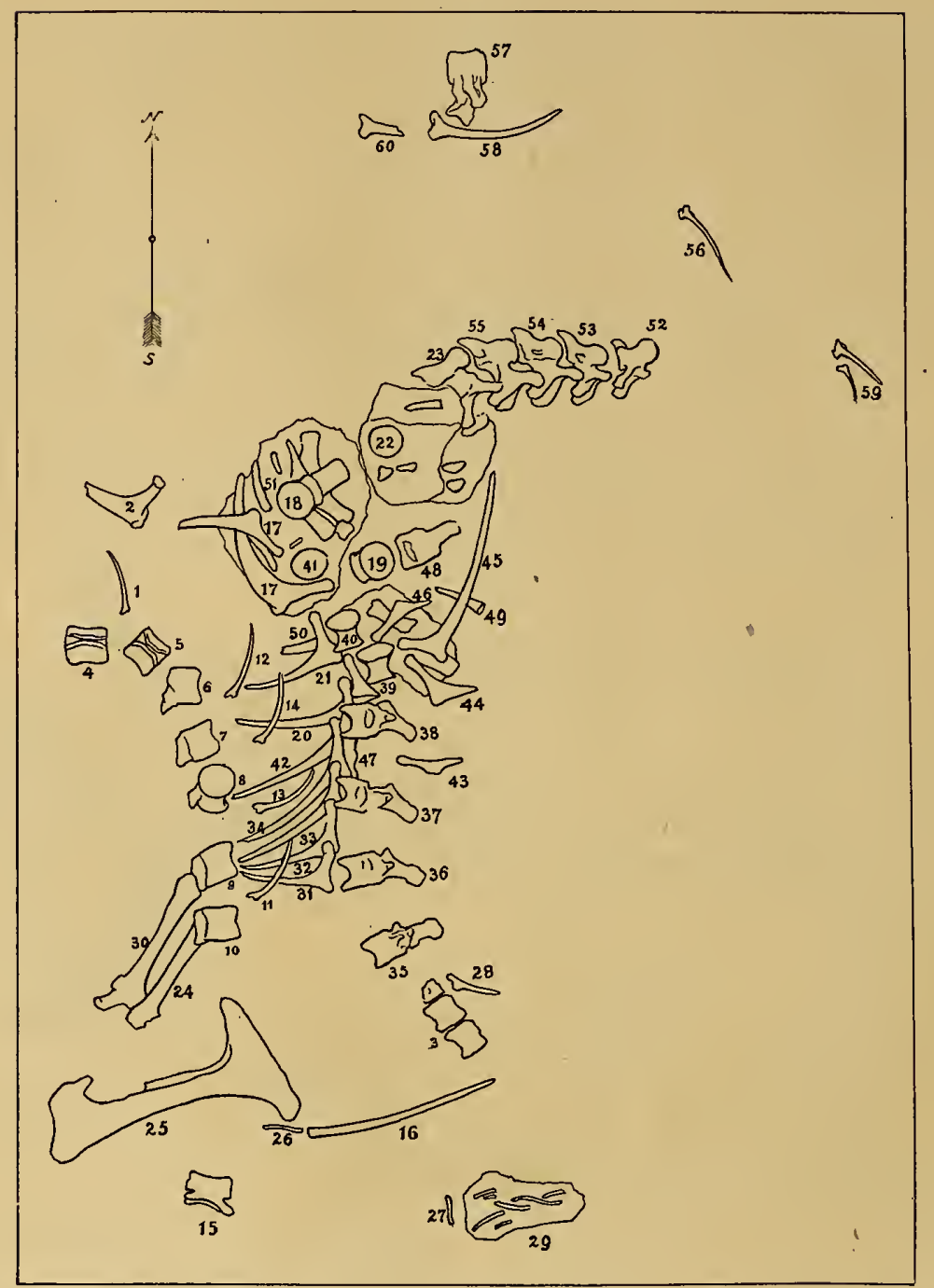

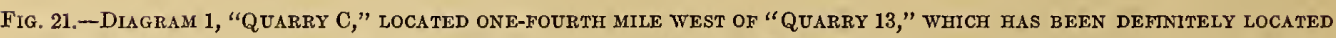
IN NORTHEAST QUARTER OF SECTION 5, TOWNSHIP 22 NORTH, RANGE 76 WEST, ALBANY COUNTY, WYOMING. THIS MAP SHOWS THE EXACT RELATIVE POSITIONS OF THE BONES BELONGING TO SPECIMEN NO. 8367, U.S.N.M., ANTRODEMUS VALENS LEIDY. Collected in 1886 by Fred Brown. SCale about one-half foot to the inch.

1. Slxth chevron; 2. Thoracic rib, No. 4, R. (See B, Fig. 36.); 3. Third, Fourth, and FIFTh SACral CENTRA; 4. Seventh CaUdal vertebra; 5. Sixth CaUdal vertebra. (See Fig. 28, also PL. 1 Figs. 4, 5, AND 6.); 6. FifTh CAUdaI vertebra; 7. Fourth caudal vertebra; 8. Third CaUdal vertebra; 9. Second CaUdal vertebra; 10. First CaUdal Vertebra. (See Fig. 2, PL. 31.); 11. Second chevron; 12. Fifth chevron; 13. Third chevron; 14. Fourth Chevron; 15. Median caudal vertebra. (See fig. 29.); 16. Thoracic rib. No. 6, L; 17. Thoracic ribs, Nos. 2, 3, AND 9, R; 18. Presacral vertebrae, Nos. 12 and 13. (See figs. 22 and 23.); 19. Seventh dorsal verteeral centrum; 20. Thoracic rib, No. 7, R. (See fig. 36, C.); - 21. Thoracic rib, No. 6, R; 22. Sixth cervical vertebra. (See Fig. 18, 6.); 23. Seventh cervical vertebra. (See fig. 18, 7.); 24. Ischium; 25. Pubes. (See fig. 47.); 26. A bdominal Ribs. (See Fig. 38.); 27. A bdominal RiBs. (See fig. 38.); 28. First chevron; 29. A bdominal ribs. (See fig. 38.); 30. Ischium; 31. Thoracic RIB; 32. Thoracic RIB, No.11, R; 33. Thoracic rib, No, 10, R; 34. Thoracic RIB. No 9, R. (SeE FIG. 36 D.); 35. Fourteenth dorsal vertebra. (See fig. 27.); 36. Twelfth doksal vertebra. (See fig. 26.); 37. Eleventh DORSAL Vertebra. (SEE FIG. 25.); 38. TENTH DORSAL VERTEBRA; 39. EIGHTH DORSAL VertebRA; 40. NINTH DORSAL VERtebra. (See fig. 24.); 41. Sixth dorsal vertebra. (See fig. 23.): 42. Thoracic ribs No. 8, R; 43. Head of thoracic 
surface on the ventral side for articulation with the tuberculum of the rib. They are supported from beneath by converging laminae arising from the front and back pedicles which unite to form a single vertical plate that supports the diapophysis at the central line throughout its entire length. A deep cavity extends inward beneath and back of the prezygapophysis, greatly lightening the bone but without materially decreasing its strength.

The anterior zygapophyses project but slightly beyond the face of the centrum. They look upward and inward; are of large size with the greatest diameter transverse. The neural spine is relatively short, wide behind, with a deeply concave surface, narrow in front, with broad convex surface. The median part of both front and back presents rough rugose surfaces. Between the postzygapophyses at the base of the spine a pit extends forward and downward into the arch above the neural canal.

The articular surfaces of the posterior zygapophyses are nearly horizontal, with a slight pitch downward toward the front. Their posterior borders are within the posterior face of the centrum.

The fourth dorsal (fig. 23) vertebra differs from the preceding by the development of a slightly heavier, transverse and spinous processes; more elevated position of the capitular facets on the sides of the neural arch; the distal end of the centrum less deeply cupped, with anterior extremity plain; great increase in the overhang of the prezygapophyses. The absence of a lateral pit, and apparently the last appearance of the two converging lamina giving support to the transverse processes. In

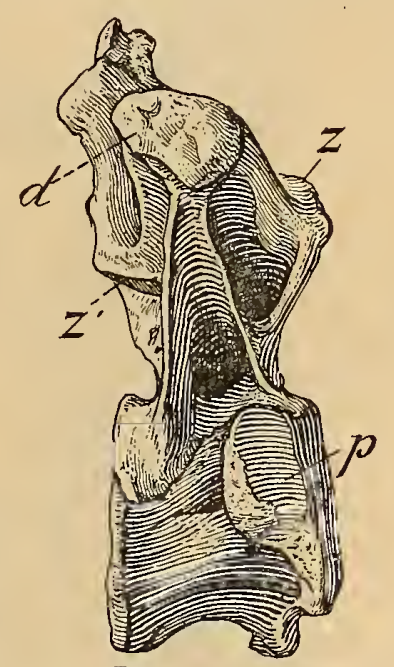

FIG. 22.-THRD DORSAL VERTEBRA OF ANTRODEMUS VAlens LeIDY. No. 8367, U.S.N.M. Ż NAT. SIZE. SIDE VIEW. $d$, DIAPOPHYSIS; $p$, PARAP OPHYSIS; $z$, ANTERIOR ZYGAPOPHYSIS; $z^{\prime}$, POSTERIOR ZYGAPOPHYSIS. the succeeding dorsals a single plate arises from the posterior pedicle, the anterior one having disappeared. The last appearance of the pinched in sides which makes the lower median portion keel-like.

Fifth dorsal (No. 14.).--The fifth dorsal vertebra appears to be missing in No. 8367, U.S.N.M., but the centrum lacking most of the neural arch is present in No. 4734 , U.S.N.M. In so far as it can be compared it differs from the preceding vertebra by the deeper excavation of the sides and bottom, thus making the ends appear more flangelike, and by the higher position of the parapophysis.

Sixth to the thirteenth dorsal (Nos. 15 to 23.).- Though found disarticulated, as shown in figure 21, these vertebrae are thought to represent a continuous series; and since they differ so little from one another, can be best described collectively. In size they increase gradually from front to back.

RIB, No. 11, L; 44. HeAD of thoracic RIB, No. 9, L; 45. THORACIC RIB, No. 10, L; 46. HEAD OF thoraCiC RIB, No. 8, L; 47. Fragment; 48. Process to Seventh dorsal vertebra; 49. Capitulum to Rib; 50. Thoracic RIB, No. 5, R; 51. CapituLUM TO RIB, No. 2, L; 52. AXIS AND PORTION OF ATLAS. (SEe FIG. 18 AX.); 53. THIRD CERVICAL Vertebra. (SeE FIG. 18, 3.); 54. Fourth cervical vertebra. (See fig. 18, 4.); 55. Fifth cervical vertebra. (See fig. 18, 5.); 56. CerviCal Rib, of axis, left side; 57. Ninth cervical vertebra. (See fig. 18, 9.); 58. Thoracic Rib, No. 2, L; 59. Two (AXIS RIGHT SIIE) CERVICAL RIBS, ONE TOOTH; 60. THORACIC RIB. 
The centra are deeply excavated on the sides and inferiorly, this feature becoming more pronounced as the posterior part of the series is approached, where the en-

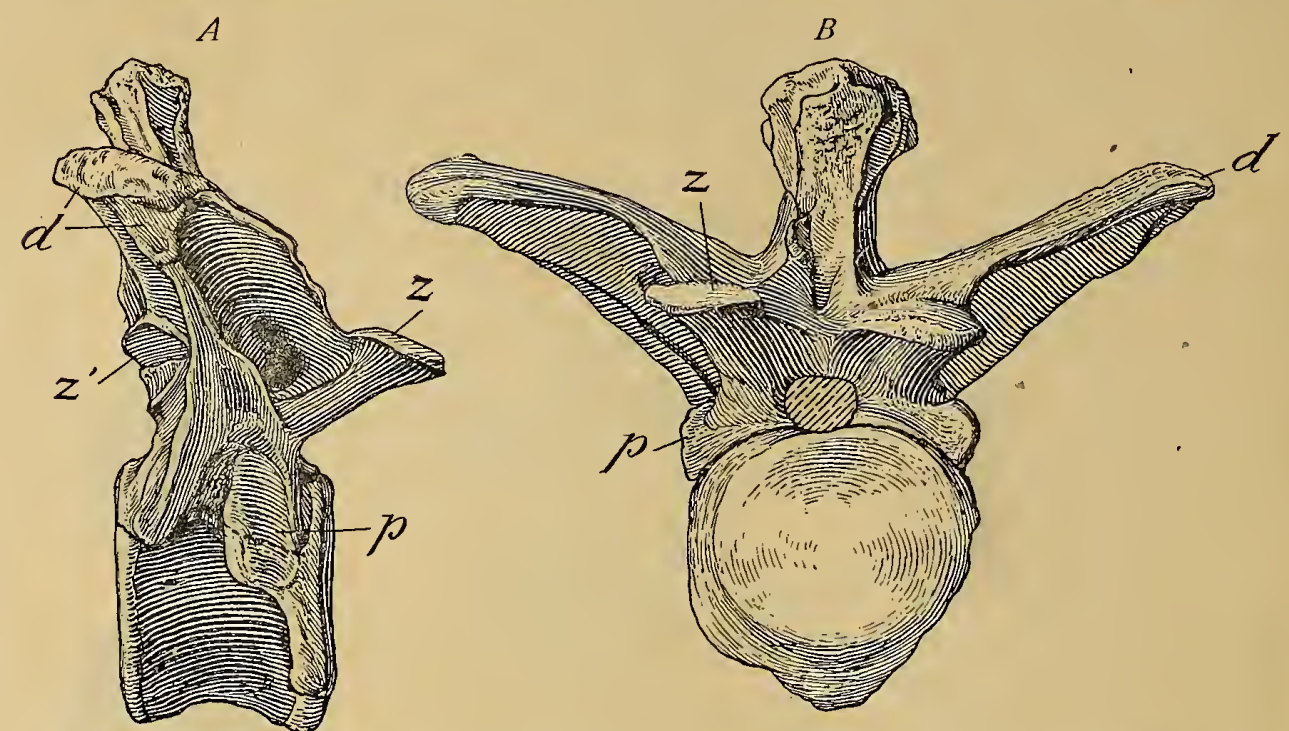

Fig. 23.-Fourth dorsal vertebra of ANtrodemus valens Leidy. No. 8367, U.S.N.M. $\frac{1}{4}$ Nat. Size. A, Side view. B, FRONT VIEW. $d$, DIAPOPHYSIS; $p$, PARAPOPHYSIS; $z$, ANTERIOR ZYGAPOPHYSIS; $z^{\prime}$, POSTERIOR ZYGAPOPHYSIS.

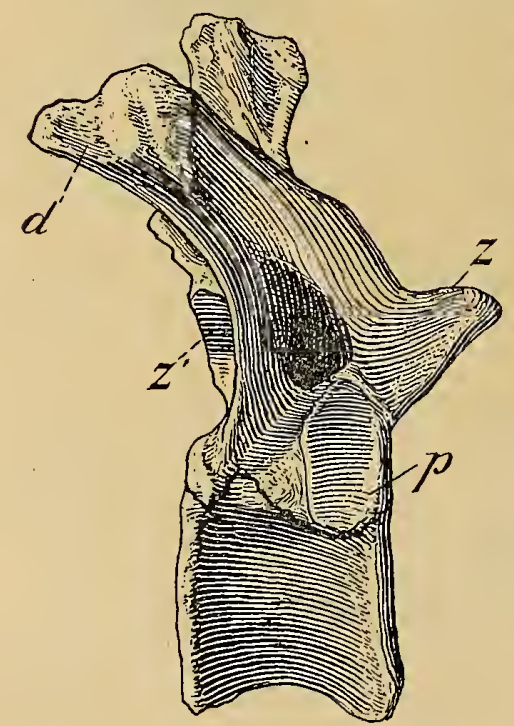

Fig. 24.--SiXTH DORSAL VERTEBRA OF ANTRODEMUS VALENS LEIDY. No. 8367, U.S.N.M. NAT. SIZE. SIDE YIEW. d. DIAPOPHYSIS; $p$, PARAPOPHYSIS; $z$, ANTERIOR ZYGAPOPHYSIS; $z^{\prime}$, POSTERIOR ZYGA OPHYSIS. larged ends are flangelike. The median sides above the middle are pinched in, forming a shallow longitudinal depression as shown in figures 26 and 27. In passing backward in the series these depressions become slightly deeper, though on none except perhaps the last dorsal could they be classed as pits. In both Gorgosaurus and Tyrannosaurus lateral pits are present in most of the dorsal centra.

The anterior face of the sixth dorsal is nearly plane, but in the seventh it is slightly concave, this concavity continuing back through the series. The posterior articular surfaces are partly amphiplatyan, with a characteristic slight anterior concavity in the upper portion of the face below the neural canal. This feature is especially pronounced on the last dorsal, where it articulates with the sacrum. The centrum of the twelfth dorsal viewed from the side is slightly wedgeshaped, being narrower below than above-a condition observed in the seventh dorsal of Tyrannosaurus as depicted by Osborn. ${ }^{1}$ To a less degree some of the other dorsals are also shorter longitudinally at the bottom than at the top, thus forming a slight upward bow of the articulated vertebral column. The height of the centra exceeds their breadth.

1 Plate 27, Bull. Amer. Mus. Nat. Hist., vol. 35, 1917. 
The neural arches are attached to the centra by low, stout pedicles, having expanded ends, more especially the posterior. Long, broad diapophyses are given off well up on the arch. On the sixth dorsal they extend backward and upward at an angle of $30^{\circ}$ above the horizontal, but passing posteriorly in the series they gradually assume a more and more horizontal position. In the posterior members they also extend outward at right angles instead of backward as in the mid-dorsal region. These processes gradually lengthen from the front to the back, reaching their maximum length on the ninth and tenth dorsals, posterior of which they decrease slightly in length and also in other proportions. Where they attach, these processes are broad, narrowing slightly outward. Vertically both front and back they

A

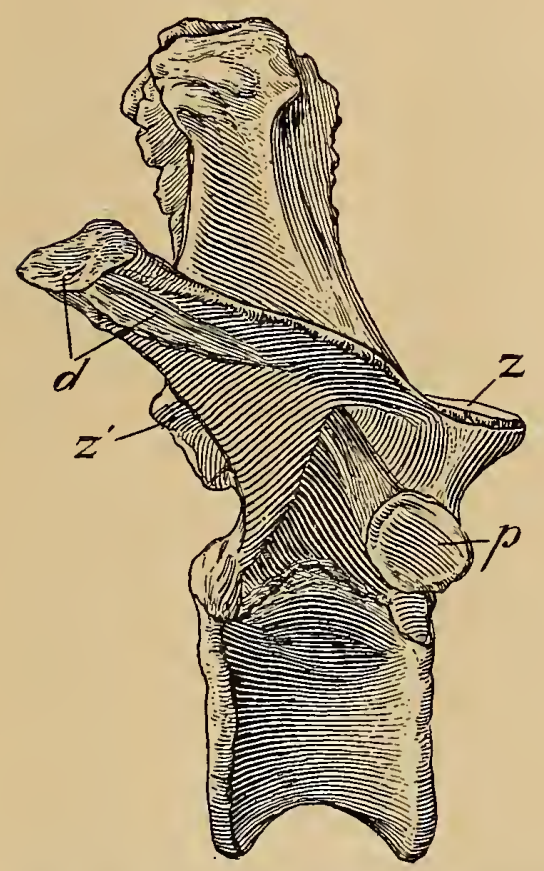

$B$

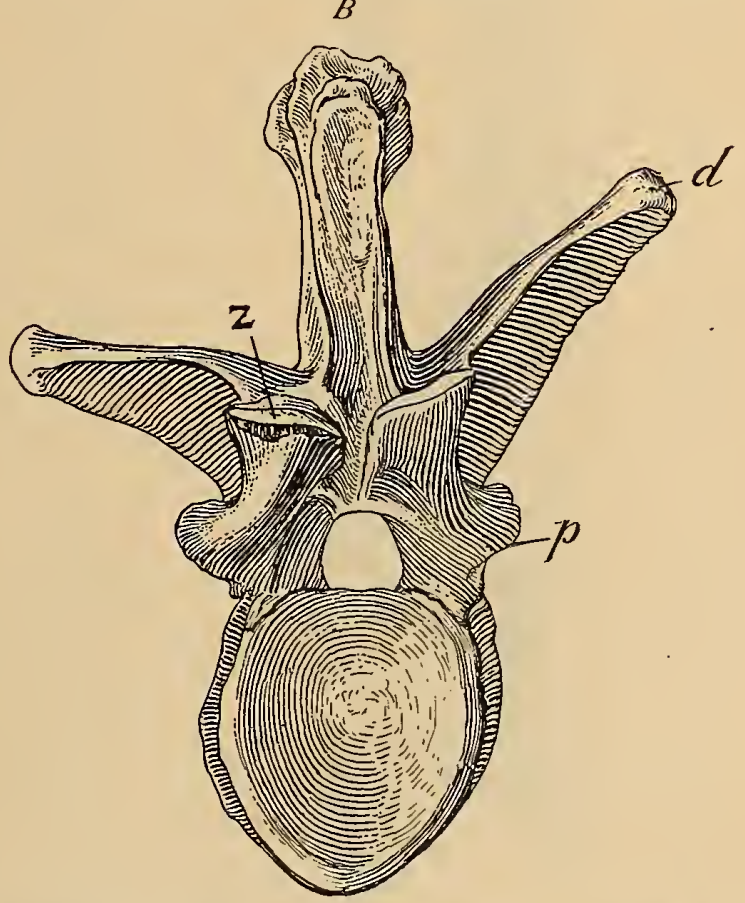

Fig. 25. -Ninth dorsal vertebra of Antrodemus valens Leidy. No. 8367, U.S.N.M. $\frac{1}{4}$ Nat. Size. A, Side view. B FRONT VIEW. $d$, DIAPOPHYSIS; $p$, PARAPOPHYSIS; $z$, ANTERIOR ZYGAPOPHYSIS; $z^{\prime}$, POSTERIOR ZYGAPOPHYSIS.

are thin, but supported and strengthened from beneath at mid-breadth by a single vertical lamina that extends outward nearly to the distal end. Proximally it ends below in the posterior lateral pedicle of the arch.

The parapophyses in all the vertebrae posterior to the sixth occupy approximately the same position on the median side of the anterior pedicle, extended outwardly but little, though in Ceratosaurus they stand out prominently. This facet is cupped and subcircular in outline (fig. 24).

The large anterior zygapophyses look upward and very little inward, their articular faces being nearly horizontal. All overhang the anterior face of the centra. The posterior zygapophyses are separated at the center by a thin vertical plate that widens distally, forming a zygosphene articulation as in the Sauropodous dinosauria. 
The neural spines are large and robust. They gradually increase in height from front to back, reaching their maximum development in the last dorsal (fig. 27). There is also an increase in the fore and aft diameter of the spines.

Viewed from the side, the spines are narrower at the top than at the bottom. The basal width is brought about by the development of thin marginal lamina-like extensions of the spine. The posterior laminae turn backward and merge into the surface above the posterior zygapophyses. Anteriorly they merge into the arch posterior to and usually slightly above the level of the anterior zygapophyses.

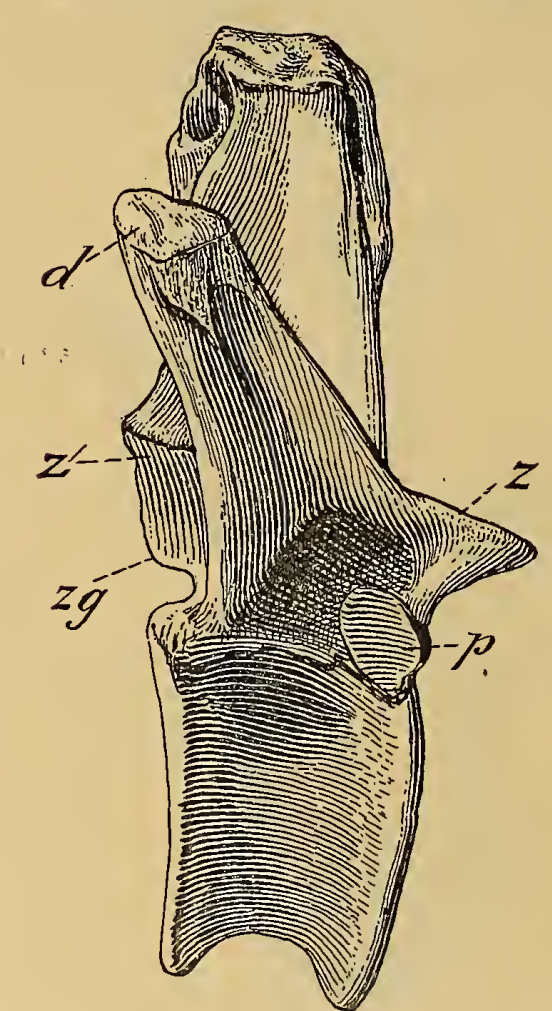

FIG. 26.-TENTH DORSAL VERTEBRA OF ANTRODEMUS VALENS LEIDY. No. 8367, U.S. N.M. $\frac{7}{3}$ NAT. SIZE. VIEWED FROM THE RIGHT SIDE. $d$, DIAPOPHYSIS; $p$, PARAPOPHYSIS; $z$, ANTERIOR ZYGAPOPHYSIS; $z g$, ZYGOSPHENE; $z^{\prime}$, POSTERIOR ZYGAPOPHYSIS.

Between these laminae the median surfaces both front and back are rugosely roughened for ligamentious attachment. Above the midheight, this roughened median portion of the spines extends forward and back respectively of the side faces, which are smooth, in a gradually narrowing axial area, being sharply defined both front and back from the rugose central portion. This roughening is by means of deeply pitted projections and anastomosing channels running irregularly in a general vertical direction.

The upper or distal ends have roughened transversely expanded ends, and as in Gorgosaurus, and also in Tyrannosaurus the spines have increased to such an extent in an anterior, posterior direction as to approach one another closely at the top. This development is most prominently displayed in the eighth and tenth of this series whereas in Gorgosaurus from the fifth to the ninth and in Tryrannosaurus from the seventh to the thirteenth.

Fourteenth dorsal (No. 23).- The fourteenth dorsal is so very much. like the preceding vertebra as to require but little description. It is the most robust element of the entire backbone. The transverse processes are slightly shorter than those immediately preceding it, and extend outward at right angles to the arch on a nearly horizontal plane. The parapophysial facet is smaller, and the roughened articular surface for the tuberculum of the rib has changed to a more anterior position on the diapophyses, the face looking forward and downward instead of directly downward as in the anterior dorsal region. In the last dorsal of No. 4734 the median wall between opposite sides of the centrum is only $7 \mathrm{~mm}$. in thickness.

The principal dimensions of the two vertebral columns discussed above are given in the table of measurements. 
OSTEOLOGY OF CARNIVOROUS DINOSAURS.

Measurements of presacral vertebrae of Antrodemus valens Leidy.

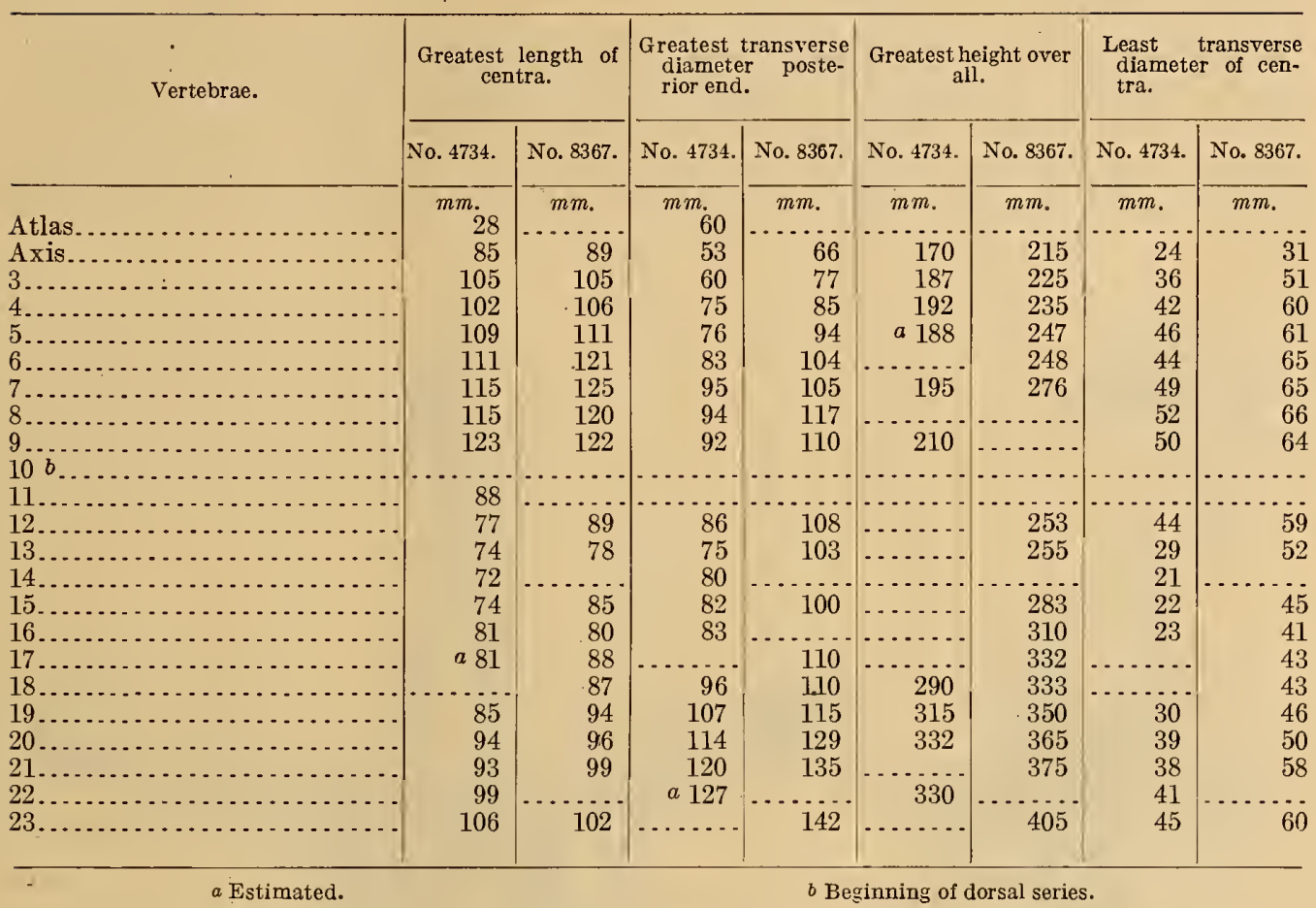

Sacral vertebrae.-The description to follow of the sacral vertebrae of Antrodemus is based on the sacra of four individuals, Nos. 4734, 8405, 8423, and 8367, arranged in the order of their importance, but more especially on the splendidly preserved sacrum of No. 4734, U.S.N.M., shown in all aspects in plates 8, 9, and 10. Three of these specimens each have five coosified vertebrae in the complete sacral arcade. As in Tyrannosaurus and Ceratosaurus, $\mathrm{S}_{1}$, is directly opposite the pubic peduncle of the articulated ilium (see pl. 9, fig. 2), while $S_{3}$ is opposite the ischiac peduncle. It is quite probable that $S_{2}$ and $S_{3}$ represent the primary sacrals, $S_{1}$ being a modified dorsal, and $\mathrm{S}_{4}$ and $\mathrm{S}_{5}$, modified caudal vertebrae.

The five sacral centra have concave sides and ventral surfaces, though the flange-like ends of the preceding dorsals are only found on the anterior end of $S_{1}$. $\mathrm{S}_{2}$ and $\mathrm{S}_{3}$ are much compressed transversely, with the ends little expanded. The lateral depressions on the superior sides of the centra are present in all the sacrals of No. 4732 , but in the other individuals these depressions grow shallower from front to the back of the series.

The ilia are united to the sacrum by stout but exceptionally short sacral ribs and by the transverse processes. There appear to be four distinct sacral ribs (pl. $8 \mathrm{sr}$.). These unite with the sacrals intervertebrally. The anterior rib articulates about equally with roughened facets on $\mathrm{S}_{1}, \mathrm{~S}_{3}$, but the succeeding two are supported more by the posterior centrum-that is, $\mathrm{S}_{3}$ and $\mathrm{S}_{4}$, respectively. The 
fourth rib assumes a higher and more posterior position and extends outward and upward from about the center of $\mathrm{S}_{1}$.

In No. 4734 a notch separates the outer expanded diapophysial ends of $\mathrm{S}_{2}$ and $S_{3}$ from the distal ends of the sacral ribs as shown in plate 8 , but in No. 8405 they form continuous articular ends for union with the ilium. Internal to the distal ends they are joined by suture, as they do in the Sauropoda by a thin diapophysial lamina sent down from the underside of the diapophysis. The complete

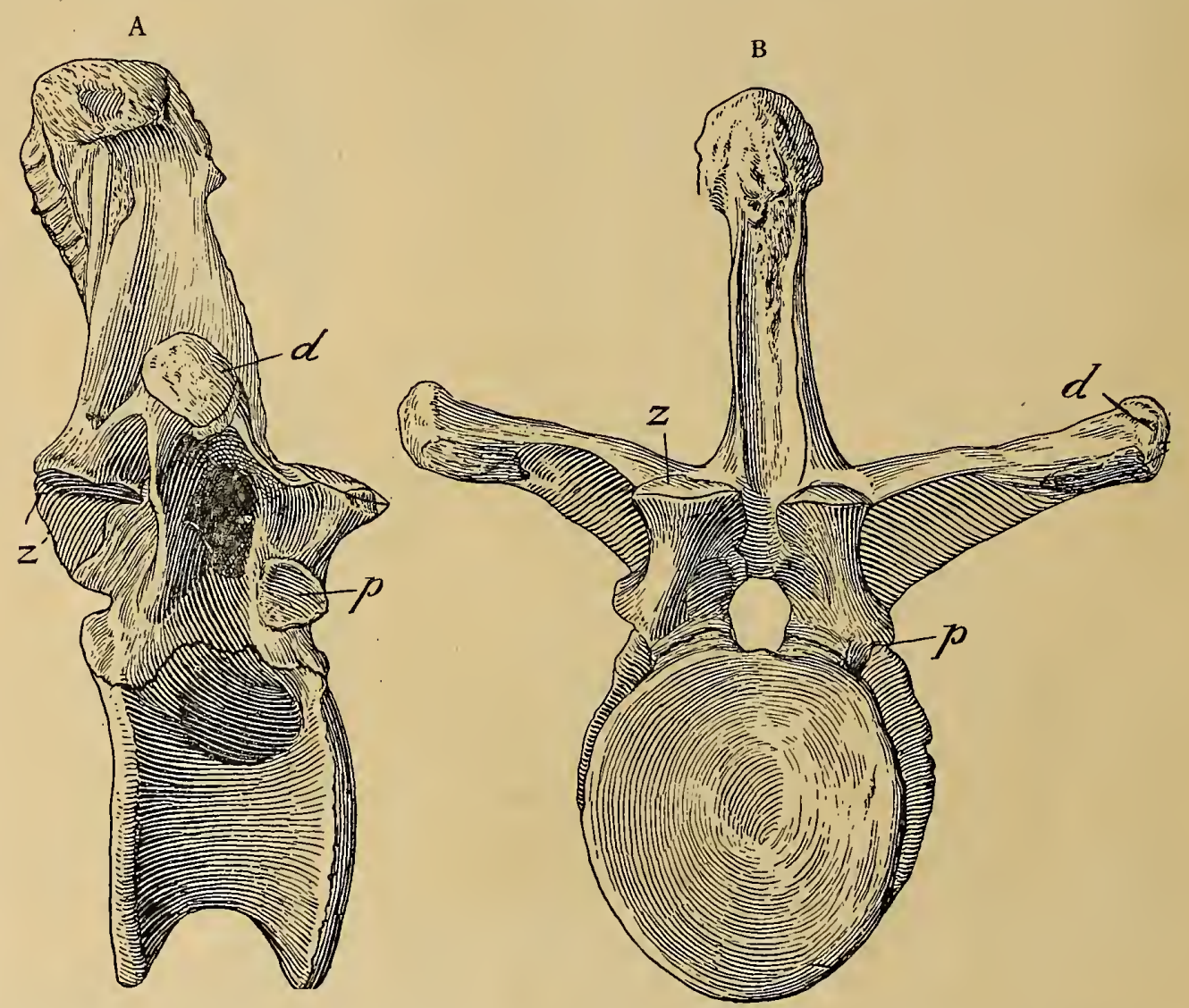

Fig. 27.-Fourteenth or last dorsal vertebra of Antrodemus valens Leidy, No. 8367, U. S. N. M, 年 Nat. Size. A. SIDE VIEW. B. FRONT VIEW. $d$, DIAPOPHYSIS; $p$, PARAPOPHYSIS; $z$, ANTERIOR ZYGAPOPHYSIS; $z^{\prime}$, POSTERIOR ZYGAPOPHYSIS.

union of these ends in $S_{4}$ and $S_{5}$ is well shown in plate 8 , where they are seen to also unite with one another at the top. The third rib is the stoutest and heaviest of the series.

The neural spines are all united to form a continuous plate. Though coossification has led to complete obliteration of the sutures their line of union can be clearly determined by indentations along the top. The neural spines of the three anterior sacrals are below the level of the ilia and can not be seen from a lateral view; but in Ceratosaurus the first, as shown in plate 30, projects well above 
this border of the ilium. The upper ends of the neural spines are roughened and slightly expanded transversely.

The principal dimension of the sacral vertebrae are given in the accompanying table of measurements below:

Measurements of Antrodemus sacral vertebrae in millimeters.

\begin{tabular}{|c|c|c|c|c|}
\hline & $\begin{array}{l}\text { No. 4734, } \\
\text { U.S.N.M. }\end{array}$ & $\begin{array}{l}\text { No. } \$ 423, \\
\text { U.S.N.M. }\end{array}$ & $\begin{array}{l}\text { No. 8405, } \\
\text { U.S.N.M. }\end{array}$ & $\begin{array}{l}\text { No. } 8367, \\
\text { U.S.N.M. }\end{array}$ \\
\hline 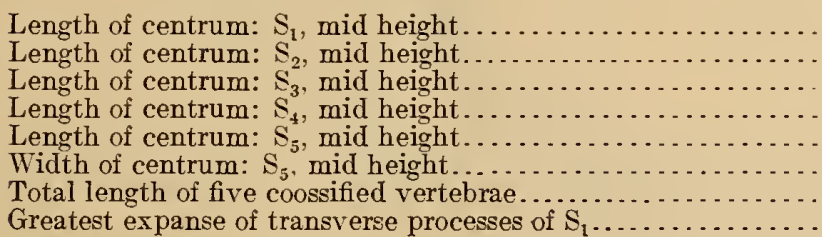 & $\begin{array}{l}116 \\
104 \\
104 \\
108 \\
104 \\
108 \\
536\end{array}$ & $\begin{array}{r}e 90 \\
99 \\
104 \\
120 \\
114 \\
117 \\
540\end{array}$ & $\begin{array}{r}120 \\
96 \\
107 \\
125 \\
118 \\
125 \\
575 \\
190\end{array}$ & \begin{tabular}{r|}
$\cdots$ \\
$\ldots \ldots$ \\
152 \\
132 \\
146 \\
$\ldots \ldots$
\end{tabular} \\
\hline
\end{tabular}

$\epsilon$ Estimated.

Caudal vertebrae.-Though the United States National Museum collections do not contain a complete articulated caudal series of Antrodemus, after a study of the incomplete tail of No. 4734, U.S.N.M., it is estimated that the entire series would consist of at least 45 caudal vertebrae. In number, therefore, it is intermediate between Gorgosaurus, with Lamb's estimate of 36 and Tyrannosaurus, with Osborn's estimate of 53.

In specimen No. 4734, U.S.N.M., there are vertebrae present from all parts of the tail except the extreme tip, but most of these are poorly preserved. When first found in the quarry, as all of the available evidence appears to indicate, the caudal series of this individual was articulated with the sacrum and nearly if not quite complete. Unfortunately, before it was recognized as pertaining to so perfect a skeleton, the bones were quarried out and thrown on to the pile of detrital material. In the subsequent attempt to salvage these rertebrae from the "dump" many of the vertebrae were entirely lost, as shown by the impressions in the sandstone blocks, and those caudals recovered in most instances were so mutilated br the loss of processes and other parts as to destroy much of their original value. Howerer, having vertebrae present from different sections of the tail, gives some information of the changes that take place from front to back and it is especially valuable for comparison with the quite different series of Ceratosaurus. From this "dump" material 33 caudal vertebrae are recognized.

With specimen No. 8367, U.S.N.M., there are eight caudal rertebrae, seven of which represent the first seven of the caudal series, as shown in figure 21. (Quarry Nos. 10, 9, 8, 7, 6, 5, and 4.) The remaining caudal (quarry No. 15) is from the mid-region of the tail.

The characteristics of the anterior caudal vertebrae will be largely described from specimen No. 8367, U.S.N.M. These vertebrae are heary and stout, the first four having centra that are higher than long. In passing backward they soon assume a lengthened cylindrical form as the diminution in lengtl is less rapid (see table of measurements) than the decrease in height. 
Measurements of anterior caudal vertebrae of Antrodemus valens, No. 8367 .

\begin{tabular}{|c|c|c|c|}
\hline \multirow{2}{*}{$\begin{array}{c}\text { Number } \\
\text { of } \\
\text { vertebra. }\end{array}$} & $\begin{array}{c}\text { Length at } \\
\text { center of } \\
\text { centrum. }\end{array}$ & $\begin{array}{c}\text { Width ante- } \\
\text { rior end } \\
\text { of centrum. }\end{array}$ & $\begin{array}{c}\text { Height ante- } \\
\text { rior end } \\
\text { of centrum. }\end{array}$ \\
1 & $m m$. & $m m$. & $m$. \\
1 & 121 & 133 & 138 \\
2 & 123 & 133 & 140 \\
3 & 125 & 123 & 130 \\
4 & 120 & 113 & 126 \\
5 & 118 & 115 & 115 \\
6 & 120 & 112 & 115 \\
7 & 120 & 95 & 97 \\
\hline
\end{tabular}

The vertebral centra are concave on the sides and below. The first caudal has a transverse rounded ventral surface, but in the succeeding caudals as far back

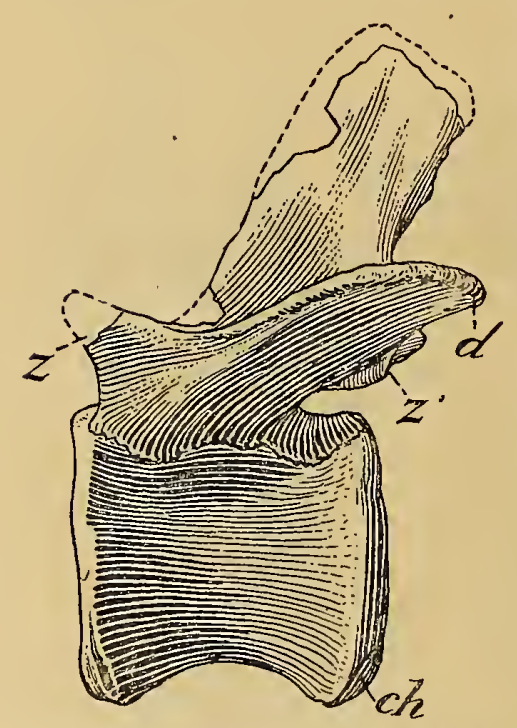

Fig. 28.-Sixth CAUdAL vertebra OF ANTRO. DEMUS VALENS LEIDY, No. 8367, U.S.N.M. I NAT. SIZE. VIEWED FROM THE LEET SIDE. $c h$, FACET FOR CHEV RON; $d$, DIAPOPHYSIS; $z$, ANTERIOR ZYGAPOPHYSIS; $z^{\prime}$, POSTERIOR ZYGAPOPHYSIS. THIS VERTEBRAL CENTRUM WAS SECTIONED AS SHOWN IN PLATE 1, FIGS. 4, 5 , AND 6. as the seventh, this surface is obtuse, but none are longitudinally grooved in this aspect as in Ceratosaurus.

The articular faces of the centra are biconcave. On the anterior caudals this concavity is most pronounced on the anterior face, but in the mid caudal region these faces become subequal. On both ends the lower articular faces are beveled off for the chevron articulation (fig. $28 \mathrm{ch}$.).

None of the neural spines are perfectly preserved, the most perfect one is on the sixth caudal, as shown in figure 28. At the base it is wide from front to back, heavy transversely, with a broken upper. extremity that is beginning to widen transversely, thus indicating an expanded upper end. The spines are inclined strongly backward, their upper ends overhanging the posterior face of the centra. Proceeding posteriorly the spinous processes grow smaller, so that in the median caudal region it has been reduced to a short thin upstanding plate of bone without distal expansion as shown in figure 29. In Ceratosaurus the last distinct spine is on the thirty-first caudal; in Antrodemus, however, they must surely have disappeared forward of that point.

The diapophyses or transverse processes in the anterior region have their origin on the side of the neural arch, being directed outward, backward, and slightly upward. In the anterior region they are long, outwardly expanding processes that come to rather of a square end distally. Dorso-ventrally on the outer end they gradually thicken toward the point of attachment on the sides of the arch. A caudal of No. 4734, U.S.N.M., intermediate in position between those vertebrae 
illustrated in figures 28 and 29 has the left process almost perfectly preserved. It is thin dorso-ventrally without especial distal expansion and extends directly outward from the superior median side of the centrum.

Further back, as shown in figure 29, the transverse process is still further reduced in size and its position has shifted downward to the middle of the centrum.

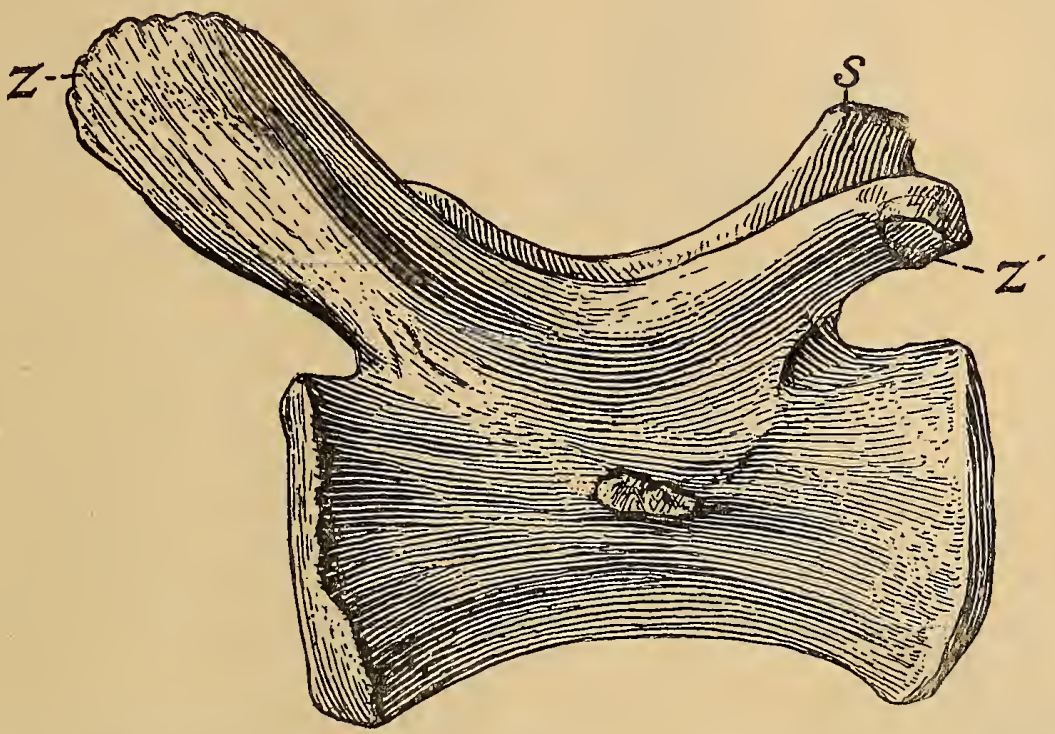

Fig. 29.-Median caudal vertebra of Antrodemus valens Leidy. No. 8367, U.S.N.M. $\frac{1}{2}$ Nat. Size. Viewed From the LEFT SIDE. $s$, SPINOUS PROCESS; $z$, ANTERIOR ZYGAPOPHYSIS; $z^{\prime}$, POSTERIOR ZYGAPOPHYSIS.

In all probability it would have entirely disappeared on the second or third vertebrae posterior to this one.

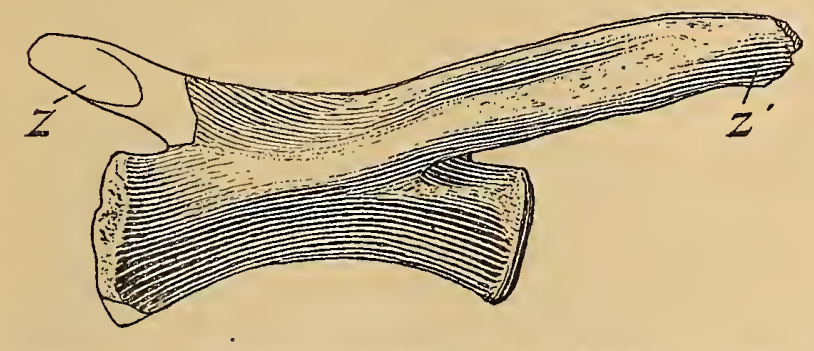

Fig. 30.-CAUdAL Vertebra From distal FoURTh of the tail of ANTroDEMUS VALENS LEIDY. No. 4734, U.S.N.M. I NAT. SIZE. VIEWEd FROM RIGHT SIDE. $z^{\prime}$, ANTERIOR ZYGAPOPHYSIS; $z$, POSTERIOR ZYGAPOPHYSIS.
Concurrent with the reduction of the transverse processes there is a great enlargement and pro-. longation of the anterior zygapophyses, as shown in figures 29 and 30 . These zyga pophyses have wide expanding ends which stand high above the centrum with inner faces that look almost directly inward. More posteriorly (fig. 30) the upward inclination is less and the zygapophyses gradually narrow in width dorso-ventrally to its free end. More posteriorly still, as shown in figure 31, the anterior zygapophyses become more rod like, though their great anterior prolongation is maintained. These are in striking contrast to the comparatively weak zygapophyses of the Ceratosaurus caudals, but very similar in those of Gorgosaurus and Ornithomimus. 


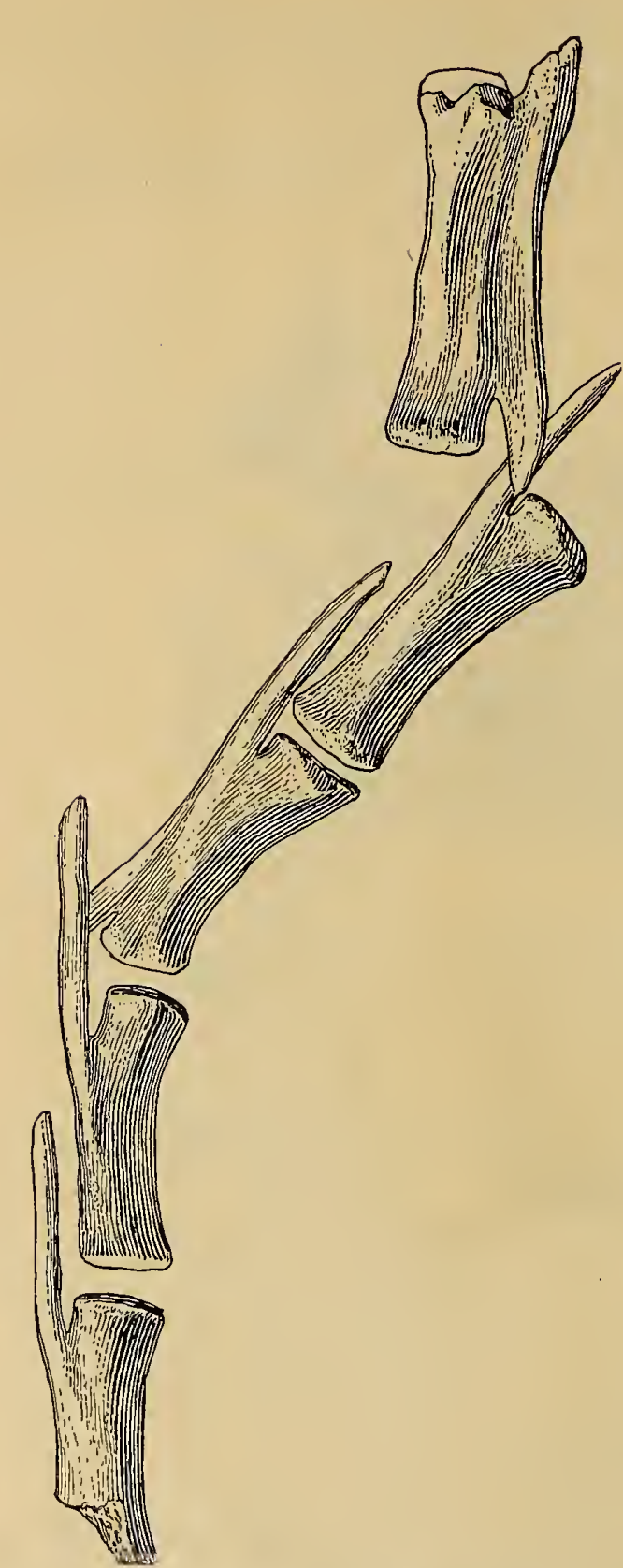

FIG. 31.-SERIES OF FIVE CAUDALS FROM NEAR THE DISTAL END OF TAIL OF ANTRODEMUS VALENS LEIDY. NO. 4734, U.S.N.M. $1 \frac{1}{2}$ NAT. SIZE. DRAWN FROM THE RIGHT SIDE AS FOUND IN THE MATRIX. Marrix.
vical vertebrae. Apparently, it is the first specimen found having a considerable num-
ber of the ribs preserved, and they show those restored on the mounted skeleton of ber of the ribs preserved, and they show those restored on the mounted skeleton of

With specimen No. 8367, U.S.N.M., there are six chevron bones preserved. Judging largely from their relative positions as found in the quarry (fig. 21) they appear to represent the first, second, third, fourth, fifth, and seventh of the 'series.

The anterior cherrons of Antrodemus valens can be at once distinguished from those of Ceratosaurus nasicornis, by their greatly expanded articular proximal ends, the wider, antero-posteriorly, and more backwardly curved shaft, and their relatively shorter lengths.

One of the most striking peculiarities of the Antrodemus chevrons is the development on the anterior side of the proximal end of two projecting spurs, which extend forward on either side of the haemal opening, as shown in figure 32 . The two branches of the chevrons are joined together by a bridge of bone above the haemal canal. In this respect they differ from Gorgosaurus with its two articular ends distinct from one another. The width of the articular end increases posteriorly. The longest chevron, probably the fourth, has a greatest length of $252 \mathrm{~mm}$. with a greatest transverse width at the proximal end of $79 \mathrm{~mm}$.

The lack of a distinct beveled facet on the lower posterior border of the first caudal would appear to indicate that the series of chevrons in Antrodemus begins between the first and second caudal vertebrae, as in Ceratosaurus where it was found in position.

$$
\text { RIBS. }
$$

Cervical ribs.-In specimen No. 4734, U.S.N.M., there are present on the right side, the ribs belonging to the third, fourth, fifth, sixth, eighth, and ninth cer-
cimen found having a considerable num- 
Antrodemus (pl. 16), in the American Museum of Natural History, New York, and also of Ceratosaurus in the National Museum, to be in error in several particulars. Specimen No. 8367, U.S.N.M., has the proximal portions of all the cervical ribs of the right side present (see fig. 18) and a few of the left side. Those of cervicals 4,5 , and 6 are firmly anchylosed to the vertebrae.

The rib of the third cervical of No. 4734 is preserved entire and is remarkable on account of its extreme slenderness and great length. Its distal fourth bends downward, as shown in figure $33, A$. From tip to tip it measures $268 \mathrm{~mm}$. in length. When articulated, if brought straight back along the vertebrae its posterior extremity reaches the posterior border of the centrum of the fifth cervical. The capitular portion of the rib is short and heavy, with an angular, obtuse, roughened articular face (fig. 33, B), that unites closely with the cupped capitular facet on the vertebra. In aged individuals it doubtless becomes fully coalesced. The tubercular process rises from the antero-external side and slightly posterior to the capitular process. The articular end is slightly expanded, cupped, and fits closely with the outer and under side of the diapophyses. On the anterior side and near the base of the tubercular process the bone is continued

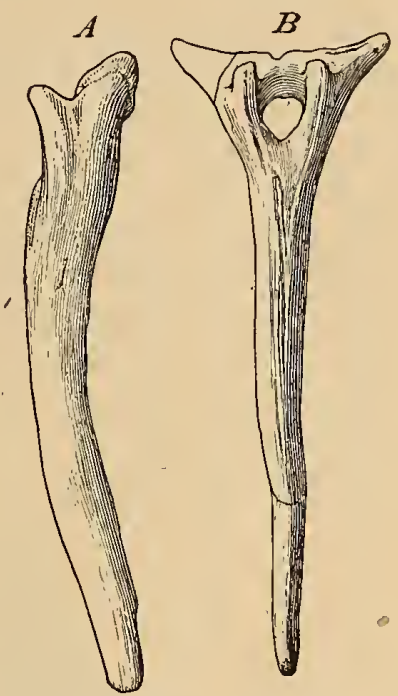

Fig. 32,- $\Lambda$ NTERIOR CHEVRON OF $\Lambda \mathrm{N}$ TRODEMUS VALENS LEIDY. No. $836 \%$. U.S.N.M. $\frac{1}{4}$ NAT. SIZE. A, SIDE VIEW. $B$, POSTERIOR VIEW.

forward and downward forming a slender tapering anterior extension that is curved in toward the centrum, resembling the cervical ribs of the Sauropod dinosaurs in

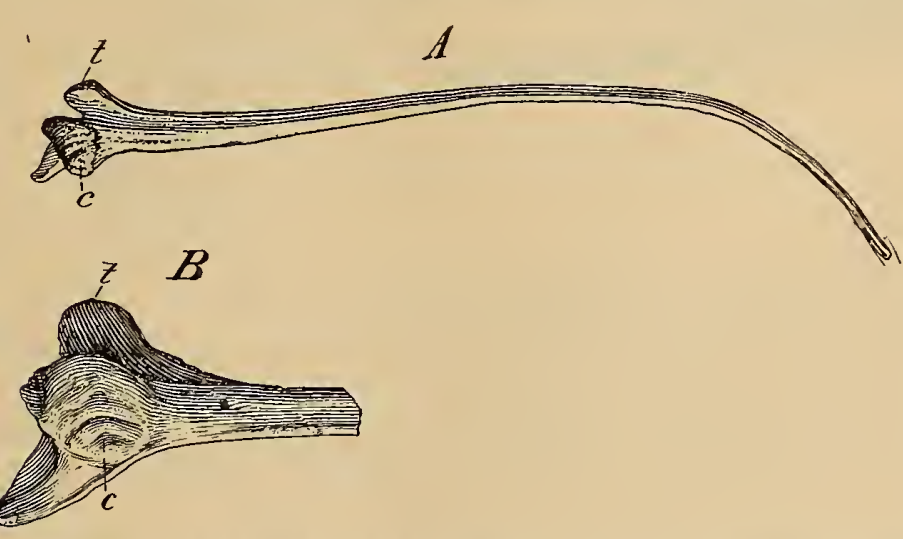

Fig. 33.-Cervical Rib of the Right side of the third cervical, ANtrodemus valens LEIDY. NO. 4734 , U.S.N.M. A, $\frac{1}{3}$ NAT. SIZE. B, HEAD OF SAME, $\frac{2}{3}$ NAT. SIZE. C. Capitulum, $t$, tuberculum. this respect, as in many others. On the inner side at the base of the tubercular process a small circular opening gives entrance to chambers within the heavier portions of the rib. This opening becomes larger and more elongate in the posterior ribs. The above description of the rib of the third cervical vertebra would apply almost equally as well

to the succeeding ribs with the exception that the capitular processes become heavier, the tubercular processes longer and the ribs as a whole more robust. 
Whether they increase or decrease in length posteriorly can not be determined from the present specimens, as all except the one described above lack their distal extremities.

The changes that take place in the cervical ribs from first to last are well shown in figure 18. The rib of the sixth cervical was found articulated with it. The others, though disarticulated, were not far removed from their respective vertebrae in the matrix.

The right rib of the eighth cervical, which may be considered typical of the more posterior cervical ribs, as regards their general shape, is shown in figure 34 .

The tuberculum is not lengthened, being braced on the inner side by a thin vertical plate of bone that rises from the top of the short capitular process. Anteriorly this rib is broad at the base, but narrows rapidly backward. It is thin throughout; the anterior half, concave above, and convex below. The process extending in front of the tuberculum is incomplete, but it was probably roundly pointed. It extends more directly forward and not downward, as in the more

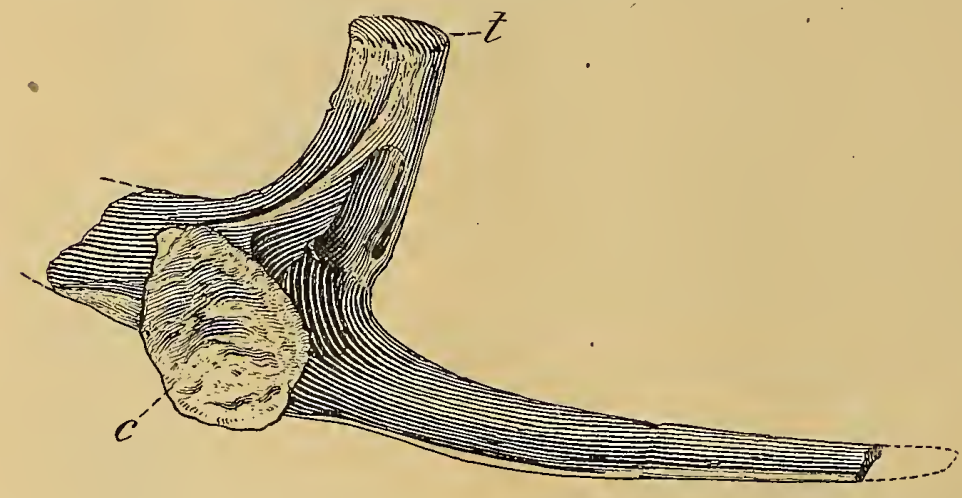

Fig. 34-CERVICAL RIB OF the RIGHT SIDE OF THE EIGHTH CERVICAL OF ANTRODEMUS VALENS LEIDY. INNER ASPECT. NO. 4734, U.S.N.M. 3 NAT. SIZE. c, CAPITULUM; $t$, TUBERCULUM.

The rib of the ninth cervical, No. 8367, U.S.N.M. (fig. 18), differs principally in its larger size and the more rapid diminution of its posteriorly directed process.

Thoracic ribs.-In Antrodemus there are fourteen ribs in the complete thoracic series on each side. With specimen No. 8367, U.S.N.M., there are eleven ribs from the right side, most of which are nearly complete, though all lack their extreme distal ends. They appear to represent a continuous series from the first back to the twentieth presacral.

The changes that take place in their form from front to back are well shown in figure 36.

In figure 35 is shown the inner view of what I regard as the first dorsal rib, though it might with almost equal propriety be considered as belonging to the cervical series. Certainly it is transitional in character, and the distal end in all probability was not attached to the sternum. The head of this rib takes on the general form of the succeeding thoracic ribs in so much as the tuberculum and capitulum are wide apart and lie in the same plane with articular surfaces of about equal 
dimensions. The capitular process is the heavier of the two, and when articulated is directed downward and forward instead of inward almost at right angles to the main part of the bone, as in the preceeding cervical ribs. The vertical supporting lamina of the bone described as strengthening the tubercular process on the rib of cervical eight, on the inner side is here the thin connecting plate of bone that forms the median part of the anterior end between the tuberculum and capitulum. The lateral process (fig. 36, A. $7 . p$.) has almost disappeared, and that part remaining is well posterior to the articular processes, where as in the cervical ribs it extends anterior to them. On the internal side the heaviest part of the bone is lightened by deep cavities, as shown in figure 35 . The tapering distal extremity is directed backward-a feature that persists in the next three or four ribs of the series.

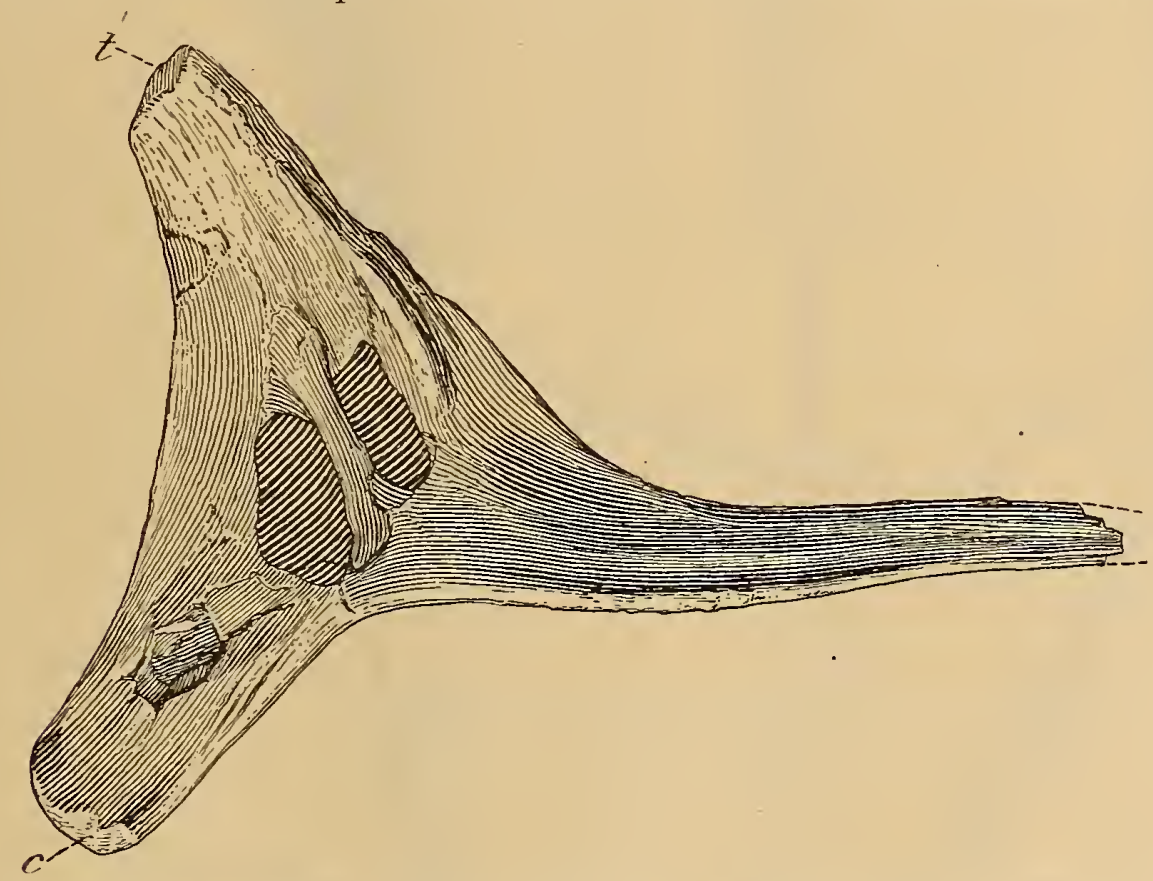

Fig. 35.-First thoracic rib, ANtrodeyus valens Leidy, No. 4734, U.S.N.M. INNer ASpect. $\frac{1}{2}$ NAt. Size. c, CAPItulum; $t$, TUBERCULUM.

The next rib back, here considered the second, is of the true thoracic type. The heaviest and strongest part of the rib is in the neighborhood of the tubercle. The process bearing the capitulum is the shortest of any of those present except the first. The processes gradually lengthen in the posterior members reaching their maximum development in the ninth and tenth, which are about subequal. Posteriorly they again gradually shorten. They also become progressively more slender from the fifth rib, with a change in direction in relation to the shaft. On the second rib this process is given off at nearly right angles to the main axis of the shaft, but posteriorly it gradually assumes a more upward direction until in the eleventh it reaches an angle of nearly $45^{\circ}$ above the horizontal.

The change in direction of this process is accompanied by a change in the curvature of the shaft of the rib; so that while the first of the series, when articulated, 


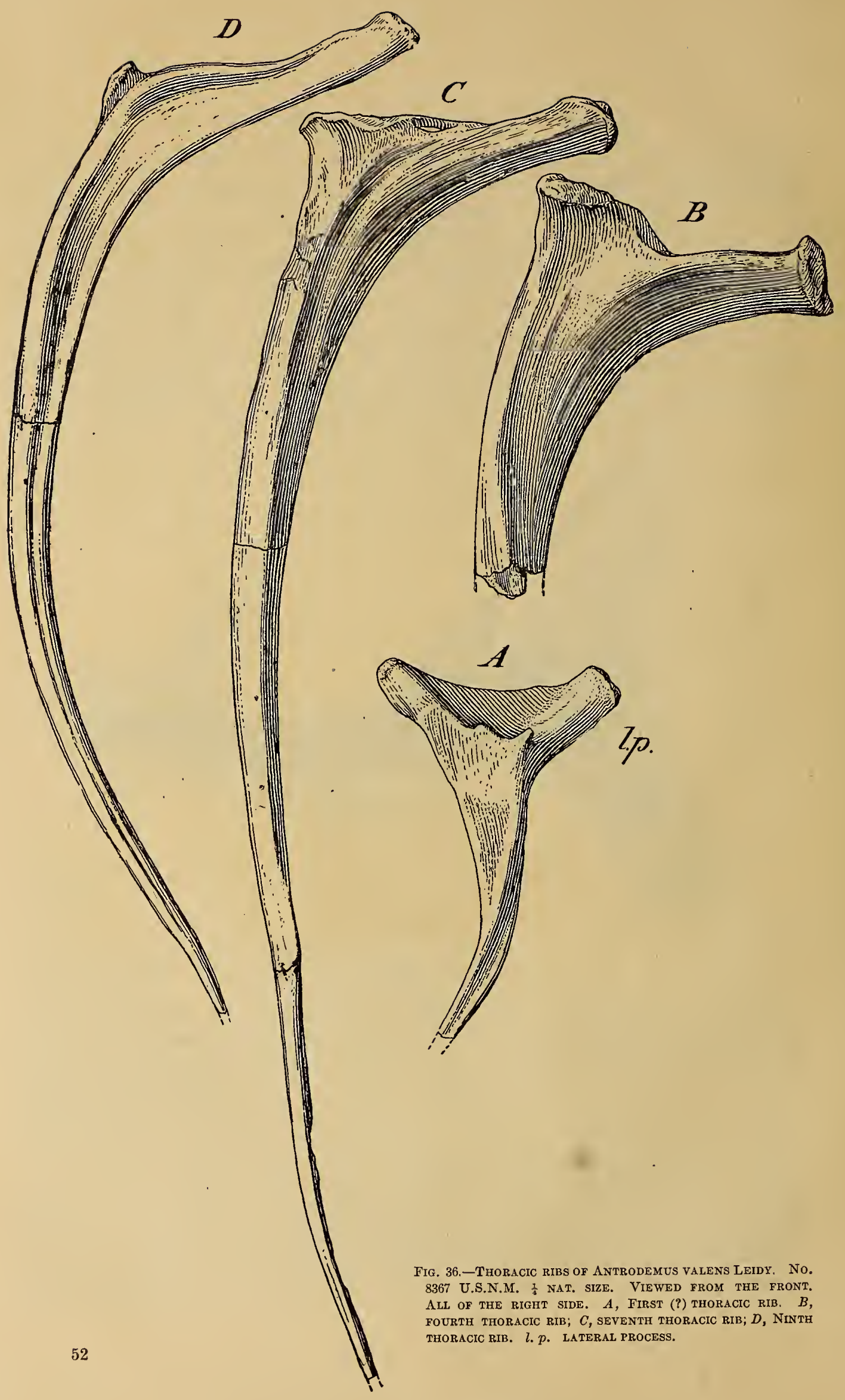


extend nearly straight downward, the median and posterior ribs form a more barrellike thoracic cavity. These progressive changes from first to last may be observed in the ribs illustrated in figure 36.

The external surface of the second rib is narrow and bladelike proximally, but on the third this blade is produced posteriorly, thus presenting a broader aspect to the outer face, which becomes more pronounced in the succeeding ribs. In cross section it would be the form of an inverted $L$. With an increasing slenderness downward they become subtriangular, then subcircular, and finally narrowly oval. Some of the ends in the mid-thoracic region as shown by ribs of the opposite side are slightly enlarged.

The longest ribs of the series appear to be in the mid-dorsal region, probably the sixth, posterior of which they commence to shorten. The most posterior rib is beneath the anterior crest of the ilium as in Ceratosaurus. The length of the ribs can not be given because of the missing distal ends.

Abdominal ribs. - The presence of abdominal ribs in Antrodemus was first made known by Osborn ${ }^{1}$ in 1906 . In plate 15 is shown the abdominal ribs belonging to to specimen No. 4734 , U.S.N.M., as they were found in the rock. Unfortunately these are so disarranged and their state of preservation so incomplete as to make it impossible to determine the total number of these ribs, or the shape of the cuirass which they formed. Lambe ${ }^{2}$ has recently given a most interesting and Fig. 37.-Double abdominal Rib of ANTrodemus VaLens Leidr. No. 4734, instructive detailed account

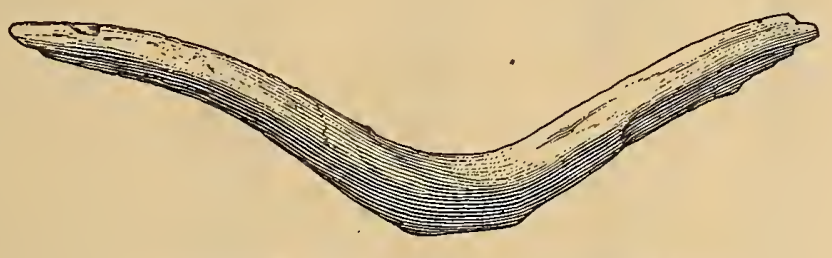
of the abdominal ribs in Gorgosaurus libratus. A comparison of the abdominal ribs before 'me with Lambe's excellent illustrations and descriptions appears to indicate only a general resemblance in the structure of these bones. They occur in a longitudinal series, of which parts of 14 from one side, probably the right, are in sequence in the rock as shown in plate 15. In Gorgosaurus, Lambe provisionally regards the full series of one side to consist of 19 ribs. In that genus each rib consists of two parts, an elongated bone with an enlarged and flattened inner end for overlap with the rib at the opposite side at the center, and a shorter, slender, tapering, rodlike bone, the greater portion of which is applied along the side of the outer end of the large bone. Portions of similar paired bones are clearly shown in the photograph of these elements as found in the sandstone, see plate 15. Only one (fig. 37) of the double abdominal ribs, such as are present in Gorgosaurus and Tryannosaurus, was found with this specimen.

Associated in the rock with the bones described above are a number of short rodlike pieces of bone, varying in length from 80 to $110 \mathrm{~mm}$. with slightly expanded ends that I will presently attempt to show are additional segments of the abdominal ribs.

1 Osborn, Henry Fairfield, Bull. Amer. Mus. Nat. Hist., vol. 22, p. 283, 1906.

2 Lambe, L. M. Memoir 100, Canadian Geol. Surv., No. 83, Geol. ser., 1917, pp. 37-44.

${ }^{3}$ Osborn, H. F., Bull. Amer. Mus. Nat. Hist., vol. 22, p. 295, fig. 12. $144035^{\circ}-20-5$ 
With specimen No. 8367, U.S.N.M., are a considerable number of parts of the abdominal ribs, several of which are in a beautiful state of preservation, as shown in figure 38. While these were found disassociated, a study of them in conjunction with those of specimen No. 4734 , U.S.N.M., enables me to determine with some degree of certainty several points hitherto obscure. The more characteristic of these segments are shown in figure 38.

The long slender bone shown in $A$, (fig. 38) is unquestionably the outer or most lateral segment of an abdominal rib. Its outer half is rounded in section and sinu-

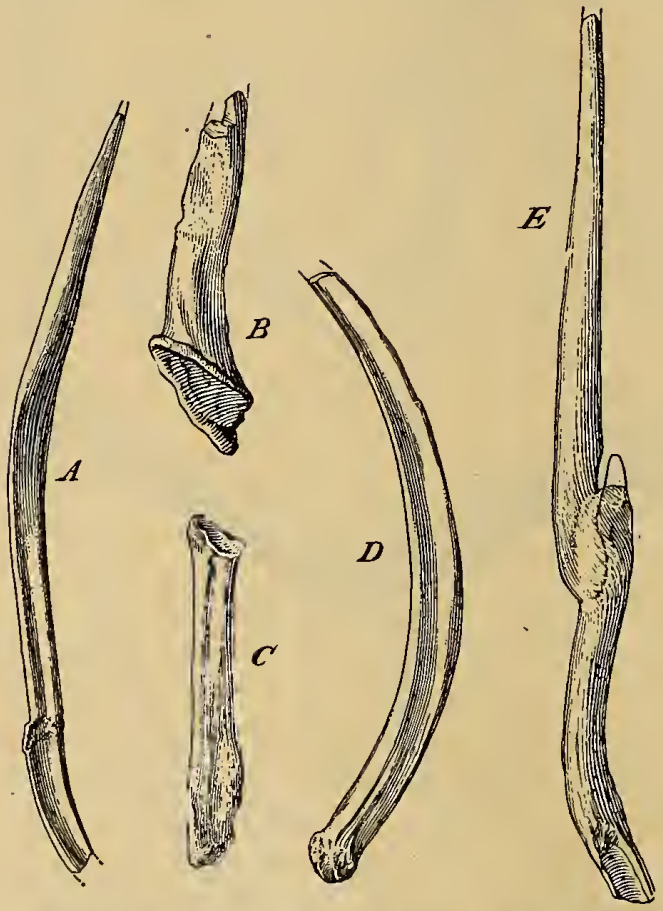

Fig. 38.-SEgments of abdominal Ribs of ANtrodemus VaLENS LEIDY. No. 8367 , U.S.N.M. $A$, LATERAL SEgMENT; $B$, THIRD SEGMENT WITH ARTICULAR PROXIMAL END; $C$, SHORT SEGMENT POSITION UNDETERMINED; $D$, SECOND SEGMENT SHOWING THE EXPANDED DISTAL ARTICULAR END; $E$, SECOND SEGMENT, SAME AS $D$, BUT COOSSTFIED BX OBLIQUE TRANSVERSE JOINT WITH THIRD SEGMENT. ALL FIGURES $\frac{1}{3}$ NAT, SIZE. ous in its curvature, with a tapering extremity. The inner or proximal half is flattened on one side, probably the anterior, along which a similar, though oppositely flattened side of the second segment laps (fig. 39 and pl. 15), where they are shown articulated as found in place.

The second segment (D and E, fig. 38) is a regularly curved bone deeper than wide, with a tapering outer extremity, and a slightly enlarged proximal articulating end, the face of which is oblique to the longer axis of the bone. The posterior face of this end of the bone is flat, but gradually changes to a longitudinal groove as the outer end is approached. The articular end articulates with the third segment as shown in $\mathrm{E}$, figure 38 .

The third segment ( $B$, and lower part of $\mathrm{E}$, fig. 38 ) is short with a very much expanded distal end having a cupped articular surface that is oblique to the longer axis of the bone. It is this expanded, cupped end that articulates with the proximal end of the second segment as illustrated in $\mathrm{E}$, figure 38 .

The opposite end, as rather unsatisfactorily shown by two bones, appears to be grooved on the superior side for the articulation of a fourth segment, and in specimen No.4734, U.S.N.M.(pl. 15) a series of four segments are to be observed in the third rib from the bottom of the block. It may be that the unidentified segment shown in C, figure 38, represents the fourth of the series. Whether this fourth segment joined the one of the opposite side at the median line, or whether there was a median bone that joined the two series, no explanation is afforded by the materials now before me. There is no evidence of a bilateral median segment among the many abdominal parts preserved with the two specimens except the one shown in figure 37 , and this appears 
to represent one of the double ribs such as found by Lambe at the posterior end of the cuirass in Gorgosaurus.

- A study of these rather meager materials, therefore, shows that in Antrodemus some of the abdominal ribs of the cuirass were certainly composed of three and probably four segments on each side of the median line, so that a complete section across the abdomen would consist of either six or eight distinct ossifications, with every probability of there being a single median bone connecting the two lateral series, thus making either seven or nine in all (fig. 39).

FORE LIMB AND FOOT.

Plates 5-7, fig. 3.

The fore limb of Antrodemus as compared with the hind limb is relatively small, but the large size of the processes and the rough nature of their surfaces imply a powerful musculature. The great size of the terminal phalanges and the general structure of the foot indicate that it was used exclusively for seizing, holding, and tearing and that it had long ago lost its functions as an organ of progression.

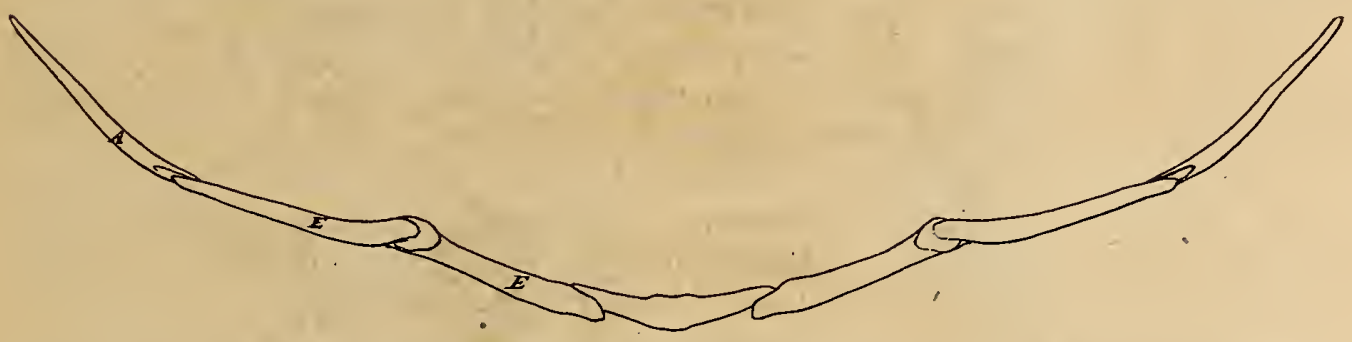

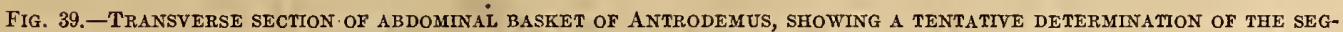
MENATION OF THE ABDOMINAL RIBS. ABOUT $\frac{2}{6}$ NAT. SIZE.

The hand is relatively of enormous size, being slightly longer that the humerus and nearly one and one-half times as long as the forearm. In general it resembles the foot of Ornitholestes, but the bones are more robust, and there is no trace with either foot of metacarpal IV.

The carpus is ossified, being made up of two transverse rows, but the precise number of elements composing it yet remains to be determined. These are three digits, which have the phalangial formula of 2,3 , and 4 . Digit 1 is the heaviest of the series, and digit 3 is somewhat reduced (fig. 40).

In a previous article ${ }^{1} \mathrm{I}$ have given a detailed description of a forelimb and foot of Antrodemus, at that time referred to Allosaurus fragilis, but in order to make the present account of the osteological structure of the genus complete it is here repeated with some few omissions and emendations.

The fore limb figured by Marsh in the Dinosaurs of North America, ${ }^{2}$ plate 11, figure 1, as being that of Allosaurus fragilis Marsh, is a composite drawing, and is not representative of the genus Antrodemus (Allosaurus), but is largely that of Ceratosaurus. 
In going over a lot of tracings and drawings of Theropodous dinosaur bones made for Professor Marsh, a slip of paper in Marsh's handwriting was found, on which he had written instructions to the draftsman for the composition of the Antro-" demus (Allosaurus) fore limb (fig. 58) which reads as follows:

\section{Fore limb Allosaurus.}

1. Enlarged scapula (1933 as 83.5 is to 100 ).

2. Make coracoid to correspond (See Phillips, p. 208).

3. Draw humerus (1894 nat. size).

4. Make radius $9 \frac{1}{2}$-inches long.

5. Make ulna $9 \frac{1}{2}$-inches long + olecranon.

6. Enlarged foot as 83.5 is to 100 .

The number 1933 is the catalogue number of the Peabody Museum originally given to the type-specimen of Ceratosaurus nasicornis Marsh before its transfer to the United States National Museum. The coracoid, which is not present with the Ceratosaurus skeleton, was evidently modified from a figure of that bone in Phillips Geology. The humerus is from another specimen, and the radius, ulna, and foot were evidently drawn from those bones pertaining to the type-specimen of Ceratosaurus nasicornis Marsh, shown in figure 60, and plate 27, figure 3.

From this brief review it becomes'at once evident that this figure is not to be relied upon as being of the genus Antrodemus, and it may therefore be dismissed from further consideration in that connection.

In the American Museum of Natural History in New York is a beautifully mounted skelton of Antrodemus (Allosaurus), (pl. 16, fig. 1) the fore limbs and feet of which are partially restored. In a letter, bearing the date 1909, Mr. Walter Granger of the American Museum'staff wrote me regarding their composition as follows:

In reconstructing our own fore limb of Allosaurus we had scapula and coracoid, ulna and one claw. The humerus we got from a cast of one in Kansas University; the remainder of the limb and foot was modeled from the Ceratosaurus specimen (Type, No. 4735, U.S.N.M.), which was borrowed from your Museum.

Following the Ceratosaurus as a pattern the foot was given four digits, whereas the specimen before me shows quite conclusively that Antrodemus had but three digits, with a reduced metacarpal III. The phalangial formula in the New York specimen is correct, and the relative proportions of the various segments of the limbs are entirely in accord with the associated material forming the basis of the present discussion. In view of the limited fore limb and foot material available at the time of reconstruction this limb and foot of Antrodemus, those in charge of this work are to be congratulated upon their close approximation to the facts as revealed by this more recent material.

Remove the fourth digit, replace metacarpal III by metacarpal IV and insert the carpal bones and the limb would be quite in accord with the fossil specimen before me. This change has now been made.

Hay ${ }^{1}$ in 1908 in commenting upon this New York specimen concluded that it had been wrongly identified as Allosaurus, because of the great size of the hand in relation to the other segments of the limb, being led into this error ${ }^{2}$ by relying on the authenticity of the figure of the limb and foot published by Marsh. 
Williston ${ }^{1}$ in 1901 in describing some limb material secured by him in Wyoming, refers to the so-called Allosaurus fore limb figured by Marsh in the following:

There were two scapulae obtained that certainly show a generic distinction from Allosaurus, as I have convinced myself from inspection of the scapula referred by Marsh to that genus,' and figured by him in various places. It remains to be seen, however, whether this scapula of Marsh indubitably belongs with the bones first referred by him to Allosaurus. I do not think there is conclusive evidence of this.

The facts regarding this scapula as presented on a preceding page bears out Doctor Williston's contention.

The limb described and figured by Williston undoubtedly belongs to the genus Antrodemus. Its close resemblance may be clearly seen by comparing his illustration with figure 40 .

Scapula (Sc.)-Both scapulae are preserved with the present specimen, the right being perfect, as shown in plate 5, figure 2, with the exception of a small portion of the upper anterior corner of the blade, which is missing. The left scapula was injured in life, and subsequent healing produced the deformation shown in plate 5, figure 1. This pathologic condition caused a widening of the blade that would be entirely misleading as to its true form had not the opposite scapula been present. The scapula of Antrodemus is distinctive on account of its bird like form as has previously been pointed out by Williston. ${ }^{2}$ The shaft is exceptionally long and slender, being nearly of equa! width throughout, except the uppermost or distal extremity which is perceptibly widened. This expansion is about equal in fore and aft direction. The upper third is flattened and thin, while more proximally the shaft is trihedral in cross section, the

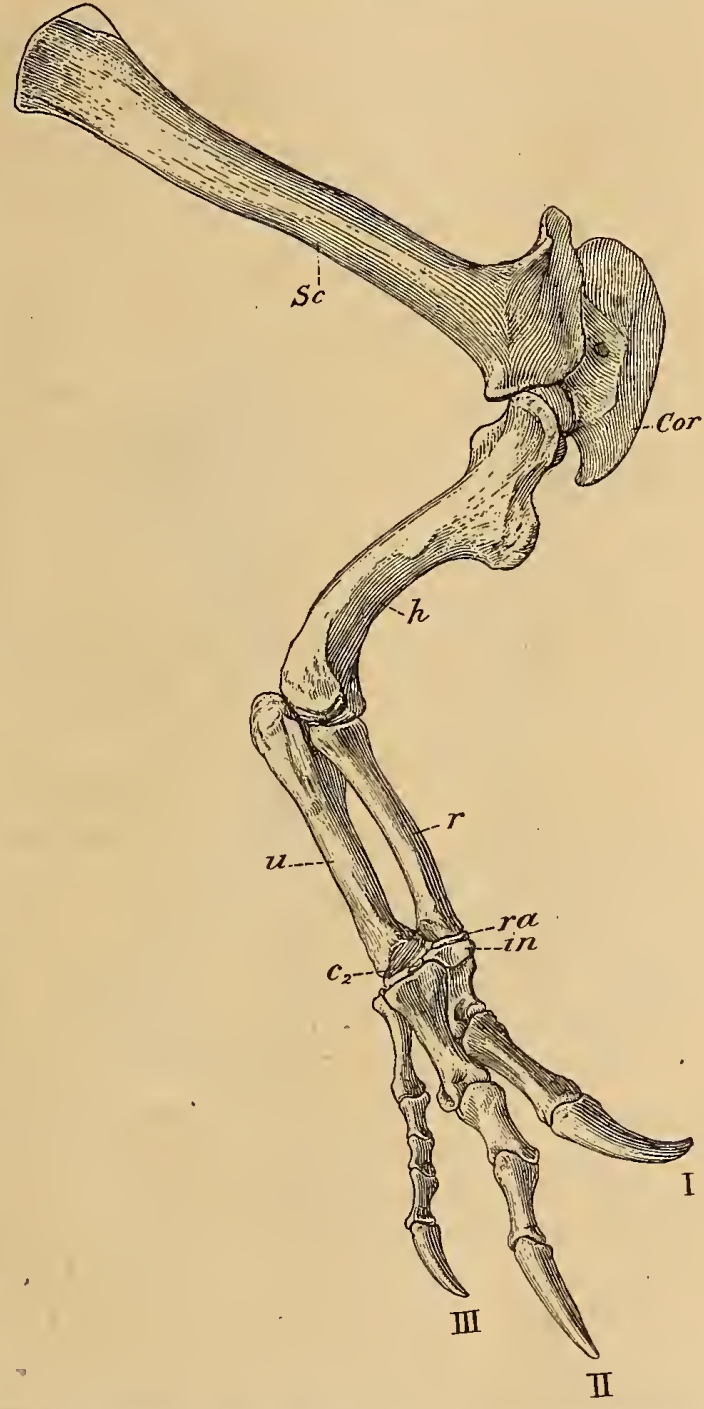

FIG, 40,-RIGHT FORE LIMB AND FOOT OF ANTRODEMUS VALENS LEIDY. Cat. No. 4734, U.S.N.M. $\frac{1}{8}$ Nat. Size. Lateral VIEW. $c_{2}$ CARPALE TWO; $C o r$, CORACOID; $h$, HUMERUS; $i n$, INTERMEDIUM; $r$, RADIUS; $r a$, RADIALE; Sc, SCAPULA; $u$, ULNA; I, II, AND III, DIGITS ONE, TWO, AND THREE. THE POSITION OF THE MISSING ULNARE IS INDICATED BY DOTTED LINES.

anterior border being sharp, the posterior one rounded. Longitudinally the external surface is convex, though nearly straight in its middle portion, a shape that probably conformed closely with the convex curve of the body carity. The inner 
surface of the greater part of the blade is flattened antero-posteriorly: while the outer surface, excepting the upper fourth is rounded in this direction. The articular end being expanded both antero-posteriorly and transversely is heavy, especially on the posterior half, which has a maximum thickness immediately above the glenoid fossa of $58 \mathrm{~mm}$. The scapula unites with the coracoid by a straight suture that bisects the glenoid fossa and is terminated above by a deep notch between the scapula and coracoid on the anterior border. In this individual both scapulae are firmly coossified with their respective coracoids. The scapula of this specimen appears to agree in all particulars with the one found with the mounted skeleton of Antrodemus in the American Museum. of Natural History, and it also shows that the limb described by Williston should be referred to this genus. In this connection it is of interest to know that the Ceratosaurus scapula which formed the basis for the illustration of this bone in the so-called fore limb of Allosaurus is now in the United States National Museum collections (pl. 26, fig. 1). I have recently examined the bone and find that its upper extremity is incomplete, so that it is not positively known whether this blade has a nonexpanded end as represented by Marsh or whether it was expanded as in Antrodemus. It differs, however, from Antrodemus in having a thinner and wider shaft, and a more abrupt backward curve of the heavy posterior border just above the glenoid fossa. Both inner and outer surfaces of the lower three-fourths of the shaft in Antrodemus are rounded. Both of these specimens came from the famous "Quarry No. 1," near Canon City, Fremont County, Colorado.

$$
\text { Measurements of scapula of Antrodemus valens. }
$$

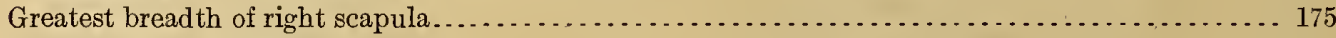

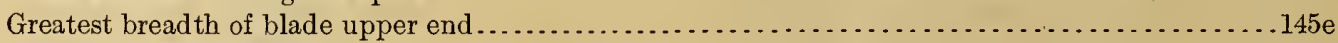

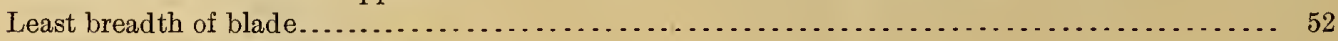

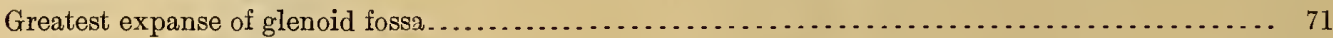

Coracoid (Cor.).- The coracoid in Antrodemus is quadrangular in outline, this measurement exceeding the antero-posterior diameter. The outer surface is convex in all directions, the inner decidedly concave antero-posteriorly. There is a broad notch on the inferior border.

The coracoid is pierced by the usual foramen, which runs diagonally through the bone, the external exit being larger than the internal. This foramen is entirely inclosed (fig. 40), not a notch as shown in Marsh's figure of the coracoid (pl. 11, fig. 1. Dinosaurs of North Amelica). 'I'he superior border presents a thin flattened edge, the anterior edge gradually thickening toward the inferior border.

Measurements of coracoid of Antrodemus valens. $m m$

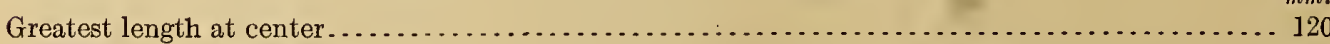

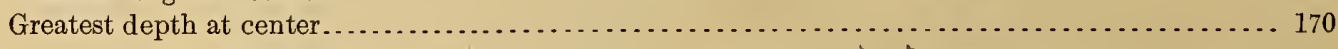

Humerus ( $h$ ).-Comparatively the humerus of Antrodemus is short and somewhat sigmoid in form. The shaft is hollow, as are all of the limb and foot bones of this genus. Planes passed through the greatest diameter of the articular ends would cut one another at an angle of $50^{\circ}$. This unusual angulation throws the 
articulated radius and ulna well out away from the body. The deltoid or radial crest is strongly developed, as a short but high thin plate of bone, that is situated on the anterior-external border immediately above the middle of the shaft. Viewed from the front it renders the anterior surface deeply concave transversely (fig. 41). Below this crest the shaft is constricted and angularly rounded in cross section. The head is situated in about the middle of the proximal end with the articular portion overhanging the posterior surface of the shaft. The radial and ulnar condyles are well defined. Posteriorly they are separated by an unusually broad but shallow depression which continues somewhat upward on the shaft of the bone. The articular ends of the humerus are rugosely roughened. A prominent roughened oval shaped area on the posteroexternal surface at the lower border of the radial crest, probably represents the point of insertion for the humero-radialis muscle (pl. 6, figs. 2 and 4). The measurements given, below were made from the humerus of the right side, which is the better preserved of the two:

Measurements of humerus of Antrodemus valens.

$\begin{array}{ll}\text { Greatest length } \ldots \ldots \ldots \ldots \ldots \ldots \ldots \ldots \ldots \ldots & 310 \\ \text { Greatest width of proximal end } \ldots \ldots \ldots \ldots \ldots & 118 \\ \text { Greatest width of distal end } \ldots \ldots \ldots \ldots \ldots \ldots \ldots & 100 \\ \text { Least diameter of shaft } \ldots \ldots \ldots \ldots \ldots \ldots \ldots \ldots & 38\end{array}$

Una $(u)$.-The ulna is expanded and heavy proximally with a less expanded distal end. It exceeds the radius in length but is shorter than the humerus. The proportion being as $1: 1.17$.

There is a heavy olecranon process $(o$. fig. 42) that extends considerably above the articular surface for the humerus. The surface of this process is roughened for muscular insertion. The olecranon process is less well developed in Ceratosau-
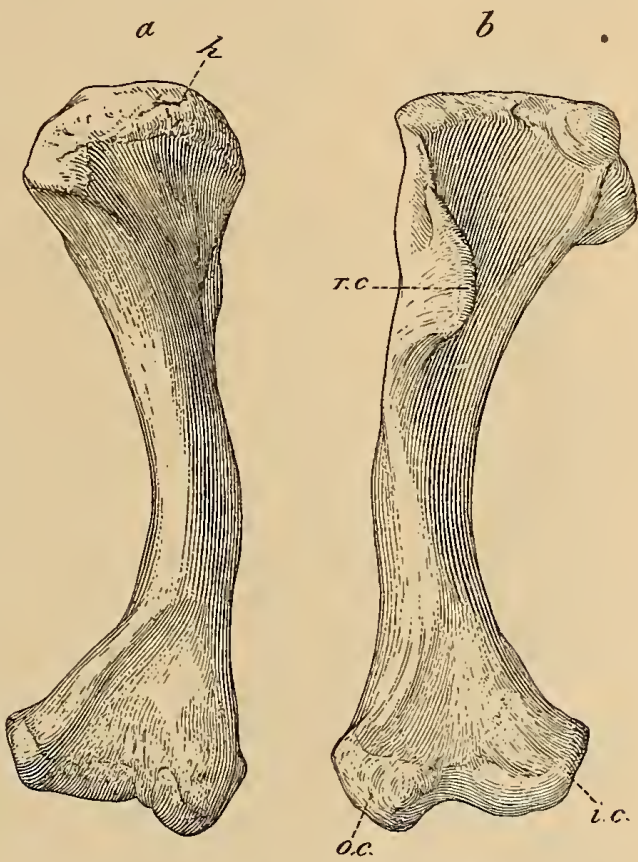

Fig. 41.-Right humerus of ANTrodemus valens Leidy. CAT. No. 4734, U.S.N.M. 1 NAT. SIZE. $A$, POSTERIOR VIEW; $B$, ANTERIOR VIEW; $h$, HEAD; r.c., RADIAL CREST; i.c. INNER CONDYLE; O.c., OUTER CONDYLE.

rus nasicornis and appears to be entirely wanting on the ulna of Ornitholestes hermanni, though robust in Ornithomimus.

The articular surface for the humerus is comparatively narrow transversely, with a shallow concave surface antero-posteriorly. The concavity on the proximal end for the reception of the head of the radius is shallow. The shaft of the ulna is slender, suboval in cross section, and in a distal direction, gradually expanding into a moderately large end, the greatest diameter being antero-posteriorly. The distal end is oblique to the longer axis of the bone, the surface of which looks downward and forward in the articulated limb. On the inner anterior face of the distal end, a prominent roughened protubrance presents a surface for union with the radius. 
$\mathrm{mm}$.

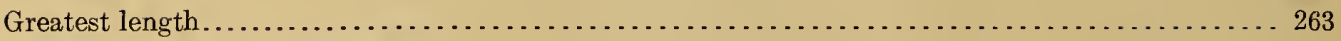

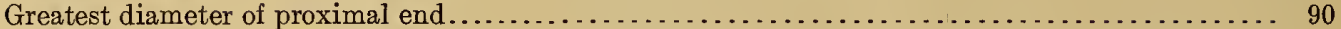

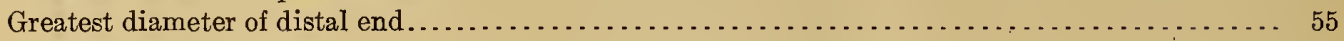

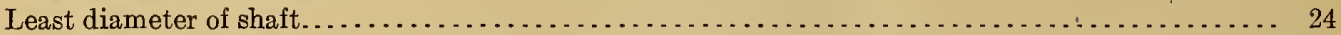

Radius $(r$.$) .- The radius is more slender and somewhat shorter than the ulna.$ The proximal and distal ends are expanded, more especially the former (fig. 43). In cross section the shaft is angularly rounded throughout the greater part of its length. The proximal end is shallowly concave in its greatest diameter. Viewed from above this end is suboval in outline. The distal end is subtriangular in outline, with an oblique surface that looks downward and outward. It

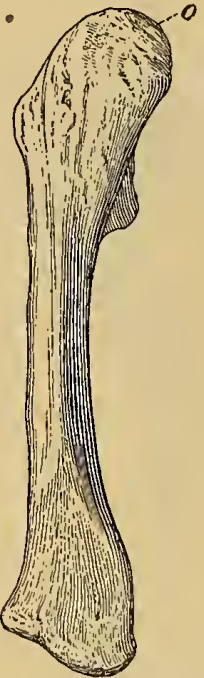

Fig. 42.-LEFT ULNA OF ANTRODEMUS Y ILENS LEIDY. CAT. NO. 4734 U.S.N.M. $\frac{1}{4}$ NAT. SIZE. POSTERIOR VIEW. 0 OLECRANON PROCESS. articulates exclusively with the radiale of the carpus. The inner surface where the-radius meets the ulna is slightly roughened.

Measurements of radius of Antrodemus valens.

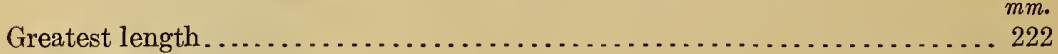

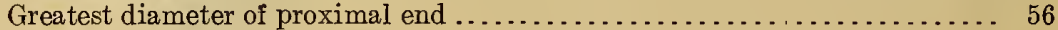

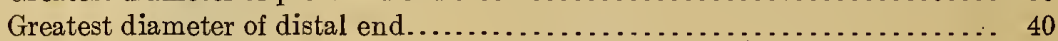

Least diameter of shaft.................................... 20

Carpus.-The ossified carpus in Anirodemus consists of at least five elements, with a possibility of there being one more. Three disarticulated elements were found with the bones of the left foot and three with the right, but since there is an element with each foot that is not present in the other, and the ulnare is lacking in both, the presence in the complete carpus of five ossified carpals is quite conclusively demonstrated. Fortunately two of those pertaining to the right foot (figs. 40 and 45 , in. and $c_{2}$ ), the intermedium and a carpale, probably $c_{2}$, were found in position, firmly attached to metacarpals I and II, and these give the first definite knowledge we have of the exact manner of their articulation. Without such evidence it would be almost impossible to place them properly. I was also able to determine the proper articulation of the radiale by its position as found in the matrix and also by its close articulation with the grooved surface of the intermedium.

The radiale is a flattened discoidal element, irregularly oval in outline (fig. $44, a)$. The upper articular surface is shallowly concave, while the distal surface is angularly convex. This surface in the articulated foot articulates for more than half its area with the intermedium, and slightly, if at all, with the outer anterior corner of metacarpal I. Its greatest transverse diameter is $41 \mathrm{~mm}$.; greatest thickness, $15 \mathrm{~mm}$.

The intermedium, as shown in figure $44, b$, is an irregularly quadrangular bone. Articulated, it rests about equally upon the proximal ends of metacarpals I and II (fig. $45 \mathrm{in}$. and ra.). The upper surface presents a broadly grooved surface for the radiale, with a projecting spur on the anterior face that continues to the outer border of metacarpal I, so that when viewed from the front it appears to completely 
cover the metacarpal. On the posterior external side a somewhat similar projection overlaps a beveled surface on the outer proximal end of metacarpal II. The outer end of this is separated by a notch from a smaller process on the anterior border that also rests upon a beveled articular facet on the end of metacarpal II. The intermedium has a greatest transverse diameter of $51 \mathrm{~mm}$; greatest antero-posterior diameter is $40 \mathrm{~mm}$.

The ulnare is not known. Carpale 2 is apparently represented by the small flattened ossicle that was found attached to the proximal end of metacarpal II (fig. $45 c_{2}$ ) of the right foot, which is in close apposition to the outer anterior border of the intermedium. A detached bone found near the left manus is regarded doubtfully as representing $C_{3}$. It is elongated in one diameter with angularly rounded surface. There is no clew as to the position it occupied on the foot, if indeed it represents such an element. Its longest diameter is $31 \mathrm{~mm}$., with a least diameter of $11 \mathrm{~mm}$.

Metacarpus.-The complete metacarpus in Antrodemus apparently consists of three elements, there being no trace in either foot of metacarpal IV, which is present in the manus ${ }^{1}$ of Ornitholestes hermanni Osborn.

Metacarpal $\mathrm{I}$ is a short heavy bone with a deeply grooved distal end that is turned inward away from the central axis of the foot. Resembling Ornithomimus (Struthiomimus) and Ornitholestes in this respect. The articular facets extend well

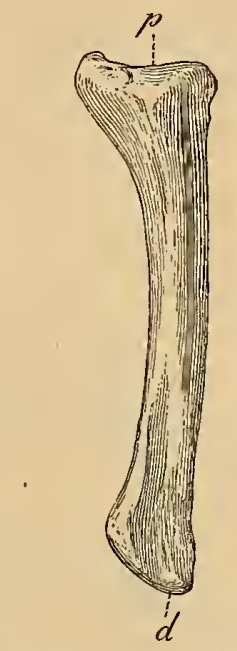

Fig. 43.-RIGHT RADIUS OF ANTRODEMUS VALENS LEIDY. No. 4734 U.S.N.M. $\frac{1}{2}$ NAT. SIZE. INTERNAL VIEW. $d$, DISTAL END; $p$, PROXIMAL END. upward on both front and back aspects (fig. $45, d$.), rising about equally above these surfaces of the shaft. The lateral pits are moderately shallow, the outer one being the better defined. Viewed from above, the proximal end is subtriangular in outline with a shallow concave articular end. This surface is opposed in the articulated
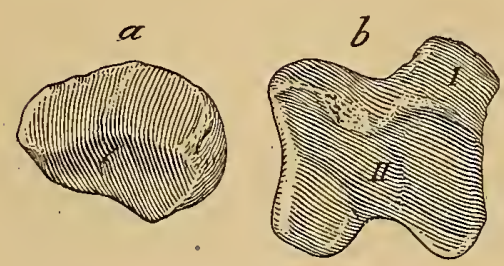

Fig. 44.-CARPal bONES OF ANTRODEMUS VALENS LEIDY. CAT. No. 4734, U.S.N.M. 2 NAT. SIZE. VIEWED DISTALIY. $a$, RADLALE OF THE RIGHT FORE FOOT; $b$, INTERMEDIUM OF THE LEFT FORE FOOT; II, SURFACE ARTICULATING WITH METACARPAI; I, SURFACE ARTICULATING WITH METACARPAL II. ward in the form of two lateral condylarlike facets, which are separated by a deep and moderately broad notch. The external one is the larger of the two. The inner border of the proximal end is beveled off, forming two facets of unequal size for the

\footnotetext{
1 Osborn, H. F., Bull. Amer. Nat. Hist., vol. 19, 1903, pp. 462, 463, figs. 2 and 3; also vol. 35, 1917, pp. 735-738, figs. 2-36.
} only touching slightly the hinder internal corner, the remaining surface being closely applied to the intermedium, as shown in the right foot, where these bones were found articulated. Metacarpal I articulates closely on its upper half with metacarpal II (fig. 40), resting in a broad shallow depression on the side of that bone. Metacarpal II is an elongate bone, having an expanded subquadrangular proximal end, rather a slender, angularly rounded shaft, and a less expanded but broadly grooved distal extremity. The articular surfaces of the distal end of this bone are continued back- 
articulation of the intermedium. The remaining proximal surface is smooth, though sloping toward the outside of the foot. Metacarpal III is reduced, being the weakest element of the metacarpus. Although present with both feet, it was detached in each instance. The character of the surfaces appears to indicate, however, that in position it has a weak articulation with metacarpal II on the postero-external angle, as shown in figure 40. Unlike the other metacarpals the distal articular end is not grooved, but is smoothly rounded (fig. $45, a$ ). The posteriorly directed facets are weakly developed, but are separated by a shallow groove, as in metacarpals I and II.

Phalanges. - The phalangial formula is $2,3,4$. All of the digits, as shown in figure 45 , are terminated with latterly compressed, sharply pointed claws, the

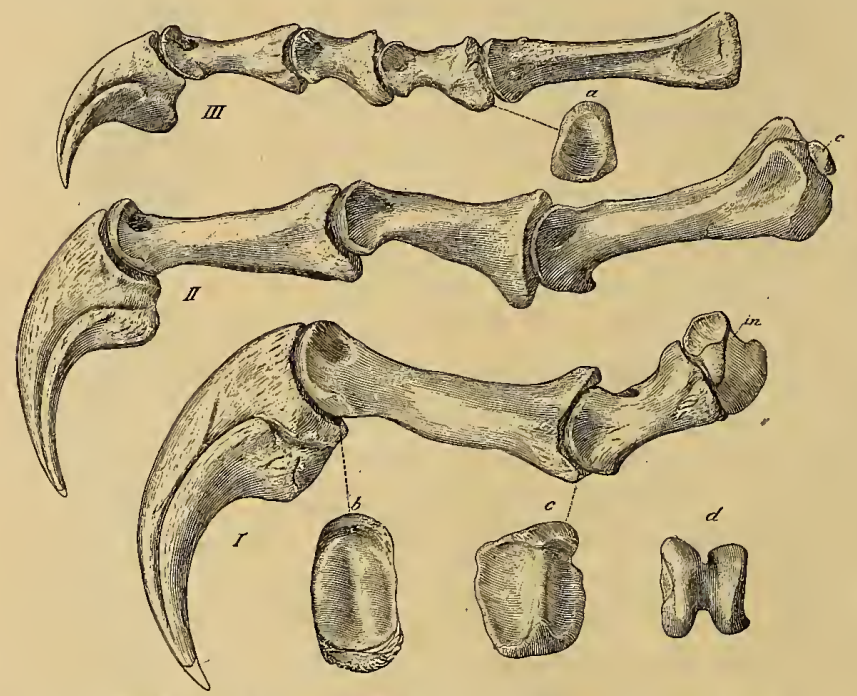

Fig. 45.-Digits of the right fore Foot of ANtrodemus valens Leidy. CAt. No. 4734, U.S.N.M. $\frac{1}{4}$ NAT. SIZE. LATERAL VIEW. $a$, PROXIMAL ARTICULAR END OF THE PROXIMAL PHALANX OF DIGIT 111; $b$, PROXIMAL ARTICULAR END OF UNGUAL OF DIGIT 1; $c$, PROXIMAL ARTICULAR END OF PROXIMAL PHALANX OF THE LEFT FOOT; $C_{2}$, CARPALE TWO; $d$, DISTAL ARTICULAR END OF METACARPAL 1 ; in, INTERMEDIUM; $1,11,111$, DIGITS ONE, TWO, AND THREE.

in figure 40. The articular surface for the claw is broadly grooved, and this surface extends well backward on the underside, thus throwing the- articulated ungual downward at nearly a right angle to the longer axis of the first phalanx. The lateral pits are comparatively shallow, the one on the external side being the better defined. Viewed from above the shaft is quite evenly rounded transversely, while the ventral surface presents a flattened aspect. The ungual of digit 1 is especially robust, with a regularly curved and sharply pointed extremity. Well-defined lateral grooves run back from the tip on both sides, but as they approach the proximal end curve downward, passing into a broad, smooth surface on the posterior ventral surface. The proximal articular surface is keeled as shown in figure $45, b$. The proximal phalanx of digit 2 is shorter than the second of that toe. The proximal end of the former is expanded, especially in the vertical direction. The proximal end as compared with the same phalanx of digit 1 is only 
slightly concave supero-inferiorly, with a comparatively low obtuse keel, placed more toward the inside of this end. Like the keel on the proximal phalanx of digit 1 it is placed at an angle to the vertical axis of the bone. The concave lateral depressions on either side near the distal extremity are so shallow and illy defined they could hardly be designated as pits. The second phalanx of this digit is slightly longer than the first, with a sharply keeled proximal end and broadly grooved distal articulating surface. The lateral pits are small but well defined. The ungual phalanx is intermediate in size between those of the first and third toes.

The proximal phalanx of digit 3 can be distinguished from all others in the foot by the keelless but cupped articular surface of the proximal end (fig. $45, a$ ). It is relatively short, as is the second, the third being more elongate. The proximal ends of the other phalanges of this toe are keeled, and the distal ends are grooved. The ungual, except for its small size, is very similar to the ungual of digit 2 . These two unguals are distinguishable from the ungual of digit 1, not only by difference in size, but also by the difference in the direction of the heavy portion below the articulating surfaces. In the two former in the articulated foot it looks almost directly backward, whereas in the first it is directed downward and backward. In all associated fore feet of Theropodous dinosaurs, as shown in the accompanying table, there are two phalanges on the first digit, with a progressive increase to the point where some of the lateral toes have begun to degenerate. The lengthening of the penultimate phalanges appears peculiar to nearly all Theropodous dinosaurs, and is a mechanical development for the more perfect use of the talons of the fore feet. The principal measurements of the bones of the manus are shown in the following table:

Measurements of fore-foot elements of Antrodemus valens.

METACARPALS.

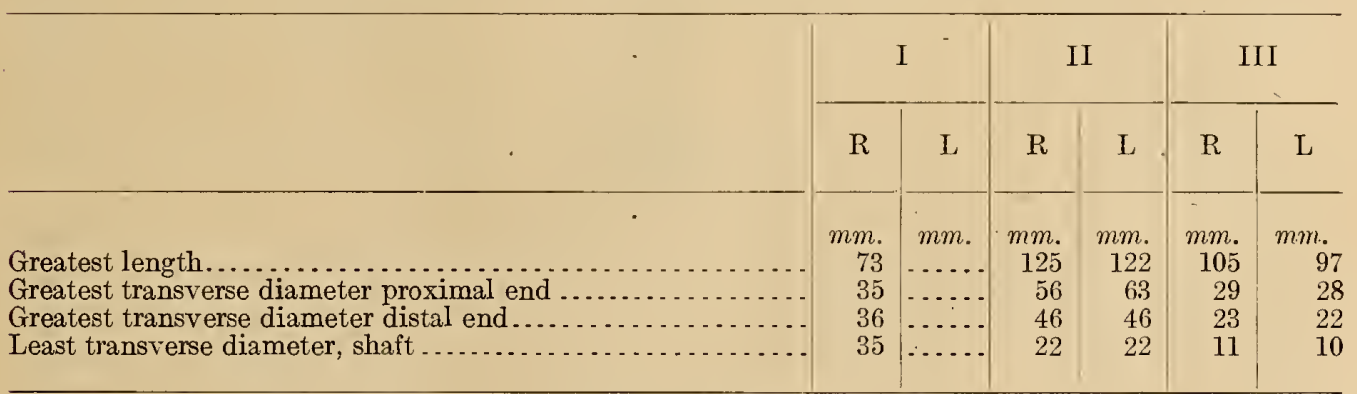

PHALANGES.

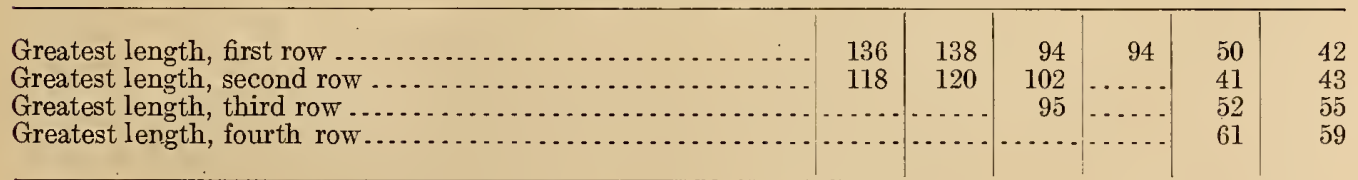


Phalangial formulae of various Theropod dinosaurs.

\begin{tabular}{|c|c|c|c|c|c|c|c|}
\hline \multirow{2}{*}{ Name. } & \multicolumn{5}{|c|}{ Digits. } & \multirow{2}{*}{ Formation. } & \multirow{2}{*}{ Remarks. } \\
\hline & $\mathrm{I}$ & II & III & IV & $\mathrm{V}$ & & \\
\hline Gorgosaurus libratus Lambe... & 2 & 3 & 0 & 0 & 0 & Belly River. & Skeleton in Museum Geol. \\
\hline Ceratosaurus nasicornus Marsh. & 2 & 3 & 3 & 1 & 0 & Morrison. & $\begin{array}{l}\text { Mounted skeleton in U.S.N. } \\
\text { M. Cat. No. } 4735 \text { Marsh's } \\
\text { fig. Pl. XI, D. of N. A. }\end{array}$ \\
\hline Ornitholestes hermanni Osborn. & 2 & 3 & 4 & 0 & 0 & ..... do. & Mounted skeleton in A.M.N. \\
\hline Antrodemus valens Leidy. & 2 & 3 & 4 & 0 & 0 & ..... do. & Mounted skeleton in A.M. \\
\hline Antrodemus valens Leidy. & 2 & 3 & 4 & 0 & 0 & ..... do. & Skeleton in U.S.N.M. No. \\
\hline Hallopus victor Marsh & 2 & 3 & 4 & 3 & 0 & Jurassic. & $\begin{array}{l}\text { Evidence for formula un- } \\
\text { known. Specimenin Yale } \\
\text { University. }\end{array}$ \\
\hline $\begin{array}{l}\text { Compsognathus longipes Wag- } \\
\text { ner. }\end{array}$ & 2 & 3 & 3 & 0 & 0 & & $\begin{array}{l}\text { From Marsh's restoration of } \\
\text { the skeleton. }\end{array}$ \\
\hline Anchisaurus polyzeius Marsh. & 2 & 3 & 4 & 2 & 1 & Triassic. & $\begin{array}{l}\text { Formula that of restoration } \\
\text { by Marsh. D. N. of Amer. } \\
\text { Skeleton in Yale Museum. }\end{array}$ \\
\hline $\begin{array}{l}\text { Ornithomimus (Struthiomimus) } \\
\text { altus Lambe. }\end{array}$ & 2 & 3 & 4 & 0 & 0 & Belly River & $\begin{array}{l}\text { Mounted skeleton in A.M. } \\
\text { N.M. No. } 5339 \text {. }\end{array}$ \\
\hline
\end{tabular}

The more important progressive changes that have taken place in the specialization of the fore limb and foot in the carnivorous dinosauria during successive geological periods appears to be: (1) Reduction in the number of digits, (2) elongation of the penultimate phalanges, (3) lengthening of the scapula, (4) shortening of the forearm, (5) relative reduction in size of the entire fore limb.

With the exception of Ceratosaurus which has both inner and outer fingers reauced, all of the other known carnivores show that the reduction in the number of digits takes place on the outside of the foot. Beginning with the oldest known Theropods from the Triassic all are found to possess the full complement of five digits, though the fifth is often rudimentary. In the Jurassic we find in Ornitholestes that the fifth digit has entirely disappeared, and the fourth is only represented by a vestigal metacarpal. Antrodemus appears to have gone still farther, and apparently the fourth has been lost and the third is somewhat reduced, and approximately the same condition obtains in the hand of Compsognathus from the Upper Jurassic of Bavaria.

Our knowledge of the manus in the Cretaceous Theropodous dinosaurs is rather meager at this time, but a specimen recently described by Lambe $^{1}$ (Gorgosaurus libratus) from Upper Cretaceous (Belly River) shows a still further reduction, there being only two functional digits, the third being represented by the vestigal metacarpal only. 
PELVIS.

Plate 13.

The pelvis of Antrodemus comprises the ilium, ischium, and pubis. These articulate to form the acetabulum. In very old individuals these bones are sometimes found coössified, especially the ilium and pubis, a condition that also obtains in certain members of the Sauropoda. The most striking feature of the pelvis is the union of the distal ends of the pubes to form a triangular foot-like end, on which it is thought the animal rested its weight when assuming a squatting posture.

Iium (il.).- In general form the ilium resembles that of other members of the Theropoda. In the present skeleton the right ilium was found attached to the sacrum. The left ilium was detached but notfar removed from the sacrum and the other pelvic elements, and is the most perfect of the pair. In figure 2, plate 10 , is shown a lateral view of the left ilium which for the first time gives the correct contour of the anterior end. Upon investigation it is found that all of the figures previously published of this bone are incorrect. The greatest discrepancy observed is in the contour of the anterior end, compare figure 2, plate 10 , with figure 46 , for instead of having a convex border from above downward, it presents an irregular but truncated end, resembling somewhat the ilium of Tyrannosaurus.

In the Dinosaurs of North America (pls. 10 and 11)

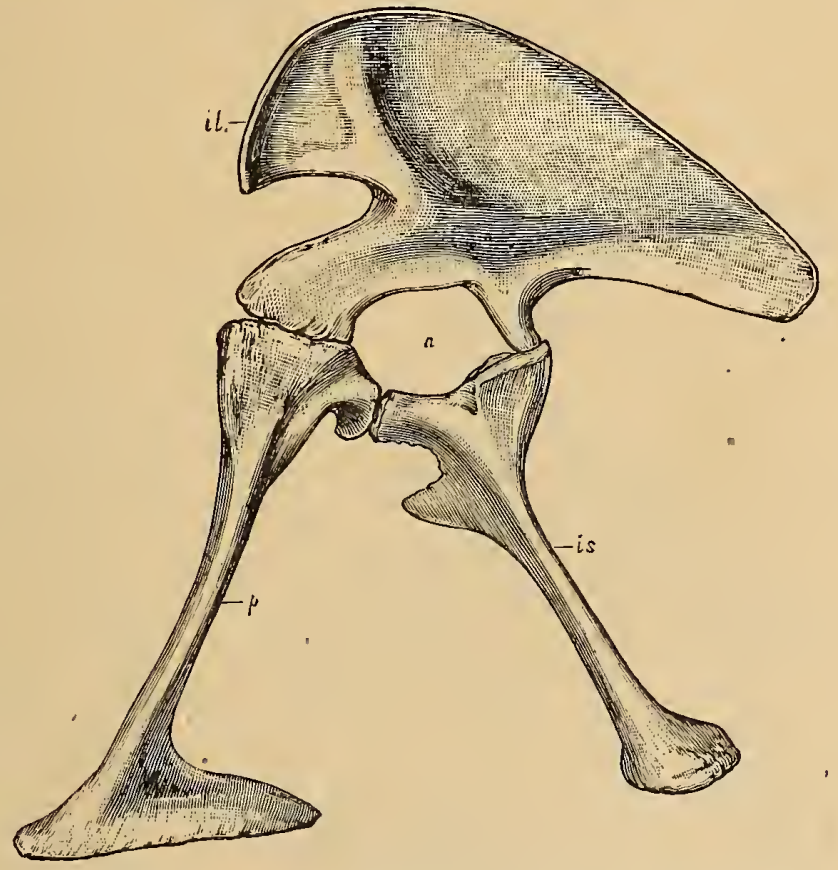

Fig. 46.-Pelvis of Antrodemus valens Leidy. No. 4734, U.S.N.M. $\frac{7}{12}$ NAT. SIZE, LATERAL VIEW. $a$, ACETABULUM; $i l$, ILIUM; $i s$, ISCHIUM; $p$, PUBIS ANTERIOR END OF ILIUM INCORRECTLY RESTORED. (AFTER MARSH.)

Marsh figures the left side of the pelvis of this same individual, but since the left ilium was only recently removed from its sandstone bed it is to be inferred that the reversed figure of the right was used in making the illustration. A recent examination of this bone shows that the anterior border is incomplete, though it is not so indicated in the figures, and this fact will account for the inaccuracy of previously published illustrations, one of which is shown in figure 46 .

The ilium has the same elongate form, with a general contour similar to the ilia of Ceratosaurus and Tyrannosaurus. The superior border is gently convex toward the anterior end, and but little expanded transversely. Above the pubic peduncle this border is $15 \mathrm{~mm}$. wide, but near the posterior end it increases to 30 
mm., its maximum thickness. The truncated anterior end of the blade presents a thin, sharp edge. The anterior portion of this blade particularly the lower border, from where it joins the peduncle flares outward, at an angle of nearly $45^{\circ}$ from the main axis of the bone (see fig. 1, pl. 10), but the posterior extremities are parallel, while in the middle, especially superiorly, the ilia of opposite sides closely approach each other along the upper median border, being very bird-like in this respect. Viewed laterally when articulated with the sacrum, the superior borders of the ilia extend above the tops of the spinous processes of the three anterior sacrals, as shown in plate 8, whereas in Ceratosaurus the opposite condition prevails.

On both the inner and outer surfaces and at right angles to the superior border are prominent striations evidently for the better insertion of the muscles which attach there.

\begin{tabular}{|c|c|c|}
\hline & Left. & Right. \\
\hline Greatest length.. & $\begin{array}{l}m m . \\
672\end{array}$ & ${ }^{m m}$. \\
\hline Height above middle of acetabulum. & 283 & 335 \\
\hline Height above pubic peduncle...... & 392 & \\
\hline Length of acetabulum... & 180 & 222 \\
\hline Length of pubic articulation... & 177 & ... \\
\hline Width of ischiac articulation... & 78 & ... \\
\hline
\end{tabular}

Pubis (p.).-In specimen No. 4734, U.S.N.M., both pubes are present although their form has been somewhat altered by transverse crushing. Fortunately others in the collection enable me to determine the amount of this distortion.

In Antrodemus the pubis is relatively long, with a heavy expanded proximal end and an elongate, triangular, massive foot-like distal end. The articular surface for the iliac peduncle is rugosely roughened, and shallowly concave anteroposteriorly, and articulates closely with the peduncle. In aged individuals it would no doubt become coossified with the ilium, as it has in the type of Ceratosaurus nasicornis, (pl. 23), and as is occasionally found in members of the Sauropoda. Posterior to the iliac articulating surface this end presents a short beveled surface that looks upward and backward, forming the pubic contribution to the boundary of the acetabulum. Posterior to this surface a vertical face, with roughened surface, articulates with an anterior branch from the ischium, thus completing the lower boundary of the acetabulum. There is no true pubic foramen, though a notch on the inferior side below the acetabular portion, probably functions in that capacity. Below the proximal end the shaft of the pubis rapidly diminishes in size, the greatest diameter changing from an antero-posterior direction to a transverse one. The shaft is very thin and sharp along its internal margin but much thickened and rounded externally, very similar in this respect to the pubes in the Sauropoda.

The distal end expands into an elongate, triangular foot, pointed behind and wide in front, or shown in figure $47, B$.; the greatest extension being in a posterior direction, whereas in Tyrannosaurus this condition is reversed. The inferior surface is flat but roughly rugose, as for the attachment of a heavy pad of cartilage. 
In discussing the use of the large foot on the pubis Marsh ${ }^{1}$ says: The only probable use is that it served to support the body in sitting down. That some Triassic dinosaurs sat down on their ischia is proved conclusively by the impressions found in the Connecticut River sandstone. In such cases the leg was bent so as to bring the heel to the ground. The same action in the present group would bring the foot of the pubes to the ground, nearly or quite under the center of gravity of the animal. The legs and ischia would then naturally aid in keeping the body balanced. Possibly this position was assumed habitually by these ferocious biped reptiles while lying in wait for prey.

When in position (pl. 13) the pubes project forward and downward. Seen from the front they form a $Y$-shaped figure (pl. 11, fig.1). Their distal extremities are usually found firmly coos. sified though occasionally immature individuals have them separate. Above this point of contact they were separated by an elongate aperture $120 \mathrm{~mm}$. in length in 4734 , U.S.N.M., while above this aperture they meet again forming a strong pubic symphysis. Where the anterior ends of the distal portion project forward there is a deep notch between the pubes of opposite sides on the median line as shown in figure 1 , plate 11.

Measurements of pubes of Antrodemus valens Leidy.

\begin{tabular}{|c|c|c|}
\hline & $\begin{array}{l}\text { No. } 4734 \text {, } \\
\text { U.S.N.M. }\end{array}$ & $\begin{array}{l}\text { No. } 8367 \\
\text { U.S.N.M. }\end{array}$ \\
\hline 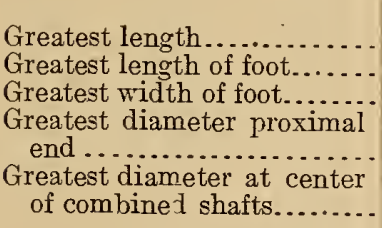 & $\begin{array}{r}m m_{-} \\
680 \\
370 \\
185 \\
210 \\
165\end{array}$ & $\begin{array}{r}m m . \\
740 \\
465 \\
240 \\
280 \\
180\end{array}$ \\
\hline
\end{tabular}

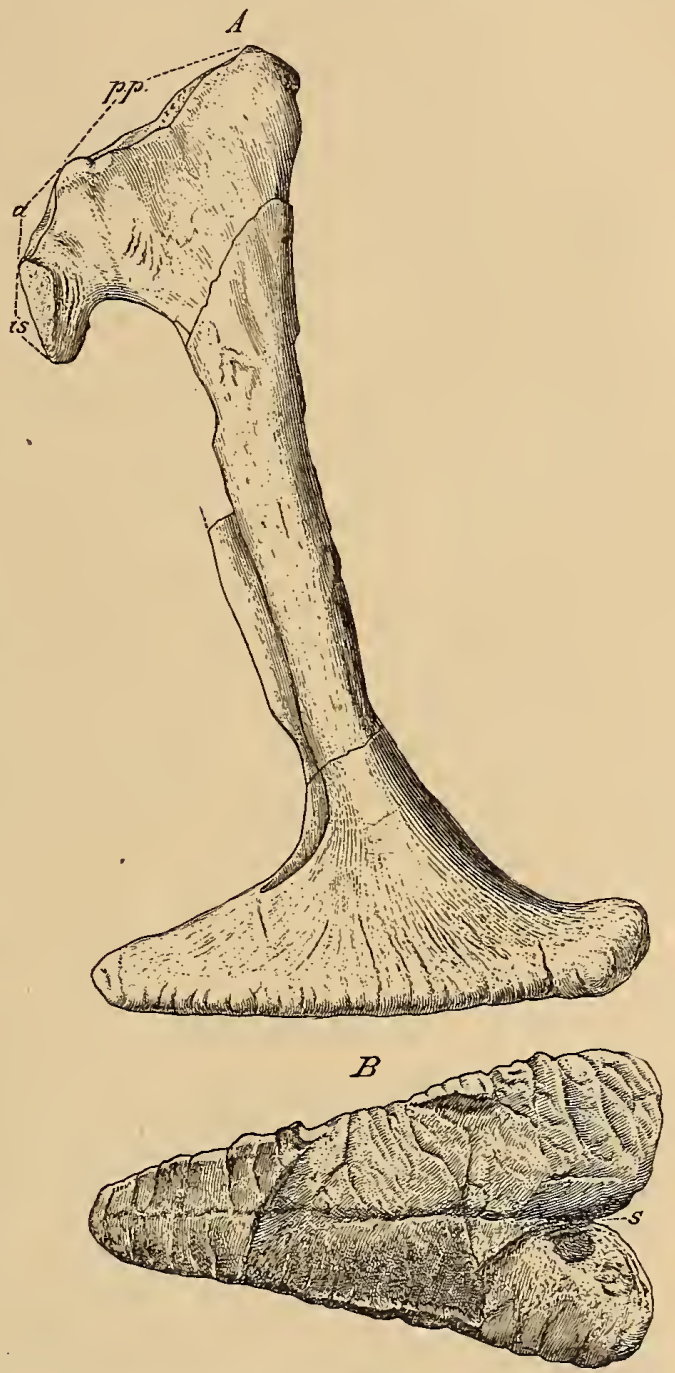

Ischium (is.).-In the United States National Museum collections there are three pairs of ischia that pertain to the species Antrodemus valens, all in a good state of preservation. Except for dif-

Ig. 47.-Right pUisis of ANtrodemus valens Leidy. No. 8367 , U.S.N.M. $\frac{1}{8}$ NAT. SIZE. $A$, SIDE VIEW. $B$, DISTAL VIEW OF COALESCED PUBES, a, ACETABULAR BORDER; is, ISCHIAC ARTICULATION; $p . p$, ARTICULATION FOR PUBIC PEIUNCLE OF THE ILIUM; $s$, SUTURE BETWEEN DISTAL ENDS OF COALESCED PUBES.

ferences in size, all of these bones closely resemble one another in their more important features. 
The ischia in Antrodemus as compared with the pubes are slender. Proximally they are expanded, forming a $Y$-shaped extremity having two distinct articulating processes (fig. 1, pl. 12), the posterior one articulates with the ischiac peduncle of the ilium, the anterior one with a posterior extension of the pubis, the superior concave surface between forming the ischiac contribution to the inferior boundary of the acetabulum. Below this head the bone rapidly contracts on the anterior and posterior borders more especially the latter, but again is widened by the development on the antero-internal side of a wide obturator proces's (ob. pr. fig. 3, pl. 12). A slight notch marks the distal extension of this process; a sharp ridge passes obliquely downward from this notch to the center of the inner surface of the shaft, where it gradually merges into the shaft below the middle of the bone shown in figure 4, plate 12. The distal end is slightly expanded antero-posteriorly, with a broadly convex rugose distal end. The inner side of the distal half of the ischium is flattened; the outer rounded throughout nearly the entire length of the shaft.

Where articulated the ischia are in contact along the median line from the proximal border of the obturator process to the distal end, except for a very small aperture formed by the notches on the side of the obturator process, as is shown in figure 1, plate 12 . This median union of the ischia and pubes renders the pelvic opening very small when the large size of the animal is taken into consideration. The greatest transverse width of this opening in specimen No. 8367, U.S.N.M., a very large individual, is only $140 \mathrm{~mm}$. wide. All aspects of the ischia are well illustrated in plate 12, which was drawn, under the direction of Prof. O. C. Marsh, from specimens in the Yale University Museum. They agree closely in every particular with the ischia of Antrodemus valens in the United States National Museum collections.

Measurements of ischia of Antrodemus valens Leidy.

\begin{tabular}{|c|c|c|c|}
\hline & $\begin{array}{l}\text { No. } 8367, \\
\text { U.S.N.M. }\end{array}$ & $\begin{array}{l}\text { No. } 4734, \\
\text { U.S.N.M. }\end{array}$ & $\begin{array}{l}\text { No. } 2323, \\
\text { U.S.N.M. }\end{array}$ \\
\hline 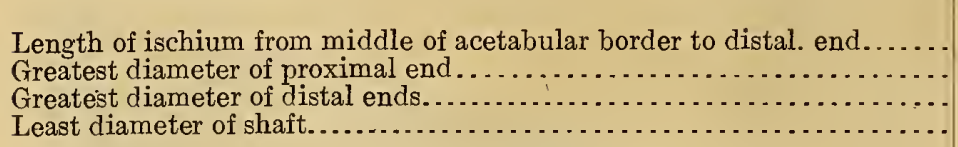 & $\begin{array}{l}m m \\
650 \\
225 e \\
135 \\
38\end{array}$ & $\begin{array}{l}m m \\
575 \\
260 \\
115+ \\
35\end{array}$ & $\begin{array}{r}m m \\
490 \\
177 \\
93 \\
27\end{array}$ \\
\hline
\end{tabular}

$e=$ estimated.

HIND LIMB AND FOOT.

Femur $(f$.$) .- The femur of Antrodemus is longer than the tibia, with a curved$ shaft, the arctuation being forward (fig. 1 and 4, pl. 14). Although somewhat larger than that of Ceratosaurus they closely resemble one another in form and in the position of the areas for muscular attachment. Both femora are present in specimen No. 4734, U.S.N.M., as shown in plate 13, and both are in an excellent state of preservation. The bone is remarkably light for its size. The middle portion of the shaft is angularly rounded in cross section with a hollow marrow cavity (fig. 6 , pl. 14). The articular head is clearly defined, and when articulated extends well within the acetabulum. The fourth trochanter is an elongate ridge on the posterior internal side and entirely upon the proximal half of the shaft. This trochanter in 
Tyrannosaurus and Gorgosaurus is nearer the top and has a stronger development posteriorly. The lesser trochanter is a wide transversely compressed blade, that is separated on its inner side from the head by a wide cleft ( $a$, figs. 1, 2, 4, and 5, pl. 14). The relatively larger size and more proximal extension of this trochanter will serve ${ }^{*}$ to distinguish the femur of Antrodemus from its contempory Ceratosaurus, as is indicated by a comparison of figure 64 with plate 14. Viewed from above (fig. 5, pl. 14) the articular portion of the head is roughly rectangular in outline, the greatest diameter being transverse. This articular surface is comparatively smooth, gently rounded antero-posteriorly and extends downward on both anterior and posterior aspects more especially the latter. The distal end has the usual condylar development, the two condyles being separated by a deep intercondylar groove (fig. 7, pl. 14). The anterior intercondylar groove is relatively narrow and extends at some distance up on the anterior surface of the shaft. On the inner anterior side of this aspect of the femur is an oblong oval depression having a roughened surface representing the point of attachment of the femoro-tibialis muscle. External to the outer condyle is the usual guidon groove, though this shelf appears to be relatively wider than found in the Predentate dinosauria.

Measurements of femora of Antrodemus valens Leidy.

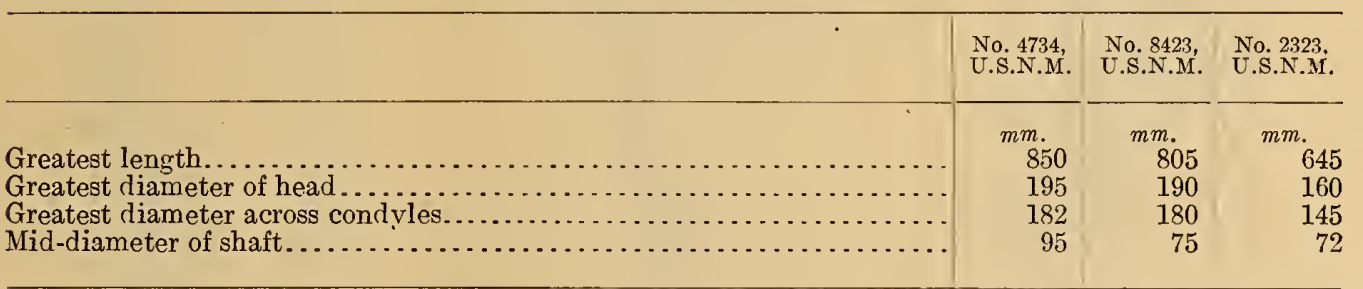

Tibia (t.)-Both tibiae are present with specimen No. 4734, U.S.N.M. The left, having been found articulated with the fibula, astragalus, and calcaneum, was selected for illustration and description here.

As in Ceratosaurus, the tibia is shorter than the femur. It has expanded ends distally, in a transverse direction, and proximally in a fore and aft direction. In lateral aspect the shaft is straight, though the upper third is inclined forward on the anterior side. The shaft is flattened on the front side, but the remaining surfaces are evenly rounded.

Viewed proximally the outline is roughly triangular, the apex being directed anteriorly (A. fig. 48). On the posterior face are two relatively small overhanging condyles, separated by a comparatively shallow and narrow intercondylar groove. An especially large and prominent process extends forward and upward from the inner half of the front face (fig. 48). It rises above the level of the articular surface of the proximal end, and extends forward with a curve outward, thus greatly increasing the antero-posterior diameter of this end of the bone. The outer side of this process is concave, the inner convex, the convexity being continued on around the inner side of the end.

Below the process described above, the antero-external border is a very large cnemial process, which is directed outward and slightly forward. This process is $144035^{\circ}-20-6$ 
much more prominently developed in Antrodemus than in Ceratosaurus. It protrudes conspicuously and comes to an irregular, blunt edge. Continuing downward from this crest there is a decided angulation, which defines a narrow external flat- tening of the shaft, marking the surface for the contact of the fibula.
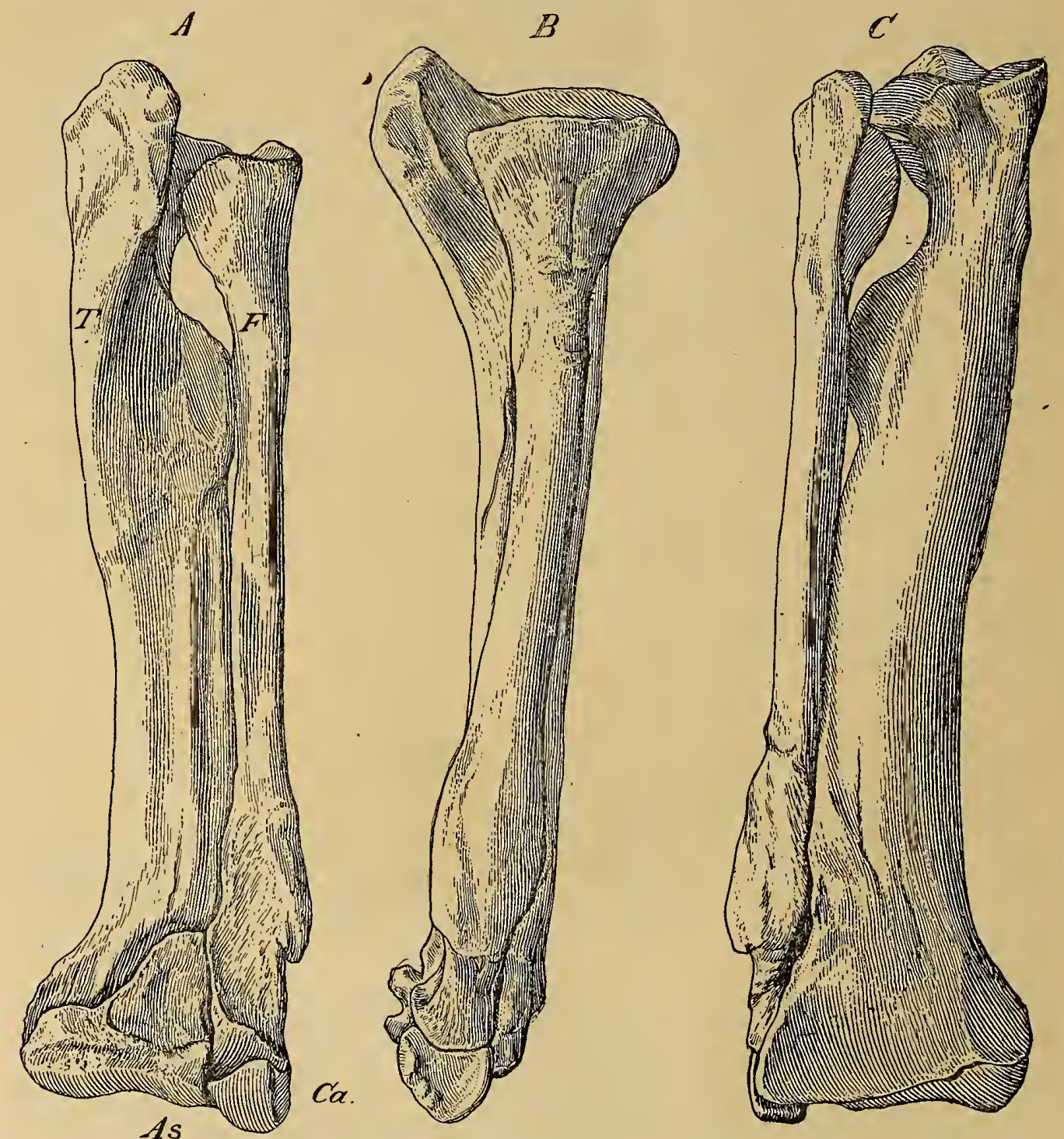

Fig. 48.-Lete tibia, fibula, astragalus, and calcaneum of ANtrodemus valens Leidy. No. 4734, U.S.N.M' $\frac{1}{4}$ NAT. SIZE. $A$, FRONT; $B$, OUTER; AND $C$, BACK VIEWs. as, ASTRAGALUS; ca, CALCANEUM; $f$, FIBULA; $t$, TIBIA.

Distally, the anterior face of the tibia is transversely concave in its contact with the ascending process of the astragalus, becoming flat where it articulates with the fibula and calcaneum. The breadth of the distal end of the tibia in Antrodemus, as in Gorgosaurus aud Dryptosaurus, is equal to the combined breadths of the astragalus and calcaneum. 


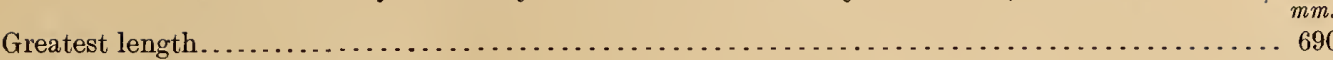

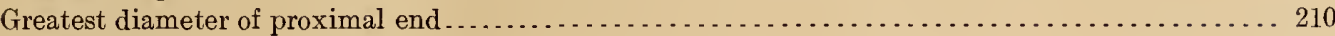

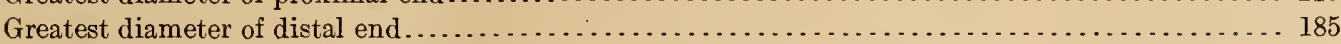

Fibula (f.).-The left fibula of No. 4734, U.S.N.M., has suffered injury in life on the distal fourth, and exostosial growth of the bone has greatly enlarged and distorted this portion of the shaft, as shown in figure 48. The normal fibula is a long, slender bone with a much expanded, antero-posteriorly proximal end and a little enlarged distal extremity. Its length is slightly less than that of the tibia. The proximal end is subcrescentic in outline, with the concave side toward the tibia. The distal end is concave from front to back with an upward turned lip on the anterior face. This end articulates exclusively with the calcaneum, though the internal side is in contact with the ascending process of the astragalus, which it slightly overlaps. The inner face of the fibula on the
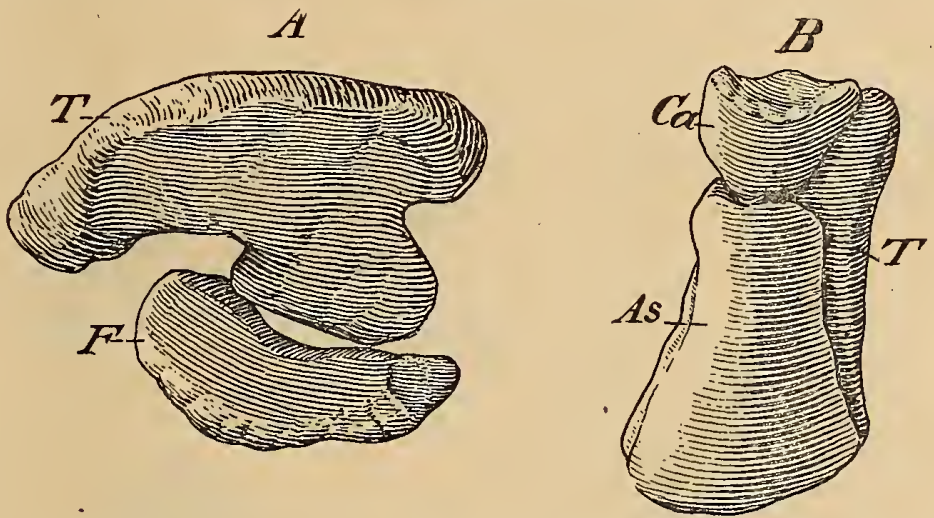

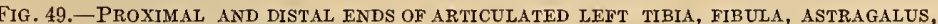
AND CALCANEUM OF ANTRODEMUS VALENS LEIDY. No. 4734, U.S.N.M. $\frac{1}{4}$ NAT. SIZE. $A$, proximal and $B$, Distal ends. as, astragalus; $c a$, Calcaneum; $f$, Fibula; $t$, TIBIA lower two-thirds is flattened, the flattened area becoming wider as the distal end is approached. This flattened side is closely applied to the tibia, especially the lower third, as shown in figure 48 .

\section{Measurements of fibula of Antrodemus valens Leidy. No. 4734, U.S.N.M.}

$\mathrm{mm}$.

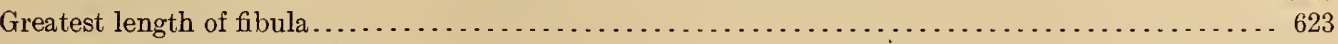

Greatest diameter proximal end........

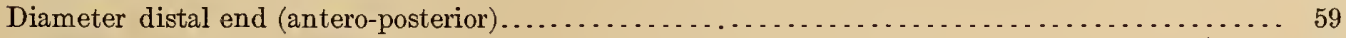

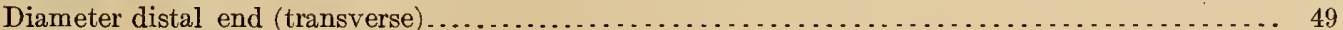

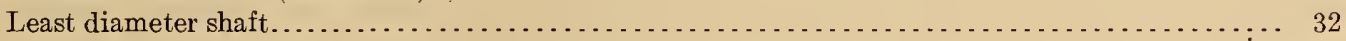

Tarsus.-The tarsus in Antrodemus is composed of four bony elements, the proximal row formed by the astragalus and calcaneum, the distal row by two discoidal bones, probably tarsalia three and four (fig. 49).

Calcaneum ( $\mathrm{Ca}$.).-The left calcaneum of No. 4734, U.S.N.M., in position is closely applied to the outer side of the astragalus and in advance of the tibia. It is narrow transversely, with the antero-posterior diameter exceeding the vertical. The upper articular surface is markedly concave from front to back, being deepest toward the front. It is rounded below and in front in an irregular semicircular curve.

The outer free surface is concave, with a raised anterior border. The inner surface appears to be concave in its contact with the tibia; the portion in contact with the outer face of the astragalus appears to present an angular convex face. 


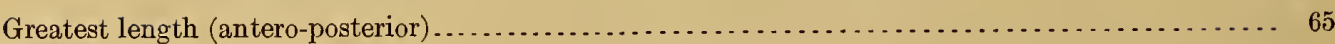

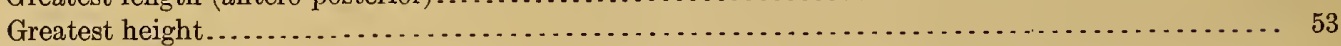

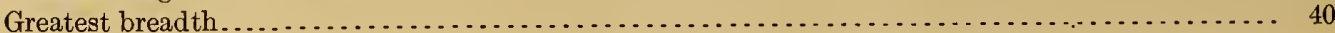

Astragalus (As.).--In specimen No. 4734, U.S.N.M., the left astragalus is firmly conjoined, if not actually coossified, with the tibia. A detached left astragalus, No. 7336, U.S.N.M., from "Quarry No. 1," Canon City, Colorado, which clearly shows all of the principal features of this element, is the basis for the detailed description given below.

Viewed from the front, the astragalus consists of a heavy rectangular lower portion from which rises on its outer half a wide, thin ascending process. At the base it is slightly more than half as wide as the lower portion from which it springs. In outline this process is angular, narrowing rapidly toward the top. The anterior face is set back from the heavier articular portion below and is further defined by a wide groove traversing its base from side to side. Thelimited extent of this process in Antrodemus, as contrasted with the Upper Cretaceous theropods, where it reaches
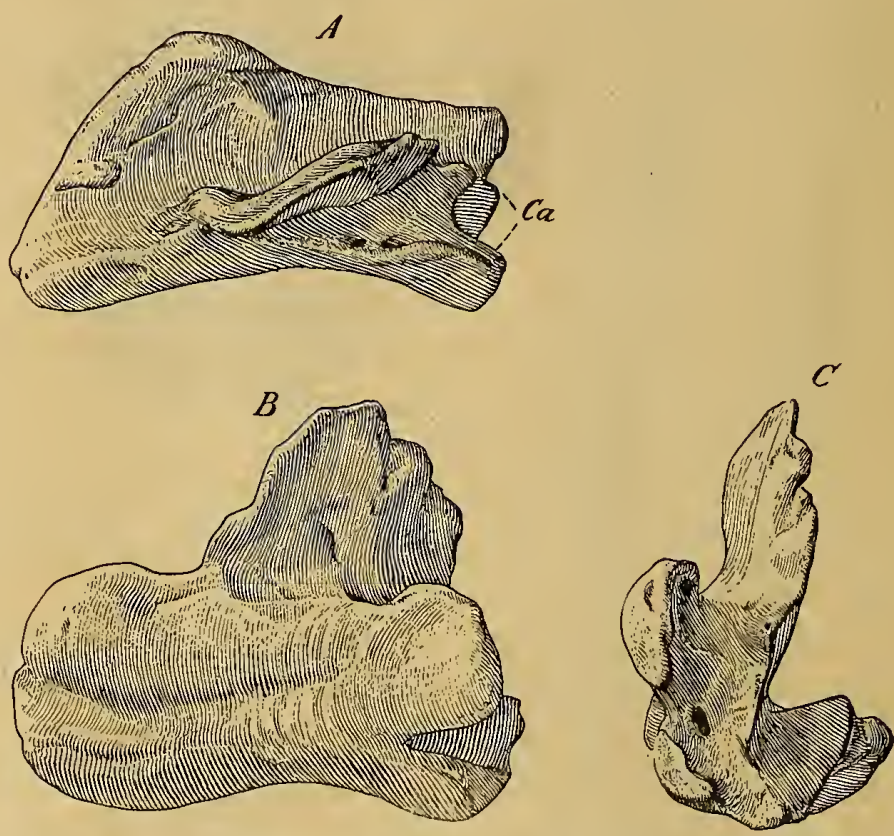

its maximum development, and the Triassic theropods, where it is

IG. 50.-LEFT ASTRAGA LUS OF ANTRODEMUS VALENS LEIDY. No. 7336, U.S.N.M. $\frac{1}{2}$ NAT. Size. $A$, ANTERIor view; $B$, Dorsal view; $C$, eXternal view. $C a$, articular SURFACE FOR CALCANEUM.

entirely absent, shows a progressive development of this process during successive geological periods.

The main lower portion of the astragalus at about its center on the anterior face is traversed by a shallow transverse groove, which deepens toward the inner margin, and which turns downward slightly toward the external border when it ends at the base of a deep notch.

Viewed from above the surface on which the tibia rests is broadly concave antero-posteriorly on the inner half, but on the outer half rapidly narrows becoming $\mathrm{V}$-shaped. At the base of the ascending process on the posterior side is a large circular depression in the bone that at first glance gives the impression of being a foramen. The inner end is heavy and obliquely truncated to the longer transverse 
axis of the bone. On the fibular side two heary blunt processes extend outward from the main body of the astragalus to articulate with the calcaneum. The upper, which is also the heavier of the two processes, shows an articular surface on the lower half of its posterior side for articulation with the calcaneum. The upper half apparently extends free, and thus with the upper articular surface of the calcaneum forms a cup-like socket for the distal end of the fibula. The lower process, which is separated from the upper by a notch (fig. 50, B), embraces a portion of the ventral surface of the articulated calcaneum.

The distal surface is subconvex antero-posteriorly, having a broad shallow depression near the middle, which makes it concave transversely.

Measurements of Astragalae of Antrodemus valens Leidy.

\begin{tabular}{|c|c|c|}
\hline - & $\begin{array}{l}\text { No. } 7336, \\
\text { U.s. N.M. }\end{array}$ & $\begin{array}{l}\text { No. 4734, } \\
\text { U.S.N.M. }\end{array}$ \\
\hline 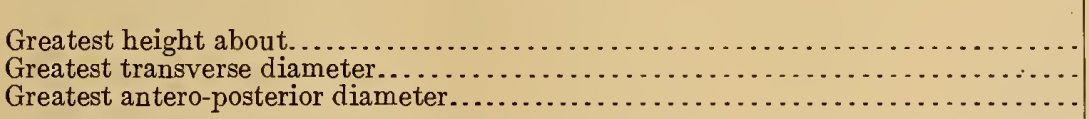 & $\begin{array}{r}m m \\
125 \\
155 \\
88\end{array}$ & $\begin{array}{l}m m \\
115+ \\
132+ \\
90\end{array}$ \\
\hline
\end{tabular}

Metatarsus.-The metatarsus of Antrodemus consists of four bones of which three are large, and support strong functional toes, and one, the first, is in the process of reduction. follows:

The first digit or hallux was first recognized and described by Osborn ${ }^{1}$ as

Of greatest interest is the first digit or hallux, not before described. Proximally [fig. 51] its metatarsal fits in a shallow groove of the upper portion (on the postero-external side) of the large metatarsal II. The shaft is entirely interrupted or composed of cartilage in the middle portion. Distally it is fitted to the rounded posterior shaft of metetarsal II, demonstrating that this digit was directed inwards like the small hallux of $A$ pteryx. [In metatarsal II of both specimens Nos. 4734 and 8423, U.S.N.M., the point of contact with the lower portion of metatarsal $I$ is indicated by a flattened rugose area]. It possesses, however, a complete and functional phalanx and claw, which undoubtedly were of service in grasping.

Specimen No. 4734, U.S.N.M., has the lower half of the first metatarsal of the right side preserved, but in none of the specimens in the United States National Museum collections is the upper half of this bone present. The proximal portion of metatarsal I is well shown in figure 2, plate 7 , reproduced from a photograph kindly furnished me by Mr. Walter Granger, of the American Museum of Natural History.

Metatarsals II, III, and IV are elongate elements, the median one being the longest of the three. Their proxmal ends are closely apposed to one another, as shown in figure 51. Metatarsals II and IV are subequal in length, the former having a straight shaft that throws the distal end outward from the median metatarsal. All three of these metatarsals have cupped proximal ends. The face of metatarsal II which is applied to metatarsal III is plane, while the opposite side is angularly convex with a notch on the posterior outer margin for the reception of the proximal 
portion of metatarsal I. On the posterior side, at a point about midway, a flattened rugose area appears to represent the point of attachment for the distal portion of metatarsal I.

The distal articular surface is rounded and produced well up in front and back. Posteriorly, this end is deeply excavated by a wide groove that passes upward from the articular surface. The lateral pits of this end are well defined, the one on the side nearest metatarsal III being the deepest. .

Metatarsal III is the longest bone of the foot. Its proximal end is compressed transversally, but is long antero-posteriorly, widest in front, with a plane lateral surface for union with metatarsal I. These two bones are in the closest apposition throughout the upper three-fourths of their length. The lower fourth of metatarsal III when viewed from the front swings outward. The distal end is pulley shaped, the rounded articular surface extending well up on the front and back. The pits

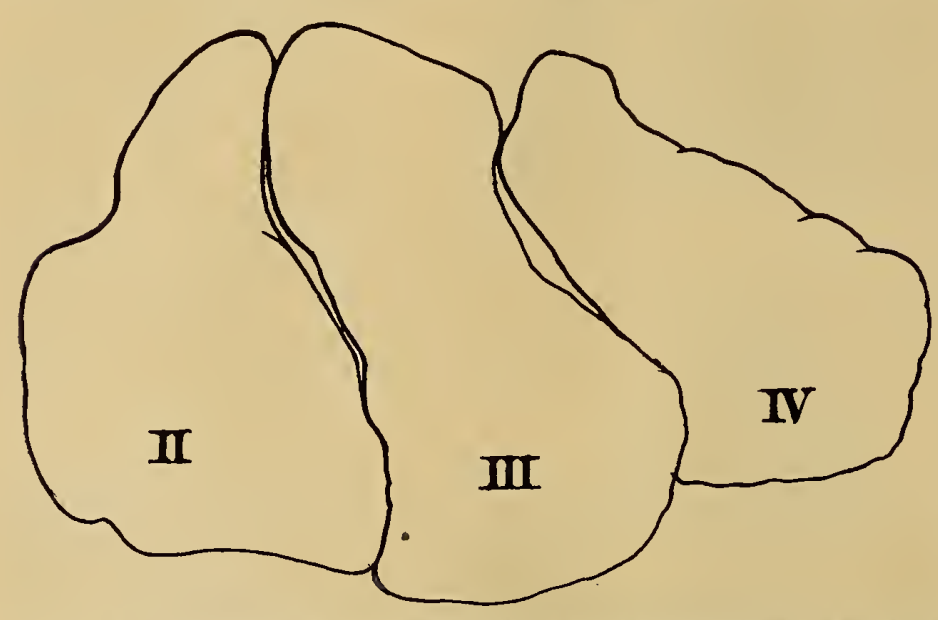

Fig. 51.-Proximal ends of the articulated left metatarsals of ANtrodemus VALENS LEIDY. No. 8423, U.S.N.M. $\frac{1}{2}$ NAT. SIZE. II, III, AND IV METATARSALS TWO, THREE, AND FOUR RESPECTIVELY. for the attachment of the la teral ligamen ts are of large size and of moderate depth. The front of the shaft is flattened on the back and external side quite evenly rounded but on the internal side bereled off from the heary obtuse longitudinal edge along the antero-internal border, which overlaps to some extent the shaft of metatarsal II when these bones are articulaterl. The upper end of metatarsal IV is

roughly surtriangular in outline, the apex being directed inward and backward, the antero-internal side of this end being widely excavated for the articulation of an outward projection from the head of metatarsal III. This bone, when viewed from the front, is bowed from end to end, which throws the lower half of this bone outward from the median or third metatarsal. The distal articular end is triangular in outline, the apex of the triangle extending well up on the front of the bone. The posterior face is bisected by a wide shallow groove. The lateral pit is wanting on the external side, while the internal one is not well defined. In section, at the center, this bone is triangular.

Phalanges.-The digits of Antrodemus have the usual number of phalanges, that is, two, three, four, and five, as in nearly all other bipedal dinosaurs.

The proximal phalanges of each digit are the most elongate of the digital series. Those of digits II and III are the longest and most robust, being subequal in length, though the former is compressed transversally, the latter depressed vertically. All proximal phalanges articulate with their respective metatarsals 
by smooth but vertically concave ends. With the exception of the joint between the first and second phalanx of digit III, all of the other joints in the pes are keeled. Those of the median or third digit are broad and illy defined, but the remaining articulations have a pronounced median keel on the proximal ends and a corresponding median rertical depression on the distal ends, thus forming strong joints that would be difficult of lateral dislocation.

Deep lateral pits are present on both sides in all of the phalanges. The terminal phalanges are moderately curved bones, sharply pointed in front, deeply grooved on the side for the external claw, which in life would have considerably increased the size of these appendages. The unguals of digits II and III are about subequal in size, while those of digits I and IV are considerably reduced.

The ungual phalanges of the pes are readily distinguished from those of the manus, by the greater curvature of the latter, and the inferior development of the bone below the articulating surface for the preceding phalanx, also those of the manus are more compressed transversely. The shape of these clawed unguals; appear to indicate that these feet were better adapted for locomotion than for grasping purposes.

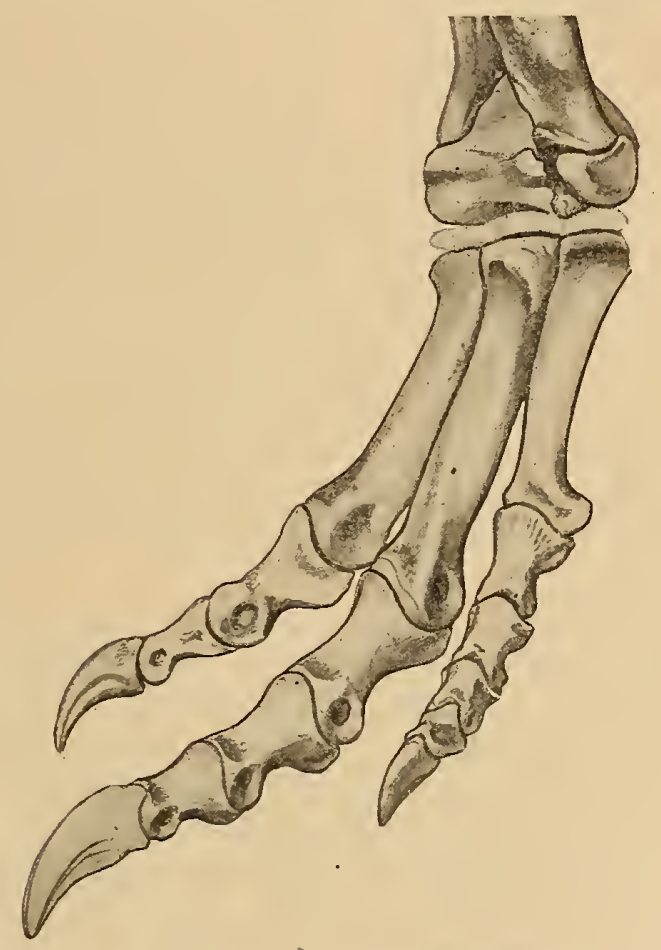

Fig. 52.-Left hiNd Foot of ANTROdemus valens Leidy. No. 4734, U.S.N.M. RESTORED. $\frac{1}{8}$ NAT. SIZE. (AFTER M.RSH.)

\section{Measurements of left hind feet of Antrodemus valens Leidy.}

DiGiTs.

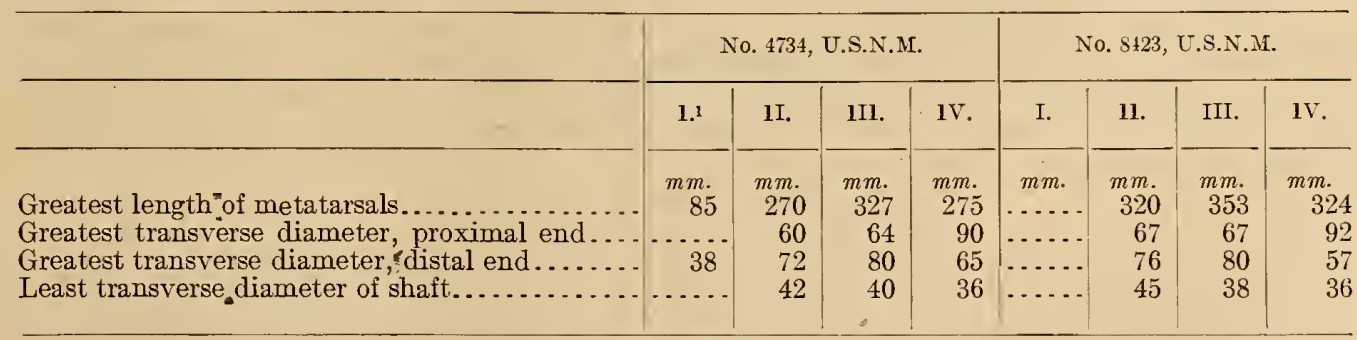

PHALANGLALS.

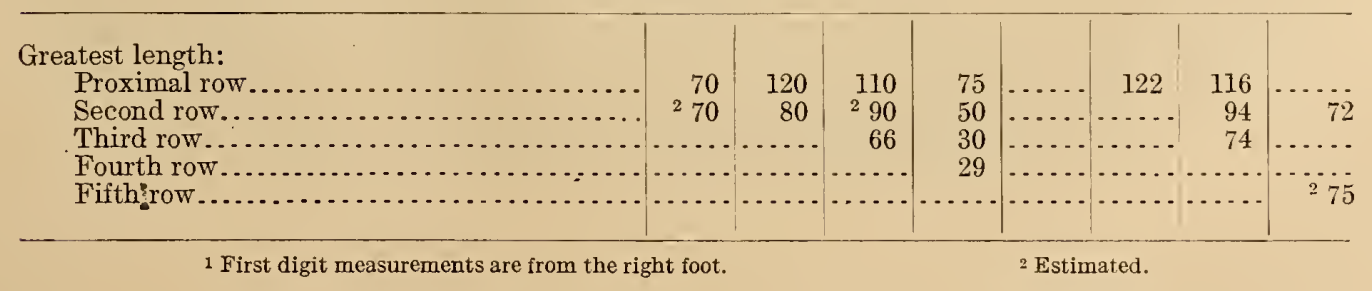




\section{Family CERATOSAURIDAE}

In $1884^{1}$ at the time of creating the genus and species, Ceratosaurus nasicornis Prof. O. C. Marsh proposed the new family Ceratosauridae which was defined as follows:

Horn on skull, Cervical vertebrae plano-concave, remaining vertebrae biconcave. Pubes slender. Pelvic bones coossified. Osseous dermal plates, Astragalus with ascending process.

The standing of the family Ceratosauridae was consistently maintained by Marsh in his later writings, though the distinctness of this family was not generally accepted by other authorities. Lydekker, in $1888^{2}$ included it under the Megalosauridae, a view adopted in succeeding years by other paleontologists. The genus Ceratosaurus, however, so far as I am able to discover, has been accepted by everyone except Cope, ${ }^{3}$ who in 1892 referred the species to Megalosaurus.

The general nonacceptance of Marsh's family I now believe was largely due to the inadequateness of his definition, for, as originally stated and subsequently amended on at least two occasions, there were only one or two characters enumerated that would not apply to any of the large Theropod dinosaurs. The presence of a horn on the skull is the one distinctive character, and that may prove to be a sexual feature.

Although in many respects Ceratosaurus approaches the megalosauroid forms, several generalized features of the skeleton, as the presence of four digits in the manus; a closed obturator pubic foramen; the long quadrate and the closer resemblance of the presacral vertebrae to the earlier Triassic forms, in my opinion, makes it the most conservative Theropod known above the Triassic.

After a thorough study of the genotype as compared with Antrodemus, Tyrannosaurus, Gorgosaurus, and other American carnivorous dinosaurs, convinces me of the family distinctness of this genus as originally classified by Marsh.

The family I would now define as follows:

FAMILY CHARACTERS-Horn on skull; pubes meeting on median line at proximal end. Manus with four digits, lateral digits reduced.

The genus Ceratosaurus I would define as follows:

GENERIC CHARACTERS: Premaxillaries with three teeth; maxillaries with 15 teeth; dentary with 15 teeth; 9 cervical vertebrae plano-concave; dorsal vertebrae biconcave; 5 sacrals; distal caudals without special lengthening of prezygapophyses; pelvis coossified; pubis with closed obturator foramen; 4 digits in manus, first and fourth reduced; probably 3 digits in pes; dermal ossifications; abdominal ribs present.

\section{Genus CERATOSAURUS Marsh, 1884.}

\section{CERATOSAURUS NASICORNIS Marsh, 1884.}

Ceratosaurus nasicornis MARSH, Amer. Journ. Sci., ser. 3, vol. 27, 1884, pp. 300-337, pls. 8, 9, figs. 1, 10, 11; vol. 28, 1884, p. 161, fig. 1; Bull. du Musee Royal d'Hist. Nat. de Belgique, vol. 4, 1884, pp. 136, 140, 145, 146, pl. 6, figs. 6, 16.-Menzbier, M., Bull. Soc. Imp. Natur. Moscou (new ser.), vol. 2, 1887, p. 533.-Lydekrer, R., Cat. of Fossil Reptilia and Amphibia in the British Museum, pt. 1, 1888, p. 157, fig. 26.-ZitтеL, K. A., Handbuch der Palaeontologie, vol. 3, 1890, p. 727, figs. 629-635.-MArsh, Amer. Journ. Sci., ser. 3, vol. 44, 1892, p. 347, pl. 7.-Cope, Trans. Amer. Philos.

1 Amer. Journ, Sci., vol. 27, 1884, p. 330.

2 Cat. of Fossil Reptilia and Amphibia in the British Museum, pt. 1, 1888, p. 157.

3 Proc. Amer. Philos. Soc., vol. 30, 1892, p. 241. 
Soc., vol. 17, 1892, p. 18.-MARSH, Geol. Mag., London, vol. 10, 1893, p. 153, pl. 6.-IXDEK KER, R., Nature, July 27, 1893, p. 48.-Hutchinson, H. N., Extinct Monsters, April, 1893, pp. 83, 84, text figs. 17, 18.-MARSH, Amer. Journ. Sci., ser. 3, vol. 50, 1895, p. 487, pl. 10, fig. 5 , text figs. 9 and 10; Sixteenth Ann. Rept. U. S. Geol. Surv. for 1894-5, pt. 1, 1896, pp. 156-162, pls. 8-10, fig. 1, pl. 14, text figs, 1, 4, 5, 64, 65; Comptes rendus des seances du Troisieme Congress, International de Zoologie, Leyden, 1895, p. 202, pl. 1, fig. 5, text figs. 9, 10; Monog. U. S. Geol. Surv., vol. 27, 1897 , p. 503, pl. 25, text fig. 60.-Woodward, A. S., Outlines of Vertebrate Paleontology, 1898, p. 200, fig. 120.-WALcotT, C. D., Science, ser. 2, vol. 11, 1900, p. 23.-HAY, O. P., Bull. No. 179, U. S. Geol. Surv., 1901, pp. 493, 494.-NopcsA, Földtani Közlony, Budapest, vol. 31, 1901, p. 199.— Luc.As, F. A., Animals of the Past, 1901, p. 106, figs. 23, 25; Animals Before Man in North America, 1902, pp. 149, 165, 166, 2 text figs.-Zitrel, Text-Book of Paleontology, Eng. ed., vol. 2, 1902, pp. 228, 229, figs. 328, 329.-L.Aмвe, L. M., Contribution to Canadian Paleontology, vol. 3, 1904, pp. 5, 8, 9, 15, 18, 22, 24.-Nopcsa, Geol. Mag., vol. 2, 1905, p. 290.-MerriLl, G. P., Cat. Fossil Verte-

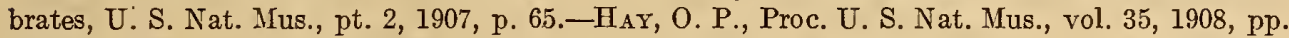
359-366, figs. 1, 2, 3, 4.-Huene, F. von, Geol. und Palaeont. abhand. Sup., vol. 1, 1907-1908, pp. 326, 335.-LuLL, Amer. Journ. Sci., vol. 29, 1910, p. 15, figs., 1, 4.-Hutchinson, H. N., Extinct Monsters and Creatures of Other Days, 1911, p. 136, text figs. 45, 46.-ZITTEI, Grundzüge der Paleontologie, vol.2, 1911, p. 281, text figs. 424, 425.-GILNore, C. W., Bull. No.89, 1914, p. 25.-SHUFELDT,

R. W., Scientific American Supplement, No. 2089, Jan. 15, 1916, p. 41, fig. 5; No. 2098, Mar. 18, 1916, p. 187.-Lambe, L. M., Memoir 100, Canada Geol. Survey, No. 83, Geol. Series, p. 15, 1917. Megalosaurus nasicornis Cope, Proc. Amer. Philos. Soc., vol. 30, 1892, p. 241.

Ceratosaurus Cope, Amer. Nat., 1885, Jan., pp. 67-68.

Genotype.-Cat. No. 4735, U.S.N.M., consists of a fairly complete articulated skeleton. The bones preserved are listed below:

Skull.

Lower jaws.

Atlas.

Axis.

Seven cervical vertebrae.

Twelve dorsal vertebrae (all fragmentary).

Sacrum complete.

Fifty caudal vertebrae.

Twenty chevrons.

Last thoracic rib.

Cervical ribs (all fragmentary).

Scapula (left).

Ulna (left).

Radius (left).
Four metacarpals, 3 phalanges (left fore foot).

Three metacarpals, 1 phalanx (right fore foot).

Two ilia.

Two pubes (lacking distal extremities).

Two ischia (lacking distal extremities).

Two femora.

Tibia (right).

Fibula (right).

Astragalus (right).

Calcaneum (rignt).

One tarsal bone of distal row (left).

Three coossified metatarsals (left).

One terminal phalanx, digit IV (left).

Several skin ossicles.

Collected by Mr. M. P. Felch, 1883-1884.

Type locality.-Quarry No. 1,' Garden Park, near Canon City, Colorado, Fremont County, Colorado.

$$
\text { Horizon.-Morrison, U̦per Jurassic. }
$$

${ }^{1}$ A letter to the writer from Mr. Charles E. Felch, a brother of the late M. P. Felch, who collected the Ccratosaurus skeleton and other fossil remains, gives some interesting first-hand knowledge of the discovery of fossils at Canon City, Colorado. With his kind permission I quote the following from his letter of February, 1915:

"I visited Colorado in 1876-77, spending most of the time at my brother's ranch. During this time we discorered, quite near the ranch, and at the foot of one of the high cliffs of sandstone so common in this vicinity, what we supposed at the time to be a section of a petrified tree, but on exhuming it from the disintegrated sandstone, we found that instead of being vegetable origin, it was a portion of a thigh bone of some gigantic prehistoric animal. Quite unaware of its scientific value, and viewing it only as a curiosity, we took it to the office of the local newspaper in Canyon City, where it attracted the attention of a visiting scientist, Prof. Mudge, State geologist of Kansas, and through his instrumentality it was sent to Prof. Marsh, of Yale, who, being greatly impressed by the importance of the discovery, visited the locality in person, and at once put Prof. Mudge in charge of excavation work, which he pursued until his death about a year later, after which my brother, who had been working with Prof. Mudge, was given charge of the work, and continued at it for eight years, shipping the fossils as quarried to New Haren. It was only very recently that I learned that the bones had been removed to Washington." 


\section{OSTEOLOGY OF CERATOSAURUS.}

Since the osteology of Antrodemus has been described in considerable detail in the preceding pages, it is only necessary to treat briefly the various elements comprising the bony structure of the present Morrison genus. The chief similarities and dissimilarities as compared with the homologous parts of other members of the Theropoda are pointed out and correction of such erroneous statements and incorrect restoration as is now rendered possible by the more complete preparation of the known material, and also on account of our greatly increased knowledge of the skeletal structure of Theropodous dinosaurs in general.

These observations are based entirely on the type specimen of Ceratosaurus nasicornis. Prof. O. C. Marsh and Dr. O. P. Hay have been the chief contributors to our knowledge of the skeletal anatomy of this animal, and I have made free use of their various contributions, although all of their work has been verified by personal examination of the specimen.

$$
\text { SKULL. }
$$

The skull of Ceratosaurus nasicornis, although constituting the most complete cranium of a Morrison Theropod dinosaur yet found, is greatly distorted by pressure (fig. 53).

This compression is largely from side to side, so that its present thickness is only a little over $100 \mathrm{~mm}$. The first restorations of the skull (pl. 7, Dinosaurs of North America), were drawn under the supervision of Professor Marsh, and present a somewhat restored view, and so far as representing the exact transverse proportions, they must remain somewhat in doubt. It would appear, after a comparison with the well-preserved articulated skull of Tyrannosaurus, ${ }^{1}$ and with the skull of Antrodemus No. 4734 U.S.N.M. that the posterior portion is not wide enough as restored. The restorations of the Ceratosaurus skull presented here (figs. 1 and 2, pl. 18) are based upon the type specimen No. 4735, U.S.N.M., and although many of the inaccuracies detected in the earlier restoration by Marsh have been eliminated, it is anticipated that future discoveries will show the present restoration to be in error in other particulars. The badly crushed condition of the skull (figs. 1 and 2, pl. 17) makes it most difficult to determine the exact proportions of some parts, and especially many of the minor details. This restudy, however, in conjunction with the beautifully preserved Antrodemus skull No.4734, U.S.N.M., has cleared up many apparent discrepancies, and has resulted, I trust, in giving a more correct conception of the skull of Ceratosaurus than could be obtained from the earlier representations.

In general, the skull of Ceratosaurus is light and open in its structure, excelling in this respect all other of the larger members of the Theropodous Dinosauria.

Its closest resemblances are with the skull of Antrodemus, though on comparison many important structural differences are found. One especial distinctive feature of the skull and one which distinguishes it from all known Theropoda is the elevated, trenchent horncore situated medially on the nasals. Other features are the elongated quadrate, the relatively large size of the lateral openings, reduced dentition, and the slenderness of the posterior half of the lower jaw. 
The principal differences found by a comparison of the skulls of Ceratosaurus and Antrodemus are contrasted in the two parallel columns below.

Ceratosaurus.

1. Prominent median horn-core on the nasals.

2. Lateral borders of nasals smooth and rounded.

3. Skull, relatively narrower, dorso-ventrally than in Antrodemus.

4. Quadrate, long.

5. Premaxillary with 3 teeth.

6. Upper dental series, 18 teeth.

7. Second antiorbital fenestra appears to be wanting.

8. Infratemporal fenestra wide (anteroposteriorly) at bottom.

9. External nares oval.

10. Pit on posterior median junction of nasals.

11. Nasals, posterior to external nares swollen.
ANTRODEMUS.

1. None present.

2. Lateral borders of nasals roughened and sharp.

3. Skull, relatively wider, dorso-ventrally than in Ceratosaurus.

4. Quadrate relatively short.

5. Premaxillary with 5 teeth.

6. Upper dental series, 20-22 teeth.

7. Second antiorbital fenestra present.

8. Infratemporal fenestra relatively narrow at bottom.

9. External nares elongated.

10. Nasals without pit.

11. Nasals gradually narrowing.

Basioccipital (bo.).-The occipital condyle is hemispherical in general form, and is inclined downwards, making an obtuse angle with the long axis of the skull. The basioccipital processes are short and stout, as compared with the narrower and more ventrally elongated processes in Antrodemus.

On account of the crushed condition of this region of the skull, the relationships of the basioccipital with adjacent bones can not be accurately determined, though I am inclined to believe they are somewhat different than in Antrodemus.

Exoccipital (ex. oc.).-The exoccipitals contribute to the upper articular surface of the occipital condyle, meeting on the median line and entirely excluding that elemenit from the boundary of the foramen magnum. It can not be determined whether these bones bridge over the foramen magnum, and thus exclude the supraoccipital from its boundary as they do in Tyrannosaurus. Latterly they coalesce with the paraoccipital processes. These processes are more widely expanded vertically toward their outer ends than in Antrodemus, and with a heavier more rugose outer extremity. In the skulls here compared the paraoccipital processes of Ceratosaurus extend more obliquely backward, but this difference may be entirely due to crushing, a point that can not be determined. Otherwise they are very similar.

Paraoccipital $(p . o c$.$) .- The paraoccipital processes are present, but they are$ so badly crushed that contrasting them with others of the Theropoda would be of doubtful value. From what can be observed of their form and relationships they appear to be very" similar to those of Antrodemus, except that vertically their outer ends are more widely expanded and more rugose than in that genus.

Supraoccipital (so.).-On account of the crushed condition of this portion of the occipital region and the coalescence of the sutures the boundaries of the supraoccipital can not be determined.

Alisphenoid (al. sp.).-The distorted condition of the alisphenoids and the coalescence of the sutures in the Ceratosaurus skull render the comparison of this element with those of other Theropod reptiles of little value. 
Basisphenoid (b. s.).-.The basipterygoid processes are more strongly developed than in Antrodemus. The cavity on the median ventral side of the basisphenoid, which probably leads up to the foramen for the median Eustachian canal is not so large as in the latter genus, and on account of being filled with matrix its upward extent can not be determined.

Parasphenoid ( $p . s p$.$) .- The parasphenoid in Ceratosaurus was first recognized$ by Hay, ${ }^{1}$ and as shown in figure 54, (21), is a vertical plate of bone with a pointed anterior extremity that extends forward from the front of the basisphenoid. Crushing and adhering matrix render its relationship with the orbitosphenoids obscure. Above, it supports what appears from its position to be the ethmoid.

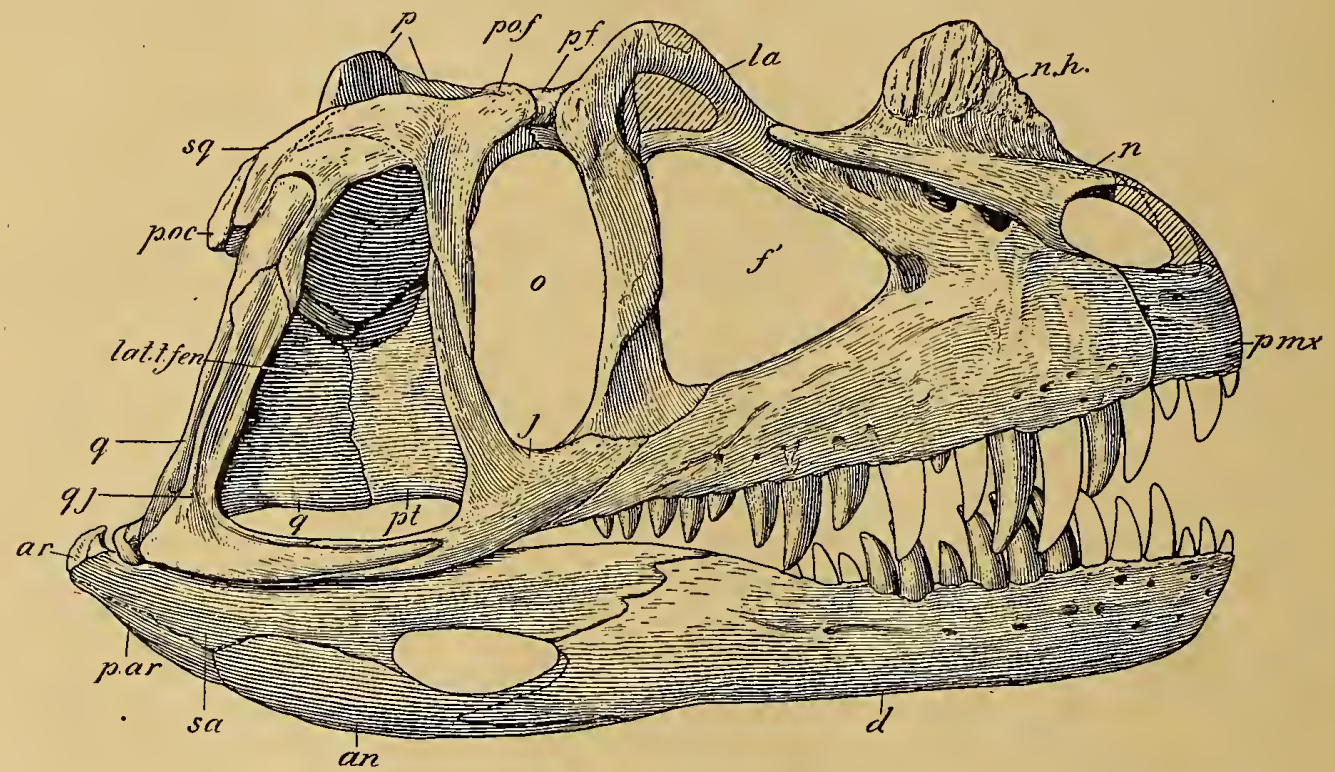

Fig. 53.-Skull of Ceratosaurus nasicorins Marsh. Side view. No. 4735, U.S.N.M. $\frac{7}{4}$ nat. Stze. an, angular; ar, ARTICULAR; $d$, DENTARY; $f^{\prime}$ FIRST ANTIORBITAL FENESTRA; $j$, JUGAL; la, LACHRYMAL; lat.t.fen, LATERAL TEMPORAL FENESTRA; $n$, NASAL; $n . \hbar$, NASAL HORN CORE; 0 , oRBit; $p$, PARIETAL; $p . a r$, PREARTICULAR; $p . f$, PREFRONTAL; $p m x$, PREMAXILLARY; po.f, POSTFRONTAL+POSTORBITAL; p.oc, PARAOCCIPITAL; pt, PTERYGoID; $q$, QUADRATE; qj, QUADRATOJUGAL; $s a$, SURANGULAR; $s q$, SQUAMOSAL.

Parietal $(p$.$) .- The sutures defining the boundaries of the parietals are largely$ obliterated. Between the supratemporal fossae, the parietal surfaces appear more rounded transversely than in Antrodemus. The thin plate-like transverse extensions of the parietal has been represented by Marsh in his figure of the superior view of the skull of Ceratosaurus nasicornis as having the dorsal border continuing outward to unite strongly with the postorbital and the squamosal bones. In this he was in error, for with the articulated skull of Antrodemus as a guide it is plainly evident the relations of these bones are very similar. There is a deep notch between the parietal and squamosal at the back of the supratemporal fossa, as in both Antrodemus and Tyrannosaurus. At the bottom of this notch, as shown in figure 1, plate 18, the parietal has a weak union with the squamosal. Moreorer the articu-

1 Proc. U. S. Nat. Mus., vol. 35, 1908, p. 360, figs. 1 and 2 (21). 
lation of the parietal with the postorbital, postfrontal complex, posterior to the supratemporal fossa, is not known so far as I can determine in any reptilian skull either living or extinct.

Frontal $(f$.$) .-The frontal bones are moderately broad with a convexly rounded$ superior surface as compared with the slightly concave surface of Antrodemus. The suture between the frontals and nasals is more strongly toothed than was represented in Marsh's superior view of the skull. The median suture between the frontals of the two sides, as well as the suture between frontals and parietals is obliterated. The frontal as in Antrodemus contributes slightly to the superior border of the orbit, in a notch between the prefrontal and postfrontal + postorbital. In the restoration of the skull by Marsh it has been incorrectly restored showing the frontal as extending outward to complete the lateral boundary above the orbit on a line with the two elements just mentioned.

Prefrontal $(p f$.$) . - Interposed between the lachrymal and the frontal on the$ right side of the skull of Ceratosaurus there appears to be a small triangular element, identified as the prefrontal. The outlines of this bone are obscure, but if what are interpretated as sutures are such, the hinder end of the dorsal surface of this bone is relatively wider transversely and considerably shorter antero-posteriorly than in Antrodemus. It appears to reach the nasals although in Antrodemus the inner anterior border is in contact with that element for some distance. In $T y$ rannosaurus the anterior ends of the prefrontal just reach the nasals though they are entirely excluded from the lateral border by the lachrymals. In Ceratosaurus their posterior end forms the greater portion of the anterior boundary of the notch above the orbit (fig. 1, pl. 18). The lower or descending branch of the prefrontal is entirely covered by matrix on the right side and its extent and relationships are not to be observed, and on the left which has been more thoroughly prepared 1 am unable to differentiate it. Marsh and Hay did not recognize this bone, but called prefrontal the element here designated lachrymal.

Postfrontal + postorbital (po.f.).-The postfrontal postorbital complex is of the usual triradiate form, its relation to the other elements of the skull is so similar to Antrodemus that a detailed description is considered unnecessary here.

This bone is well shown in two of its aspects in figures 1 and 2, plate 18. There is no "rugosity" such as found by Osborn in Tyrannosaurus, and as mentioned previously the union of this bone with the squamosal is not by a transverse suture as represented by Marsh in his restoration of the skull, but a posteriorly directed process laps along the outer surfaces of the squamosal uniting by a long squamous suture.

Lachrymal (la.).-The element here identified as lachrymal was designated by Marsh as prefrontal, and hy Hay, the lower part was called lachrymal and the upper prefrontal, the two being separated by a diagonal suture. Osborn in Allosaurus considered it a complex of prefrontal and lachrymal. This suture as represented by Hay (fig. 54) is certanly a fracture of the bone, and a critical examination of these elements fails to disclose any indication of there being a suture at this point.

The lachrymal as in Antrodemus and Tyrannosaurus has a descending process which unites the jugal and maxillary above the large antiorbital fenestra. The 
processes at their junction are surmounted by a stout tuberous projection that rises above the general level of the superior surface of the skull. In life this tuberosity no doubt had a horny covering. This process is missing on the left side, but on the right side it is largely intact. The upper borders have suffered some loss, and it is not altogether certain that this process as shown in the restored skull represents its true outlines. It appears quite probable that the tip was more sharply pointed as in Antrodemus and not obtusely rounded as here represented. As in the latter genus this bone is lightened by pneumatic cavities.

Nasals $(n$.$) .- The nasal bones are elongate and they differ principally from$ those of known carnivorous dinosaurs in giving support to a large transversally compressed horn core on the median line. The upper two-thirds of the lateral surface of this horn core is very rugose and furrowed with vascular grooves. The smooth portion near the base of the horn has a greatest transverse width of $12 \mathrm{~mm}$., which is rapidly increased to $20 \mathrm{~mm}$. at the point where the roughening by the vascular grooves begins. The horn has a greatest length antero-posteriorly at its base of $130 \mathrm{~mm}$. and an extreme height above the nasals of $70 \mathrm{~mm}$., the greatest vertical diameter being posteriorly to its middle. It evidently supported a high, trenchant horn, which formed a useful weapon for offense and defense. Additional material is required before it can be ascertained whether this feature pertained to all individuals of this genus or was only a sexual character.

Immediately posterior to the nasal horn core there is a deep elongate depression on the median line, as shown in figure 1, plate 18. The lateral borders above the antiorbital fenestrae are notched as in Antrodemus for the reception of the anterior process of the lachrymal, as may be seen in plate 18. In front of this notch the outer border is slightly roughened and rounded over, not presenting a sharply raised edge, as in Antrodemus. It overhangs the upper branch of the maxillary as in the latter genus, and is perforated likewise by a number of pneumatic cavities. The anterior ends of the nasals where they join the premaxillaries above the external narial opening are missing. Posterior to the nares the nasals widen out and arch over the nasal passages. In Antrodemus the lateral borders of the nasals converge from the anterior border of the lachrymals to their anterior extremities, whereas in Ceratosaurus they converge for a short distance and then become divergent.

Premaxillary (pmx.).- The premaxillaries in the type of Ceratosaurus nasicornis contain fewer teeth than in any other known member of the Theropoda, excepting Struthiomimus. Each premaxillary has alveoli for three functional teeth. Marsh has pointed out that in "the genera Compsognathus and Megalosaurus of this order, each premaxillary contained four teeth, the same number found in the Sauropoda. In the genus Creosaurus from the American Jurassic the premaxillaries each contain five teeth." Antrodemus also has five, while Ornitholestes from the Morrison, Gorgosaurus from the Belly River, and Tyrannosaurus from the Lance have four teeth each.

In this specimen the superior processes which curve upward and backward to meet the nasals are missing, although indicated in Marsh's restoration of the skull as being present. 
This bone in Ceratosaurus is relatively shorter than in Antrodemus, in this respect approaching Tyrannosaurus. Its greatest length anteroposteriorly is about $68 \mathrm{~mm}$; its greatest depth from the nasal to the dental border is $72 \mathrm{~mm}$.

There is present, especially on the left side, a small maxillo-premaxillary fenestra as found in both Antrodemus and Tyrannosaurus. Its position, however, is more ventral than in either of those genera. Marsh failed to indicate this opening in his restoration of the skull.

Maxillary ( $m x$.).-The maxillary bones of bot! sides, except for slight distortion from transverse crushing, are almost perfectly preserved. The maxillary in Ceratosaurus differs from Antrodemus in the same way as most of the other elements forming the lateral view of the skull, in being relatively longer and more slender in their construction. There are alveoli for 15 teeth, whereas Antrodemus has from 16 to 17. The width anteroposteriorly of the superior process of the niaxillary in Ceratosaurus nasicornis, which fills the space between the antiorbital fenestra and the anterior nasal opening, is $105 \mathrm{~mm}$. wide. In the great width of this part of the maxillary C'erutosaurus resembles T'yrannosaurus.

It can not be surely determined whether there was a second antiorbital fenestra in the maxillary as in Antrodemus and Tyrannosaurus. In his restoration of the skull Marsh did not indicate any. Hay comments on it as follows:

It will be observed that there is a large uneven depression in front of and partly above the antiorbital vacuity [fig. 54, numeral 14]. This is not well shown in Marsh's figure. This depression probably corresponds to the postnartial vacuity figured by Lambe as belonging to Creosaurus and Allosaurus [Antrodemus]. There is a similarly placed vacuity in the skull of Diplodocus, whose nasal openings are located far toward the rear of the skull. Inasmuch as this vacuity in the Theropoda and in Diplodocus appears to be wholly in the maxillary bone, it might be well called the maxillary vacuity. On the left side of the skull of our specimen of Ceratosaurus no actual opening is seen through the bone, but on the right side, near the front of the depression, $47 \mathrm{~mm}$. behind the nostril, there seems to be a foramen.

I would quite agree with the latter observation, though if it does represent the second antiorbital fenestra it is very much smaller than in Antrodemus.

Quadratojugal (qj.).--Viewed lateraliy the quadratojugal of Ceratosaurus nasicornis at the angle formed by the junction of the vertical and horizontal branches is considerably narrower than in Antrodemus. The horizontal branch also is much longer than in that genus, its forward termination stopping slightly short of the postorbital bar, whereas in Antrodemus it ends more posteriorly. The inner median surface forms the outer boundary of the quadrate foramen. Its other relations with surrounding bones are similar to Antrodemus. The greatest length of the inferior part of the quadratojugal is $124 \mathrm{~mm}$.; greatest length dorsoventrally is $131 \mathrm{~mm}$.

Jugal (j.).-The jugal is much more slender than in Antroderrus. In the restored Ceratosaurus skull, as published by Marsh, he erred in his interpretation of the anterior extent of the jugal as extending forward of the lachrymal and contributing to the formation of the boundary of the large antiorbital fenestra. It is excluded from this fenestra by the lachrymal and maxillary, as may be clearly seen upon exanination of the original specimen. (pl. 17.) Hay correctly identified its forward extent. ${ }^{1}$ It does not appear to be perforated by a foramen such as is 
present in Antrodemus and Tyrannosaurus. The right jugal measures $242 \mathrm{~mm}$. antero posteriorly and vertically at the center $130 \mathrm{~mm}$.

Quadrate (q.).-The quadrate in Ceratosaurus is relatively long, and in the articulated skull rises much higher on the side of the head than in either Antrodemus or Tyrannosaurus. Marsh says ${ }^{1}$ of the quadrate in Ceratosaurus:

One peculiar feature of the quadrate is a strong hook on the upper half of the outer surface. Into this hook a peculiar process of the quadratojugal is inserted.

A comparison of these bones with those of Antrodemus shows them to be very similar and that the peculiar features noted by Marsh were due to post-mortem distortion and not to any great structural differences.

The so-called hook is that part of the quadrate that forms the upper boundary of the foramen between the quadrate and quadratojugal. Crushing has disarticulated the quadratojugal and forced it in beneath this hook on the quadrate, whereas normally it would have been in contact with the rough sutural surface on the external border of the hook, as shown. in figure 2, plate 18, its inner side then forming the outer boundary of the foramen, as in the Antrodemus skull before me.

Bauer ${ }^{2}$ noted the presence of this foramen, but Hay thought it absent, not recognizing the outlines of the border of the foramen or the partial dislocation of the quadratojugal. This interpretation of the relationships of these elements, therefore, renders the laterai view of these bones in the skull as restored by Marsh incorrect. The greatest length of this bone in Ceratosaurus nasicornis is $212 \mathrm{~mm}$., whereas in Antrodemus, representing a larger individual, it measures only $192 \mathrm{~mm}$. Except in minor details, other than the differences discussed abore, the quadrate closely resembles the same element in Antrodemus valens.

Squamosal (sq.).-The squamosal is considerably weaker than in Antrodemus, though its relations with adjacent bones appears to be almost identical. The bar extending downward in front of the quadrate to unite with the quadratojugal is exceedingly narrow anteroposteriorly, as compared with the same element in Antrodemus. The process forming the back of the cotylus for the head of the quadrate is much more slender than in the latter genus. The union of the squamosal with the postorbital is not by a vertical suture, as indicated in the restoration of the skull by Marsh (fig. 1, pl. 8, Dinosaurs of North America), but is by a long squamous suture (frg. 2, pl. 18).

Palate.-The palate of the type skull of Ceratosaurus nasicornis has been described by Dr. O. P. Hay, ${ }^{4}$ and with the exception of interpolated notes, his description is given in its entirety:

Figure 1 [fig. 51] represents a view of the left side of the skull, that which best shows the bones of the palate. In the fossil the bones of the palate stand nearly perpendicalar, but without doubt this is to a great extent due to crushing. They probably sloped upward and inward at an angle of $45^{\circ}$, or more probably they formed a vaul ted roof for the mouth.

The postero-interior process of the pterygoid (fig. 2, numeral 28) joins the inner border of the quadrate at a point $55 \mathrm{~mm}$. above the articulation of the latter bone with the lower jaw. The posterior superior process rose to the upper end of the quadrate. [Evidently Hay had the idea that the pterygoid extended posteriorly far enough to join the heavy vertical portion of the quadrate, whereas this bone in 
Antrodemus sends forward and inward a thin vertical sheet-like process to meet the pterygoid, and there is every reason to believe that the same condition prevails in the present specimen. The squamous union of these two bones, although somewhat obscure can be traced in the specimen by an irregular vertical line that passes in front of numeral 28 in figure 54. So that this numeral, as the relation of these bones are now interpretated, does not represent the pterygoid but is the inner and forwardly directed process from the quadrate.] Whether or not the pterygoid articulated with the quadrate the whole distance between the two points mentioned is somewhat uncertain. On the left side of the skull a considerable part of the pterygoid from the quadrate forward is broken away. [The missing bone is largely from the quadrate.] Marsh neither mentions any vacuity here nor does he represent it in his figure. On the right side there is a gap between the two bones, extending about $55 \mathrm{~mm}$. along the border of the quadrate and forward from it less than $15 \mathrm{~mm}$. It seems probable that in life this gap was filled in with bone. [It is in Antrodemus.] This region is represented in the figure as it appears on the right side. In Sphenodon the quadrate sends forward a broad process between the upper and lower processes of the pterygoid. It is quite certain that this was not the case in Ceratosaurus. [In Antrodemus the union of the pterygoid with the quadrate is almost identical with that in $S$ phenodon and there is no reason to expect it to be greatly different in Ceratosaurus.]

Marsh informs us that there is a very short, thin epipterygoid closely articulated by suture with the pterygoid. The position of the suture is obscure, but it was doubtless present. Marsh was probably mistaken when he affirmed that the upper end of the epipterygoid articulated with the postfrontal. Its connection must have been with the border of the parietal. The epipterygoid of the left side has its upper end missing [fig. 54, numeral 8]. On the right side this bone is uninjured. Its upper end is moved well outward toward the postfrontal, but it is probably joined to the parietal. The suture between the latter bone and the postfrontal is obscure. Just behind the base of the epipterygoid the width of the pterygoid is $64 \mathrm{~mm}$.

The inner and anterior end of the transverse bone [fig. 54, numeral 36] overlaps the outer border of the pterygoid, as if it had been pressed somewhat out of its natural relations; but in both Sphenodon and Cyclura the transverse bone overlaps the pterygoid. From the outer border of the pterygoid and of the transverse bones a strong process, 29, descends to a point a little below the upper border of the lower jaw. Marsh indicates that this process belonged wholly to the transverse, but the suture between the two bones is distinct. The transverse measures $160 \mathrm{~mm}$. from its inner end to the extremity of the process mentioned. Just in front of the inner end of the transverse the pterygoid is $45 \mathrm{~mm}$. wide.

The sutures separating the pterygoid, the palatine, and the vomer are not as distinct as could be desired. Nevertheless their courses may be made out more or less satisfactorily. The bones of the right and left sides did not articulate on the midline. Doubtless there was, at least posteriorly, a considerable interval between them. In the skull, as preserved, the rounded inner, or upper, border of the bones of the right side rise several millimeters above those of the left side.

Mostly hidden by the lachrymal and the jugal, in a side view of the skull, is a considerable vacuity in the bones of the roof of the mouth. Its fore and aft extent is $90 \mathrm{~mm}$. This is called by Lambe the suborbital vacuity. It seems to correspond to the postpalatine foramen of lizards, turtles, and sphenodon. It is bounded behind by the transverse and mesially, in part, by the pterygoid. In figure 54 the vacuity is mostly hidden by the lachrymal. A part of it, with light shading, appears between the two numerals 20; the hinder part is shaded dark and is in front of numeral 36.

Another fissure in the roof of the mouth is seen through the antorbital vacuity and is situated just above the border of the maxilla. This is the internal nasal passage [fig. 54, numeral 16]. It extends forward to the anterior end of the antorbital vacuity and backward to a bar of bone that bounds the postpalatine vacuity in front. The whole extent of the internal nasal passage, as seen, is $85 \mathrm{~mm}$. Possibly it extended forward some distance beyond the front of the antorbital vacuity.

The bone that lies between the postpalatine vacuity and the nasal passage is undoubtedly the palatine [fig. 54, numeral 20]. A branch of this bone runs backward against the inner face of the maxilla, its hinder extremity being hidden by the maxilla, the front end of the jugal, and the base of the lachrymal. The hinder border of the bone sweeps around and bounds in part the postpalatine vacuity mesially. The suture between the palatine and the pterygoid appears to be where drawn in figure $54, \mathrm{~B}$, running first directly forward from the inner side of the postpalatine vacuity to a distinct ridge, then following upward and inward this ridge about $25 \mathrm{~mm}$. Behind this ridge the fibers of the bone are $144035^{\circ}-20-7$ 
directed fore and aft; on the ridge and in front of it they are directed upward. There can be little doubt that the surface behind the ridge belongs to the pterygoid; that in front of it. to the palatine.

When carefully examined the ascending suture appears to and about $20 \mathrm{~mm}$. below the upper border of the plate of bone of this left side. From this point there appears to be a suture that runs forward some distance. Above this supposed suture the bone fibers are directed forward; below it, near the ridge, they are directed upward; more anteriorly they run upward and forward. The part of the bone with ascending fibers is quite certainly the upper and anterior portion of the palatine. One can not be certain how far forward this bone extends; it seems to reach almost to the front of the antorbital vacuity
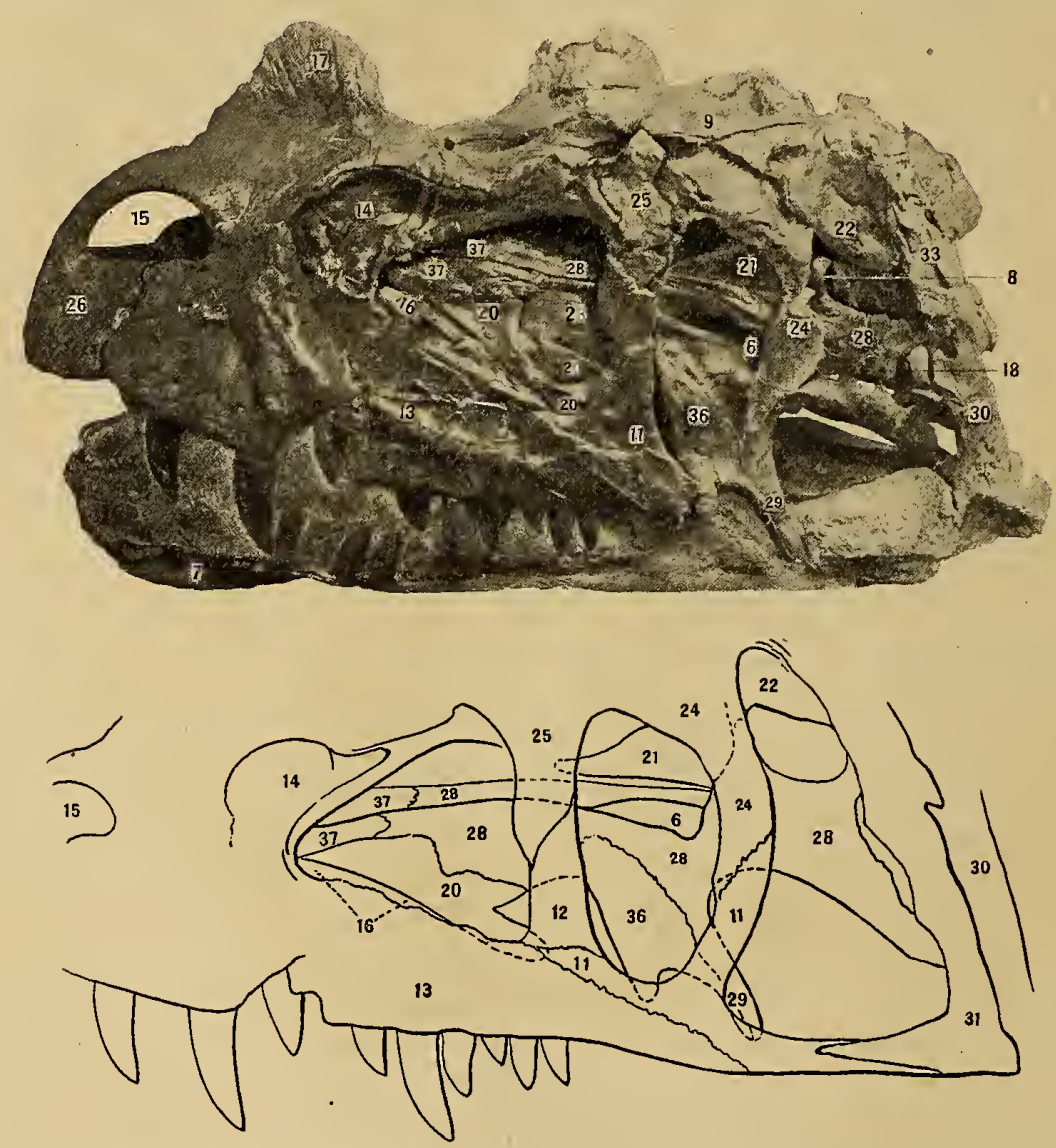

Fig. 54.-(A). Skull of Ceratosaurus nasicornis Marsh. Type No. 4735. U.S.N.M. Seen From the LefT Side. ABOUT 3 NAT. SIZE. (B), DIAGRAM OF THE SAME. BOTH FIGURES AFTER HAY. 6. ClefT BETWEEN PTERYGOIDS; 7 . DEN-

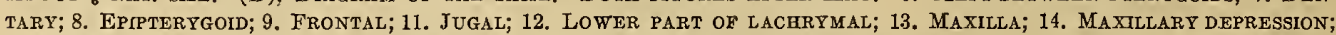
15. NARes, external; 16. Nares, internal; 17. Nasal horn; 18. OCcipital condyle; 20. Palatine; 21. Parasphenoid; 22. Parietal; 24. Postfrontal + postorbital; 25. Lachrymal; 26. Premaxilla; 28. Pterygoid; 29. Pterygoid Process; 30. QUadrate; 31. QUadratojugal; 33. SQuamosal; 36. Transverse bone; 37. Vomer.

ending there in a point. It is possible, however, that it ends on the border of the nasal passage about $35 \mathrm{~mm}$. behind the front of the antorbital vacuity.

The bone lying above the palatine and at the front of the antorbital vacuity is undoubtedly the left vomer (fig. 54, numeral 37). This appears to extend backward to meet the pterygoid above the palatine, as drawn in the figure. If this is the case, the palatines did not meet at the midline of the palate. Lambe concluded that in the skull of his Dryptosaurus incrassatus (Albertosaurus sarcophagus Osborn) the palatines were in contact posteriorly. 
If the conclusions arrived at here are correct, [it should be mentioned that the conclusions reached here by Hay, coincide almost exactly with the conditions found by Osborn in a well preserved skull of Tyrannosaurus] the internal narial passage was bounded inwardly almost wholly by the palatine; only slightly by the vomer. In any case, the vomer takes a less important part in the border of the internal nostril than it does in either Sphenodon or Cyclura. In Cyclura, perhaps in lizards generally, the palatines meet in the midline, thus shutting off the pterygoids from the vomers. In Sphenodon the pterygoids join the vomers. In the broad union of the pterygoid with the quadrate and the union of the pterygoid with the vomer, Ceratosaurus appears to show closer relationship with Sphenodon than with the lizards and crocodiles. In the crocodiles access to the supratemporal fossa from behind is cut off above the paroccipital process, but not from below.

To what extent the internal nasal passage was bounded exteriorly by the palatine in Ceratosaurus can not be determined. Possibly a process of the bone extended forward outside of the passage against the inner face of the maxilla.

A comparison of the palate of Ceratosaurus with that of Diplodocus, as represented by Marsh ${ }^{1}$ brings to light both differences and resemblances that are interesting. In describing the palate of Diplodocus it will be convenient to regard it as divided into anterior, second, third, and posterior fourths. In this genus, as in Ceratosaurus, the pterygoids extend far forward, to come into contact with the small vomers. Along the midline they are applied to each other backward nearly to a line joining the articular ends of the quadrates at the hinder end of the third quarter of the length. In the lizard Cyclura they diverge about the middle of the length of the skull. In Diplodocus the postero-inferior process of the pterygoid is very short on account of the forward swing of the quadrate. Thus the basipterygoid processes join the pterygoids but little in front of the articular ends of the quadrates.

The anterior position of the articular ends of the quadrates has not been acquired at the expense of the posterior processes of the pterygoids alone. There seems to have occurred in Diplodocus a remarkable shoving forward of structures that in Ceratosaurus lie across the second and third quarters of the length of the base of the skull. On examining Marsh's figure of Diplodocus it will be observed that there are four vacuities lying in a row across the palate in the second quarter length. The two of these which are nearer the midline are the internal nasal passages; those lying farther outward, right and left, the postpalatine vacuities. In Ceratosaurus, as in Cyclura, the latter are behind the nasal passages, being separated therefrom by the palatine bones. In Diplodocus the postpalatine vacuities seem to have been crowded forward alongside and outside of the nasal openings.

Each postpalatine vacuity is mostly inclosed by the maxilla and its processes, only a little of its hinder end being inclosed by the palatine and the transverse bone. The hinder end of the nasal passage lies between the forks of the small palatine. The rest of its inner border is formed by the slender vomer, while it is bounded in front and outwardly by processes of the maxilla.

Sereral of the nieasurcments given in the table below can not be considered altogether exact, for in the case of the Ceratosaurus skull, crushing has undoubtedly altered the true dimensions, while some allowance must be made for restoration and inexact articulation of the elements comprising the Antrodemus skull. 


\begin{tabular}{|c|c|c|}
\hline & $\begin{array}{c}\text { Antrode- } \\
\text { mus } \\
\text { No. 4734 } \\
\text { U.S.N.M. }\end{array}$ & $\begin{array}{c}\text { Cerato- } \\
\text { saurus } \\
\text { No. 4735 } \\
\text { U.S.N.M. }\end{array}$ \\
\hline Greatest length of skull, taken at center. & $\begin{array}{c}m m . \\
610\end{array}$ & $m m$. \\
\hline Greatest length of skull, taken at side... & 642 & 620 \\
\hline Least transverse diameter above center of orbits. & 128 & 140 \\
\hline Greatest expanse of nasals at center, across rugosities & 110 & 63 \\
\hline Greatest width of skull across quadratojugal.. & 300 & \\
\hline Distance from anterior border of orbit to anterior extremity of premaxillae & 400 & 395 \\
\hline Distance from distal end of quadrate to top of skull.. & 340 & 280 \\
\hline Height of skull at center of lachrymal................ & 300 & 235 \\
\hline Height of skull at center of maxillary.......... & 237 & 210 \\
\hline Height of skull taken at center of anterior nasal opening & 130 & \\
\hline Height of skull with lower jaw, measurement taken at posterior border of orbit.. & 444 & 310 \\
\hline Antero-posterior diameter of orbit at center $\ldots \ldots \ldots \ldots$ & 90 & 70 \\
\hline Vertical diameter of orbit at center........... & 210 & 130 \\
\hline Antero-posterior diameter of anterior nares. . & 118 & \\
\hline Length of dental series, left maxillary...... & 284 & 350 \\
\hline Length of dental series, right premaxillary.. & 110 & 61 \\
\hline
\end{tabular}

LOWER JAW.

Plates 17,18 , and 26, fig. 2.

Both rami of the lower mandible are present. The left, having been removed from the rock, permits examination of all aspects, while the right ramus remains in the matrix articulated with the skull, as shown in figure 1, plate 17, and presents only the outer surfaces. The left ramus has been slightly restored and many of the sutures are indistinct. The right ramus as seen in figure 1, plate 17 , shows plainly the displacement of the elements of the hinder portion, but taken together these rami enable one to work out quite accurately the extent and relationship of the various bones composing the jaws. Hay ${ }^{1}$ has described the ramus of Ceratosaurus, but I propose to supplement his brief account with a more detailed description of the several elements.

Dentary (d.).--The dentary is long, relatively slender, compressed transversely, and contains alveoli for 15 teeth. The depth of the dentary increases gradually in a posterior direction, reaching its maximum vertical diameter immediately anterior to the external mandibular foramen. This measurement at the fifth tooth from the front is $63 \mathrm{~mm}$. and at its deepest diameter $103 \mathrm{~mm}$; at the former point it has a transverse width of $21 \mathrm{~mm}$.

The anterior end of the dentary is rounded and not so truncate as in Antrodemus. The union of opposite rami was probably membranous, there being no indication of symphysial contact. The alveoli are separated by thin alveolar septa, which internally expand into intermediate "rugosae" (fig. 55). These are not so well differentiated as in Tyrannosaurus. A longitudinal groove at the base of these rugosae for the dental artery gives off side branches to the lower portion of each tooth, though small foramina. 
On the internal side the dentary is overlain by the splenial and supradentary.

Posteriorly the dentary sends back a thin pointed process on the lower border, which laps along the outer side of the angular, ending anterior about the middle of the external mandibular foramen.

The complete coalescence of the dentary and surangular renders the point of their union undetermined, though on the external surface above the external mandibular foramen there is indication of a second lapping process of the dentary upon the surangular, but of this one can not be sure.

On the external surface of the dentary are the usual foramina, which doubtless served for the transmission of nerves and nutrient blood vessels to the lips.

Supradentary ${ }^{1}$ (d.p.).-The supradentary in Ceratosaurus, recognized in this genus for the first time, is a long, thin bone, that extends along the upper, inner side of the dentary (fig. 55). It extends nearly the entire length of the dental series and hides from an internal view the greater portion of the dental "rugosae." The upper border of the anterior half of this bone is slightly below the tops of the rugosae, but on the posterior half it rises above them to form the inner parapet of

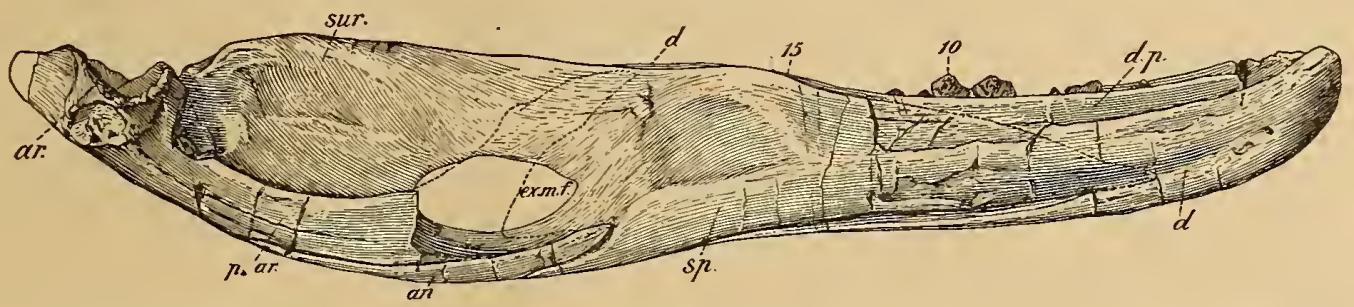

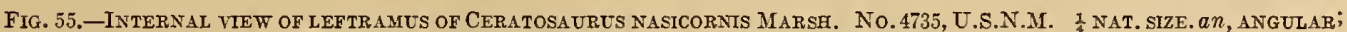
$a t$, ARTICULAR; $d$, DeNATRY; d.p, SUPRADENTARY; ex.m.f, EXTERNAL MANDIBULAR FORAMEN; par, PREARTICULAR; $s p$, SPLENIAL; sUr, SURANGULAR; 10, ROOT OF TENTH TOOTH; 15, INDICATES POSITION OF LAST ALVEOLUS.

the alreoli, and in that way it contributes somewhat to the support of the teeth. The anterior end is missing, but apparently it was pointed and ended just posterior to the most anterior tooth, as shown in figure 55 .

Hay $^{2}$ regarded this element as being the anterior portion of the splenial, but in this he certainly was mistaken, for on examination of the specimen the splenial is plainly seen to overlie this element.

In Tyrannosaurus Osborn ${ }^{3}$ concludes that the supradentary is "apparently of splenial origin, but suturally separated from it." I fail to find any evidence to bear out this assertion in the material now at hand.

Angular (an.).- In the first restoration of the Ceratosaurus skull by Marsh (pl. 8, fig. 1, Dinosaurs of North America), no attempt was made to differentiate the elements of the posterior half of 'the jaw. Hay was the first to recognize these bones, though his description of them is very brief. The angular, somewhat displaced, is plainly shown on the right ramus (fig. 1, pl. 17). It is a thin, flattened element that articulates by squamous union with the lower median portion of the

1 Name proposed by Osborn in 1912 (Mem. Amer. Nat. Hist., vol. 1, p. 5). Lambe in 1904 recognized this same element in Albertosaurus but failed to give a distinctive name, designating it as the "inner alveolar plate of dentary." (Contrib. to Canadian Paleontology, vol. 3, pt. 3, 1904, pt. 11.)

2 Proc. U. S. Nat. Mus., vol. 35, 1908, fig. 4.

3 Mem. Amer. Mus. Nat. Hist., vol. 1, pt. 1, 1912, p. 24. 
surangular. It would appear that some of the posterior end of the right element in this individual is missing, for its homologue of the opposite ramus extends more posteriorly and laps underneath the prearticular, but ends considerably short of the posterior end of the ramus, as in Tyrannosaurus. It extends forward of the mandibular foramen, being overlapped on the external side by the dentary. On the internal side, as Hay has pointed out, a posterior process of the splenial "presses itself between two processes of the angular." The angular has a limited exposure on the inner side of the jaw where it passes beneath the prearticular below the mandibular foramen.

Surangutar (sa.).- The relationship of the surangular to contiguous elements so far as they can be determined is very similar to those conditions observed in the Antrodemus ramus. Vertically it is considerably narrower than in Antrodemus, but, as in that genus, when the jaws are closed its upper border passes up inside the quadratojugal bar, as shown in figure 2, plate 17 .

Splenial (sp.). - The splenial is a deep lamellar bone that is applied to the inner side of the dentary and supradentary. It is perforated near its inferior margin on the anterior half by a foramen, as shown in figure 55. This foramen probably functions the same as the large oval foramina present in the splenial of both Tyrannosaurus and Albertosaurus. In the present specimen the splenial is only to be observed in the ramus of the left side, and its damaged condition renders an accurate description of the bone impossible at this time. Its posterior limits are only traceable on the lower posterior side, where it sends backward a fingerlike process to articulate with the angular. Its lower margin is here visible for a short distance on the external side.

Nowhere does the splenial form the inner parapet of the alveoli as would be inferred from the outline figure of the Ceratosaurus ramus as figured by Hay. ${ }^{1}$

At a point slightly posterior to the last alveolus the upper margin of the splenial sweeps downward bèlow the border of the supradentary, much as the splenial sweeps downward below the border of the supradentary as in Tyrannosaurus, though the ventral deflection of this margin is more gradual than in the latter genus. The anterior end of the splenial is missing but in all probability it terminates in a tapering process as in the other Theropods, and it has so been indicated in figure 3.

Coronoid.-The coronoid though undoubtedly present in Ceratosaurus has not as yet been recognized as a distinct element.

Articular (ar.).- The articular is small and compact, and forms the greater part of the cotylus, which is obliquely transverse and bifossate. It is overlapped on its inner and under sides by the prearticular, and on the outer side by the surangular. Unfortunately the posterior extremities of both articulars in this individual are missing, and in the restored skull, shown in figure 33, this portion of the articular has been restored after Antrodemus.

Prearticular ( $p . a r$.$) .- The prearticular is only to be observed in the left ramus,$ and this'one lacks its anterior end. In so far as one may judge from the parts preserved it is very similar to that of Antrodemus. Hay ${ }^{2}$ discusses this bone as follows: 
What he [Lambe] regards as the angular is almost certainly a long process of the articular, such as occurs in the lizards. If in Lambe's specimen there is really a suture between the articular and the bone called by him the angular the latter is a distinct prearticular. Quite certainly in Ceratosaurus the suture does not exist. Here the process reaches the foramen and a little below it.

This more recent examination confirms Doctor Hay's conclusion regarding a suture between the articular and prearticular, at this point. Osborn was unable to detect it in the ramus of Tyrannosaurus studied by him although its probable course is indicated by a dotted line. In the Antrodemus specimen No. 4734, U.S. N.M., the prearticular is shown to extend to the angle of the jaw, underneath the articular (see figure 15), and a close examination of the present specimen shows a very similar condition. In advance of the posterior broken end of the left ramus on the internal side is the broken end of the prearticular plainly shown as underlapping the articular. The rather indistinct suture can be traced forward for a short distance where it appears to rise on the front of the articular, but its further course can not be traced, except that in front of the articular it appears to unite by a vertical suture with an inwardly directed process from the surangular. Ventrally the prearticular is underlapped by the angular. The anterior portion is missing in this specimen, but in all probability it curved upward, the anterior end being received between the coronoid and splenial as in Antrodemus and as indicated in figure 55 .

The prearticular extends posteriorly nearly to the end of the articular, but the surangular is slightly shorter and allows the articular to appear in a lateral riew. The posterior sutures between articular and surangular are very distinct, but more anteriorly, especially those on the inner side, are coalesced and can no longer be traced. Viewed from above the suture between the surangular and articular runs diagonally across the outer fossa of the cotylus, but can not be traced further than a deep pit between the inner fossa of the cotylus and the prearticular. All of the evidence appears to indicate the presence of the prearticular as a distinct element as found in Tyrannosaurus and some other dinosaurs. Hay considered this part of the lower jaw in Ceratosaurus as being a forward prolongation of the articular, but I believe when a younger individual is known it will be found to be a distinct element as in other Theropodous dinosaurs. The deep pit mentioned above is bounded on the inner side by a thin sheet of bone, but how much of it is articular I am unable to determine because of the complete coalescence of the sutures. The articular has a greatest transverse diameter of $73 \mathrm{~mm}$; and an anteroposterior diameter of $69 \mathrm{~mm}$.

Comparative measurements of Antrodemus and Ceratosaurus jaws.

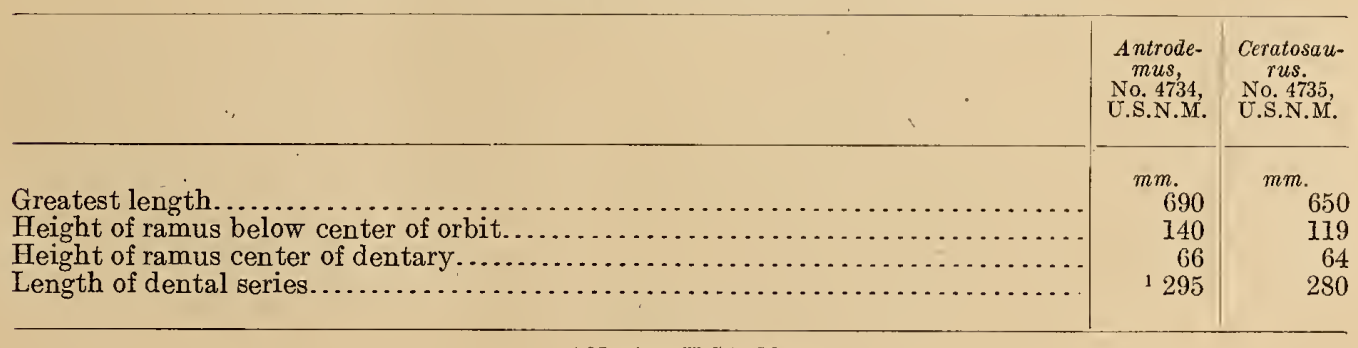

1 No. 8335 U.S.N.M. 
Hyoid:-Marsh says: ${ }^{1}$ The hyoid bones appear to be four in number. They are elongate, rod-like bones, somewhat curved, and in the present specimen were found nearly in their original positions.

The only evidence I find of the presence of bones of the hyoid arch is a small section of a rounded rod-like bone attached by the matrix in an oblique position from the vertical to the inner side of the right ramus, slightly in advance of the articular. Both ends show fractured surfaces. There is a second and longer flattened element held in the matrix parallel with and internal to the dentary of the right side. Both of these bones may represent hyoid elements, but as to this one can not be certain.

TEETH.

In the type skull of Ceratosaurus nasicornis the dental formula is as follows:

Upper jaw: Premaxillary, 3; maxillary, 15; total, 18.

Lower jaw: Dentary, 15.

Counting backward from the front of the jaws the following teeth are present in the specimen: Right maxillary, the second complete (displaced), and the root of the fifteenth. Left maxillary, the second, fourth, sixth, eighth, ninth, tenth, eleventh, twelfth, and thirteenth, roots of the fourteenth and fifteenth. Right dentary, the sixth, twelfth, and thirteenth. Left dentary, the seventh, root of the eighth, ninth, and tenth complete roots of the eleventh to the fifteenth inclusive. There are three detached teeth lying in the matrix between the jaws, as shown in figure 1, plate 17. All of the premaxillary teeth are missing.

The maxillary series are compressed, recurved, teeth of robust size in front, but from the ninth posteriorly gradually decreasing in size; the fourteenth and fifteenth are both of relatively diminutive size. All display the serrate edges on the anterior and posterior borders so characteristic of nearly all Theropoda. The carinations are minutely serrated, there being about 10 denticulations in a space of $5 \mathrm{~mm}$. The anterior carina passes gradually to the inner side of the crowns of the anterior half of the series, while the posterior carina follows a straight course well toward the outer side of the crown.

The great irregularity in size of contiguous teeth, to some extent, is due to the different degrees of extrusion brought about by the loss of functional teeth at different times and their subsequent replacement by the growing germ teeth. Whether the functional teeth are forced out at intervals by the continued development of the germ teeth, or whether they are lost through accident, has not yet been determined. It may be that both conditions prevail.

The largest tooth preserved in this specimen is the fourth of the left maxillary, which extends $70 \mathrm{~mm}$. below the border of the socket, and is $27 \mathrm{~mm}$. wide anteroposteriorly at the base of the crown.

The anterior maxillary teeth of Ceratosaurus appear to be more robust in their proportions than in any individual of Antrodemus available for comparison at this time, some of which apparently represent larger individuals. Except possibly this difference in size, I have been unable to find characters that would enable one to 
distinguish detached teeth of Ceratosaurus from those of Antrodemus. So far as the material at hand will admit of comparison, no essential differences were detected. They have the same number of denticulations within a given space, the same irregularity of size, same curvature of tooth, the same placing of the carina, and apparently the same method of replacement of lost or worn out teeth by younger germ teeth.

BRAIN.

The superior and lateral views of the cast of the brain cavity of Ceratosaurus nasicornis shown in figures 1 and 2, on plate 36, were made under the direction of Professor Marsh, and in all probability at the time the skull was being prepared. Since the investing bones of the brain case have been again securely cemented together it was not deemed expedient to attempt their separation for fear of doing damage to this rare specimen, so at this time there is no way of verifying their accuracy.

The cast shows but few of the exits of the cranial nerves that lead from the brain to the outer surface of the cranium, but it gives a good idea of the general shape and extent of the dura mater envelope. Either the cranial openings for the exit of the nerves were closed by the crushing to which the skull has been subjected or else they were not properly developed at the time of clearing the matrix from the brain cavity. The present condition of the skull is such that none of the nerve exits can be positively, recognized.

As Marsh has pointed out, the brain in Ceratosaurus is "comparatively much larger than in herbivorous dinosaurs." When compared with the superior aspect of the brain cast of Tyrannosaurus rex, there is a striking similarity between them, though they differ somewhat in proportion. The protrusions observed in the superior and lateral views of the Tyrannosaurus cast are not present in the Ceratosaurus brain, but again their absence may be due to lack of preparation.

The transverse swelling of the cerebral portion of the brain is relatively greater, the constriction of the olfactory region is more decided and the olfactory nerves are more widely separated than in Tyrannosaurus, and the pituitary body appears more robustly developed.

VERTEBRAL COLUMN.

Plates 19-22.

Although parts of nearly all of the vertebrae of the backbone of Ceratosaurus nasicornis are preserved, there were at least three breaks in the articulated series, which renders somewhat uncertain a precise determination of the vertebral formula.

The mounted skeleton has the following vertebral formula. C, $9 ; \mathrm{D}, 15 ; \mathrm{S}, 5$; $\mathrm{C} 51+$. It was the intention at the time of mounting the skeleton to make the presacral series correspond in number with a complete articulated series of Antrodemus (No. 666) in the American Museum of Natural History, New York, which has twenty-three presacral vertebrae, ${ }^{1}$ for there is every reason to expect the vertebral formula of Antrodemus and Ceratosaurus to be the same.

- There are no true lumbars. The first restoration of the skeleton of Ceratosau$r$ s $^{2}$ shows 29 presacral vertebrae, the back being made too long by the unwarranted

\footnotetext{
1 Regardung this specimen Dr. W. D. Matthew writes me as follows: "It is positively known (auct. Granger) in one of our skeletons No. 666 from Bone Cabin Quarry, in which all the presacrals were in series with the skull, except the last, wbich was a little displaced. There is some uncertainty as to the number of dorsals and cervicals, but none as to their combined number."

2 Marsh, Amer. Journ. Sci., ser. 3, vol. 44, pl. 7.
} 
insertion of several dorsal vertebrae, which obviously throws the animal out of balance (see upper figure pl. 27). A preliminary sketch restoration of Ceratosaurus found among some drawings made for Professor Marsh, shows fewer presacrals which made a better proportioned animal than was his final restoration which has been so widely published.

In order to place on record all of the evidence relating to the primary association of the various elements of the vertebral column of the type specimen of Ceratosaurus nasicornis, a complete list of the free and articulated vertebrae is given below:

Atlas, axis, third to ninth vertebrae, inclusive, found articulated with the skull. The tenth is entirely restored in the mounted skeleton. The eleventh to the sixteenth, inclusive, were articulated. The remaining presacrals, that is, from the nineteenth to the twenty-third, were articulated with the sacrals, they in turn with the first sixteen caudals. The seventeenth to the twenty-sixth caudal, inclusive, were articulated. The twenty-seventh is restored. The twenty-eighth was found separated from the matrix, so there is no clue as to its original association. The twenty-ninth to the fifty-first were articulated.

Atlas (at.).-The atlas in Ceratosaurus consists of the usual four elements, the intercentrum, two neurapophyses, and odontoid process. The intercentrum viewed from the front, (fig. 5, pl. 19), is a subquadrangular block-like bone, the median anterior face being hollowed out for the reception of the occipital condyle of the skull. The superior median surface is deeply concave, especially on the posterior side which receives the forward end of the odontoid in the articulated neck. On either side of the median depression, beveled surfaces that look upward and outward receive the pedicels of the neuracentra.

The posterior view (fig. 3, pl. 19), presents a nearly vertical face for articulation with the hypocentrum of the axis. The median ventral surface is shallowly concave transversely, on either side of which are facets for the articulation of the cervical ribs.

The neurapophyses articulate with expanded pedicals upon either side of the neuracentrum. These articular ends have three faces that meet at obtuse angles. The posterior face looks downward and articulates with the neuracentrum as does a smaller posterior face which looks backward and downward and is partially apposed by an upwardly projecting spur of the intercentrum, while the largest face looks downward and forward and contributes to the formation of the cup for the condyle (figs. 3, 4, and 5, pl. 19). Just above the neck-like constriction of the pedicel the neurapophyses gives off two processes, a short thin curved portion directed inward which with a similar process of the opposite side forms the subcircular openings for the passage of the spinal cord. The neurapophyses did not meet on the median line. The postzygapophysial processes extend well backward, their posterior ends being directed away from the median line (figs. 1, and 2, pl. 19). On their interior surfaces at a point about midway between the two ends well developed postzygapophyses are present for articulation with the axis. The odontoid is firmly coossified with the axis, (fig. 10, pl. 19), in this individual though doubtless it will be found to remain free in younger specimens. It is a small bone with the upper surface slightly concave, having a rounded and bluntly pointed anterior end 
which articulates with the upper concare surface of the intercentrum. The greatest length of the intercentrum is $37 \mathrm{~mm}$; the greatest transverse width is $54 \mathrm{~mm}$.

Axis (ax.). - The axis of Ceratosaurus is so fully illustrated in all aspects in plate 19 as to make it unnecessary to enter ińto a detailed description of it here. This bone may be distinguished at once from the axis of Antrodemus by the well developed longitudinal keel on the ventral surface of the centrum; the better defined and more rentral position of the parapophysis; the more plate-like shape of the neural spine; the absence of notches between spine and.postzygapophyses and the oblique posterior end of the centrum. The second hypocentrum and the odontoid are so thoroughly fused with the centrum that all traces of the sutures have been entirely obliterated.

The axes of both Ceratosaurus and Antrodemus are to be distinguished from the homologous element in Tyrannosaurus by the relatively longer centra and the more plate-like development of the neural spines.

Measurements of axis of Ceratosaurus nasicornis Marsh.

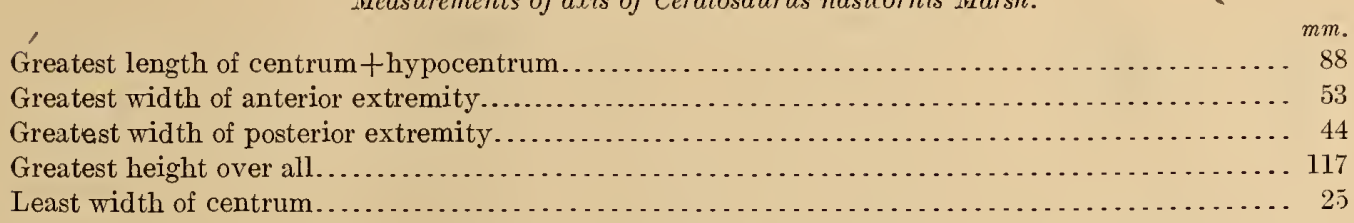

Cervicals posterior to the axis. - The total number of cervical vertebrae in Ceratosaurus is somewhat uncertain though it appears to be nine the same as in Antrodemus. The five vertebrae suceeding the axis in the type specimen are in a fair state of preservation.

The eighth, however, now consists of the neural spine, anterior zygapophyses and a small portion of the centrum; the ninth by only a median section of the neural spine, as shown in plate 30 . Excepting the atlas and axis, which had been entirely freed from the matrix, the remaining cervicals, when they came into my hands, were retained in the rock in their relative positions as shown in the skeleton. All of the centra are strongly cupped on the posterior end, and as Marsh ${ }^{1}$ first pointed out, "in place of an equally developed ball on the anterior end there is a perfectly flat surface. The size of the latter is such that it can be inserted only a short distance in the adjoining cup, and this distance is accurately marked on the centrum by a narrow articular border, just back of the flat anterior face. This peculiar articulation leares more than three-fourths of the cup unoccupied by the succeeding rertebra, forming apparently a weak joint." In Antrodemus there is a well-developed ball at the cup preceding it, and a flattening of this ball is only to be observed in the transitional vertebrae at the base of the neck.

The third cervical, which may be considered typical of the anterior part of the series, is shown in all aspects in plate 20, figures 1 to 4 . It differs principally from the third of Antrodemus by the presence of a more decided ventral keel. The top of the neural spine is capped with an irregular shaped bony ossification evidently of dermal origin. 
Compared with Antrodemus, the neural spines of the cervical vertebrae are relatively longer, especially in the posterior half of the series, though they go through much the same change of fore and aft dimensions; that is, narrow to wide, becoming narrow again in the posterior members.

The sixth cervical shown in plate 20 , figure 5 , when compared with the corresponding vertebra of Antrodemus, shows striking differences in the structure of the neural arch, especially in the shape and downward development of the diapophyses, the articular extremity reaching nearly to the lower median border of the centrum, whereas in Antrodemus this end is but little below the level of the neuocentral suture. This feature has perhaps been somewhat exaggerated by crushing.

Though none of the cervical ribs are present in Ceratosaurus the closeness of the diapophysial and parapophysial facets indicates quite a different style of cervical rib than is found in Antrodemus. The anterior and posterior zygapophyses also occupy a lower position on the neural arch in relation to the centrum, especially

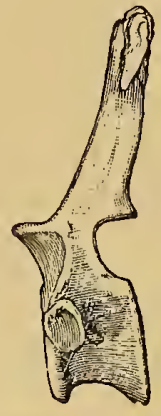

FIG. 56. TWELFTH PRESACRAL OK THIRD DORSAL VERTEBRA OR CERatosaUrus NaSiCORNIS Marsh. No. 4735 , U.S.N.M. TYPE. $\frac{1}{6}$ NAT. SIZE. VIEWED FROM LEFT SIDE. THIS DRAWING IS DEFICIENT IN SO MUCH AS THE TRANSVERSE PROCESS IS NOT INDICATED. (AFTER MARSH.)

$$
\text { bones have been lost duri }
$$
the former. There are well-developed spurlike processes extending upward and backward from the tops of the postzygapophyses of the cervicals, as in Antrodemus, but these are not shown in the illustrations of the cervicals on plate 20, which were prepared under the direction of Marsh. Since they were drawn from the left side, which is now hidden from view in the mounted skeleton, it is presumed they were missing from that side. The cervicals posterior to the sixth have suffered to such an extent, either by crushing or loss of parts, as to render them of little value for comparison or descriptive purposes.

Dorsal vertebrae.--In all of the thoracic region there are parts present of 12 dorsal vertebrae in the type specimen. All except the last of the series (dorsal 14 or presacral 23) have much of their processes missing, and a comparison of the outline drawing of the mounted skeleton (pl. 30) with the first skeletal restoration of this animal by Marsh (pl. 27 , upper figure), indicates that some portions of these bones have been lost during the considerable interval of time that has elapsed since Marsh's restoration was made. This observation applies particularly to the vertebrae of the anterior dorsal region.

While there is reason to believe the number of presacral vertebrae in Ceratosaurus to be 23, as in Antrodemus, Tyrannosaurus, and Gorgosaurus, the determination of this point must await the discovery of a more perfect specimen.

The dorsal centra, according to Marsh, have the articular ends moderately biconcave. The sides and lower surfaces are concave, but are not so deeply excavated as in Antrodemus, as may be seen by comparing the posterior dorsals shown in plate 30 , with text figures 25,26 , and 27 . The centra are relatively longer than in Antrodemus and none exhibit the expanded flangelike ends of that genus.

In the anterior dorsals the centra are short, the pleuropophyses is on the side of the centrum as shown in figure 56, and on the fourteenth presacral (fifth dorsal) 
it reaches its maximum height on the side of the arch-a position that is maintained throughout the rest of the series. This facet stands out prominently from the side of the arch on a pedestallike projection. The narrow spine of the third dorsal is succeeded by a slightly wider one on the fourth, and it in turn by a much wider platelike spine that apparently continues throughout the rest of the series. These vertebrae show the zygosphene articulation found in Antrodemus and in the Sauropodous dinosaurs.

Presacrals 21 and 22 both bear ribs, though the latter is within the anterior wings of the articulated ilia. Presacral 23, however, I am inclined to believe, did not have a rib, but was in contact with the ilium through its transverse processes. The broad, flattened neural spine extends well above the superior border of the ilium (see pl. 30) and.was, evidently firmly coossified with the succeeding spine of sacral 1. Measurements of the presacrals are given in the table below.

Measurements of presacral vertebrae of Ceratosaurus nasicornis Marsh. No. 4735, U.S.N.M.

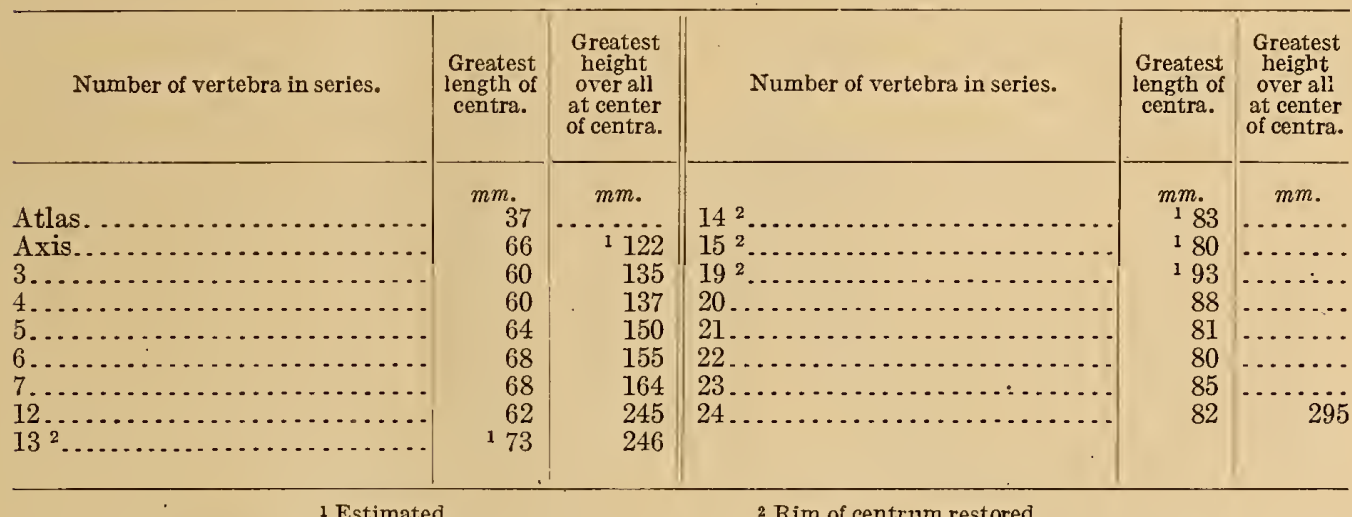

Sacral vertebrae.-The lateral view of the sacral vertebrae is almost entirely bidden by the attached ilia; only the tops of the coalesced spinous processes and the ventral portions of the centra show where they project above and below the ilium, as shown in plates 27 and 30 . The ventral aspect, however, is beautifully illustrated in figure 1 of plate 21-an unpublished drawing made many years ago under the direction of Professor Marsh.

There are five vertebrae in the complete sacral arcade. The centra of the sacrals are very much reduced in size and all are firmly coossified, not only with one another but with the ilia as well, the fusion being so complete as to almost obliterate the line of suture. This great reduction in size of the sacral centra and their close coalescence is one of the striking dissimilarities between Ceratosaurus and Antrodemus, as may be clearly seen by comparing figure 1, plate 21, with figure 2, plate 9 .

The transverse processes are short, all except those on $S_{5}$ being supported by two vertebrae. An examination of the specimen appears to indicate that their outer ends do not meet, and in this respect the drawing appears to be misleading. 
The pubic and ischiac peduncles of the attached ilia coincide with $S_{1}$ and $S_{3}$, respectively, as they do in Antrodemus, Tyrannosaurus, and Gorgosaurus.

Only the spinous processes of the two posterior sacrals are preserved intact (see pl. 30); but from the fact that they are fused throughout their length it is inferred that all were probably fuscd to form a continuous plate, the upper end of which extended somewhat above the superior borders of the ilia, and it has so been restored in the mounted skeleton. Whether this plate was perforated by fenestrations, as in Tyrannosaurus ${ }^{1}$ remains yet to be determined.

The greatest length of the coalesced sacral vertebrae is $380 \mathrm{~mm}$.

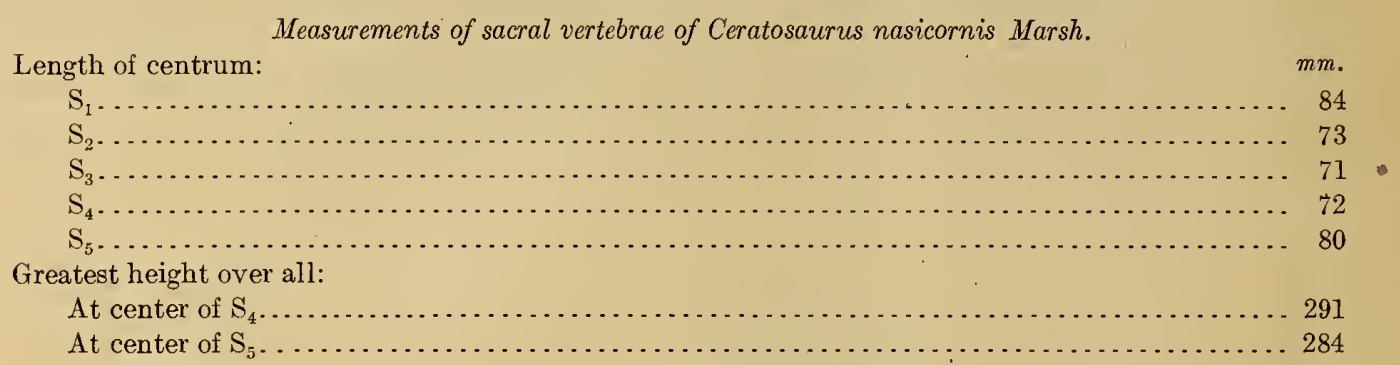

Caudal vertebrae.--There are 50 caudal vertebrae prescnt in the type specimen. In the mounted skeleton (see pl. 30) there are 51 vertebrae, the twenty-seventh being entirely restored. There is at least one vertebra missing from the distal end of the tail, and in all probability two or more, so that in the complete caudal series of Ceratosaurus there would be at least 53 vertebrae.

The first 16 antcrior caudal vertebrae were found articulatcd with the sacrum. The seventeenth to the twenty-sixth, inclusive, formed a second articulated series, and though no contact could be found connecting this series with the one anterior to it, the structure and relative size of these vertebrac was such as to indicate that none were lacking between. In the original quarry map the collcctor indicated two slightly displaced vertebrae between the second and third series. Only one of these (the twenty-eighth in the mounted skeleton) was located in the collections, and it was largely on this evidence that the restored vertebrae (the twentyseventh) was introduced to take the place of the missing one. The twentyninth to the fifty-first, inclusive, formcd the third and final series and are shown in the mounted skelcton (pl. 30), as found articulated.

The tail is more than one-half the total length of the animal, mcasuring 9 feet 6 inches along the vertebrae, whereas the anterior half is 8 fect 10 inches to the tip of the nose. It must have served as an efficient organ for maintaining the creature's balance during locomotion. Although all of the caudals have interlocking zygapophyses, even down to the extremely small ones ncar the tip, the tail was capable, I think, of considerable flexion, as is indicated by the original and apparently natural curves which are retained in the mounted skcleton.

The caudal vertebrae are slightly prococlous relatively slender and light in their construction, especially when compared with those of such forms as Antrodemus, Gorgosaurus, and Tyrannosaurus. The centra of the anterior vertebrae are 
longer than high, whereas in the upper Cretaceous genera mentioned above the anterior centra are as high as long.

In passing backward from the sacrum there is a gradual shortening of the centra, and they become more and more cylindrical in form, though all except the terminal ones have flattened sides. The vertebral centra are deeply concave on both sides and below, the anterior ones being shallowly grooved longitudinally on the ventral side as shown in figure 2, plate 22 .

The neural spines are unusually high, relatively narrow antero-posteriorly, with flattened sides and ending above in a slightly expanded rugose end. The expansion is not only slight in transverse diameter, but expands pronouncedly fore and aft. Proceeding posteriorly the shaft of the spinous processes narrows more rapidly than they shorten in length, thus making them tall and slender. Their point of origin also shifts from the middle. of the centrum to a point entirely above the posterior half. They rapidly decrease in height on the median part of the series, the last distinct spine being on the thirty-first caudal. On account of their crushed condition the spines posterior to the twenty-eighth do not show in the lateral view in plate 30 .

The transverse processes on caudal 1 are directed backward at an acute angle to the centrum, but do not unite with the ilia, as apparently indicated in figure 1, plate 21 . These processes on the succeeding vertebrae are long, broad, thin vertically, and terminated by straight ends without any especial expansion. On the second caudal they are directed backward at an angle of $45^{\circ}$, but they gradually assume a more direct outward position

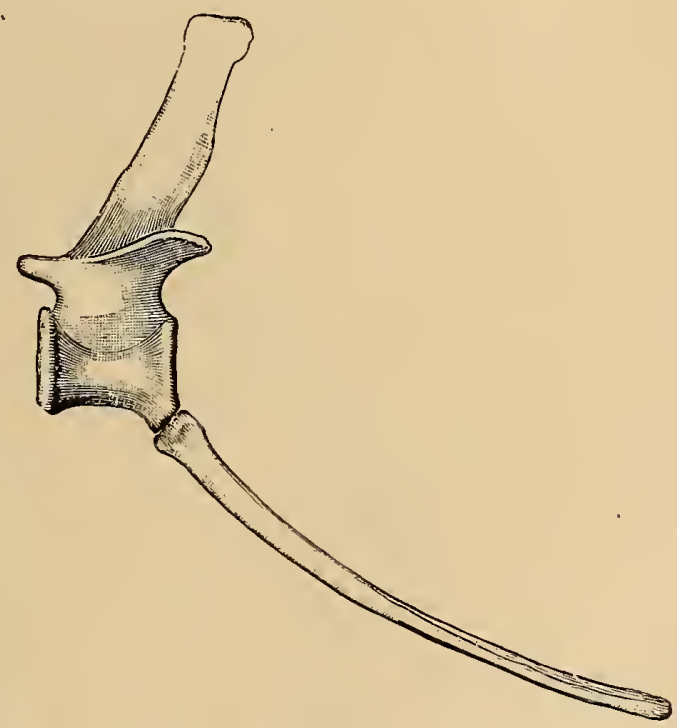

FIG. 57.-Fifth CAUdAl Vertebra aND CHEVRON OF CERATOSAURUS NASICORNIS MARSH. TYPE. NO. 4735, U.S.N.M. $\frac{1}{6}$ NAT. SIZE. VieWED FROM THE LEFT SIDE. (AFTER MARSh.) at the same time; diminishing in size, they end abruptly, the last one appearing as a thin pointed process on the thirty-third vertebra, whereas in Gorgosaurus libratus Lambe they end with the fourteenth caudal from the sacrum. In fact, I know of no other carnivorous, or, for that matter, herbivorous dinosaur, where the transverse processes persist so far back on the tail. On the anterior portion of the caudal series the transverse processes have their origin on the neural process, and above the neural canal, but passing backward they gradually shift their position downward, so that somewhere between the twenty-second and the twentysixth it has changed its position to the center of the side of the centrum.

The prezygapophyses are relatively short throughout the anterior two-thirds of the tail, but on the distal third they rapidly lengthen, extending well beyond the end of the centrum as two slender finger-like processes, which clasp between them 
the postzygapophyses of the preceding vertebra, as shown in the drawing of the skeleton (plate 30 ). The postzygapophyses slightly overhang the centrum in the distal caudal region. Most of the caudals have well-defined oblique chevron facets, as shown in figure 1, plate 22 . These become less and less well defined as the distal end of the tail is approached.

The tall neural spines and long slender chevrons of the anterior half of the series would indicate a high thin tail for this part, but it becomes more and more cylindrical toward the end. The whole apparently indicates, in life, a tail capable of great transverse flexibility for the proximal portion, with a more sinuous movement possible for the distal half.

Measurements of caudal vertebrae of Ceratosaurus nasicornis Marsh.

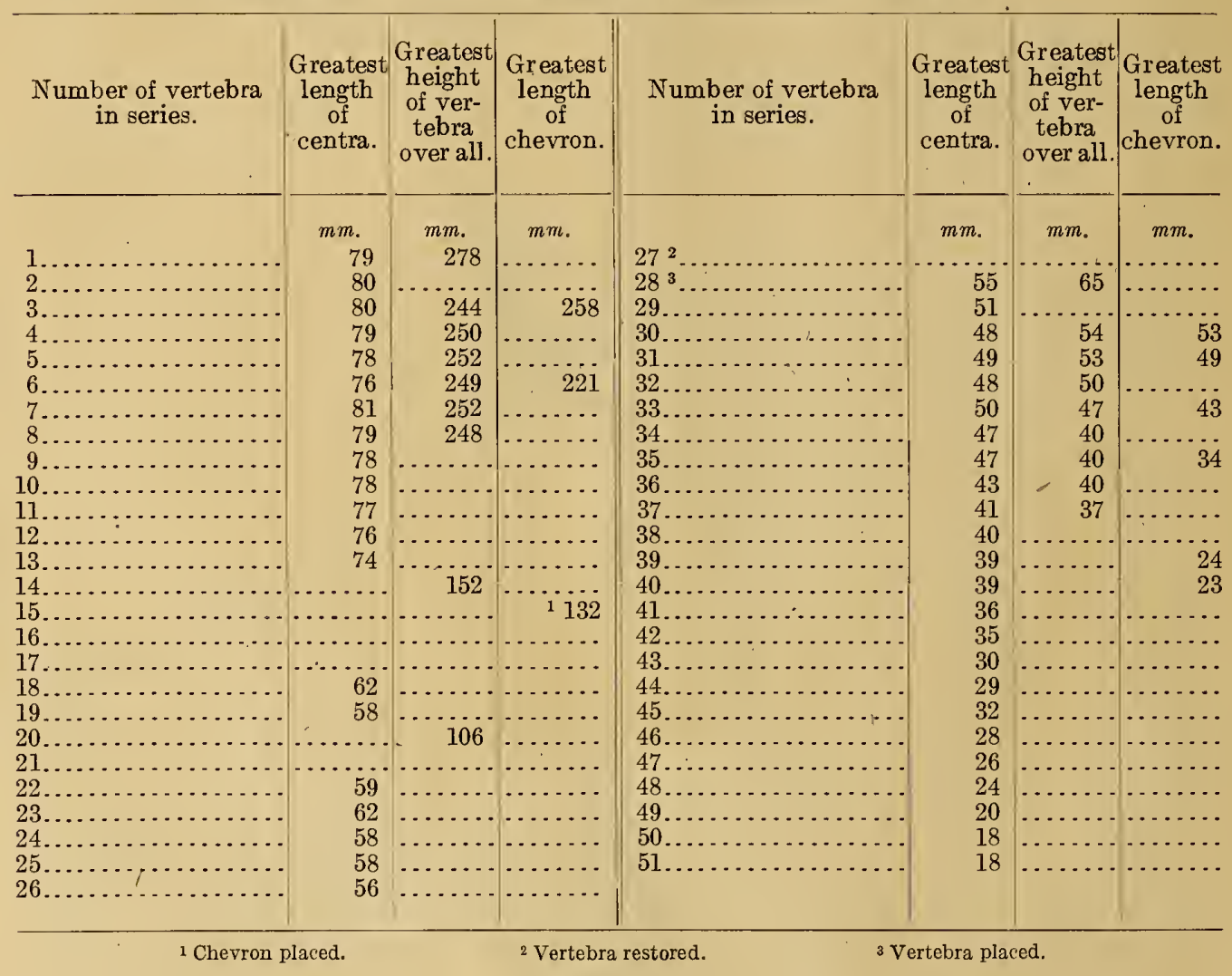

CHEVRONS.

The chevron bones present in the type are the second to the ninth, and the distal series of 12 from the twenty-ninth to the fortieth. All were found articulated excepting the fifteenth, which was placed as shown in plate 30 . It was found detached, but in a block of sandstone containing other bones of the skeleton, and on the basis of this association was considered as belonging to the type. The anterior chevrons have suffered loss of parts since the drawing was made for Marsh, as may be seen at once by comparing figure 1, plate 22, with upper figure, plate 27. 
The anterior chevrons of Ceratosaurus are especially long, slender, and with but slight backward curve. They articulate intervertebrally with beveled articular facets on the ends of the? They begin between the first and second vertebrae and continue to the forty-first caudal. The second, the longest one of the series, measures $254 \mathrm{~mm}$. in length. The haemal opening between the branches forming the $\mathrm{Y}$-shaped proximal ends are very much constricted transversely. The proximal end is very slightly expanded, but it forms a bridge across the upper boundary of the haemal opening. These chevron bones of Ceratosaurus can be readily distinguished from the homologous elements of other American Theropodous dinosaurs by their greater relative length and slenderness, and by the very slight expansion of their proximal and distal ends.

The distal series are short, with expanded free ends that curve decidedly backward. Chevrons 29 to 34 , viewed from the side, show a spur-like prolongation that extends well upward between the two centra. In a lesser degree the anterior chevrons of Tyrannosaurus ${ }^{1}$ have a somewhat similar development, as they do also in Gorgosaurus libratus Lambe. ${ }^{2}$

RIBS.

Thoracic ribs.-The thoracic ribs of Ceratosaurus are unknown at this time, except the

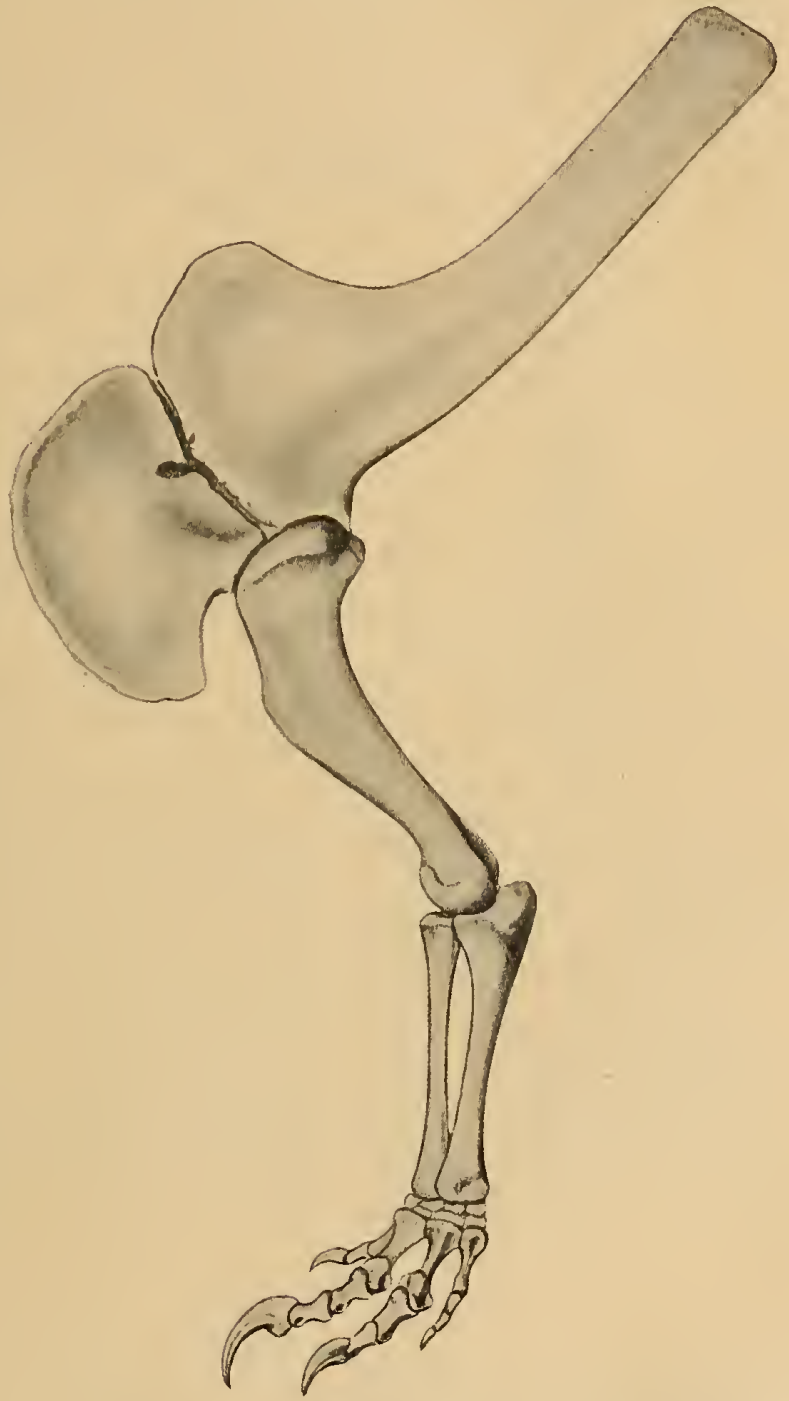

Frg. 58.-Left Fore LIMB AND FOOT OF CERATOSA UR US NASICORNIS MARSH. CAT. No. 4735, U.S.N.M. TYPE. ABOUT $\frac{1}{8}$ NAT.- SIZE. VIEWED FROM THE FRONT. GREATER PART OF THE CORACOID, DISTAL END OF SCAPULA, HUMERUS, CARPUS, AND TERMINAL PHALANGES OF CERATOSAURUS UNKNOWN. THESE ARE RESTORED HERE FROM ALLIED FORMS. This figure was fIRST PUBLISHEd bX MARSH AS THE FORE LIMb OF Allosaurus fragilas. (AFter Marsh.)

right articulating with presacral No. 21, shown as found in position in plate 21, figures 1 and 2.

1 Osborn, H. F. Bull. Amer. Mus. Nat. Hist., vol. 35, 1917, pl. 27.

2 Lambe, L.M. Mem .100 Geol. Surv. Canada, 1917, fig. 49. 
In the mounted skeleton they have been restored, but have been made much too heavy, especially their distal portions, which are probably attenuated as found in Antrodemus.

Abdominal ribs.-That a cuirass of abdominal ribs was present in the complete Ceratosaurus skeleton is indicated by a few fragmentary rod-like pieces of bone found preserved in a block of sandstone which accompanied the other parts of the type specimen. The determination of the character of these ribs must await the discovery of more complete materials.

SHOULDER GIRDLE.

Plates 26 and 30.

The incomplete left scapula and the fragmentary proximal border of the coossified coracoid is all that is known of the pectoral girdle in Ceratosaurus nasicornis at this time. These bones have suffered considerable crushing, so that a true concept of their original shape and proportions is somewhat difficult of determination. No traces of the sternal elements have been found.

Elsewhere I have pointed out that this scapula formed the basis for the drawing of the shoulder blade in the so-called fore limb of Allosaurus fragitis as published by Marsh (see fig. 58). The coracoid illustrated in the same fore limb was made from a drawing in Phillips Geology, reduced to the proper proportions, as explained on page 56 of the present paper.

Scapula.-The scapula as now preserved (fig. 1, pl. 26) is lacking the distal extremity, so that it is not positively known whether the blade was nonexpanded, as represented by Marsh, or whether it was expanded as in Antrodemus valens. I am inclined to the opinion that it was expanded somewhat, as shown in the mounted skeleton, plate 30 , though as represented there the scapula is probably too short.

The shaft is relatively thin with a sharp upper and thickened lower border. The part of the shaft preserved is quite uniform in width, and although pertaining to a considerably smaller individual than the scapula of Antrodemus valens Leidy, No. 4734, U.S.N.M., with which I have compared it, the shaft is very much wider, as shown in the comparative measurements given below.

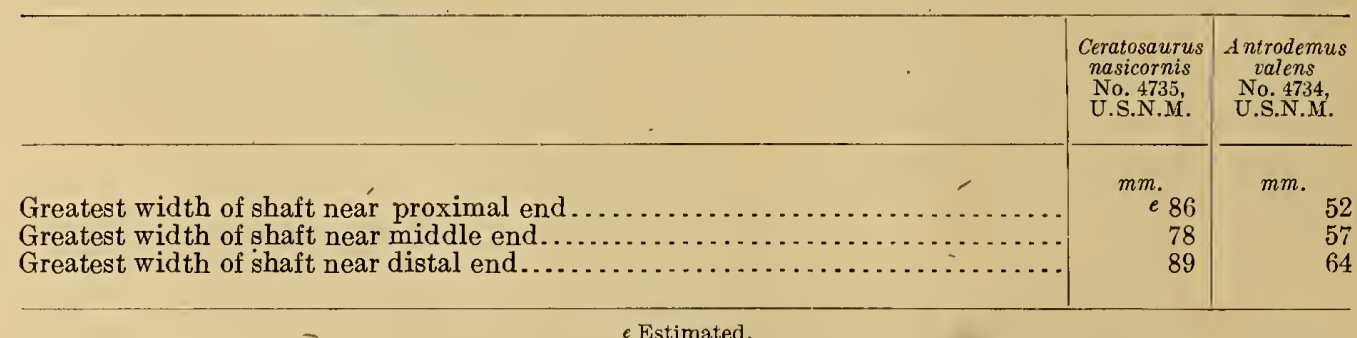

Longitudinally the scapula is concave on its inner aspect, though doubtless much straightened by crushing. The expanded proximal end, though poorly preserved, shows this extremity to be much wider (vertically) than the corresponding part of the Antrodemus scapula. The thickened ventral border above the glenoid fossa turns downward with a more decided sweep than it does in the latter genus. 
FORE LIMB AND FOOT.

The fore linb of Cerutosaurus is relatively of snall size, with a very short foot as compared with the greatly lengthened hand in Antrodemus. There were four digits in the manus, of which the two median ones are the more robust. The phalangial formula is unknown, though it has been restored (largely following Marsh) on the mounted skeleton (pl. 30), as 2, 3, 3 1. From the evidence of known Theropod fore feet it would appear more in accord if given 2, 3, 4, 2 or 3 . The humerus and ossified carpus of Ceratosaurus are unknown.

Ulna (u.).- The ulna and radius were found in place as shown in figure 60 , nearly in articulated position as related to one another and also in reference to the accompanying metacarpals.

The ulna lacks a considerable section of the shaft but the total length nay he considered correctly determined since the proximal and distal ends were found retained in rock.

The proxinial end is widely expanderl and roughly triangular in cross section. The anterior face is hollowed out for the close approximation of the head of the radius. There is a prominent olecranon process (fig. 59), which increases the length of the bone posteriorly. It is also robust and shorter than in Antrodemus. The distal end is only slightly expanded, the articulating surface being convex, while the whole end lacks the great obliquity of the Antrodemus ulna.

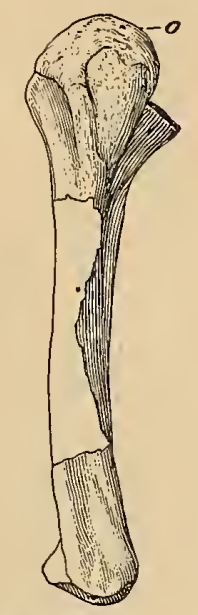

Fig. 59.-Left UlNa of CeraTOSAURUS NASICORNIS MARSH. TYPE-NO. 4735, U.S.N.M. $\frac{1}{3}$ NAT. SIZE. VIEWED FROM THE BACK. O, OLECRANON.

Comparative measurements of ulnae of Ceratosaumes and Antrodemus.

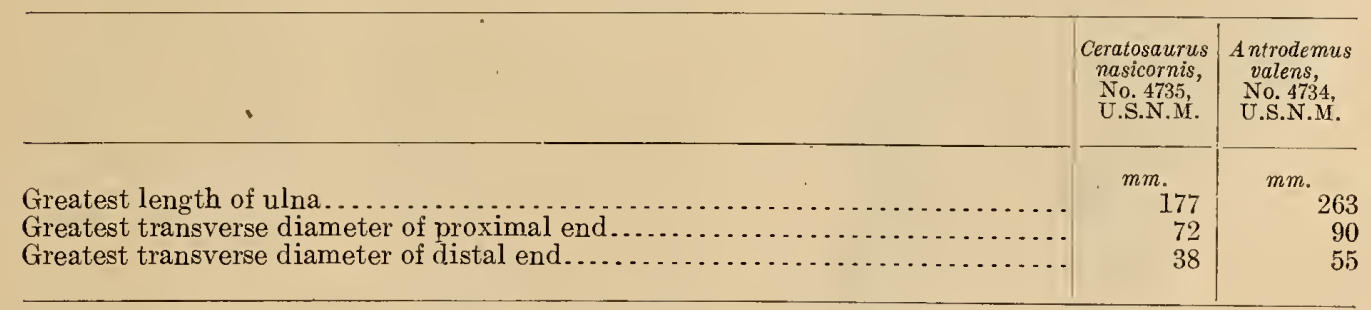

Radius (r.).--The shaft of the radius of Ceratosaurus has been so flattened by crushing that its transverse diameters are greatly exaggerated. The proximal end is elongated transversely (fig. 61), the articular surface shallowly concave in the same direction. The less expanded distal end is subcircular in outline and shallowly cupped. On the ulna side of this end is a flattened area that in life was probably closely opposed by the ulna. The distal end in relation to the longer axis of the bone is squarely truncated, there being no indication of the obliquity found in the radius of Antrodemus.

The radius of Antrodemus is neariy half again as long as that of Ceratosaurus, the proportion being as $1:: 1.48$, but the relative proportions of length of radius to length of ulna is exactly the same in both genera. 


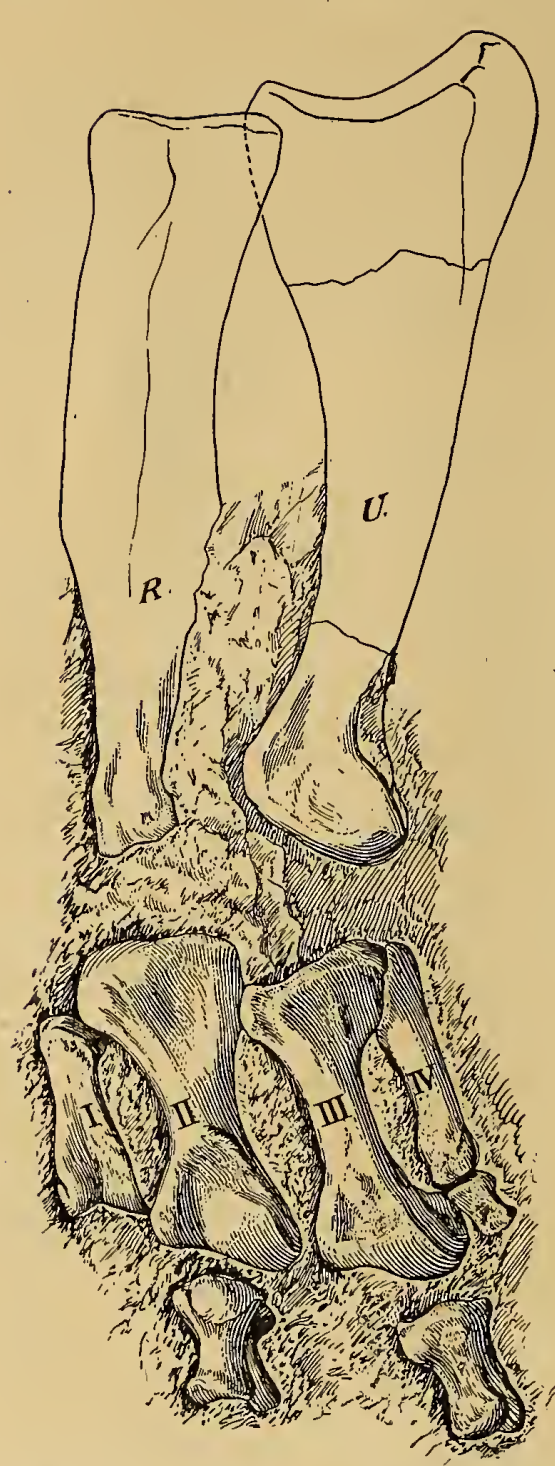

Fig. 60.-LEFT RADIUS, ULNA AND FORE FOOT OF CERATOSAURUS NASICORNIS MARSH. No. 4735, U.S.N.M. TYPE- $\frac{1}{2}$ NAT. SIZE. $R$, RADIUS; $U$, ULNA, I, II, III, and IV, METACARPALS ONE TO FoUR. SHOWN AS FOUND IN THE MATRIX, SEVERAL OF THE BONES NOT ENTIRELY UNCOVERED.$$
\text { tale }
$$
tal end is deeply grooved and turns inward away from the central axis of the foot as in most other Theropod dinosaurs. This diversion is due to the unequal development of the articulating facets, the outer one being the larger and extending farther forward, as in Gorgosaurus. It is unlike Antrodemus in this respect, where a bend in the shaft diverts it inward. Both facets on this end curve down and fore foot of Ceratosaurus is as yet unknown, though the articulated left inanus gives a fairly good idea of its structure. The phalangial formula, however, remains to be definitely determined. With the type the following bones of the fore feet are preserved: Metacarpals I, II, III, IV, and proximal phalanges of digits 2, 3, and 4 of the left nianus; metacarpals IV, distal halves of metacarpals I and II, and proximal phalanx of digit 2 of the right foot.

Carpus.-Ossified carpal bones are unknown in Ceratosaurus, and although the articulated foot mentioned above was found in position in relation to the distal ends of the radius and ulna (fig. 60), no carpal ossifications were found in the intervening matrix. This would appear to indicate an unossified carpus, for this specimen is an old individual, as clearly demonstrated by the coossified pelvic and metatarsal bones.

Metacarpus.-The metacarpus consists of four bones, as shown by the foot found in place as depicted in figure 60 . The two median metacarpals are moderately robust elements, but I and IV are much reduced.

Metacarpal I is a short bone with slightly expanded proximal and distal ends. The dis- 
back on the lower surface of the bone. It articulates as shown in figure 62 , with metacarpal II, with a flattened facet on the internal side of the proximal end. Metacarpal II, the most robust element in the foot of Ceratosaurus, has widely expanded ends, with a somewhat slender, rounded shaft. 'The distal end, viewed from the front, looks downward and slightïy outward, and is shallowly grooved. On the front near the distal articular end there is a prominent depression or pit, in which a posterior median projection of the proximal phalanx appears to rest when the foot is strongly flexed. The upper articular end is squarely truncated with a slightly rugose articular surface. Except for being relatively shorter this bone resembles the second netacarpal of Antrodemus. Metacarpal III is the longest element of the metacarpus. The proximal end is widely expanded, and triangular in outline when viewed from the end. The distal end is quadrangular in outline, grooved but rather shallowly so, with a pit on the FIG.61.-LEFT RADIUS OF CERATOanterior face near the distal extremity as in metacarpal II. SAURUS NASICORNTS MARSH. The distal articular end as in metacarpal II is slightly oblique to the longer axis of the bone, and looks in

The whole end is rounded antero-posteriorly much as in metacarpal II. Metacarpal IV is the smallest elenient of the metacarpus, and apparently is fast becom-

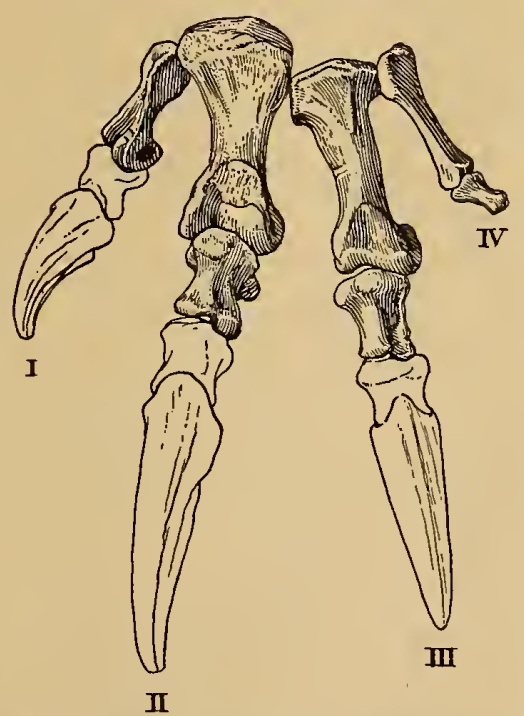

Fig. 62.-Left fore foot of Ceratosaurus NASICORNIS MARSH. No. 4735, U.S.N.M. TYPE. $\frac{1}{3}$ NAT. SIZE. FRONT VIEW, I, II, III, AND IV, DIGITS ONE TO FOUR. SHOWN AS RESTORED ON MOUNTED SKELETON. ing functionless. It has a weak articulation with metacarpal III on the posterior external side of the proximal end. The proximal end is considerably expanded antero-posteriorly, but little so transversely. On the inner side the bone is hollowed out for articulation with metacarpal II. The distal end is little expanded, presenting a rounded articular end without grooving.

Metacarpals II and III form the main support of the foot.

Phalanges.-In the left fore foot the proximal phalanges of digits II, III, and IV were found in place, so that their position in the manus niay be considered absolutely. determined.

The fore foot of Ceratcaurus also differs from other known "Theropods in having the proximal phalanges of digits two and three of about equal length. Proxinal phalanx of digit II is exceptionally short and stout. The proximal end is especially expanded antero-posteriorly, the expansion being largely on the palmar side, so that its diameter $(29 \mathrm{mn}$.) is equal to the length of the bone. This end is keeled to fit the groove of the netacarpal. The distal end is grooved, dividing the end unequally, the outer articulating facet or condyle 
extending, farther forward than the inncr which is broadest transversely. The dorsorentral expansion of this end is only one-half that of the proximal end.

The proximal phalanx of digit III closely resenbles the one described above, except that the dorsoventral expansion of the proxinial end is much less, measuring only $20 \mathrm{~mm}$. The distal end is also narrower transversely, though it has the same unequal development of the articular facets. These would appear to indicate a turning in toward the body of the extremities of the three first digits of the hand, instead of extending straightforward, as shown in figure 62 .

The proximal phalanx of digit IV has a slightly expanded proximal end that articulates with a cupped end with metacarpal IV. The distal end is nonexpanded, presenting a truncated end that may support a terminal phalanx, but probably nothing more than a pointed bony ossicle. I doubt the presence of three phalanges on this digit as restored by Marsh (fig. 58).

Measurements of the left fore foot elements of Ceratosaurus nasicornis Marsh. No. 4735, U.S.N.M.

METACARPALS.

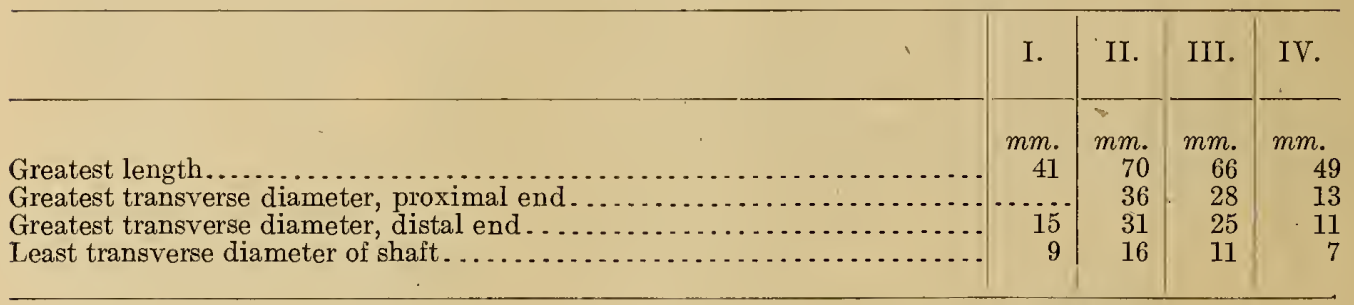

PHALANGES-FIRST ROW.

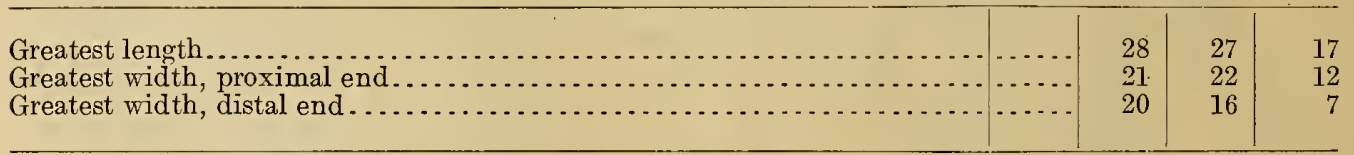

PELVIS.

Plates 21 and 23.

The pelvis of Ceratosaurus nasicornis Marsh, is one of the most perfectly preserved among the Theropoda. The ilia, ischia, and pubes are firmly coossified, so that their relative positions have never been called into question. The ilia were securely attached to the sacrum, which was found in its natural place in the skeleton. The extremely small size of the pelvic orifice is one of the marked features of the carnivorous group as contrasted with the large opening in the herbivorous dinosaurs found with them. If the Theropoda were viviparous, as some facts seem to indicate, one difficulty naturally suggested in the case of a reptile is removed.

The coossification of these pelvic bones does not appear important as a diagnostic character; far more probablc that it represents an individual characteristic due to advanced age, such as is occasionally found in the Sauropoda; as, for example, a specimen of Diplodocus in the Carnegie Museun, Pittsburgh, has the pubes coossified with the pubic peduncle of the ilium. 
Ilium (il.)-The ilium of Ceratosuurus, though of nearly the length of the much larger Antrodemus ilium, is nearly a third narrower dorso-ventrally above the acetabulum. It differs also in having a much narrower preacetabular notch. The exact contours of the anterior and posterior ends of the ilium are unknown at this time, both having been restored by Marsh as shown in figure 63. I am of the opinion that the anterior end, instead of being rounded from above downward, had a straight truncated outline following the lines of the Antroderrus ilium shown in figure 2, plate 10.

Both ilia are present and firmly attached to the sacrum, the right element being the more complete. The bone as a whole has an inclination inward in its upper part, this inclination being most pronounced posterior to the acetabulum. The tops of the ilia do not rest against the spinous processes of the sacrum, as in Ornithomimus along the center, but more closely resemble Tyrannosaurus, in being parallel to but removed from them by 50 to $60 \mathrm{~mm}$. of space, though flaring outward both front and back, and thus rendering a considerable area of the bone concave from front to back. The superior border when viewed from the side (pl. 30) is considerably below the tops of all the sacral spines, whereas in Antrodemus, Ornitholestes, Gorgosaurus, and Ornithomimus only the posterior sacral processes project above. The postacetabular portion is strengthened on the inside by a strong, inwardly turned flange, running obliquely upward and backward from the ischiac peduncle, which articulates with the posterior sacral vertebrae as shown in figure 1, plate 21.

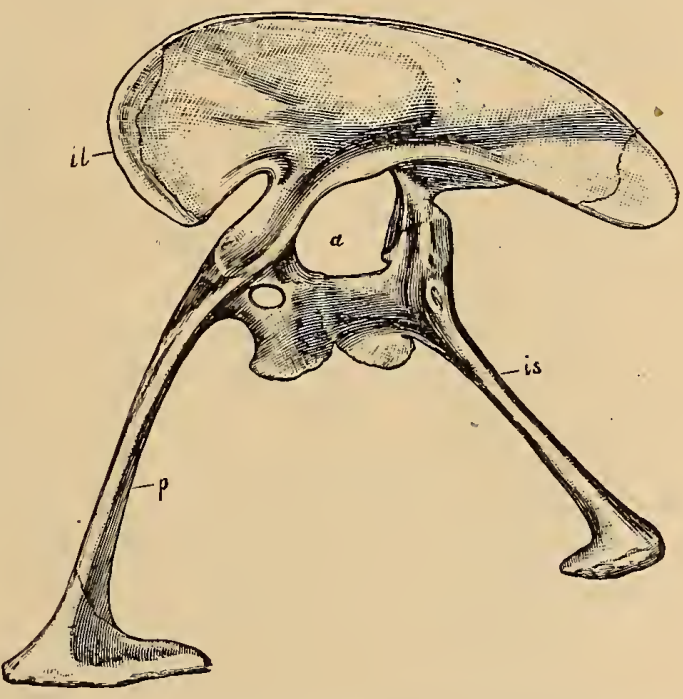

Fig. 63.-Pelvis of Ceratosautu nasicornis Marsh. Type. NO. 4735 , U.S.N.M. $\frac{1}{8}$ NAT. SIZE. VIEWED FROM THE LEFT SIDE. a, ACETABULUM; $i l$, ILIUM; is, ISCHIUM; $p$, PUBIS. (AFTER MARSH.)

The iliac surface of the acetabulum is especially wide transversely, the outward part being a thin shelf-like extension that comes to a sharp projecting edge.

Measurements of the right ilium of Ceratosaurus nasicornis Marsh.

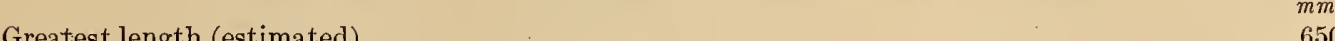

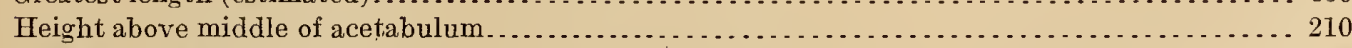

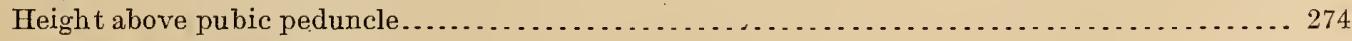

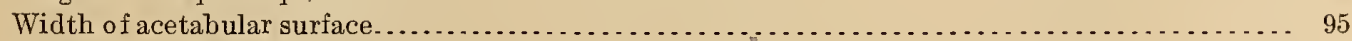

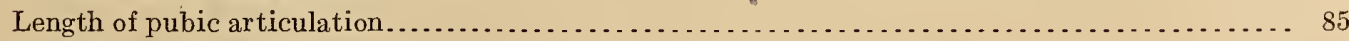

Width of ischiac articulation........... 45

Pubis (p.).-The pubes in Ceratosaurus are distinguished from those of all other known Morrison and Upper Cretaceous Theropod dinosaurs by the presence of an inclosed obturator foramen, such as is found in the Sauropodous dinosaurs and in some of the Triassic Theropoda. The plate-like expansion of the ischial process of 
the pubes is also unusual, as is the inward curvature of these processes where they are in contact on the median line, as shown in figure 2, plate 21.

- Seen from the front the cojoined pubes form a $V$-shaped orifice instead of the Y-shaped opening of most other carnivorous forms. The union of the shafts of the pubes may have extended more proximally than is shown in figure 2, plate 21 , for the damaged condition of this portion of these bones makes the exact condition somewhat uncertain.

There appears to be no median aperture between these bones above the distal triangular foot-like extremity as found in Antrodemus, but again crushing has somewhat obscured the precise condition.

The distal extremity is missing, but in the restored skeleton has been modeled after Antrodemus. Whether this portion of these bones was present when the drawing of the pelvis (see fig. 63, also pl. 23) was made under Professor Marsh's direction is not known.

Measurements of pubis of Ceratosaurus nasicornis Marsh.

Greaco $m$.

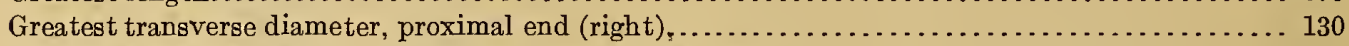

Greatest transverse diameter at center of combined shafts............................. 120

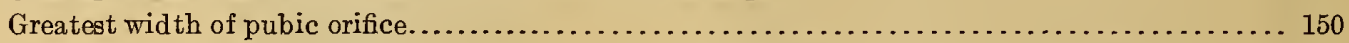

Ischium (is.).-The ischia of Ceratosaurus are comparatively slender, project downward, and well backward in the articulated pelvis. The distal three-fourths of their length are in close apposition and firmly coossified. There is no distinct obturator process present, as in Antrodemus. The pubic process of the ischium is much wider dorsoventrally than the corresponding process in Antrodemus. The ventral part of this process, like the ischiac process of the pubes, turns inward and meets its fellow on the median line, thus completing the boundary of the posterior part of the U-shaped pelvic orifice.

The distal ends of the ischia are missing, and as with the pubes one can not be certain that Marsh had them when drawings for figure 63 and plate 23 were prepared. The bone, however, does show that there was an abrupt forward expansion of the enlarged distal end but as to its extent or shape there is no clue in the type specimen.

Measurements of ischium of Ceratosaurus nasicornis Marsh.

Greatest length of ischia, from middle of acetabular border to distal end, estimated.......... 505

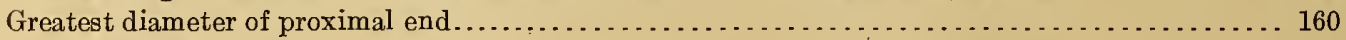

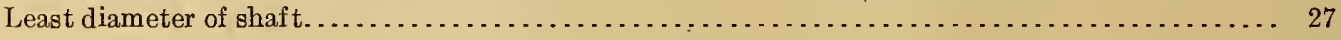

HIND LIMB AND FOOT.

Femur.-The femur of Ceratosaurus is so like that of Antrodemus as to be almost indistinguishable. It is longer than the tibia, has the same curvature of the shaft, and practically the same position of the trochanters and roughened areas for muscular attachment. Crushing has somewhat altered certain portions of the bone, so that in comparing it certain differences observed disappear when this factor is taken into consideration. Its smaller size relatively smaller fourth trochanter and shorter lesser trochanter constitute the chief features for distinguishing it from the femur of Antrodemus. 
The head is set almost at right angles to the shaft, with a slight inclination upward and forward. There is but slight indication of a neck, as the proximal
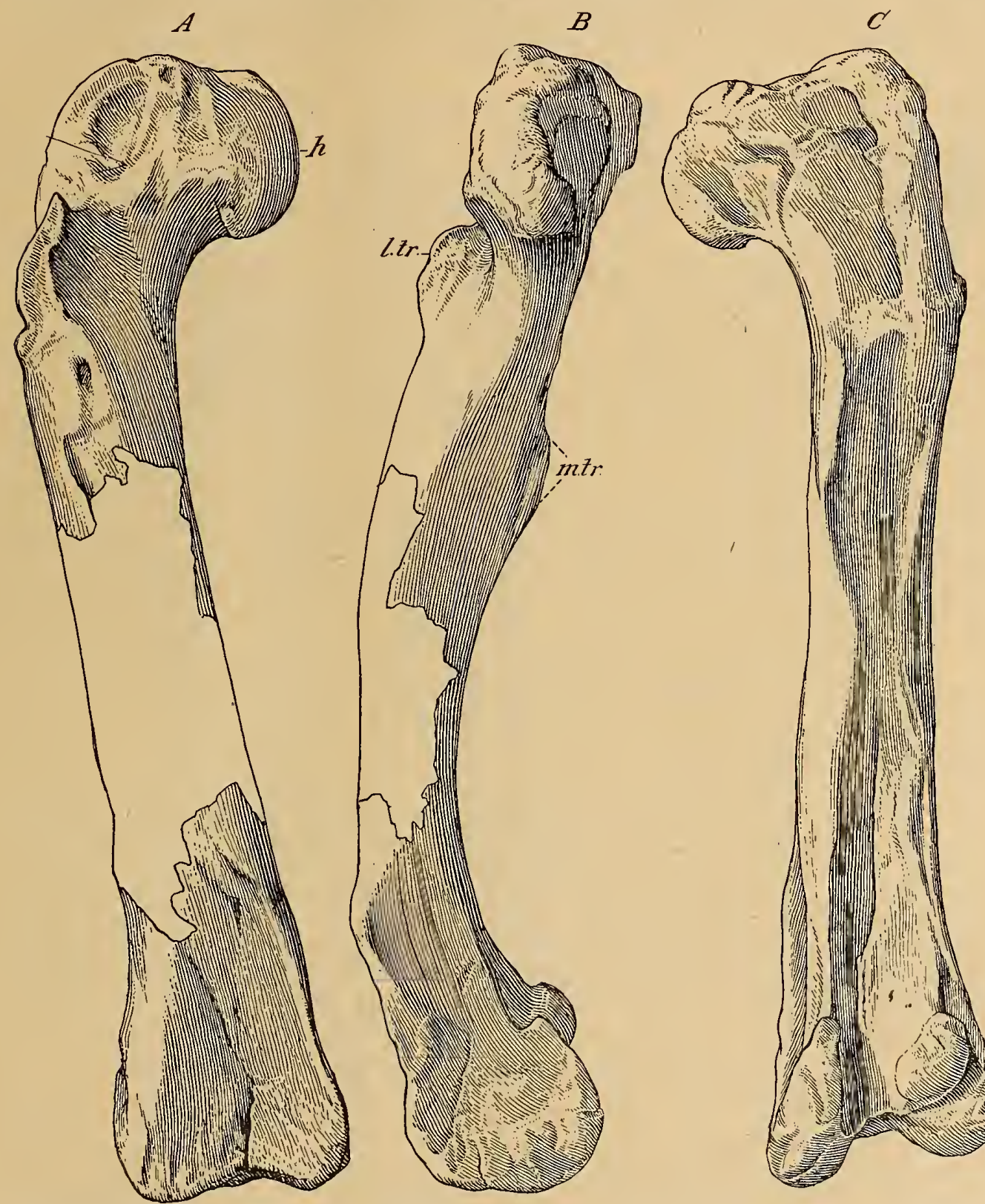

Fig. 64. $\rightarrow$ Right Femur of Ceratosaurus nasicornis Marsh, CAt, No. 4735, U.S.N.M. Type. 1 Nat, size" $A$, anterior ASPECT; $B$, INTERNAL ASPECT; $C$, POSTERIOR ASPECT; $h$, HEAD; $l . t r$, LESSER TROCHANTER; m.tr, INNER OR FOURTH TROCHANTER.

surface of the head runs into the great trochanter without appreciable constriction. The lesser trochanter does not extend so high proximally as in Antrodemus, but as in 
that genus it is separated from the greater trochanter by a wide diagonal interoexternal groove. The inner or fourth trochanter is shorter in its longitudinal length and occurs slightly higher proximally on the shaft than in Antrodemus. The principal features of this bone are well shown in figure 64 , where it is illustrated in three aspects.

Measurements of femur of Ceratosaurus nasicornis Marsh. No. 4735, U.S.N.M.

mm.

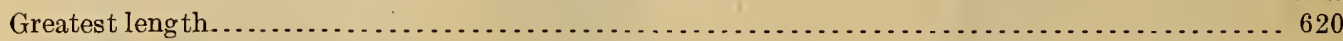

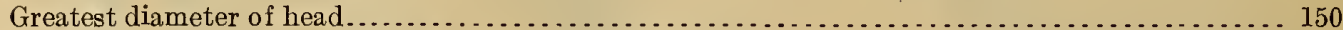

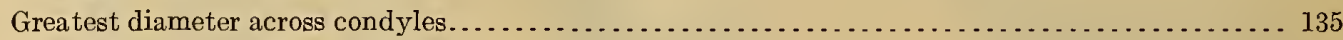

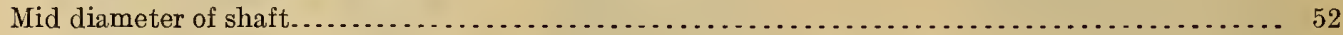

Tibia $(t$.$) .- The right tibia, and fibula of Ceratosaurus, articulated with the$ astragalus and calcaneum, all completely preserved, are shown in figure 65.

As in Antrodemus the tibia is shorter than the femur and with quite similar contours and similar attachments. The greatest observable difference between these two bones is in the greatly reduced size of the cnemial process in the Ceratosaurus tibia and its relatively narrower shaft when viewed from the front. Compare figure $65 \mathrm{~A}$ with $48 \mathrm{~A}$.

The anteriorly directed process on the proximal end is also longer and extends more directly forward than in Antrodemus, though the latter peculiarity may be partly due to crushing to which this part of the bone has been subjected. The area covered by the ascending process of the astragalus is also restricted as compared with Antrodemus.

The principal features of this bone are well shown in three aspects in figure 65 . Measurements of tibia, Ceratosaurus nasicornis Marsh. No. 4735, U.S.N.M.

Greatest length ................... 555

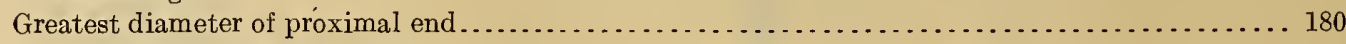

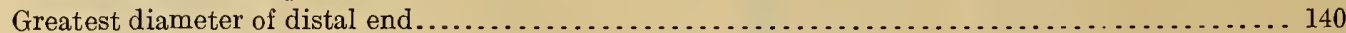

Fibula $(f$.$) .-Like the tibia, the fibula of Ceratosaurus bears a close resemblance$ to that of Antrodemus. The greatest dissimilarity is found in the form of the proximal end. When viewed from the side-compare $B$, figure 65 and $B$, figure 48 -it will be seen in Ceratosaurus the fore and aft expansion of this end begins much lower down on the shaft, whereas in Antrodemus there is no widening until close to the upper articular end. This end is subcresentic in outline. The distal end when viewed from the side is squarely truncated as compared with the evenly rounded end in Antrodemus.

Measurements of fibula of Ceratosaurus nasicornis Marsh. No. 4735, U.S.N.M.

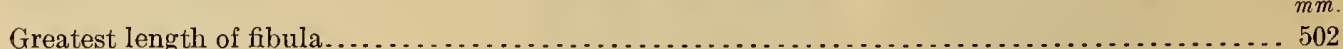

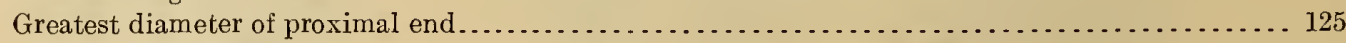

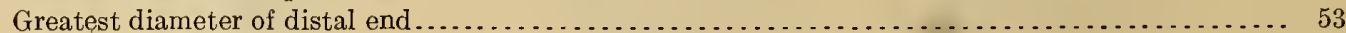

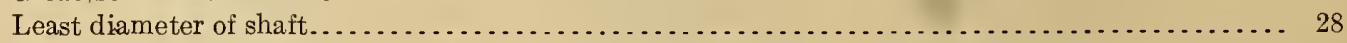

Tarsus.-The tarsus of Ceratosaurus so far as known at this time consists of three bony elements; the astragalus and calcaneum forming a proximal row, and a single disk-like tarsale found attached by matrix to the proximal end of metatarsal III. There was probably a second tarsale above metatarsal IV, as in Antrodemus, these two forming the distal row of the tarsus. 
Astragalus and calcaneum (as. and ca.).-The right astragalus and calcaneum, firmly fused with one another and closely adjoined with the distal ends of the tibia and fibula, were found as shown in figure 65 . These bones have been carefully
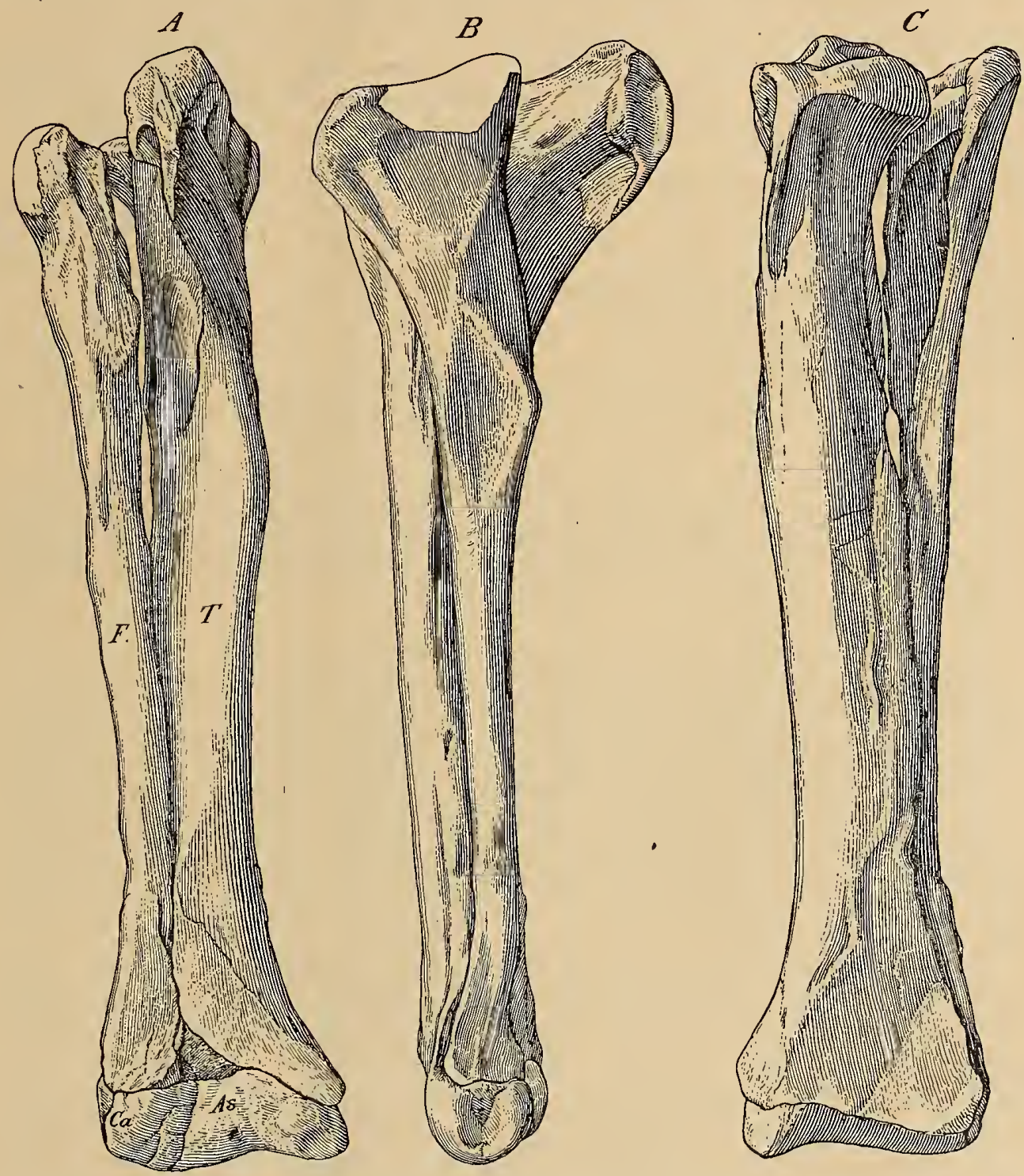

Fig.65.-Right tibia, fibula, astragalus, and Calcaneum of Ceratosaurus nastcornis Marsh. No. 4735, U.S.N.M . $\frac{7}{6}$ Nat. Size. $A$, Front; $B$, oUter; $C$, BaCK views; $A s$, astragalus; $C a$, calcaneum; $F$, fibula; $T$, tibia.

compared with the homologous elements of Antrodemus, and I fail to find any very distinctive differences, except their smaller size. The astragalus has a prominent ascending process, which appears to be of about the same relative proportions as in Antrodemus, except that the ascending process is shorter. 
Viewed from in front the superior border internal to the ascending process extends downward the ventral until it reaches the inner margin, whereas in Antrodemus this border extends inward about parallel with the ventral border. Were the astragalus of Ceratosaurus detached, other differences might be observed.

The calcaneum is so completely fused with the astragalus that the line of union is quite obliterated. This bone appears to be wider than high, with a concave proximal surface for articulation with the fibula, with which it is also closely articulated. The outer surface is deeply concave.

Measurements of the combined astragalus and calcaneum. Ceratosaurus nasicornis Marsh. No. 4735, U.S.N.M.

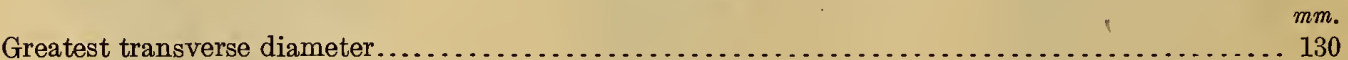

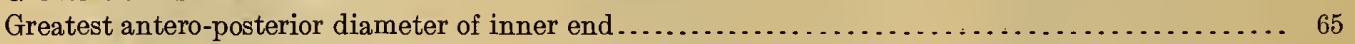

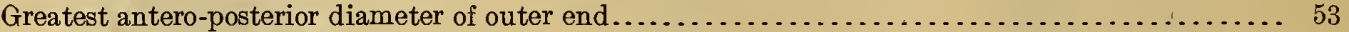

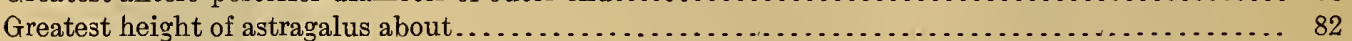

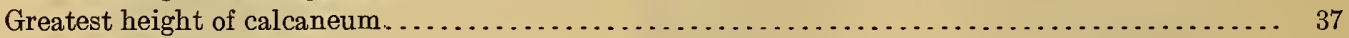

Metatarsals. - The metatarsals of Ceratosaurus nasicornis are described $^{1}$ by Marsh as follows:

The most interesting feature in the extremities of this dinosaur is seen in the metatarsal bones, which are completely ankylosed, as were the bones of the pelvis. There are only three metatarsal elements in each foot, the first and fifth having apparently disappeared entirely. The three metatarsals remaining, which are the second, third and fourth, are proportionally shorter and more robust than in the other known members of the order Theropoda, and, being firmly united to each other, they furnish the basis for a very strong hind foot.

In figure [1, pl. 24], these coossified metatarsals of Ceratosaurus are represented, and for comparison the corresponding bone of a penguin is given in figure 0 . In comparing these two figures it will be seen that the three metatarsal elements of the dinosaur are quite as closely united as those of the bird. To the anatomist familiar with the tarso-metatarsal bones of existing birds, the specimen represented in figure 1 [pl. 24] will appear even more like this part in the typical birds than the one shown in figure 2 .

The position of the foramen, as seen in figure 1 [pl. 24], is especially characteristic of recent birds, and, as a whole, the hind foot of this Jurassic dinosaur was evidently similar to that of a typical bird.

All known birds, living and extinct, with possibly the single exception of Archaeopteryx have the tarsal bones firmly united, while all the Dinosauria, except Ceratosaurus, have these bones separate. The exception in each case brings the two classes near together at this point, and their close affinity has now been clearly demonstrated.

It has been suggested ${ }^{2}$ that the uniting of the metatarsals in Ceratosaurus was due to a pathologic condition, but since there appears to be but little evidence of exostosial growth on the bones I am inclined to believe it to be a normal but rather unusual condition. That there is a tendency toward the fusion of the metatarsal bones in some of the carnivorous dinosaurs is shown in several known specimens, especially those of Tyrannosaurus, as pointed out by Osborn..$^{3}$ He says they exhibited a "less mobile arrangement of the metatarsals, because they show sutural attachments but not actual coalescence in the middle portion of the shaft."

An exceedingly aged individual would probably show coalescence, as they do in Ceratosaurus. Marsh considered the first digit as having entirely disappeared, but a roughened area on the posterior side of the shaft of metatarsal II (I, fig. 1, pl. 25) apparently indicates the point of attachment of the retroverted digit as has been 
found in Antrodemus; ${ }^{1}$ and in the mounted skeleton this digit has been restored as shown in plate 30 . The metatarsals are so fully illustrated in all aspects in plates 24 and 25 that a detailed description appears unnecessary.

Measurements of metatarsals of Ceratosaurus nasicornis Marsh. Cat. No. 473.5, U.S.N.M.

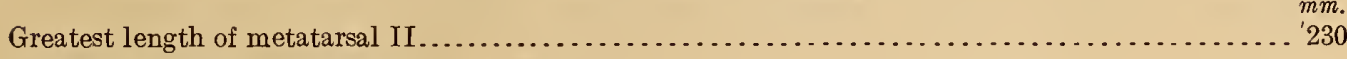

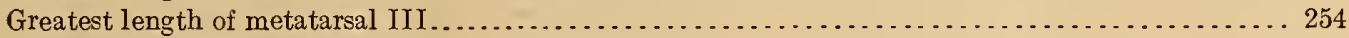

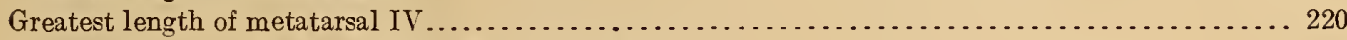

Greatest width of coalesced metatarsal, proximal ends................................. 120

Greatest width of coalesced metatarsal, distal ends................................. 146

The metatarsals of Ceratosaurus are nearly a third shorter than the corresponding elements of a fully adult Antrodemus specimen, though the relative lengths of of the metatarsals to one another in the respective feet are very similar.

The most pronounced differences observed are found in comparing the proximal ends to the metatarsals of these two genera. This end of metatarsal III in Antrodemus is elongated anteroposteriorly, wide in front, and rapidly narrowing posteriorly, whereas in Ceratosaurus it is wider behind than in front. Viewed from above metatarsal III of ${ }^{*}$ Ceratosaurus is subrectangular in outline as compared with the elongated triangular end of the Antrodemus metatarsal. Viewed from the posterior side metatarsal III of the Ceratosaurus foot forms the greater part of this view, whereas in Antrodemus the fourth has the greatest expanse. These and other differences can be clearly seen by comparing figure 51 with figure 4 , plate 24 .

DERMAL ARMOR.

Plates 22 and 29-30.

Several dermal ossifications were found with the type specimen of Ceratosaurus nasicornis, and some of these were so retained in the matrix as to indicate their exact position in relation to the internal skeleton of the living animal. Reference is made here to the row of elongate, irregularly shaped, bony ossicles present above the spinous processes of caudals (fig. $1, \mathrm{pl} .22$ ) 4 to 10 inclusive, and above cervicals 4 and 5 (0. pls. 29 and 30 ). The position of these ossicles would appear to indicate a continuous row of dermal ossifications, extending along the median line of the back from the base of the skull well down on the tail, if not the greater part of its length. In the life restoration of this animal by Knight and Gleeson (pl. 28, upper figure) such an external ornamentation has been indicated, though the size of the plates is somewhat exaggerated.

The ossifications above the tail are from 25 to $38 \mathrm{~mm}$. above the tops of the spinous processes of the vertebrae, evidently indicating the thickness of skin and muscles between them and the tops of the spines. Those on the neck are much closer to the vertebrae, and in one instance appears to rest on the spine (figs. 1, 2, and 3, pl. 20).

That there were other dermal ossifications is shown by the presence of a small skin plate found with the bones of this skeleton. It had been freed from the matrix when it came into my hands, so there is no evidence as to its probable position in 
the skin. It is a relatively small subquadrangular plate of bone, 58 by $70 \mathrm{~mm}$., with a comparatively smooth ventral and a roughened dorsal surface. The under surface is gently concave in the direction of its shortest diameter, with a low longitudinal swelling extending through the middle of its longest diameter. The roughening of the external surface is without definite pattern.

THE MOUNTED SKELETON OF CERATOSAURUS NASICORNIS MARSH.

Plates 29-30.

In plate 30 is a drawing of the mounted skeleton of Ceratosaurus nasicornis which clearly shows the original and restored parts, the latter being indicated in outline only. A comparison of this illustration with the first skeletal restoration (pl. 27, upper figure) would indicate that the skeléton was more perfect at the time Marsh made his reconstruction than it is now, for during the period of 18 years, from 1892 to 1910, the skeleton worked out in relief in blocks of sandstone suffered some breakage and loss of pieces due to packing and shipping from New Haven to Washington and one or two subsequent moves since its arrival in the United States National Museum; but, on the other hand, many of the bones shaded in full in the first drawing of this animal were never present and have been drawn from the opposite element when a paired bone, or from bones of an allied form like Antrodemus. The small bones of the pes and many of the manus, together with the humerus and coracoid, are examples of the latter, while the loss of parts of the caudal vertebrae, chevrons, and cervical vertebrae illustrate the former reason. I doubt very much that Marsh ever had the distal ends of the pubes and ischia and the portions missing from the ends of the ilia.

This specimen was collected in 1883 and 1884 by the late M. P. Felch from quarry No: 1, a quarry made classic by the successful researches; there by Mudge in 1876; Williston and Lakes in 1877; Felch from 1883 to 1888; and Hatcher and Utterback in 1901 and 1902. Quarry No. 1 is situated on the west side of Oil Creek (Four Mile Creek) at the entrance to "Garden Park," and some 9 or 10 miles east by north of Canon City, Fremont County, Colorado.

Quarry maps made at the time the skeleton was disinterred show the position in which all of the bones of the skeleton were found. It was inclosed in a very hard sandstone, with the skull and axial part of the skeleton very much compressed. This lateral crushing to a great extent determined the bas-relief method of mounting as being the best adapted to this particular specimen. Upon assembling the blocks containing the skeleton preparatory to mounting it was found that some had been cleaned on the right side and others on the left, and a few of the more important elements, as the skull, atlas, axis, and limb bones, had been entirely removed from the matrix. It was finally decided that the right would make the best exhibition side, and this is well shown in the reproduced photograph of the specimen shown in plate 29 .

The pose of the specimen was largely determined by the position of the bones as originally found. This applies particularly to the left femur, which was held by the rock in its true position with respect to the pelvis. It is directed backward at such an angle as to demand a walking stride for bipedal locomotion. An attempt was therefore made to carry out the idea of a rapid walking motion and to make 
the other parts of the skeleton contribute to that effect. The long tail being raised clear of the ground and acting as a counterpoise to balance the weight and compensate for the swaying of the body and fore legs.

The backbone stands largely in relief to the original sandstone matrix, but the greater part of the background is covered with a mixture of sand and cement that when chiseled gives so close an imitation of the original sandstone as to make it difficult to distinguish one from the other.

The entire length of the animal measured from the tip of the nose to the end of the tail is 17 feet 6 inches; the tail measures 9 feet 4 inches; the height of the head above the base is 6 feet 10 inches; the top of the hips above the base is 5 feet 5 inches.

\section{RESTORATIONS OF CERATOSAURUS.}

Plates 27-31.

During the years that have elapsed since Professor Marsh described Ceratosurus nasicornis in 1884 , there hare appeared from time to time various pictorial illustrations depicting the life appearance of this animal. These are of interest as showing the diversity of opinions held as to its probable life appearance.

Arranged in chronological order in plates 27 to 30 are the more striking of these restorations. The history of each, so far as it is known, and comments on the more important structural differences to be observed, are given below.

In plate 27 , upper figure, is shown the first restoration of the articulated skeleton, made under Professor Marsh's direction and first published by him in $1892 .{ }^{1}$ It was based on the type specimen (No. 4735, U.S.N.M.) described in the preceding pages. From the study of allied forms it appears pretty certain that the dorsal region was made too long by the insertion of at least six too many vertebrae, which obviously throws the animal out of balance. A preliminary sketch restoration of Ceratosaurus found among some drawings made for Marsh shows fewer presacrals and thus makes a much better proportioned animal than the final draft, which has been so widely copied in scientific publications of this country and abroad. It would also appear that at the time of making this restoration many of the bones, such as certain presacrals, pelvic bones, etc., were more completely preserved than they are to-day, as may be observed by comparing this figure with the line drawing of the mounted skeleton shown in plate 30 .

The first life restoration to be made of Ceratosaurus, so far as I am aware, and until now unpublished, is shown in plate 27, lower figure. It was drawn by Mr. Frank Bond, in 1899, under the direction of the late Prof. W. C. Knight, of the University of Wyoming. The drawing was based on the earlier skeletal restoration by Marsh, and in it are incorporated the faults of proportion of that restoration.

In 1901 Lucas $^{2}$ published the restoration shown in plate 28, upper figure, a drawing by J. M. Gleeson, done under the direction of Charles R. Knight. This is the best and most artistic portrayal of the probable life appearance of Ceratosaurus that has yet appeared. 
In $1911^{1}$ the Rev. H. N. Hutchinson presented the restoration by T. Smit shown in plate 28 (lower figure). The basis of the main figure in this picture is at once indicated by a comparison of this restoration with the skeletal restoration by Marsh. It has practically the same pose and also the incorrect lengthing of the dorsal region commented on above.

In 1910 and 1911 the type specimen of Ceratosaurus nasicornis was mounted in bas-relief for exhibition in the United States National Museum as shown in plate 29. The interest in this reconstruction lies not only in its being the first and to this day the only skeleton of Ceratosaurus thus exhibited, but also that corrections made in the length of the back brings about a truer conception of the general proportions of the animal than had hitherto been obtained. The mounted skeleton is composed entirely of the bones of the type individual and only such parts as were missing have been restored in plaster. These are given a conventional color, which at once distinguishes the restored from the fossil parts.

The pose of the specimen was largely determined by the position of the articulated bones as found. The skeleton was mounted by the writer, assisted by Mr. $\mathrm{N}$. H. Boss; but the author must alone be held responsible for whatever discrepancies are detected.

In plate 31 is shown a model restoration by the author of Ceratosaurus, done in 1915 and depicting his conception of this reptile. It is based on the mounted skeleton shown in the previous plate. In order to depict graphically the flesheating habits of Ceratosaurus, the animal is shown completing the kill of a small Camptosaurus nanus, a herbivorous contemporary and one which could well have been the prey of this carnivorous brute.

\section{REVIEW AND REVISION OF TYPE AND OTHER THEROPOD SPECIMENS.}

Family MEGALOSAURIDAE Huxley. 1870.

DRYPTOSAURUS? POTENS (Lull), 1911.

Plate 32.

Creosaurus potens LulL, R. S., Maryland Geol. Survey, Lower Cretaceous, 1911, pp. 186, 187, pl. 14, fig. 4.

Type specimen.-No. 3049, U.S.N.M. A vertebral centrum from the anterior caudal series. Collected by J. K. Murphy.

Type locality.-F Street between First and Second Streets, Southeast, Washington, District of Columbia. "From big 40 feet sewer, 45 feet below surface and above high tide level; light clays below ferruginous conglomerate."

Horizon.-Arundel formation, Lower Cretaceous.

The original description by Lull, is as follows:

The type specimen is a vertebral centrum (No. 3049, U. S. National Museum) from the ferruginous conglomerate of Washington, D. C., which seems to represent a theropod dinosaur otherwise unrecognized in the Arundel formation.

1 Extinct Monsters and Creatures of Other Days, 1911 (new edition) plate 14 
The vertebra (fig. 3), [66] evidently a posterior presacral, is of peculiar proportions; nearly as deep as long and strongly compressed laterally, the lower surface forming a distinct keel, which is nearly straight in profile. The neural canal is broad, though somewhat constricted in the middle of the centrum.

The vertebra differs materially from those of Allosaurus in lacking the decided constriction in the middle and in the presence of the keel. It resembles most nearly the vertebra belonging to the type of Creosaurus atrox (No. 1890, Yale Museum), not however, the one figured by Marsh as Creosaurus. ${ }^{1}$

The vertebra in question is much larger than those of the type of $C$. atrox, but the latter show the same compressed form, though with a less straight ventral outline.

The present vertebra is slightly opisthocoelous and its dimensions are as follows:

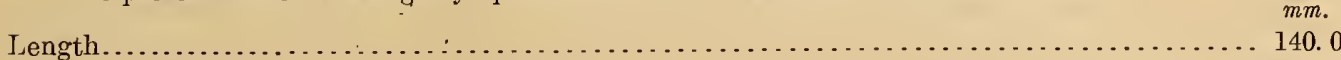

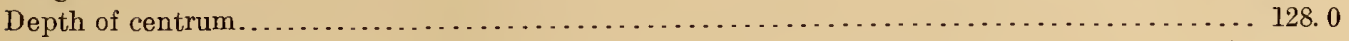

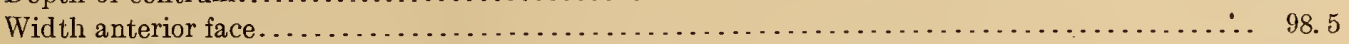

Widtl posterior face................................................... 97.0

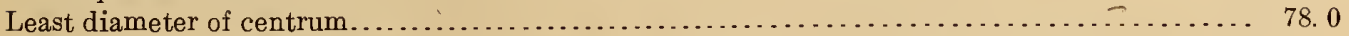

This vertebra represents by far the largest carnivore known from the Arundel formation.

The vertebral centrum described above as "evidently a posterior presacral" is most certainly a proximal caudal, as is clearly shown by a comparison with the anterior caudals belonging to Antrodemus valens Leidy, No. 8367, U.S.N.M. (see pl. 32), and also with the caudal centra of Tyrannosaurus as figured by Osborn.

The absence of a decided transverse constriction of the middle of the centrum, the beveled chevron border on the postero-ventral end, and the cancellous internal structure of the bone, are all features indicating its caudal affinities. The posterior dorsal centra of Antrodemus, as shown by two individuals now before me, have a decided transverse constriction at their middle, with flaring flange-like ends,

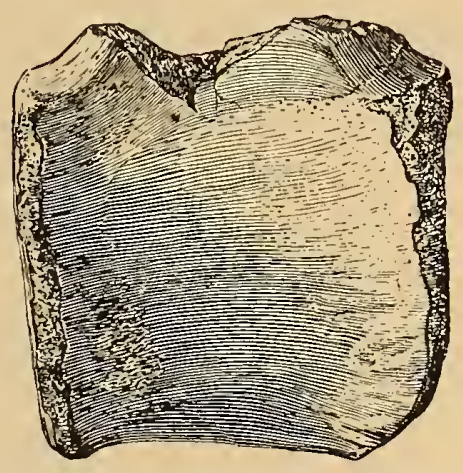

Fig. 66.-ANterior c.iUdal vertebra of DRyptosaurus? POTENS (LULL). TYPe. No. 3049, U.S.N.M. $\frac{1}{3}$ NATUR.AL SIZE. (AFter LULl.) and with the internal structure made up of large pneumatic cells.

The nearly straight ventral border, as Lull has pointed out, forms "a distinct keel, which is nearly straight in profile," and is one of the characters cited for distinguishing it from Antrodemus (Allosaurus). When compared with a proximal caudal of Antrodemus (see pl. 32), it will be seen that this difference exists between them, - a difference that seriously reflects on its assignment to the genus Creosaurus, here considered a synonym of Antrodemus, as will be discussed below.

In Marsh's original description, ${ }^{2}$ as well as in later discussions ${ }^{3}$ of the genus, but few characters were given for Creosaurus, and apparently Marsh was not able to satisfactorily distinguish it from Antrodemus. Williston ${ }^{4}$ in 1901 and Hay ${ }^{5}$ in 1908 both question the validity of the genus Creosaurus, though both were misled

1 Marsh, 16th Ann. Rept. U. S. Geol. Survey, pt. 1, 1896, pl. 1?, figs. 5, 6.

2 Marsh, O. C., Amer. Journ. Sci., vol. 15, 1878, p. 243.

${ }^{3}$ Marsh, O. C., Idem, vol. 17, 1879, pp. 90, 91, pl. 10, figs. 1 and 2; vol 27, 1884, pp. 334, 337, pl. 9, figs. $3,3 a$, and $3 b$ and pl. 14; Dinosaurs of North America, 1896, pp. 163-239, pl. 13.

4 Williston, S. W. Amer. Journ. Sci., vol. 11, 1901, pp. 111-114.

5 Hay, O. P. Proc. U.S.Nat. Mus, vol. 35, 1908, pp. 353-356.

$$
144035^{\circ}-20-9
$$


in their final conclusions through the inaccuracy of the fore limb and foot assigned to Antrodemus by Marsh. Fortunately the true structure of the Antrodemus fore limb is now known, ${ }^{1}$ and differences which the above authors were unable to reconcile now disappear. Both Williston and Hay were of the opinion that Creosaurus atrox, type species of the genus, was based chiefly if not entirely on the left ilium. In reply to my inquiry as to the material in the Yale Museum comprising the type specimen of $C$. atrox Marsh., Prof. R. S. Lull, very kindly wrote me under date of April 14, 1916, as follows:

Skull-jugal and premaxillary containing teeth, ? hyoid: two sacral vertebrae without the neural arches, a proximal caudal without neural arch, and a small distal caudal. Apparently the caudal (lumbar) figured by Marsh does not belong to the original type specimen and its characteristics are somewhat different. There is, in addition, a sternal bone, an ilium complete, an astragalus with two and a half proximal phalanges of the foot, and two unguals, one a powerful grasping claw.

$\mathrm{Hay}^{2}{ }^{2}$ after a careful and detailed comparison of the published figure of the Creosaurus ilium, with the ilium of No. 4734, U.S.N.M., says:

Whatever may be true of other parts of the skeleton of Creosaurus, there do not appear to be any characters in the ilium that distinguish it generically from Allosaurus.

The premaxillary carries five teeth, as in Antrodemus. When the figures of this bone as given by Marsh are compared with the actual specimen in Antrodemus, No. 4734 , U.S.N.M. (see figs. 10 and 11), its proportions and chief characteristics are found to be identical.

Williston 's ${ }^{3}$ summing up of the few characters given for Creosaurus by Marsh is as follows:

The ilium, it is true, is of somewhat different shape, as figured, but even this difference may be due to imperfect preservation, as Marsh himself suspected. The only other things mentioned by Marsh are the number of vertebrae ( $t w o$ ) in the sacrum, of very little value as already demonstrated in other genera of the Wealden dinosaurs; the position of the transverse processes, which I am confident will not prove distinctive.

Hay also states in the publication cited above:

The metapodial whose measurement was given by Marsh has the same length relative to the length of the ilium that the fourth metapodial of Allosaurus fragilis has to its ilium, being about 40 per cent.

From the above review it will be observed that none of the more important bones constituting the type specimen of Creosaurus atrox show generic differences from Antrodemus, and I believe therefore that the genus should be abandoned, to become a synonym of Antrodemus. As to the validity of the species $A$. atrox, a careful study of the specimen itself will be necessary before a decision can be reached, and that is a question outside the scope of the present study.

While the brief review of Creosaurus, given above, seems to indicate its being a synonym of Antrodemus, a comparison of the type of Creosaurus potens Lull with an anterior caudal of Antrodemus (see pl. 32, figs. 1 and 2) shows such dissimilarities as to render its assignment to that genus out of the question. Furthermore, none of the known Morrison Theropod genera have the straight inferior profile of the anterior caudals as seen in this Arundel specimen. 
In Tyrannosaurus and Gorgosaurus, however, from the western Upper Cretaceous, the concavity of this lower surface of the anterior caudals is markedly straighter, and in Dryptosaurus aquitunguis (Cope) from the Upper Cretaceous of New Jersey is found the nearest approach to the straight ventral border of the specimen under consideration. After a careful comparison of the type of $C$. potens with the description, measurements, and illustration of the anterior caudals of the type of Dryptosaurus aquitunguis. (Cope), ${ }^{1}$ and after taking into account the morphological resemblances and the geographical distribution of these specimens, I believe that, tentatively, it may be best referred to the genus Dryptosaurus. Thus this species becomes Dryptosaurus? potens (Lull) until such time as the discovery of adequate materials will permit the determination of its true affinities.

The median portion of a very large ungual (No. 8505 U.S.N.M.) collected by Arthur Bibbins from the Arundel formation near Contee, Maryland, is, on account of its great size, provisionally referred to the present species. This bone lacks both its proximal and distal ends, but its slightly curved contours with lateral longitudinal grooves indicate the terminal phalanx of digit I of the fore foot. A large medullary cavity is to be seen on the broken proximal end. In size it considerably exceeds any unguals in the collection.

DRYPTOSAURUS? MEDIUS (Marsh), 1888.

Plate 34, figs. 1-3.

Allosaurus medius Marsh, O. C., Amer. Journ. Sci., ser. 3, vol. 35, 1888, p. 93.-Hay, O. P., Proc. U. S. Nat. Mus., 1908, vol. 35, p. 353.-Merrild, G.P., Bull. U. S. Nat. Mus., 53, pt. 2, p. 63, 1907.-Schuchert, Charles, Bull. Geol. Soc. Amer., vol. 20, p. 586, 1910.-Luld, R. S. Maryland Geol. Surv., Lower Cretaceous, 1911, pp. 183-186, pl. 14, figs. 1-3.

Antrodemus medius HAx, O. P., Bull. No. 179, U. S. Geol. Surv., 1902, p. 489.

Type specimen.-No. 4972, U.S.N.M. Consists of a single broken tooth. Collected by J. B. Hatcher in 1887.

Type locality.-Near Muirkirk, Prince Georges County, Maryland.

Horizon.-Arundel formation, Lower Cretaceous.

The original description by Marsh is as follows:

Besides the herbivorous Dinosaurs described above, remains of two carnivorous forms were secured from the same horizon The larger of these, which may be provisionally referred to the genus Allosaurus, is represented by various specimens, the most characteristic of which are teeth and bones of the limbs and feet. The teeth are remarkably flat and trenchant, with the edges finely serrated and the surfaces very smooth. The limb bones and even the phalanges are unusually hollow, and the latter have the articulation finely finished. The principal dimensions of some of the parts preserved are as follows: One tooth has the crown $30 \mathrm{~mm}$. in heighth; its antero-posterior diameter at base $75 \mathrm{~mm}$; ; and its transverse diameter $7 \mathrm{~mm}$. [See fig. 2, pl. 34.].

The astragalus is $55 \mathrm{~mm}$. in width, and $50 \mathrm{~mm}$. in fore and aft diameter. A first phalanx of the kind foot is $90 \mathrm{~mm}$. in length. These specimens would indicate an animal 10 or 12 feet in length.

In 1911 Lull reached the conclusion that the tooth alone constituted the type of this species, the other material mentioned by Marsh being removed to the genus Dryosaurus. I have examined the cotypes thus referred and concur in the conclusion reached by Lull that these bones do not pertain to a Megalosauroid dinosaur. 
The type tooth has been carefully compared with teeth of Antrodemus and Deratosaurus, and with those of Upper Cretaceous Theropods; but I have failed to find characters that would distinguish it from any of those genera. In fact on the basis of a single tooth I believe it is impossible to determine the genus to which it pertains, and certainly there are not diagnostic characters available for generic or specific differentiation. In so far as the type specimen is concerned it will always remain a form of doubtful affinities. For the present, however, it would seem best to continue the use of the species in order to have a name for those scanty Theropod remains that are found from time to time in the Arundel formation. The generic. assignment is seriously in doubt, and I here provisionally refer it to the genus Dryptosaurus, largely on geographic considerations. A more definite conclusion must await the discovery of better and more diagnostic materials.

In his paper on the vertebrata of the Lower Cretaceous of Maryland, Lull identified and described a number of separate bones as belonging to this species. All of these specimens are now deposited in the United States National Museum and in order to assemble here all available information relating to Dryptosaurus? medius, Lull's remarks are given in full as follows:

There are several larger, better preserved teeth ${ }^{1}$ among the material, one of which (No. 5685, Goucher College $)^{2}$ shows decided wear. The most perfect is one in possession of the Hon. Charles E. Coffin, Muirkirk, Maryland, [pl. 34, fig. 1]. It is about 3 inches $\left(76 \mathrm{~mm}\right.$.) in length and $1 \frac{1}{2}$ inches $(28.7 \mathrm{~mm}$.) in the antero-posterior diameter. The crenulations of the margin cease about midway toward the root on the anterior convex border, but extend the length of the crown on the posterior edge. There is a slight variation in the size of the crenulations as they are somewhat coarser in the larger teeth.

The two vertebrae which are here referred to this species indicate an animal of the same approximate size as the teeth and phalanges. One (No. 2534 , G. C. $)^{3}$ which seems to be a posterior presacral ${ }^{4}$ has a form quite similar to the type of Allosaurus frayilis; but relatively somewhat less constricted in the middle. It agrees in having the same somewhat flattened inferior surface. Anteriorly, the centrum has a shallow concavity, while posteriorly it is nearly plane. . The pedicels of the neural arch are stout, and the neural canal seems to be broader than in the type of $A$. fragilis, possibly owing to the fact that the vertebra is a more posterior one. The two agree in the depression on either side, which however, is somewhat less marked in the present species.

Dimensions.

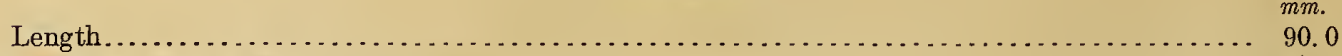

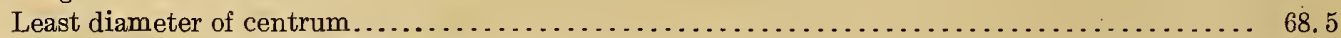

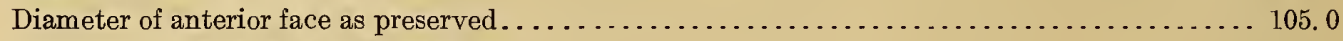

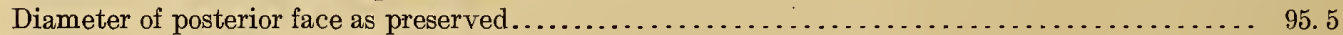

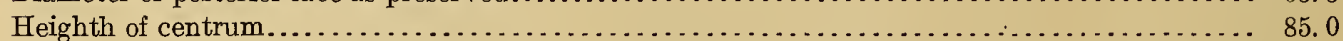

The anterior caudal vertebra (No. 2614, $a$, G. C.) $)^{5}$ is that of a young individual, as the neural arch had not coossified with the centrum. Internally it seems to have been composed of rather coarse, cancellous tissue, with no trace of an internal cavity, as in the type of Antrodemus, as figured by Leidy. ${ }^{6}$

The anterior face is slightly concave, the posterior one nearly plane, and while the centrum is decidedly constricted in the middle there is no trace of the lateral depressions seen in the presacrals.

1 Other teeth in the U. S. National Museum Collections arc Nos. 5693, 3446, and 8447.

2 Wrongly attributed to Goucher College as this is the Catalogue number of the U. S. National Museum.

3 Now Cat. No. 8502 U.S.N.M.

4 I regard this vertebra as being the anterior vertebra of the sacral series and the plane end (which appears to be sutural) as being posterior. That it is a sacral is indicated not only by comparison with the articulated sacral series of No. 4734 U.S.N.M. (Antrodemus valens), but also by the character of the plane articular cnd for close articulation with the centrum which followed it and the rapid widening of the anterior half of the neural canal.

5 Now Cat. No. 8503 , U.S.N.M.

${ }^{6}$ Leidy, Report of U. S. Geological Survcy of Tenncssee, vol. 1, 1873, pl. 15, fig. 18. 
Dimensions.

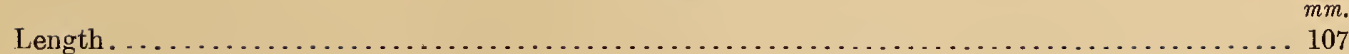

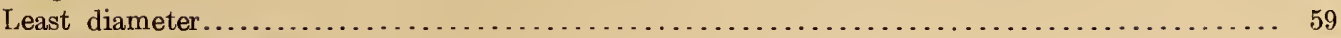

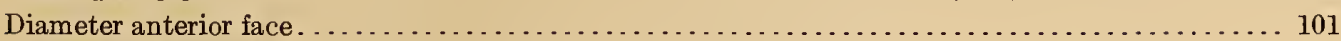

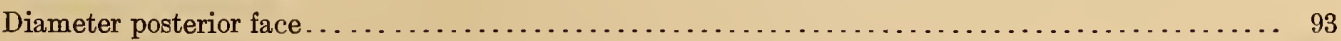

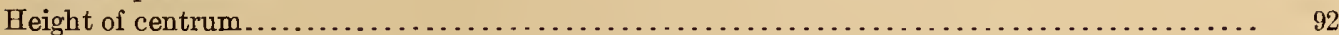

The first phalanx of the second digit is represented by the proximal half (No. 2536, G. C.),' and is peculiar for its height as compared with its width and the two very prominent ridges on the inferior face. The articulation is a smooth cylindrical concavity with no trace of ridges to limit lateral motion. It is probable that it was formerly somewhat cuplike, as the preparator has slightly altered the shape of the bone. The articular end is full of a cancellous tissue, nevertheless there was a well-defined medullary cavity in the shaft. The portion preserved measures in height $73 \mathrm{~mm}$.; in width $58 \mathrm{~mm}$.

The first phalanx of the third digit (No. 2521, G. C.) $)^{2}$ (fig. 2) [pl. 34, fig. 3] is entire, most excellently preserved, and presents a decided similarity to the type of Allosaurus fragilis, differing therefrom in being more depressed proximally, especially in the broader, flatter under surface. Distally, the present type is not so broad relatively as that of $A$. fragilis and the articular face is more concave transversely. Altogether the two bones are quite distinct in conformation.

Dimensions.

$m m$.

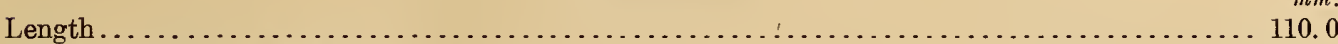

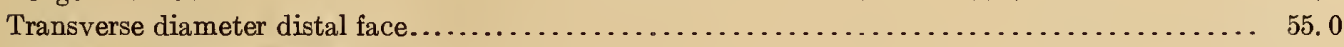

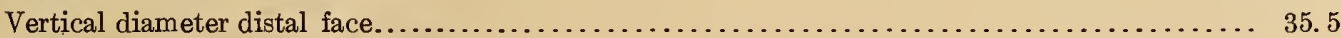

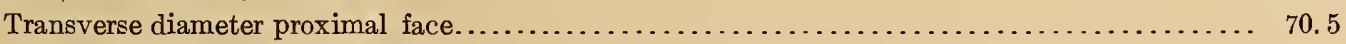

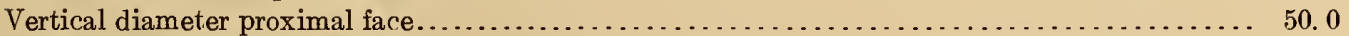

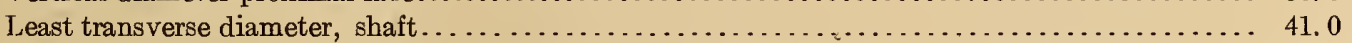

'All of the remains which Lull referred to Allosaurus medius are from the Arundel formation in the vicinity of Muirkirk, Prince Georges County, Maryland.

The two distal caudal vertebrae described by Lull in the article quoted above undoubtedly pertain to an Ornithomimid dinosaur and are here referred to the new species Ornithomimus affinis (see p. 141).

While there may be two large carnivorous dinosaurs (Dryptosaurus? potens (Lull) and D. medius (Marsh) present in the Arundel fauna, I can see no good reason at the present time for believing there is more than one, even though, as a matter of expediency, both species are retained in the present paper. Certainly the scattered teeth and other bones assigned to $D$. medius indicate an individual or individuals of sufficient size to have had an anterior caudal of the dimensions of the type of Creosaurus potens, here referred to the genus Dryptosaurus.

TYRANNOSAURUS REX Osborn, 1905.

Tyrannosaurus rex OsBorn, Bull. Amer. Mus. Nat. Hist., vol. 21, pp. 262-263; vol. 22, pp. 281-296, 1906; Mem. Amer. Mus. Nat. Hist., vol. 1, pt. 1, pp. 3-30, 1912, pls. 1-4, 27 text figures; Bull. Amer. Mus. Nat. Hist., vol. 32, pp. 91-92, 1913; vol. 35, pp. 761-771, 1917.

Ornithomimus grandis MaRsH, O. C., Sixteenth Ann. Rept., U. S. Geol. Surv., pt. 1, 1896, p. 206. (Not O. grandis of 1890.)

In the United States National Museum collection there are a number of isolated bones which are here regarded as pertaining to the genus Tyrannosaurus, and in all probability to the species T. rex Osborn.

1 Now Cat. No. 8504, U.S.N.M. This bone belongs to the right hind foot.

2 When the Goucher College collection was deposited in the U. S. National Museum this specimen was missing. 
The best specimen (No. 6183, U.S.N.M.) consists of an excellently preserved femur, tibia, and fibula of the left side (the latter lacking its distal half), from Alkali Creek, Niobrara County, Wyoming. Collected by J. B. Hatcher in 1891.

This specimen was referred by Marsh in 1896 to Ornithomimus grandis (p. 206, Dinosaurs of North America). The large size of these bones and their very close resemblance to the same elements in Tyrannosaurus as described and figured by Osborn clearly indicate their generic affinities, which are nore in accord with their geological occurrence, as Tyrannosaurus remains at the present time are known only from the Lance formation or its equivalent, whereas the genotype of Ornithorimus grandis was found in the much more ancient Eagle formation.

The principal dimensions of these bones as compared with the genotype of Tyrannosaurus are given below.

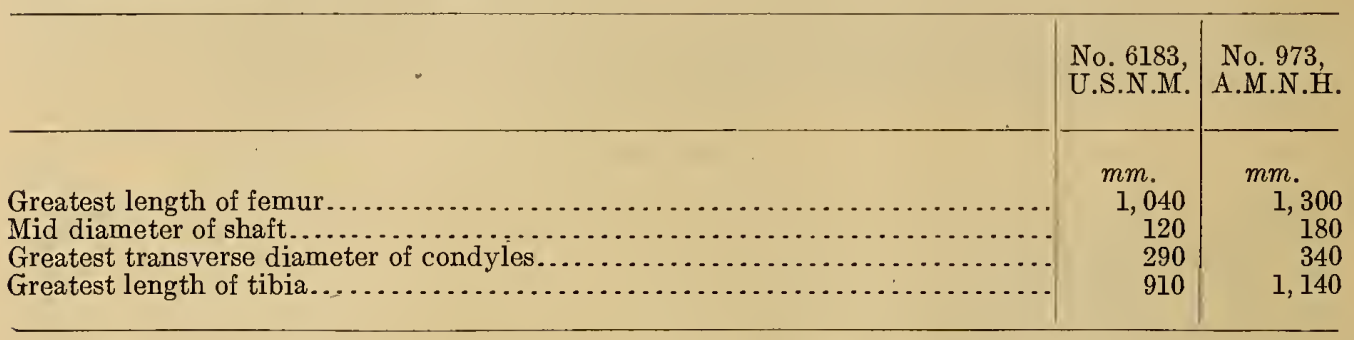

A second specimen (No. 2110, U.S.N.M.), represented by metatarsal IV of the right hind foot and lacking the proximal end, has about the same dimensions as given by Osborn for metatarsal IV of the genotype of Tyrannosaurus. It is estimated that the complete length of this bone would be about $590 \mathrm{~mm}$., and the greatest diameter anteroposteriorly is $100 \mathrm{~mm}$. This is probably the same bone mentioned by Marsh ${ }^{1}$ as Ornithomimus grandis. He says:

In the other specimen the second metatarsal is in fair preservation and shows the same form as in the type of the genus.

This specimen was collected by J. B. Hatcher from the Lance formation on Lance Creek, Niobrara County, Wyoming, in 1890.

A third specimen (No. 8064, U.S.N.M.) is provisionally referred to this genus. It consists of a right ilium, collected by J. B. Hatcher and A. E. Sullins, October 16, 1891, on Alkali Creek, Niobrara County, Wyoming. This specimen, except for its smaller size, closely resembles the ilia of Tyrannosaurus as described by Professor Osborn.

\section{DEINODON? GRANDIS (Marsh), 1890}

Ornithomimus grandis Marsh, Amer. Journ. Sci., ser. 3, vol. 34, p. 85, 1890; Sixteenth Ann. Rept. U. S. Geol. Surv., pt. 1, p. 296, 1896.-HAy, O. P., Bull. No. 179, U. S. Geol. Surv., p. 494, 1901.-Nopcsa, F. Baron, Földtani Közlony, Budapest, vol. 31, p. 201, 1901.—OsBorN, H. F., Contr. Canadian Paleont., vol. 3, pt. 2, p. 13, 1902.-Hatceer, J. B., Bull. U. S. Geol. Surv., No. 257, pp. 12, 41, 87, 1905.-Bowen, C. F., Prof. Paper U. S. Geol. Surv., 901, p. 134 1915.-Osborn, H. F., Bull. Amer. Mus. Nat. Hist., vol. 35, art. 43, pp. 470, 741, 1917.

Type material.-Location of type unknown. Marsh in his original description mentions only the third metatarsal, but Hatcher states ${ }^{2}$ that it consists of "frag- 
ments representing a considerable portion of a skeleton." Collected by J. B. Hatcher, 1888.

Type locality.-Near the mouth and on the east side of Cow Creek, Fergus County, Montana.

Horizon.-Eagle sandstone, Upper Cretaceous.

The brief original description by Marsh is as follows:

A third species much larger may be called Ornithomimus grandis. The third metatarsal was about $600 \mathrm{~mm}$. in length, and its distal end $90 \mathrm{~mm}$. in transverse diameter, and $80 \mathrm{~mm}$. in antero-posterior. diameter.

It would appear that the type specimen should be in the United States National Museum collections, but after a search extending over a period of several years I have been unable to locate it. Portions of two other individuals referred to this genus and species by Marsh are Nos. 2110 and 6183, U.S.N.M., both from the Lance formation of Niobrara County, Wyoming. Of these Marsh says:

Portions of two other skeletons have since been obtained, which apparently pertain to this species. In one [No. 6183, U.S.N.M.] of these the femur, tibia, and fibula are in good preservation, and they clearly demonstrate that this reptile was one of the largest of the Theropoda. The femur and tibia have each a very large cavity in the shaft, with well-defined walls. Even the fibula has a cavity in its upper portion. In the other specimen [No. 2110, U.S.N.M.] the second metatarsal is in fair preservation and shows the same form as in the type of the genus.

Both of these specimens are here referred to the genus Tyrannosaurus, and in all probability the type of $O$. grandis when found will also be referable to a genus distinct from Ornithomimus. Osborn ${ }^{1}$ has suggested "it may belong to the genus Deinodon Leidy, but until the type is located, it must remain of doubtful position as regards its generic affinities."

DEINODON, species.

Deinodon? Gilmore, C. W., Prof. Paper, U. S. Geol. Surv., 98-Q, 1916, pp. 287-288, pl. 73, figs. 1 and 4.

The following specimens in the United States National Museum are provisionally identified as pertaining to the genus Deinodon.

Specimen No. 8346, U.S.N.M., consisting of the greater portion of a left dentary, ${ }^{2}$ collected by J. B. Reeside, jr., "28 miles south of San Juan River and about 12 miles east of the Navajo Reservation line at the head of Hunter, Wash," from the upper part of the Kirkland Shale, in 1915.

In this bone there are alveoli for 13 large teeth, but excepting a germ tooth in the ninth alveolus from the front all the others have been lost. This germ tooth is compressed laterally, lenticular in section in the upper portion and serrate on both borders. The 13 alveoli occupy a space about 354 millimeters long. At the third alveolus the dentary on the external side has a depth of 93 millimeters; at the eleventh alveolus it is 110 millimeters deep. As in other Cretaceous Theropoda, the alveolar partitions expand internally into interdental rugosae. In the number of tooth sockets this jaw agrees with Dynamosaurus imperosus Osborn, but in the general form of the dentary, particularly the contour of the anterior 
end; it approaches Albertosaurus (Dryptosaurus) most nearly; but as the dentary of Albertosaurus has sockets for 15 teeth the presence of 13 in this individual would appear to show its distinctness.

Is is quite possible that this dentary pertains to the genus Deinodon, but that can not be absolutely determined because the dentary of that genus is unknown. The positive identification of this specimen must therefore await the discovery of additional material.

Specimen No. 8355, U.S.N.M., consisting of a single tooth, ${ }^{1}$ resembling in nearly every detail the D-shaped tooth figured by Leidy ${ }^{2}$ and which he attributed to Deinodon horridus, was collected by C. F. Bauer, "30 miles south of Farmington, New Mexico, 1 mile east of reservation line from the lower part of the Kirtland formation in 1915.

\section{LABROSAURUS FEROX Marsh.}

Plate 33 , figs. 1,2 , and 3.

Labrosaurus ferox Marsh, O. C., Amer. Journ. Sci., ser. 3, vol. 27, 1884, p. 333, pl. 9; Sixteenth Ann. Rep. U.S. Geol. Surv., pt. 1, 1896, p. 163, pl. 13, figs. 2-4.-WALcotr, C. D., Science, ser. 2, 1900, vol. 11, p. 23.-Merrilu, G. P., Cat. Fossil Vertebrates U. S. Nat. Mus., pt. 2, 1907, p. 73.-Gilmore, C. W., Bull. No. 89, U. S. Nat. Mus., 1914, p. 25.

Antrodemus valens $\mathrm{H}_{\mathrm{AY}}$, O. P., Bull: No. 179, U. S. Geol. Surv., 1902, pp. 489-490.

Labrosaurus ferox $\mathrm{H}_{\mathrm{AY}}$, O. P., Proc. U. S. Nat. Mus., vol. 35, 1908, pp. 352-353.

Type specimen.-No. 2315, U.S.N.M. Consists of a left dentary in which are the roots of several teeth and one or more germ teeth. Collected by M. P. Felch in 1883.

Type locality.-Quarry No. 1, Garden Park, near Canon City, Fremont County, Colorado.

Horizon.-Morrison, Upper Jurassic.

The original description ${ }^{3}$ by Marsh is as follows:

a peculiar dentary bone, recently found, and here referred to Labrosaurus, is shown on plate 9 , figure 4. It is edentulous in front, and the posterior portion is much decurved. The teeth are more triangular than in the other genera of this order. The species it represents may be called Labrosaurus ferox.

This brief description constitutes practically all that had been written regarding this species up to the year 1908, when Hay ${ }^{4}$ reviewed the genus. This review is most thoroughly done, and since the conclusions reached largely apply to-day, his remarks are here quoted in their entirety:

In $1879^{5}$ Marsh established the genus Labrosaurus, with his Allosaurus lucaris as the type. This species had been described. in $1878^{\circ}$ and was based on materials found in the Upper Jurassic of Colorado. In this earliest description there was mentioned only an anterior dorsal vertebra. In the description of 1879 cervical and dorsal vertebrae and fore-limb bones were briefly described. So far as the writer knows no part representing this species has ever been figured.

In $1884^{7}$ Marsh added a second species to the genus, Labrosaurus ferox. The only part of this animal that was mentioned is the left dentary. Marsh here made the statement that in Labrosaurus the

I Prof. Paper 98 Q, p. 288, pl. 73, fig. 4, 1916.

2 Leidy, Joseph, Amer. Philos. Soc., Trans., vol. 11, 1859, pl. 9, figs. 41, 42.

8 Amer. Journ. Sci., ser. 3, vol. 27, 1884, p. 333, pl. 9, figs. 4-6.

1 Proc. U. S. Nat. Mus., vol. 35, 1908, pp. 352-353.

5 Amer. Journ. Sci., vol. 17, p. 91.

6 Idem, vol. 15, p. 243.

7 Idem, vol. 27, p. 333, pl. 9, figs. 4-6. 
teeth are more triangular than in the other genera of the order; but whether or not this statement had its basis in this specimen is doubtful, inasmuch as the crowns of all the teeth are missing and the roots almost wholly concealed by matrix. This dentary bone (Cat. No. 2315, U.S.N.M.) probably came from the same locality and level as the type of $L$. lucaris Marsh.

In $1896^{1}$ Marsh again mentioned this species and presented the same figures. In a footnote on page 163 he remarked that the skull of Allosaurus ferox had an aperture in the maxillary in front of the antorbital opening. The context appears to indicate that "Allosaurus ferox" is a slip of the pen for Allosaurus fragilis, just as Labrosaurus ferox seems to be called Labrosaurus fragilis on page 270. At any rate, this is the only mention that Marsh made of the skull of either $L$. ferox or $A$. fragilis. In the definition of the family Labrosauridae ${ }^{2}$ he mentioned no part of the skull but the lower jaw.

On page 270 of the work cited Marsh referred a third species to Labrosaurus-namely, L. sulcatus. This is done in the explanation of plate 13, figure 1; and, so far as the writer is aware, Marsh nowhere else mentioned this species. Three views of a single tooth are given, but there is no description and no statement as to the origin of the specimen.

Inasmuch as no teeth or parts of the skull were, so far as Marsh informs us, present with the type of $L$. lucaris, and only teeth or parts of the lower jaw appear to have been represented in the types of the other species, one is at a loss to understand on what grounds the second and third species were referred to Labrosaurus. Furthermore, it may be worth while to inquire whether L. ferox and L. sulcatus are congeneric.

The type of $L$. sulcatus is a tooth which, judging from Marsh's figures, represents a crown $30 \mathrm{~mm}$. high, with a base whose antero-posterior diameter is $12.5 \mathrm{~mm}$. and whose transverse diameter is $12 \mathrm{~m}$. There is a posterior face which appears to have been somewhat concave, its outer boundary being formed by a crenulated, its inner by a smooth, carina. The outer face of the tooth is ornamented at the base by about eight ridges, of which only three remain at the apex. The inner and the posterior faces are represented as being smooth.

As already stated, the jaw of $L$.ferox presented to Marsh little or nothing of the teeth. The crowns of all the functional teeth are missing and the roots were almost wholly concealed by matrix. A section of the base of the crown furthest in front showed above the enveloping sandstone. Of this matrix the writer has removed enough to expose a part of the outer and front faces of the tooth. The inner face had been almost wholly absorbed by the successional tooth, of whose apex about $9 \mathrm{~mm}$. are now laid bare. The functional tooth had an antero-posterior diameter of $15 \mathrm{~mm}$. and a transverse diameter of $9 \mathrm{~mm}$. The later diameter was near the front of the tooth-a fact which indicates that the anterior cutting edge had subsided far above the base of the crown. The hinder edge seems to gave reached the base. The outer and anterior faces and the little that remains of the inner face are wholly smooth. The inner face, too, of the successional tooth is perfectly smooth and both the anterior and posterior cutting edges are crenulated.

The writer has likewise exposed the tooth which was displacing the sixth functional tooth, the outer wall of whose base still remains. The apex of the successional tooth is broken off. The long diameter at the section thus furnished is $8.5 \mathrm{~m}$; the short diameter, $5.5 \mathrm{~m}$. The inner and outer faces are equally convex, both are smooth, and both cutting edges are crenulated.

Such being the structure of the teeth of the types of Labrosaurus ferox and $L$. sulcatus, it becomes evident that the two species belong to quite distinct genera and almost certainly to different families; but which of them belongs to Labrosaurus, if either, can be determined only by future discoveries.

In the lower jaw of $L$. ferox there were plainly 12 teeth. The first was placed $63 \mathrm{~mm}$. behind the tip of the jaw, between which and the tooth there is a deep notch. The posterior part of the dentary is bent downward in an extraordinary way, somewhat like that of a fringilline bird. These peculiarities show that this species belongs to a family entirely distinct from that typified by Allosaurus.

Although I have not had the opportunity of examining the type of Labrosaurus sulcatus Marsh the illustrations lead me to believe that it is a premaxillary tooth. In the event of this suggestion proving correct, the differences noted by Hay between it and a tooth of the dentary of Labrosaurus ferox would form no basis for the con-

1 Dinosaurs of North America, pp. 163, 270, pl. 13, figs. 2-4.

2 Amer. Journ. Sci., vol. 50, 1895, p. 493 ; Dinosaurs of North America, p. 239. 
clusion reached by him that they pertain to distinct genera, for teeth of both the styles discussed are to be found in the jaws of a single individual. As stated elsewhere in this paper, I do not believe that the teeth alone furnish diagnostic characters that will serve to distinguish species or in most cases even genera of the Theropoda.

Now, a suggestion regarding the type of Labrosaurus ferox. The deep notch in the edentulous part of the dentary and the decided bending down of the posterior portion of the bone are features so entirely peculiar to anything known among the Theropodous dinosauria, as to suggest that this dentary is abnormal in these respects, and that it may have keen produced through injury, though, to be sure, the bone as now preserved shows no evidence of such malformation.

\section{Family COELURIDAE Marsh 1881.}

COELURUS? GRACILIS Marsh.

Plate 36, fig. 4.

Coelurus gracilis MARSH, Amer. Journ. Sci., ser. 3, vol. 35, 1888, p. 94.-ZITTEL, Handbuch der Palaeontologie, Abt. 1, vol. 3,1890, p. 732.-HAY, Bull. No. 179, U. S. Geol. Survey, p. 493.LuLd, Maryland Geological Survey, Lower Cretaceous, p. 1911, pp. 187, 188, pl. 15, fig. 1.

Type specimen.-No. 4973, U.S.N.M., consists of an ungual phalanx, lacking the tip. Collected by J. B. Hatcher in 1887.

Type locality.-Near Muirkirk, Prince Georges County, Maryland.

Horizon.-Arundel formation, Lower Cretaceous.

The original description is as follows:

The smallest dinosaur found in these deposits is a very diminutive carnivore, apparently belonging to the genus Coelurus. It was not more than one-half the size of the western species, and its proportions were extremely slender. The bones are very light and hollow, the metapodials being much elongated and their walls extremely thin. An ungual phalanx of the manus measures about $25 \mathrm{~mm}$. in length, and $14 \mathrm{~mm}$. in vertical diameter at the base. This animal could not have been more than 5 or 6 feet in length.

Lull in 1911 recognized additional specimens pertaining to this species in material in the Goucher College collection, Nos. 3336, ${ }^{1} 3338$, and 8176 , consisting of three teeth, the first two coming from the same locality as the type.

The teeth resemble very closely that of Coelurus fragilis figured by Marsh ${ }^{2}$ but differ in the total reduction of the crenulation of the anterior convex border, which is perfectly smooth in one of the three specimens, has serrations of almost microscopical fineness for a short distance from the tip in the second, while in the third specimen the border is broken away where the crenulation would occur if present. The curvature of the teeth is similar in each species, while the variation in size may be accounted for by a difference in the stage of growth of individual teeth; as it is, two of the Maryland ones are slightly larger than the tooth of Coelurus fragitis figured by Marsh.

The type specimen as shown in figure 4 [plate 36], lacks a considerable portion of the pointed extremity. When compared with the unguals of the manus of Ornitholestes hermanni Osborn it would appear to represent the ungual of digit III of the manus.

1 Now deposited as a loan in the United States National Museum. No. 3336 G. C. $=8444$, U.S.N.M.; No. 3338 G. C. $=8445$ U.S.N.M. No. 8176 not found when collection was transferred.

2 Marsh, 16th Amer. Rept. U. S. Geol. Surv., pt. 1, 1896, pl. 7, fig. 1. Reproduced on plate 34, fig. 4. 
Since an ungual and three separate teeth apparently constitute all of the known material of this species, such observations as "its proportions were extremely slender; the bones are very light and hollow, the metapodials being much elongated and their walls extremely thin," are difficult of understanding. That from such scanty remains it is possible to positively recognize the genus to which they belong seems to me exceedingly doubtful. And to use a species thus founded to swell a list of like genera in order to prove the synchronous age of widely separated geological formations is a mistaken and misleading practice.

I have made a thorough search of the niscellaneous materials in the National Museum collections from the Lance and Morrison formations for small unguals with which to compare this type, but have failed in finding any that agree with it in all particulars. Recently in going over a similar collection from the Belly River formation of Canada, in the American Museum of Natural History, I found at least four unguals, that, except for their larger size, were exact counterparts of the type under consideration. One of these (No. 5387, A. M. N. H.) selected for reproduction is shown in figure 3 , plate 36 . None of these American Museum unguals have been identified as yet, but it appears highly significant that two bones from supposedly widely separated geological horizons should so closely resemble one another in every particular (see pl. 36), especially since an Ornithomimid dinosaur and other dinosaurs of Upper Cretaceous affinities appear to be present in the Arundel fauna.

\section{COELURUS FRAGILIS Marsh.}

Plate 34 , figs. 4, 7, and 8 .

Coelurus fragitis Marsh, Amer. Journ. Sci., ser. 3, vol. 18, 1879, p. 504.--Cope, Amer. Nat., vol. 15, 1881, p. 413 (Amphicoelias fragillissimus, a synonym).-MARSH, Amer. Journ. Sci., ser. 3, vol. 21, 1881, pp. 339-340, pl. 10; vol. 27, 1884, p. 340, pl. 13.-Cope, Amer. Naturalist, vol. 21, 1887, p. 369 (=Coelophysis).-SeELey, H. G., Journ. Comp. Med. and Surg., vol. 9, 1888, p. 5.-Zrttel, K. A., Handbuch der Palaeontologie, vol. 3, 1890, p. 731, figs. 637-340.-Marsh, Sixteenth Ann. Rept. U. S. Geol. Survey, 1896, pt. 1, pl. 7, p. 155.-HaY, O. P., Bull. No. 179, U. S. Geol. Surv., 1901, p. 493.-Nopesa, F. B., Földtani Közlony, Budapest, vol. 31, 1901, p. 202.-Grlmore, C. W., Proc. U. S. Nat. Mus., vol. 37, 1909, pp. 39, 40, fig. 3; Bull. No. 89, U. S. Nat. Mus., 1914, p. 4.-Mook, C. C., Ann. New York Acad. of Sci., vol. 28, 1916, p. 142.

A number of vertebrae in the United States National Museum collection are identified as pertaining to Coelurus fragitis. These are sacral vertebra No. 5809; cervical vertebra No. 5810; caudal vertebra No. 6624; caudal vertebra No. 6625; caudal vertebra No. 6626; distal caudal vertebra No. 6627; caudal vertebra No. 6628. These vertebrae agree closely in dimensions and other characteristics with the vertebrae figured by Marsh (on pl. 10) in his Dinosaurs of North America.

All of the United States National Museum vertebrae were collected in Quarry 9 (from which Morrison mammals came), Como, Albany County, Wyoming.

The type of Coelurus fragitis Marsh is in the Yale Museum. It consists, according to a letter of June 28, 1915, from Prof. R. S. Lull, of a "Vertebra, dorsal, figure 3 (pl. 7, figs. $3,3 a, 3 b$ ); catalogue number 1991, and is marked 'type' in Marsh's handwriting. This is the only bone of the so called type specimen figured, the others being plesiotypes." 
In 1903 Dr. H. F. Osborn ${ }^{1}$ described and figured a well-preserved skeleton from the famous "Bone Cabin" quarry in Wyomimg, as the type of the new genus and species Ornitholestes hermanni. This specimen comes from approximately the same geological level as the type of Coelurus fragitis Marsh, and only a few miles distant from where the type was found. Osborn distinguished Ornitholestes from Coelurus by the "nonserration of the teeth, by the relatively short cervical vertebrae, by the less extreme hollowness of all of the vertebrae."

A review of the material on which Coelurus was based renders the distinction made less obvious. Although the genus Coelurus was established in 1879 no mention was made of the presence of teeth until 1896, ${ }^{2}$ when Marsh figured a tooth ascribed to Coelurus fragitis (see fig. 4, pl. 34). Lull, in a letter of June 28, 1915, has been kind enough to furnish me with the following information concerning this tooth:

The tooth, figure 1 [fig. 4, pl. 34], was entirely disassociated from the rest of the material and bears the accession number $\mid 1271$, being collected by Reed in 1879 from Como, Wyoming; but I can not tell from which quarry; but, as you will see, the tooth came in some time in advance of the rest of the material [refers here to the figured specimens]. Hence there is no indication of the association. As the original description is based on the vertebrae, the association of the serrated tooth is highly conjectural.

In this connection it is of interest to quote further from Lull's letter regarding the bones figured by Marsh (on pl. 7) in his Dinosaurs of North America: "Vertebra, figure 2, is catalogue number 1993. Caudal, figure 4, is catalogue number 1992." Osborn's distinction "by the relatively short cervical vertebrae" in Ornitholestes can hardly be considered a good distinctive character unless found to exist in an articulated series. And in Ornitholestes only two cervicals were present, and as has been shown above the cervical figured by Marsh does nor pertain to the type specimen. Furthermore, it is now known that the relative length of the cervicals vary with the position they occupy in the cervical series. Articulated cervical series in Antrodemus and Ceratosaurus show the posterior members to be more elongated than the anterior cervicals and this is probably true also of the forms under discussion.

The extreme hollowness of the vertebrae is a difference of degree and certainly not a character upon which to base generic distinctions. Since a comparison of the vertebrae of the type specimen Coelurus with those of the skeleton on which Ornitholestes is based show only minor differences I do not see that their generic distinctness has been established.

\section{COELURUS AGILIS Marsh.}

Plate 34, figs. 5 and 6.

Coelurus agilis MARSH, Amer. Journ. Sci., vol. 27, 1884, p. 335, pl. 10, figs. 3a, 3b; Sixteenth Ann.

- Rept. U. S. Geol. Survey, 1896, pt. 1, pl. 10, figs. 3, 4.-ZiтTeL, K. A., Handbuch der Palaeontologie, vol. 3, 1890, p. 732.-HAY, Bull. No. 179, U. S. Geol. Survey, 1901, p. 493.- NopcsA, F. B., Földtani Közlony, Budapest, vol. 31, 1901, p. 202.-GiLmore, Bull. 89, U. S. Nat. Mus., 1914, p. 25.-Mook, C. C., Ann. New York Acad. Sci., vol. 27, 1916, p. 142.

A pair of articulated pubes (No. 5737, U.S.N.M.) from which portions of the proximal articular ends are missing is here provisionally referred to the present

I Bull. Amer. Mus. Nat. Hist., vol. 19, 1903, pp. 459-464, figs. 1, 2, 3.

216 th Ann. Rept. U. S. Geol. Surv., pt. 1, 1896, pl. 7, fig. 1. 
species. This specimen was collected by M. P. Felch from "Quarry No. 1," near Canon City, Colorado, in 1884. They are slightly shorter than those figured by Marsh of this species (see pl. 34, figs. 5 and 6), and it is largely on account of this close agreement in size that they are identified as pertaining to $C$. agilis, for if Marsh correctly gives their relative dimensions in the type description ": "This animal was at least three times the bulk of the type," meaning the genotype $C$. fragilis.

The type of this species is in the Yale Museum and bears the No. 2010. In a letter of June 11, 1915, Professor Lull very kindly furnished me the following information concerning the type specimen:

C. agitis is one specimen only, consisting of two trays of material only partly prepared. As the material now is, I recognize the following bones: pubes, femur, tibia, fibula, humerus, radius, ulna, coracoid, an ungual, several podial bones, and several vertebrae. Preparation would doubtless increase this list.

Collected from Quarry 13, Como, Albany County, Wyoming, by W. H. Reed in 1881. At present the distinction of this species from C. fragilis rests on Marsh's statement of its larger size. Since $C$. fragilis is based on vertebrae alone and there are no vertebrae present in the type of $C$. agilis I question the authenticity of this species.

\section{Family ORNITHOMIMIDAE Marsh, 1890.}

\section{Genus ORNITHOMIMUS.}

The genus Ornithomimus was proposed by Prof. O. C. Marsh in $1890^{2}$ where he described ${ }^{3}$ the genotype 0 . velox, based on material from the Denver formation. In the same article two other species, $O$. tenuis and $O$. grandis, were briefly described on meager materials. The new family Ornithomimidae was also proposed but without definition. In the same year Zittel ${ }^{4}$ gave the first definition of the family as follows:

Shädel unbekannt. Vorderbeine kurz. Hand dreizehig. Hinterbeine sehr lang. Astragalus mit langern, aufsteigendem Fortsatz. Von den drei funktionirenden metatarsalia ist der mittlere (III) proximal verschmalert und durch die verdickten Gelenkenden der beiden andern ganz nach hinten gedrängt.

In $1892^{5}$ Professor Marsh briefly described two more species Ornithomimus sedens and 0 . minutus. He also correctly concludes that this genus should be referred "not to the Ornithopoda, but to the Theropoda."

In $1895^{\circ}$ Marsh included the family Ornithomimidae under the suborder Ceratosauria, and here gave his first definition of the family:

Pelvic bones coossified with each other and with sacrum; ilium expanded in front of acetabulum. Limb bones very hollow. Four limbs very small; digits with very long, pointed claws. Hind limbs of true avian type. Feet digitigrade and unguiculate.

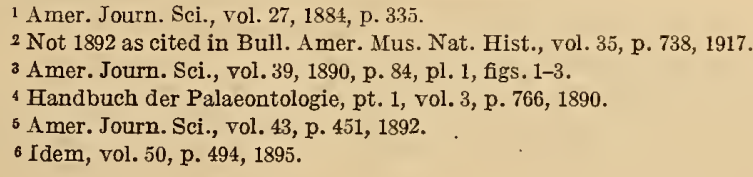


In $1896^{1}$ the same author gives a compilation of what has been written before of Ornithomimus; the plate illustrating the genotype $O$. velox is republished, and a text figure illustrating the terminal phalanx of the manus of $O$. sedens shows the character of that bone.

In $1897^{2}$ this same compilation was republished, with little change. In $1902^{3}$ Zittel included Ornithomimus under the family Megalosauridae without definition or remarks for so doing. In $1902{ }^{4}$ Lambe described the new species Ornithomimus altus from the Belly River formation of Red Deer River, Alberta, Canada, and contributed considerable to our knowledge of the skeletal anatomy.

In $1911^{5}$ Zittel, without comment, included Ornithomimus in the family Compsognathidae.

In $1917^{\circ}$ Osborn gave the first adequate knowledge of the skeletal anatomy of a representative of this family, the description and illustrations being based on a beautifully preserved skeleton from the Belly River formation as exposed along the Red Deer River, Alberta, Canada. This specimen on inadequate characters is made the genotype of the new genus Struthiomimus. He also gives a most interesting discussion of its probable habits, accompanied by life restorations illustrating the views set forth.

Professor Osborn says:

Ornithomimus, as a geologically more recent stage, is distinguished (from Struthiomimus) by the loss of metatarsal $\mathrm{V}$ in the pes, for which no facet remains, and other characters.

Quoting further from the above author, the principal reason for separating these genera is given in the following:

It is noteworthy that only a single genus or species of dinosaur is known to pass from the MoncloniusCeratops zone (Belly River, Judith River) into the Triceratops-Torosaurus zone (Hell Creek, Lance, Denver). This is the genus Trachodon. The known carnivorous and herbivorous dinosaurs underwent profound modifications and it is not probable, therefore, that the Ornithomimidae remained generically unchanged.

I do not believe the above reasons as enumerated by Osborn justify the establishment of a new genus. That the genus Ornithomimus does range through from Judith River to Lance time now appears to be indicated by a recent comparison of the type specimen of Ornithomimus sedens of the Lance formation (consisting of the articulated pelvic arch, sacrum, and 12 anterior caudals) with the Belly River specimen (Struthiomimus). It fails to disclose, differences that could by any possibility be construed to be of more than specific importance. In this connection it is also of interest to note that 14 specimens of the Ornithomimidae from the Triceratops-Torosaurus zone, listed by and apparently available to Osborn for comparison, failed to disclose generic characters beyond those quoted above.

In the light of our present knowledge, therefore, I shall for the present consider Struthiomimus to be a synonym of the earlier described Ornithomimus.

1 Dinosaurs of North America, pp. 204-206, pl. 58, text fig. 49-52, 1896

2 Vertebrate Fossils of the Denver Basin, p. 518, 1897.

3 Textbook on Paleontology, English Translation, vol. 2, p. 230.

4 Contr. Canadian Paleont., vol. 3, pt. 2, pp. 50-53, pls. 13, 14, and 15, figs. 1-8, text fig. 11, 1903.

$\checkmark$ Grundzuge du Palaeontologie, vol. 2, p. 283, 1911.

6 Amer. Mus. Nat. Hist., Bull. 35, pp. 738-761, pls. 26, 29, text figs. 3-8, 11-16, 1917. 
The family Ornithomimidae may now be characterized as follows:

Skull relatively small and edentulous. Pelvic elements coalesced; cervical ribs coossified to vertebrae, as in birds.

Generic characters.-Fore limbs slender and elongate, with three digits, provided with long, slightly recurved terminal phalanges. Femur shorter ${ }^{1}$ than tibia; pes with three digits, with or without vestigal fifth digit; distal caudals having an anterior rod-like elongation of the prezygapophyses.

Below is given a list of the species assigned to the genus Ornithomimus, the location of the type, its catalogue number, and the geological formation from which the type specimen was obtained:

Ornithomimus velox Marsh, 1890, Cat. No. 542, 548, Yale University Museum, Denver Formation, Upper Cretaceous.

Ornithomimus tenuis, 1890, Cat. No. 5814, U.S.N.M. Judith River formation, Upper Cretaceous.

Ornithomimus grandis=Deinodon (?) grandis. (Marsh), 1890. Type lost. Eagle formation, Upper Cretaceous.

Ornithomimus sedens Marsh, 1892, Cat. No. 4736, U.S.N.M., Lance formation, Upper Cretaceous.

Ornithomimus minutus Marsh. Type lost. Denver (?) formation, Upper Cretaceous.

Ornithomimus altus Lambe, 1902, Cat. No. 930, Ottawa Museum, Belly River formation, Upper Cretaceous.

Ornithomimus affinis, new species, Cat. Nos. 5704, 5684, 5453, 5652, 6108, 5703, 8456, and 6107, U.S.N.M., Arundel formation, Lower Cretaceous.

ORNITHOMIMUS SEDENS Marsh, 1892.

Plate 35, fig. 1 .

Ornithomimus sedens MARse, O. C., Amer. Journ. Sci., ser. 3, vol. 43, 1892, p. 451: Sixteenth Ann. Rept. U. S. Geol. Surv., pt. 1, 1896, p. 205, figs. 49-52.-HAy, O. P., Bull. No. 179, U. S. Geol. Surv., 1901, p. 494.-Nopcs A, F. Baron, Földtani Közlony, Budapest, vol. 31, 1901, p. 201.Osborn, H. F., Contrib. to Canadian Paleontology, vol. 3, pt. 2, p. 13, 1902.-Merrict, G. P., Cat. of Vertebrate Fossils, U. S. Nat. Mus., pt. 2, 1907, p. 74.-BoweN, C. F., U. S. Geol. Survey, Professional Paper 90-I, p. 134, 1915.

Type material.-No. 4736, U.S.N.M. Consists of the sacrum and 12 caudals in series, 6 chevrons, portions of both ilia and pubes, and both ischia. Collected by J. B. Hatcher and A. E. Sullins, 1891.

Type locality.-Alkali Creek, Niobrara County (formerly Converse County), Wyoming.

Horizon.--Lance formation, Upper Cretaceous.

The description of the type specimen of Ornithomimus sedens by Professor Marsh is as follows:

The present species is based upon the nearly complete pelvis, with various vertebrae, and some other parts of the skeleton. The most striking feature of the pelvis is the fact that the ilium, ischium, and pubis are firmly coossified with each other, as in recent birds. This character has been observed hitherto among dinosaurs only in Ceratosaurus, described by the writer from the Jurassic of Wyoming. ${ }^{2}$

1 Not longer, as stated by Marsh in his diagnosis of the genus, p. 240, Dinosaurs of North America.

2 A mistake; the specimen is from Colorado. 
[Amer. Journ. Sci., 1884, vol. 27, p. 329]. The present pelvis resembles that of Ceratosaurus in its general features, but there is no foramen in the pubis.

There are five vertebrae in the sacrum, firmly coossified with each other, as are also the sacral spines. The sacral vertebrae are grooved below, with the sides of the centra excavated. The caudals have the diplosphenal articulation; and the first caudal bears a chevron. All the bones preserved are very delicate, and some of them, at least, are apparently pneumatic.

The sacrum measures 15 inches in length, and the 12 caudals following occupy a space of 31 inches. The known remains indicate a reptile about 8 or 10 feet in length.

The known remains of all the above species are from the Ceratops Beds [Lance formation] of Wyoming.

The above description by Marsh constitutes practically all that has been written ${ }^{1}$ regarding this species, and the type specimen is here figured for the first time. That Ornithomimus sedens Marsh is closely related to Ornithomimus altus Lambe recently described by Osborn ${ }^{2}$ is at once apparent upon the most casua]

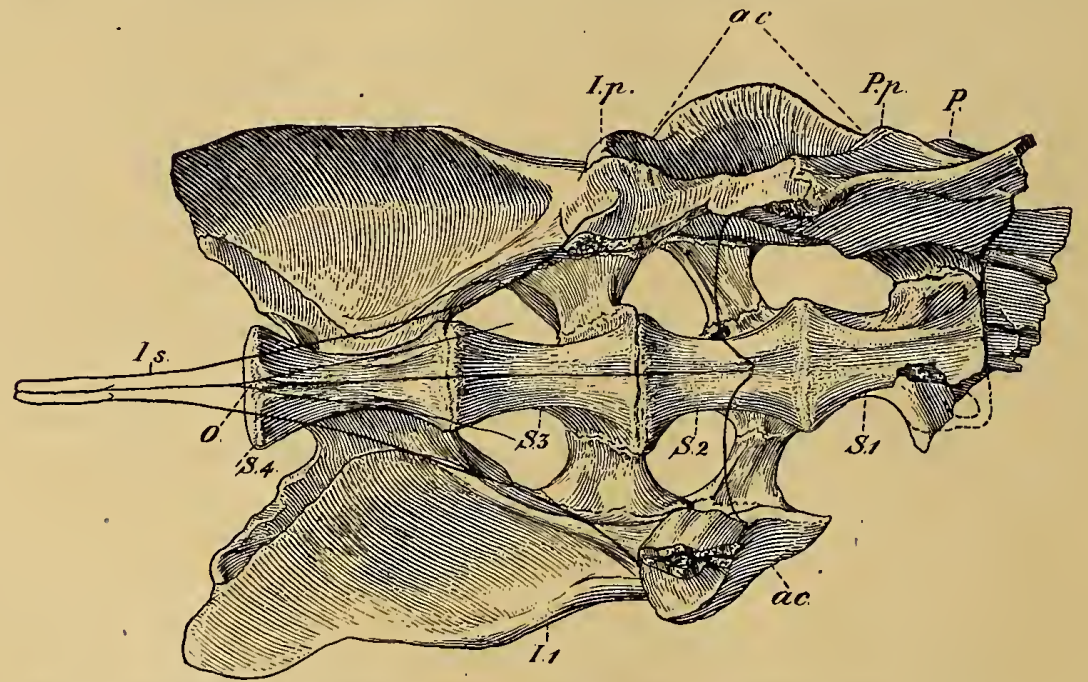

Fig. 67.-SACRUM OF ORNITHOMIMUS SEDENS MARSH. VENTRAL VIEW. TYPE No, 4736, U.S.N.M. 1 NAT. SIZE. ac, ACETABULUM; $I l$, ILIUM; $I s$, COALESCED ISCHIA, SHOWN IN OUTLINE; $I . p$, ISCHIAC PEDUNCLE OF THE ILIUM; 0 , OPENING BETWEEN COOSSIFIED ISCHIA; $P$, PUBIS; $P$. p., PUBIC PEDUNCLE OF THE ILIUM; $S_{1}, S_{2}, S_{3}, S_{4}$, SACRAL VERTEBRAE 1 TO 4.

comparison, and, as I have attempted to show, good reasons for their generic separation does not exist at this time.

The sacrum of Ornithomimus sedens is unusually well preserved and is worthy of a detailed description, especially since this portion of the beautiful skeleton described by Osborn (pl. 35, fig. 2) is somewhat imperfect.

Sacrum.-The sacral region in Ornithomimus sedens consists of five coossified vertebrae, but of these only four are preserved; the presence of a fifth is clearly indicated by the roughly rugose articular end of the most anterior vertebra for close union with the vertebra which preceded it. In position this missing vertebra corresponds to dorsal 13 in the Struthiomimus skeleton as described and figured by Osborn in the paper cited above. Thus in Ornithomimus sedens and in Ornithomimus altus it would appear that only four vertebrae functioned as sacrals.

1 A terminal phalanx of the fore foot of this specics was figured by Marsh (see figs. 49 to 52, p. 265, Dinosaurs of North America) but the basis of the identification is unknown to me.

${ }^{2}$ Bull. Amer. Mus. Nat. Fist., vol, 35, pp. 738-761, 1917. 
Sacral 1 is opposite the anterior (pubic) peduncle of the ilium, while sacral 3 is largely posterior to the posterior (ischiac) peduncle of the ilium. The centra of sacrals 1, 2, and 3 are relatively broad on their ventral aspects, but their surfaces are concave transversely, thus forming a shallow longitudinal groove. This groove is only slightly indicated on the last sacral. One of the striking features of the genus Ornithomimus and perhaps of the family Ornithomimidae is the presence of deep pneumatic cavities on the sides of the centra of sacrals 1, 2, and 3. Such cavities are not present in Antrodemus, Ceratosaurus, and Tyrannosaurus, nor are they mentioned by Lambe in his description of Gorgosaurus.

The sacral centra are joined to the ilia by short but stout sacral ribs. These ribs do not unite with the centra intervertebrally, but with large buttresses developed on the sides close to the anterior ends. This buttress on the second sacral extends posteriorly somewhat back of the center of the centrum, as shown in figure 67. The neural spines of the sacrals are all joined along the top; transverse thickening alone indicates the point of coalesence of these processes. Between sacrals 2 and 3 , and 3 and 4 there are vertical apertures, though in old individuals doubtless these openings would also have filled across with bone to form a continuous plate. Presumably the spinous process of dorsal 13 was also coalesced with the others, though all evidence on this point is missing in the present specimen. - In the articulated skeleton only the processes of the sacrals posterior to the first rise above the superior crests of the ilia, the first being on a level with the superior borders of the ilia, which closely lap it on either side. In the genotype of Struthiomimus the spinous process of sacral 4 is entirely separated from those preceding it, thus differing from Ornithomimus sedens, where it is coalesced at the top, though this represents a difference of degree rather than an important structural change. Anteroposteriorly the spinous process of sacral 3 measures $100 \mathrm{~mm}$.; sacral 4 measures $65 \mathrm{~mm}$.; while the spine of the first caudal measures only $38 \mathrm{~mm}$. in this dimension.

The length of the four sacral centra is $305 \mathrm{~mm}$., divided as follows: First, $71 \mathrm{~mm}$; second, $71 \mathrm{~mm}$.; third, $79 \mathrm{~mm}$.; and fourth, $84 \mathrm{~mm}$.

Caudal vertebrae. - In sequence with the sacrals are the first twelve vertebrae of the caudal series. Their principal measurements are given in the accompanying table:

Measurements in millimeters of the caudal vertebrae of Ornithomimus sedens.

\begin{tabular}{|c|c|c|c|c|c|c|}
\hline No. in series. & $\begin{array}{l}\text { Length of } \\
\text { centrum. }\end{array}$ & $\begin{array}{l}\text { Width pos- } \\
\text { terior end. }\end{array}$ & $\begin{array}{l}\text { Height over } \\
\text { all. }\end{array}$ & $\begin{array}{l}\text { Height of } \\
\text { spine above } \\
\text { neural canal. }\end{array}$ & $\begin{array}{l}\text { Greatest ex- } \\
\text { pansion of } \\
\text { transverse } \\
\text { processes. }\end{array}$ & $\begin{array}{l}\text { Length of } \\
\text { chevrons. }\end{array}$ \\
\hline 1 & 71 & 46 & 160 & 94 & 150 & 155 \\
\hline 2 & 66 & 41 & 144 & 82 & 118 & $\ldots$ \\
\hline 3 & 62 & 38 & 126 & 68 & 126 & 130 \\
\hline 4 & 61 & 36 & 119 & 62 & 122 & 121 \\
\hline 5 & 58 & 34 & 110 & 59 & 11.6 & \\
\hline 6 & 57 & 33 & 102 & 54 & 114 & 108 \\
\hline 7 & 55 & 30 & 95 & 4.9 & 110 & 97 \\
\hline 8 & 56 & 29 & 88 & 45 & 106 & $\ldots$ \\
\hline 9 & 56 & 29 & 82 & 38 & 102 &. \\
\hline 10 & 58 & 29 & 74 & 35 & 102 & \\
\hline 11 & 58 & 30 & 68 & 28 & $\ldots$ & . \\
\hline 12 & 58 & 32 & 61 & 24 & & \\
\hline
\end{tabular}

$144035^{\circ}-20--10$ 
Proceeding posteriorly the spinous processes of the caudals suffer a very rapid reduction in their height (pl. 35, fig. 1), the twelfth being about one-fourth the height of the first. Both the anterior and posterior borders of these processes are vertically grooved, the bottoms of the grooves being roughened for the attachment of ligaments (figs. 68 and 69). The tops of all of the processes are squarely truncated, and without
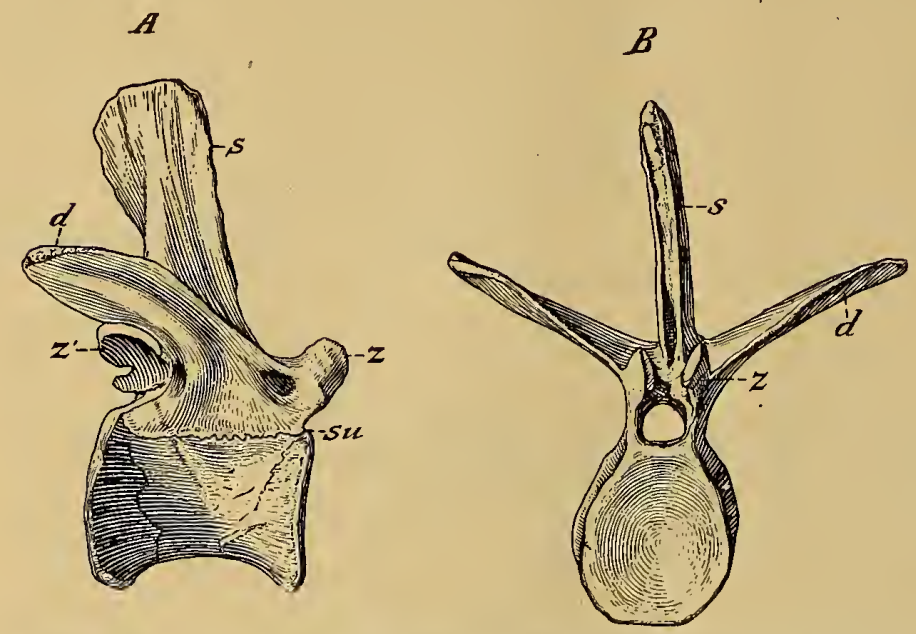

Fig. 68.-First CAUdal Vertebra OF ORNithomimus SEDENS MARsh. Type, No. 4736 U.S.N.M. $\frac{1}{3}$ NAT. SIZE. A, VIEWED FR TM THE RIGHT SIDE; B, VIEWED FROM THE ANTERIOR END; $d$, DIAPOPHYSIS; $s$, NEURAL SPINE; $s u$, SUTURE BETWEEN CENTRUM AND SPINOUS PROCESS; $z$, ANTERIOR ZYGAPOPHYSIS; $z^{\prime}$, POSTERIOR ZYGAPOPHYSIS.

transverse thickening except on the front and posterior margins, the median portion presenting an acutely edged border, especially pronounced in this respect, posterior to the eighth.

The transverse processes are especially broad an ter oposteriorly and placed well down on the sides of the neural arch. The first of the series are slightly elevated above the horizontal, but proceeding backward they gradually assume a horizontal, and finally in the most posterior ones are depressed below the horizontal. Marsh has pointed out the diplosphenal articulation of the caudal vertebrae and also that the first caudal bears a chevron, the longest of the series, as in Ornithomimus altus. Osborn ${ }^{1}$ describes the cherron of the latter as "elongate and rod-like." The close resemblance
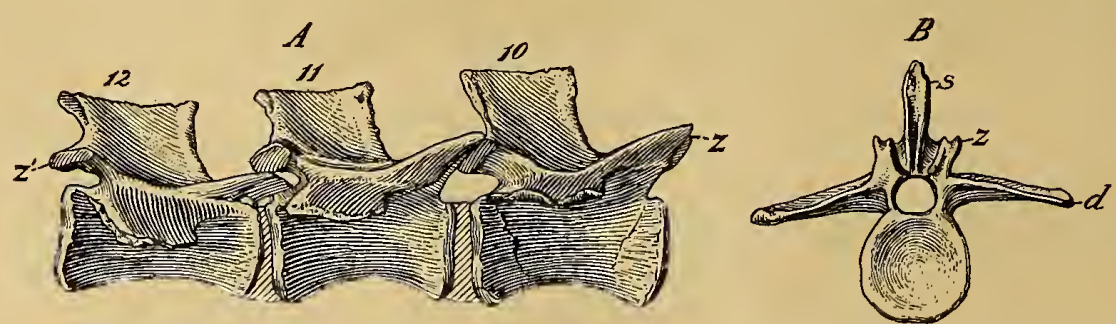

Fig. 69.-CaUdal Vertebrae 10,11, and 12 OF ORnithomimus Sedens Marsh. TyPe, No, 4736, U.S.N.M. $\frac{1}{3}$ Nat. SIZE. A, VIEWED FROM THE RIGHT SIDE; B, TENTH CAUDAL VERTEBRA VIEWED FROM FRONT; $d$, DIAPOPHYSIS; $s$, NEURAL SPINE; $z$ ANTERIOR ZYGAPOPHYSIS; $z^{\prime}$, POSTERIOR ZYGAPOPHYSIS. $10,11,12$, CAUDALS 10,11 , and 12 , RESPECTIVELY.

of this chevron to the first of $O$. sedens would indicate the above description not to be altogether accurate. None are especially elongate and certainly none are "rod-like," all being flattened transversely, and cimeter-like in their general outline. The first, third, fourth, part of fifth, sixth, and 
seventh chevrons are present (pl. 35, fig. 1). The articular end bridges across the haemal arch in all those preserved.

Pelvis. - The pelvic bones are firmly coossified with each other, as in Ceratosaurus nasicornis Marsh from the Morrison beds-a condition that also prevails in the Belly River Ornithomimus altus.

The postacetabular portion is especially thin, elongated, and terminates in an abruptly truncated end which is without thickening of the border. On the internal side there is the usual shelf of bone that extends inward and backward from the ischiac peduncle (fig. 67) to join with the sacral ribs of sacrals 3 and 4.

Viewed from above the articulated ilia lap closely along either side of the spinous processes of sacrals 1 and part way on that of sacral 2, at which point they begin to diverge until their upper posterior borders are $110 \mathrm{~mm}$. distant from one another. The postacetabular portion of the ilium at the end is $115 \mathrm{~mm}$. deep. The bone as preserved in this specimen has a greatest length of $420 \mathrm{~mm}$. It is estimated that the total length would be about $520 \mathrm{~mm}$. The preacetabular portion has a greatest vertical width at broken end of $150 \mathrm{~mm}$. The acetabulum measures $97 \mathrm{~mm}$. antero-posteriorly and $81 \mathrm{~mm}$. dorsoventrially.

Pubes. - The head of the right pubis is firmly coossified with the ilium and ischium and is all that remains of this pair of bones. This head has a greatest width of $125 \mathrm{~mm}$., subdivided as follows: $82 \mathrm{~mm}$. represents the part joining the public peduncle, while $43 \mathrm{~mm}$. represents its contribution to the boundary of the acetabulum. Viewed laterally the pubic peduncle and pubis form a much wider plate at their junction than in Ornithomimus altus as figured by Osborn, but I am inclined to think that this portion is missing in the restored skeleton, as suggested by the missing centra that pass back of this region, and which are indicated by dotted lines only. Compare figure 1, plate 35, with Osborn's figures of the restored skeleton of Struthiomimus altus.

Ischia.-Both ischia are present, and, with the exception of a small portion missing from their distal ends, are perfectly preserved. The proximal ends have the usually $Y$-shaped expansion with articular faces that articulate with the ilium and pubis (fig $67, i s$.). In the articulated pelvis the ischia extend downward and inward to meet on the median line throughout the greater part of their length. This union on the upper two-thirds by their inner edges is on the lower third made very strong by the great anteroposterior expansion of their distal ends, which are closely applied on the median line. A short aperture ( 0 , fig. 67) passes between the bones immeriately above the expanded distal ends.

\section{ORNITHOMIMUS TENUIS Marsh, 1890.}

Ornithomimus tenuis Marsh, Amer. Journ. Sci., ser. 3, vol. 39, p. 85, 1890--HAY, O. P., U. S. Geol. Surv. Bull. 179, p. 494, 1901.-Osborn, H. F., Contributions to Canadian Paleontslogy, vol. 3, pt. 3, p. 13, 1901.--HATCHER, J. B., Science, new. ser., vol. 16, No. 412, p. 831, 1902; U. S. Geol. Surv. Bull. 257, p. 87, 1905.-Bowen, C. F., U. S. Geol. Surv., Professional Paper 90-I, p. 132, 1915.

Struthiomimus tenuis OsBorn, H. F., Amer. Mus. Nat. Hist. Bull., vol. 35, pp. 740, 741, 1917.

Type.-No. 5814, U.S.N.M., consists of the distal half of metatarsal III, of the left foot. Collected by J. B. Hatcher, 1888. 
Locality. ${ }^{1}$-Near foot of the bluffs on the south banks of the Missouri River, opposite Cow Island, Montana.

Horizon.-Judith River formation, ${ }^{2}$ Upper Cretaceous.

The original description is as follows:

One of these, which may be called Ornithomimus tenuis, was about twice the bulk of the present form [0. velox]. The third metatarsal was much more compressed transversely, both in the shaft and distal end. The bone was also much more slender medially than in the above species. The transverse diameter of this metatarsal at its distal end was $30 \mathrm{~mm}$., and the anteroposterior diameter $35 \mathrm{~mm}$.
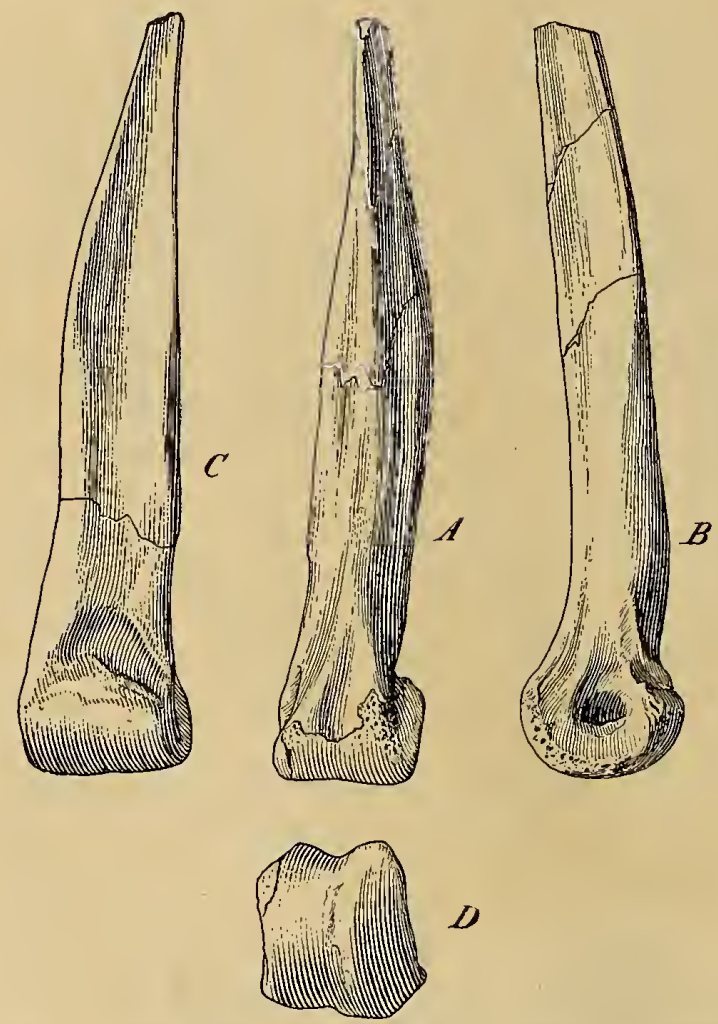

Fig. 70.-Distal half of Metatarsal III, ORNithommus tenUt MARSH, LEFT PES. TYPE, NO. 5814, U.S. N.M.; $A$, VIEWED FROM BACK; $B$, VIEWED FROM LEFT SIDE; $C$, VIEWED FROM THE FRONT. $D$, VIEWED FROM DISTAL END; ALL FIGURES $\frac{1}{3}$ NATURAL SIZE.

The chief features of the specimen are clea type specimen is illustrated for the first time.

1 This is the precise location given by Hatcher (Science, vol. 16, p, 831, 1902), but with the specimen there was a label that contained the following information: "Birch Creek, Montana, J. B. Hatcher, July 3, 1818 (1975) Box 5." This label also had written on it the same accession and box number as waspainted on the type specimen, and thisled me to believe it was written for this particular specimen, and I so wrote Professor Osborn prior to the appearance of his bulletin on Struthiomimus, Ornitholestes, and Tyrannosaurus.

2 Hatcher estimates the geological position of this specimen to be as follows (see Osborn, H. F., Science, vol: 16, p. 675, 1902): "From 1,500 to 1,600 feet below the summit of the Judith River beds and 500 to 600 feet below the level of Marsh's type of Ceratops montanus."
The above quotation gives practically all that had been written of this specimen, although it has been in the United States National Museum since the transfer of the Government collection from New Haven in 1899. Until recently it was unrecognized as being the type of this species. It was not distinctively marked, but that it does represent the specimen on which Professor Marsh established Ornithomimus tenuis appears to be indicated: First, by the exact agreement with the measurements given by Marsh of the distal end; second, it agrees with the brief description, especially as to the great transverse compression of the shaft; third, itwas marked as being metatarsal III. Inquiry discloses that the type specimen is not in the Yale University collections, and it is the only specimen in the United States National Museum collections that comes anywhere near filling all requirements. It would seem, therefore, that there can be little doubt that this is the original specimen which Marsh had before him when describing the above species. 
In size the type of Ornithomimus tenuis is intermediate between O. velox Marsh and $O$. altus Lambe. Resembling the latter more nearly in the more sudden contraction of the median portion of the shaft, but except for its very much smaller size (being one-third smaller), this bone resembles the corresponding element in Gorgosaurus more closely than it does any of the Ornithomimus metatarsals which have been figured or with which it has been compared. When viewed from the front the shaft is seen to have very little expansion toward the outer side, and the presence of a decided transverse excavation just above the distal articulating surface on the front are both features in which it differs from Ornithomimus and Struthiomimus and in which it resembles Gorgosaurus.

I am of the opinion that there is reason for considerable doubt to be cast on the present generic assignment, and that eventually it will be found to pertain to some other Upper Cretaceous theropod genus.

ORNITHOMIMUS AFFINIS, new species.

Allosaurus medius Marsh (part), Amer. Journ. Sci., ser. 3, vol. 35, 1888, p. 93.

Dryosaurus grandis LuLL, Md. Geol. Surv., Lower Cretaceous, 1911, pp. 204-206, pl. 19. figs. 6, 7; pl. 20, figs. 1-4.

Cotypes.-No. 5704, U.S.N.M., distal extremity of metatarsal II, right foot; Cat. No. 5684, U.S.N.M., distal extremity of metatarsal III, right foot; Cat. No. 5453, U.S.N.M., and 6108, proximal phalanges, digit II, both pertain to left feet; Cat. No. 5703, U.S.N.M., second phalanx, digit III, right foot; Cat. No. 8456, U.S.N.M., second phalanx, digit IV, left foot; 6107 , U.S.N.M., ungual phalanx, right hind foot, astragalus, No. 5652, U.S.N.M.

Type localities.-All of the cotypes, excepting No. 8456, U.S.N.M., collected near Muirkirk, Prince Georges County, Maryland, by J. B, Hatcher in 1888. The latter from Contee, Maryland, was collected by Arthur Bibbins.

Horizon.-Arundel formation, Lower Cretaceous.

In 1888 Marsh established the species Allosaurus medius on a number of separate bones, all of which, excepting a tooth, were subsequently referred by Lull to the genus Dryosaurus.

I now propose to remove all of the material mentioned by Lull, in his original description of Dryosaurus grandis to the genus Ornithomimus, these to become the cotypes of the new species Ornithomimus affinis.

I have compared these cotypes with the homologous elements of the Ornithomimus skeleton, and with other Ornithomimid specimens in the American Museum of Natural History from the Edmonton and Belly River formations, and find such close resemblances as to leave no doubt of their generic identity. Mr. Barnum Brown examined the typical specimens, and he concurs in my determination that they represent an Ornithomimid dinosaur.

The recognition of an Ornithomimid dinosaur in the Arundel fauna of Maryland comes naturally as a surprise, for prior to this time remains of the Ornithomimidae have only been found in the Judith River, Belly River, Edmonton, Denver, and Lance formations of the Rocky Mountain region, all Upper Cretaceous, while the Arundel has, on the best authority, been considered Lower Cretaceous in age. This discovery, therefore, greatly extends the known geographical and geological 
range of this dinosaurian family. It also raises a serious question as to the correctness of the accepted conclusions that the Arundel fauna is to be correlated with that of the Morrison; but that question is beyond the scope of the present study and will be treated elsewhere.

In describing these bones Lull has contrasted them with the hind feet of Dryosaurus altus Marsh and Laosaurus consors Marsh, especially the former, and the differences pointed out are invariably those which exist between Ornithopod and Theropod hind feet, as clearly shown by a comparison with a foot of Camptosaurus dispar Marsh (No. 5473, U.S.N.M.) and with a foot of Antrodemus valens Leidy (No. 8423, U.S.N.M.), which are now before me.

The left astragalus when viewed from below is somewhat hourglass shaped, narrowing toward the calcaneal facet. That it pertains to a member of the

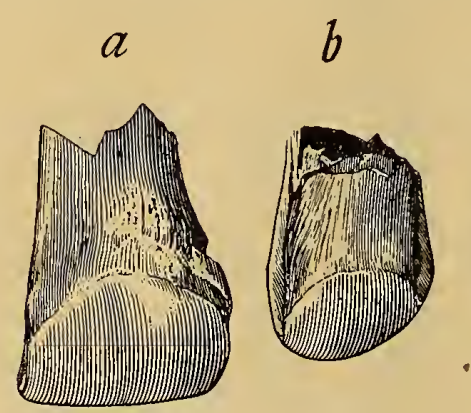

FIG. 71.-METATARSALS OF ORNITHOMMUUS AFFINIS NEW SPECIES. COTYPES. ( $a$ ) DISTAL END OF RIGHT METATARSAL III, No. 5684, U.S.N.M.. VIEWED FROM FRONT. (b) DISTAL END OF RIGHT METATARSAL II, No. 5704, U.S.N.M. VIEWED FROM FRONT. BOTH FIGURES $\frac{1}{2}$ NAT. SIZE (AFTER LULL).
Theropoda is clearly shown by the presence of an ascending process and its narrowness fore and aft as compared with its width. The ascending process as preserved does not show its full extent, having been much worn down by abrasion. Lull gives the following dimensions of this bone:

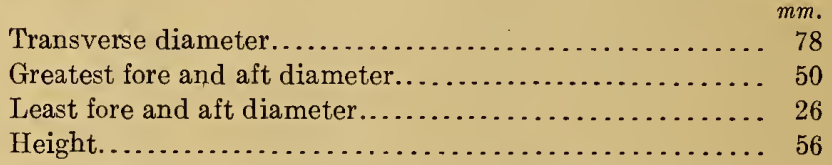

Metatarsal II, No. 5704, U.S.N.M., pertains to the right foot, and consists only of the distal articular end, as shown in figure $72 b$. I have compared it (as well as all the other cotypes of Ornithomimus affinis) with the same bone in the Ornithomimus altus foot No. 5339, A. M. N. History, and, except for being slightly heavier, is identical in all other respects. "The greater roundness of the articular face, lesser prominence of the other outer keel," and the more pronounced depressions upon the lateral faces of this metatarsal, as pointed out by Lull in comparing it with $D$. altus, are all Theropod characteristics as mentioned above. Its principal dimensions are as follows:

Width of articular extremity . . . . . . . . . . . . . .

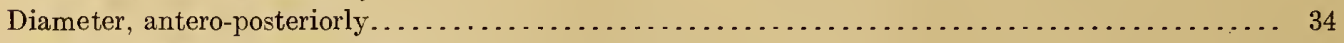

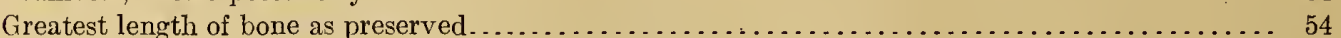

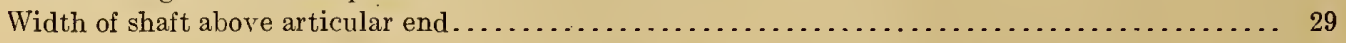

Metatarsal III, No. 5684, U.S.N.M., also pertaining to the right foot, consists of the complete distal articular end and a considerable portion of the lower third of the shaft as shown in figure 72 . Since Lull figured this bone ${ }^{1}$ the working up of the fragments has more than doubled its original length.

It is identical in shape but slightly smaller in size than metatarsal III of the Ornithomimus foot, with the exception that the transverse depression on the ante-

1 Maryland Geol. Surv., Lower Cretaceous, 1911, pl. 19, figure 7, right, here shown as figure 73 A. 
rior face above the articular end is more pronounced. Lull observes: "It in turn differs from that of ' $D$. altus' in having no median fore and aft depression over its articular face except a very slight one in front," which is exactly the difference to be observed between the Camptosaurus and Antrodemus metatarsals. Furthermore, the articular face does not extend as high up on the posterior as on the anterior side-another Theropod characteristic-whereas in Camptosaurus Trachodon, Thescelosaurus, and presumably also in Dryosaurus the two aspects are about subequal.

The principal measurements of metacarpal III are as follows:

Width of articular extremity . . . . . . . . .

.

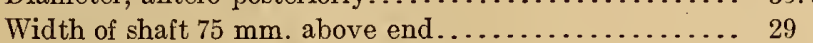

Greatest length of bone as preserved.............. 139.5

The proximal phalanx of digit $\mathrm{II}^{1}$ is represented by two bones, one slightly smaller than the other. The larger of these, No. 5453, U.S.N.M., is practically the same size as the proximal phalanx of digit II in the foot of Ornithomimus altus, which it closely resembles in all details. Both of these bones, Nos. 5453 and 6108 , pertain to left feet. The former is illustrated in two aspects in figure 73 . Their principal dimensions are as follows:
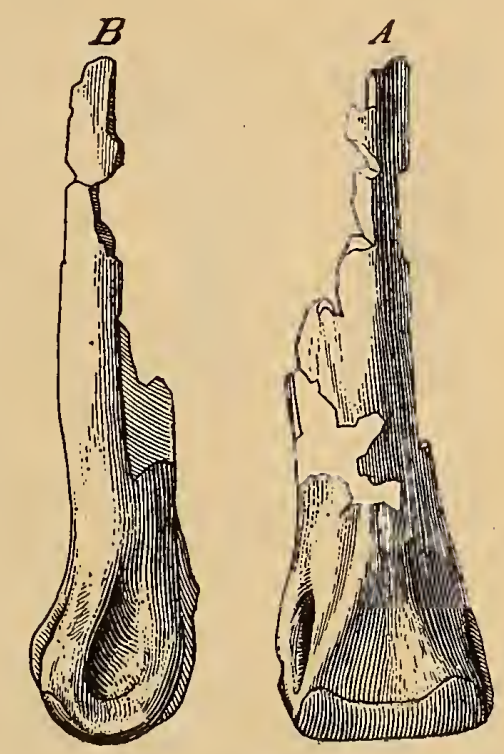

Fig. 72.-Right METATARSAL III OF ORNITHO. MIMUS AFFINIS, NEW SPECIES. COTYPE. No. 5684, U.S.N.M. ( $A$ ), POSTERIOR VIEW; $(B)$ EXTERNAL VIEW. BOTH FIGURES NAT. SIZE. SAME BONE AS $A$, FIG. 71, SHOWING ADDITIONAL FRAGMENTS FITTED ON SINCE THAT DRAWING WAS MADE.

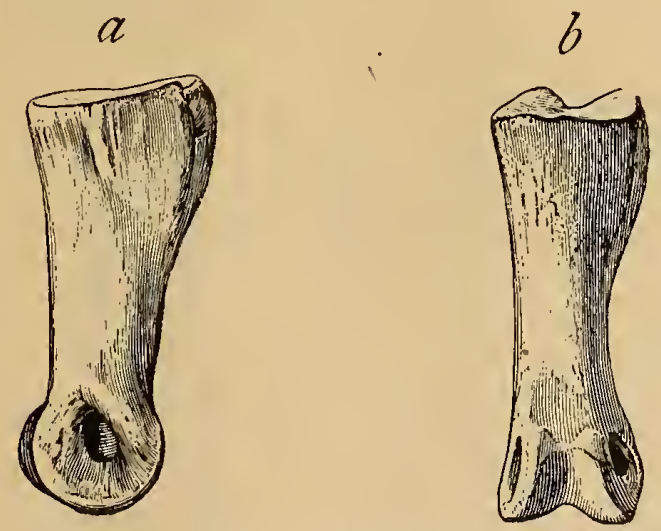

FIG. 73.-PROXTMAL PHALANX OF DIGIT, II, LEFT, OF ORNITH OMIMUS AFFINIS. COTYPE. No. 5453, U.S.N.M. (a) ANTERIOR VIEW; (b) LATERAL VIEW. BOTH FIGURES $\frac{1}{2}$ NAT. SIZE. (AFTER, LULL.) ulars. This bone is to be distinguished at once from the proximal phalanx of digit III 
by the decidedly deeper and more curved dorso-ventral concavity of the proximal end, whether it is compared with Camptosaurus or Antrodemus. From the Orni-

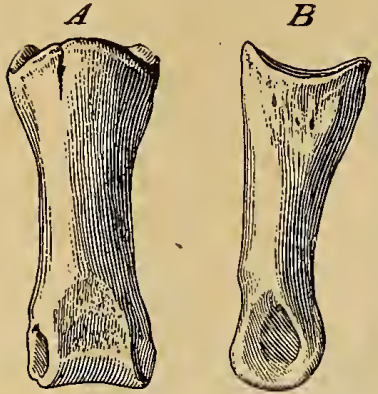

FIG. 74.-SECOND PHALANX DIGIT III RIGHT, OF ORNITHOMIMUS AFFINIS, NEW SPECIES. COTYPE No. 5703, U.S.N.M. (A) ANTERIOR VIEW, (B) LATERAL VIEW. BOTH FIGURES $\frac{1}{2}$ NAT. SIZE. thopod foot it is further distinguished by the absence of a deep median groove on the distal end and the presence of well-defined lateral pits, as in Antrodemus and Ornithomimus and probably all other Theropod foot bones. In all Ornithopod feet these pits on the phalanges are either illy defined or wanting. Its dimensions are as follows:

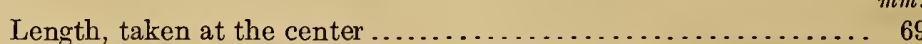

Width of proximal end $\ldots \ldots \ldots \ldots \ldots \ldots \ldots \ldots \ldots \ldots \ldots \ldots \ldots \ldots \ldots, 32$

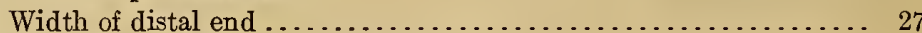

Least tränsverse diameter of shaft.................... 19

The second phalanx, No. 8456, U.S.N.M., of digit IV right hind foot is shown in figure 75 . It has the usual proximal ridge and distal groove, the deep la teral pits near the distal end which clearly indicates the Theropod affinities of this bone.

This bone has a greatest length over all of $38 \mathrm{~mm}$.; greatest width of proximal end of $24 \mathrm{~mm}$.; greatest width of distal end of $24 \mathrm{~mm}$.

The ungual, No. 6107, U.S.N.M. (fig. 76), Lull describes as follows:

The ungual, which is here referred to this species [Dryosaurus grandis] is compressed, triangular in section, the upper face bearing a rather sharp ridge, which separates it from those of Laosaurus consors those of Dryosaurus altus being unknown. It has a gentle curve with the characteristic slightly hollowed under surface of Laosaurus and the smaller Camptosaurus species.

Dimensions. $m m$.

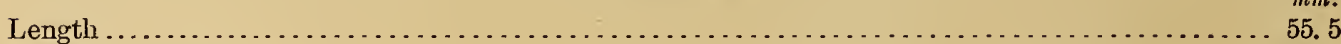

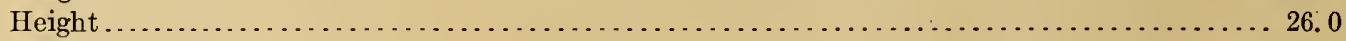

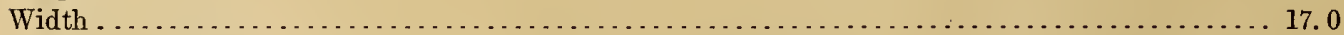

That this ungual phalanx pertains to a member of the Theropoda is at once indicated by its compressed shape, for among the dinosauria all of the herbivorous forms, with the exception of the Sauropoda, such as Laosaurus, Camptosaurus, Hypsilophodon, Thescelosaurus, Trachodon, Corthyosaurus, Iguanodon, Scelodosaurus Stegosaurus, Triceratops, etc., have depressed unguals.

This bone is the same size as the ungual of - digit I of the Ornithomimus foot, but I do not feel certain that it pertains to that digit. With the exception of being narrower transversely at the proximal end, it agrees closely in all other particulars.

In addition to the type material enumerated above there are two caudal vertebrae in the collection (Nos. 5701 and 6116 , U.S.N.M.) which are referred to this species, as is also the distal

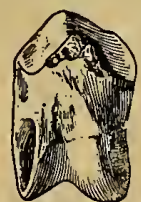

FIG. 75.-SECOND PHALANX DIGIT IV, RIGHT OF ORNITHOMIMUS AFFINIS, NEW SPECIES. COTYPE No. 8456, U.S.N.M. ANTERIOR VIEW. $\frac{1}{2}$ NAT. SIZE. (AFTER LULL.) end of a proximal phalanx No. 6115, U.S.N.M. These vertebrae are referred by Lull to Allosaurus medius Marsh, but their close resemblance to the caudals of Ornithomimus appears to indicate their Ornithomimid affinities. One of these is illustrated in figure 77. 
These caudals were compared with Ornithomimid vertebrae in the American Museum of Natural History, and so far as as comparison is possible, because of their incomplete preservation, they showed a very close resemblance in all essential features, especially in the prolongation of the anterior zygapophyses, the flattened ventral aspect, and in the much enlarged proximal end as contrasted with the smaller distal extremity. The centrum of No. 5701 has a greatest length of $68.7 \mathrm{~mm}$.; No. 6116 , a length of $67.5 \mathrm{~mm}$.

Judging from the size of some of the foot bones individuals of Ornithomimus affinis must have attained a size slightly in excess of the skeleton of Ornithomimus altus shown in plate 35 , figure 2 .

A single centrum, No. 8454, U.S.N.M. (fig. 78), was provisionally referred by Lull to Priconodon, but after comparing it with the type of Urnithomimus sedens Marsh, I now provisionally refer it to the genus Ornithomimus and tentatively to $O$. affinis. Lull's original description and discussion of this bone is as follows:

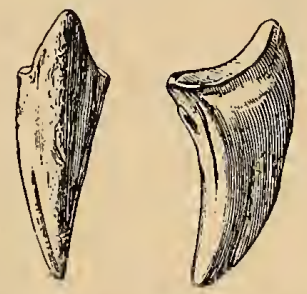

Fig. 76.-UNGUAL PHALANX RIGHT FOOT OF ORNINTHOMIMUS AFFLNIS, NEW SPECIES. COTYPE, No. 6107, U.S.N.M. ANTERIOR AND LATERAL VIEWS, 章 NAT. SIZE. (AFTER LULL.)

From the Arundel blue charcoal clay of Contee, Maryland, comes specimen No. 3101 [8454 U.S.N.M.] of the Goucher College collection, the centrum of a dorsal vertebra, unlike anything else in the entire mass of Arundel material. It represents a young animal, since the neural arch had not yet coossified with the centrum. The centrum is opisthocoelous, the anterior articular face being plane; the posterior a moderately deep concavity. The bone tapers decidedly, as the anterior face is less than four-fifths of the transierse diameter of the posterior. The sides are decidedly concave and meet in a slight keel-like angle inferiorly. The neural canal is extremely narrow, especially at a point just in front of the mid-length of the centrum. There are several tiny irreg-

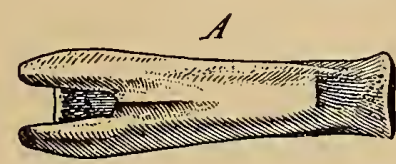
ularly placed foramina, which enter the centrum from the bottom of the canal, the two anterior ones being separated by a slight ridge. The irregular ridges on the articular face for the pedicels of the neural arch are approximately parallel, only radiating at the anterior end of the centrum. The bone appears to be solid, of fine cancellous character, with no trace of lateral depressions, such as one finds in Pleu-

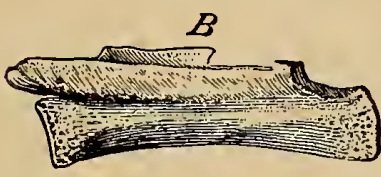
rocoelus. This vertebra, which evidently came from the mid-dorsal region, compares very closely with a vertebra of Stegosaurus ungulatus (cotype No. 1858, Yale Museum), except for size. The two vertebrae differ in the much less relative depth of the posterior concavity in Stegosaurus, and in the fact that the anterior and posterior concavity in Stegosaurus, and in the fact that the anterior and posterior faces are the same diameter in Stegosaurus; but there

Fig. 77.-Distal CAUdAL Vertebra o ORNITHOMIMUS AFFINIS, NEW SPECIES. No.5701, U.S.N.M.( $A$ ) SUPERIOR VIEW is a similar, though not quite so marked, tapering of the pedicel SLIGHTLY REstored; (B), LATERAL facets. The groove of the neural canal is wider in Stegosaurus, and VIEW. BOTH FIGURES $\frac{1}{2}$ NAT. SIZE. THE RESTORATION OF THE ZYGAPOPHYSES TOO SHORT.

seems to lack the constriction; but it is quite probable that the neural canal widened perceptibly vertically before narrowing again in the neural arch of Priconodon. There is no trace of a keel-like ridge on the lower side of the centrum of Stegosaurus, though the curve of the section is sharper here than on the sides. In neither case is there a trace of the capitular rib facet on the centrum, which in Stegosaurus is high on the greatly elevated neural arch.

In Plate 17 of the forthcoming monograph of the Stegosauria this bone is figured, together with a longitudinal section, showing its extremelydense cancellous tissue comparable to that of the centrum underdiscussion. From this comparison it seems reasonably sure that we have here the centrum of a stegosaurian dinosaur which will be provisionally referred to Priconodon. Whether it may be referred to $P$. crassus or not is an open question, for the vertebra is much smaller than that of the adult Stegosaurus ungulatus, 
while, on the other hand, the teeth of Priconodon are much larger than those of the stegosaur. Leidy says, however, that "we observe no necessary relation to the length of animals in proportion with the size of their teeth."

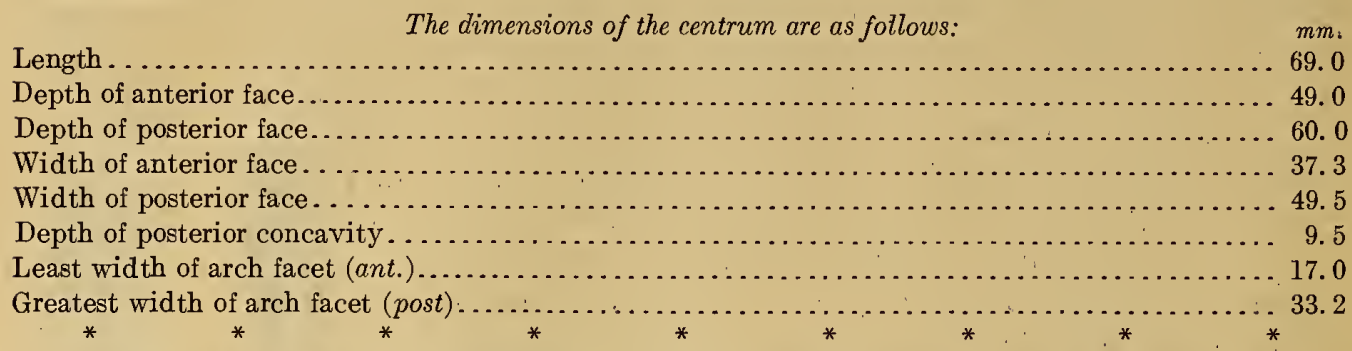

The vertebra is nearest to Stegosaurus, but the equivalent vertebra of Paloeoscincus is unknown, and the association of vertebrae and teeth is in each case conjectural.

The tapering centrum with flattened articular end, with a surface, although badly worn, highly suggestive of sutural roughening,

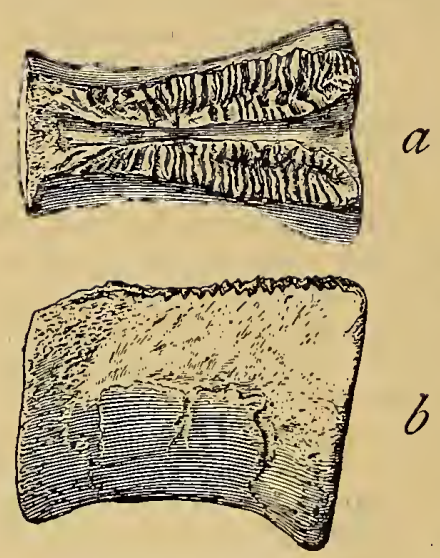

Fig. 78.-VERTEBRaL CENTRÚM OF ORNITHOMIMUS? AFFINIS, No. 8454; U.S.N.M. $\frac{1}{2}$ NAT. SIZE. $a$, DORSAL, $b$, LATERAL VIEWS. (AFTER LULL.) apparently indicates it to belong either to the sacrum or in contact with it. Certainly it does not belong to the mid-dorsal region as determined by Lull.

Compared with the sacral centra of Ornithomimus sedens, figure 67 suggests it to belong to the vertebra immediately preceding sacral 1 of that specimen, for the reason that sacral 1 has a flattened, rugose, anterior articular end, and from the fact that the present centrum can be readily distinguished from the other centra of this 'sacral series. Unfortunately, the centrum preceding the first sacral in the type of $O$. sedens is missing, as it is also in the Ornithomimus skeleton (pl. 35, fig. 2) in the American Museum of Natural History, so that a direct comparison can not be made at this time.

Compared with the posterior dorsal vertebra of Ornithomimus altus, figured by Lambe (fig. 1, pl. 13, Contrib. to Canadian Paleontology, vol. 3, pt. 2, 1902), such general resemblances were found in the outlines of the centra as to apparently show the correctness of the present provisional assignment of this specimen to the genus Ornithomimus.

\section{ORNITHOMIMUS MINUTUS Marsh, 1892.}

Ornithomimus minutus MaRSH, Amer. Journ. Sci., ser 3, vol. 43, 1892, p. 452; Sixteenth ann. Rept. U. S. Geol. Survey, 1896, pt. 1, p. 206.-HAY, Bull. 179, U. S. Geol. Survey, 1901, p. 494.- Nopcsa, F. Baron, Foldtani Kożlony, Budapest, vol. 31, 1901, p. 201.-Osborn, H. F., Contrib. to Canadian Paleontology, vol. 3, pt. 2, p. 12, 1902_-Bowen, C.'F., U. S. Geol. Survey, Prof. Paper 90-I, p. 134, 1915.

Type.-Various portions of metatarsals II, III, and IV now appear to be lost. Type locality.-Denver Basin, Colorado.

Horizon.-Denver (?), Upper Cretaceous.

The oiginal description is as follows:

In the same horizon occur the remains of a very minute species, which agrees in all its characters, so far as determined, with the members of this genus. The most characteristic portions secured are the 
metatarsal bones, and these show the same features exhibited in the type species of the genus $0 . v e l o x$. They are, however, so much smaller as to suggest that they may pertain to a bird. Various portions of the second, third, and fourth metatarsals are known, and the distinctive feature is seen in the third which has the upper part of the shaft so attenuated that it may not reach to the tarsus. The second and fourth metatarsals are very long and slender. This unique animal was about the size of the common fowl. The species has been called Ornithomimus minutus.

The type of this species appears now to be lost. In reply to my inquiry if the type specimen was not in the Yale University Museum, Dr. R. S. Lull, under date of February 7, 1908, wrote me as follows.

The type of Ornithomimus minutus is apparently in Washington. It evidently belonged to a lot of material bearing the diamond number $1871>$ received at this museum in $1887 .{ }^{1}$ Other than that we have no record of it whatever.

In my search of the paleontological collections of the United States National Museum for the missing type I found a small box, containing a glass vial in which were portions of three small foot bones. On the top of the box was the following information, apparently in Marsh's handwriting: "Ornithomimus minutus Metatarsal (new) (Bird or Ornithomimus), P. Qu. August 1-16, 1889-D. 2050." In all of the collection these were the only specimens found which could possibly represent the species Ornithomimus minutus. These bones, however, do not agree with the brief description given of the type by Marsh. He mentions having parts of metatarsals II, III, and IV, whereas there was only a considerable portion of one of the lateral metatarsals (fig. 79), and the distal portions of two phalangials found in this lot. There are a number of significant things in this connection, however; the word ("new") and above it printed on the box with a pen and probably at another time, the name "Ornithomimus

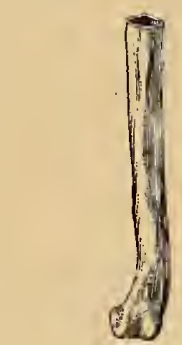

Fig. 79.-Left MetataRsal II? OF ORNITHOMIMUS MINUTUS MARSH. NO. 2909, U.S.N.M NATURAL SIZE. minutus" indicating that the bones were once recognized as representing a new form, and that later it was referred to by name. "P. Qu." was Marsh's abbreviation for Peterson's Quarry, and from the records we know that it was one of the places where Cretaceous mammal teeth were found in the Lance formation, in Niobrara County, Wyoming. The vcry fact that drawings were made of these bones would indicate that Marsh regarded them of considerable importance.

While it does not appear possible that these specimens represent the type of the species, I have gone into this matter in considerable detail, in order to place on record all of the information and its possibilities.

For the present this species must rest on the brief description cited above, and specimen No. 2909, U.S.N.M., here figured and which was identified by Professor Marsh as pertaining to this species.

The metatarsal of 2909 , U.S.N.M., lacks the proximal end, but otherwise it is perfectly preserved, as shown in figure 79. It appears to represent the second metatarsal of the left pes, though of this I can not be absolutely certain. That it is one of the lateral elements of the foot is elearly indicated by the decided deflec-

\footnotetext{
1 Records in the United States National Museum show that fossil specimens baaring the accession number $<1871>$ were r sesived at the Yale Museum during February, March, and April of the year 1887, all from the Cretaceou s of Colorado.
} 
tion of the distal portion. This distal end is slightly grooved-a feature that is not found in the other species of the genus. The bone is hollow and with thin walls. The inner side is flattened all along the shaft for contact with metatarsal III. It measures $32 \mathrm{~mm}$. in length; a greatest transverse diameter of the distal end of $5 \mathrm{~mm}$., and a greatest fore and aft diameter of $4 \mathrm{~mm}$.

The phalangials consist of the distal halves only. Their slightly expanded articular ends are grooved, the grooves and the rounded articular ridges on either side extending far up on the back of the bone. There are pronounced lateral pits on the sides, as in the larger species of the genus.

"CARnivorous dinosaurian" Cope.

Carnivorous Dinosaurian Cope, E. D., Rept. U. S. Geol. Surv. W. 100th Merid., vol. 4, pt. 2, p. 28, 1877, pl. 22, fig. 15.-Merriu, G. P., Bull. No. 53, pt. 2, U. S. National Museum, 1907, p. 65.

Specimen.-No. 2592, U.S.N.M. Consists of a single tooth.

Locality.-Gallinas Creek, New Mexico.

Horizon.-Triassic.

The above specimen Cope regarded as the tooth of a Theropod dinosaur of "the general character of Laelaps"; does not pertain to the dinosauria, at all, but to the Crocodylia to the family Phytosauridae.

\section{OBSERVATIONS ON THE PROGRESSIVE STRUCTURAL MODIFICATIONS OF THE THEROPOD SKELETON.}

In the course of this detailed study and comparison of the Antrodemus and Ceratosaurus skeletons with Theropod specimens from other geological formations, certain modifications were observed which appear to me to represent some of the progressive structural changes that the Theropod skeleton has undergone during successive geological periods.

Geologically the Theropoda have the greatest range of all the dinosaurs and should therefore furnish the most complete story of their development and specialization, but unfortunately many of the described genera and species have been founded on such scanty materials that our knowledge of the complete structure is too inadequate on which to make deductions or draw conclusions.

The work of recent years, however, is gradually correcting this condition through the recovery of more perfect skeletons, and it may be predicted with some degree of assurance that before many decades have passed our knowledge of the structural changes in the Theropod dinosaur skeleton will enable a paleontologist to determine from the stage of development its proper position in the geological column although this knowledge will probably never reach the degree of refinement attained in the mammalian structures.

Osborn ${ }^{1}$ was the first among American paleontologists to call attention to some of the progressive changes in the development of the Theropod skull. The more important of these, relating especially to members of the Megalosauridae, may be summarized as follows: 
1. Known change of slender, openly constructed skull of earlier forms to shortened: reduced fenestration with correspondingly expanded bony structures, which reaches its culmination in the Upper Cretaceous Tyrannosaurus.

2. Numerical reduction of the premaxillo-maxillary dental series.

3. A reduction in size of the prefrontals.

To these may now be added:

4. A change from the lengthened movably articulated quadrate in the Triassic and Jurassic Theropods to the much shortened and fixed quadrate of the Upper Cretaceous forms.

The specialization of the fore limb and foot in the carnivorous dinosauria during successive geological periods now appears to be (1) a relative diminution in the size of the entire fore limb; (2) a reduction of the number of digits; (3) the elongation of the penultimate phalanges; (4) lengthening of the scapula.

Beginning with the Triassic Theropods all are found to possess the full complement of five digits, though the fifth, as in Anchisaurus and the European Plateosaurus is usually reduced. In the Jurassic we find in Ornitholestes that the fifth digit has entirely disappeared and the fourth is represented by a vestigal metacarpal. $A n$ trodemus has gone still farther, and apparently the fourth has entirely disappeared, with a considerable reduction of the third, and approximately the same condition obtains in the hand of Compsognathus from the Upper Jurassic of Bavaria. Ceratosaurus is exceptional in having four digits, with both the first and fourth digits undergoing reduction. In the Upper Cretaceous we have in Gorgosaurus from the Belly River formation a still further reduction, there being only two functional digits, the third being represented by the vestigal metacarpal. The hand of Tyrannosaurus from the Lance is not yet known, but it appears quite probable that it will be found to be functionally didactyle.

In the hind feet we find that the Triassic carnivores all have five digits, the first and fifth undergoing reduction. So far as known at this time all of the Jurassic forms with the exception of Compsognathus have lost the fifth digit, with a further reduction of the hallux. While in the Upper Cretaceous genera the first digit has become relatively smaller and in Ornithomimus to have disappeared altogether, there is still a vestigal fifth present, as there is in Gorgosaurus. In Tyrannosaurus the fifth appears to have disappeared, though the first is still present and apparently not reduced much beyond the condition found in the Morrison Theropods.

The presence of the vestigal fifth in the Upper Cretaceous Theropods suggests that perhaps it is also present in such Morrison forms as Antrodemus and Ceratosaurus but has not yet been discovered. It is also to be noted that the rather loosely articulated metatarsals of Anchisaurus and Plateosaurus of the Triassic progressively become more and more compactly united, thus exhibiting a more powerful and less mobile arrangement of the metatarsals, which in this respect attains the highest degree of specialization in the Upper Cretaceous genera.

The astragalus also exhibits a progressive development of the ascending process, as shown by its absence, or, at the most, an incipient stage in the Triassic Theropoda, the intermediate stage in the Morrison forms, and its maximum development in the 
Upper Cretaceous genera, where it covers almost the entire anterior face of the distal end of the tibia.

Earlier in the present paper I have attempted to show that a complete section across the abdominal curiass of Antrodemus consists of at least seven and probably eight or nine distinct ossifications.

In this connection it is of interest to know that in the adult Sphenodon a complete section of the abdominal basket is usually composed of three parts-a median and two lateral bones-one at either end, but it has also been shown ${ }^{1}$ that in the embryo Sphenodon each of these three sections of the adult have a compound origin for all of the parts, median and paired alike. This fact explains the presence here and there of transverse joints, as observed by Günther and as are to be seen in a skeleton of Sphenodon punctatum (No. 29516, U.S.N.M.) now before me.

Howes and Swinnerton ${ }^{2}$ in the paper cited above point out that one of the most distinctive characters of Credner's Palaeohatteria of the Permian is the multisegmentated condition of its "abdominaI ribs," which, on careful examination of the originals, he has shown to be also the condition in Von Meyer's famous Proterosaurus and other genera to which he refers. In view of the obvious similarity of the embryo Sphenodon, it suggests to the above authorities 'that the 'plastron' may be undergoing reduction in the living genus. * * * Moreover, the multisegmented condition of the 'plastron' segments is nothing short of a Stegocephalian character."

Applying the above conclusions to the known American Theropods we find the very interesting suggestion that perhaps one of the progressive changes in the skeletal structure of the carnivorous dinosauria of successive geological formations is a reduction in number of the segments going to make up the abdominal ribs, for we find in Antrodemus, from the Morrison formation of the Jurassic, that each section of the curiass is composed of seven or more distinct ossifications, that Gorgosaurus, from the Belly River formation, of the Upper Cretaceous, has four, and that Tyrannosaurus, of the Lance formation, the latest of the Upper Cretaceous series, have been reduced to two.

Our knowledge of the abdominal structures of the Theropod dinosauria at this time is too deficient to determine the merit of the above suggestion; but there is, it appears to me, enough evidence to justify one in such an assumption.

In the pelvis and sacrum the progressive modifications noted at this time are: an increase in the number of coossified vertebrae in the sacrum from three to five, a lengthening of the ilium, and the devclopment of a triangular foot-like enlargement of the distal ends of the pubes. The modifications noted above were largely developed during the early part of the Mesozoic, for the Upper Cretaceous carnivores show no especial change since Morrison time in the above respects.

In the pubes wc also find that the Triassic forms had a closed obturator foramen, while in the Jurassic, with the exccption of Ceratosaurus and possibly Megalosaurus, all othcrs, including the Upper Cretaceous Theropods, have a notch which probably functioned in the same capacity.

In this brief review of the observed structural modifications of the Theropod skeleton I feel that only a small number of the changes to be found have been

${ }_{1}$ Howes and Swinnerton, Trans. Zool. Soc. London, vol. 16, 1901, pp. 35-36, pl. 2, figs. 8, 9, 10.

2 Idem., p. 36. 
touched upon. The discovery of more and better preserved materials and the description of specimens already in the collections of our museums will undoubtedly add much to our knowledge of the skeletal modifications that have taken place during successive geological periods.

Such mechanical progression as has here been recorded is in the direction or adaptation of the skeleton from the generalized to the specialized, thus producing a more efficient mechanism for the particular purpose of speed and destructive power so necessary for the maintenance of life itself.

\section{LIST OF WORKS CITED.}

AвEL, O. Das Zeitalter der Reptilienherrschaft. Vortrage des Vereines zur Verbreitung naturwissenshaftlicher Kenntruise in Wein, vol. 49, 1909, pp. 9, 10, fig. 3.

Beasley, Walter A. A Carnivorous Dinosaur; a reconstructed skeleton of a huge Saurian. Scientific American, vol. 97, 1907, pp. 446-447, three text figures and cover (frontispiece).

Cope, E. D. The Extinct Batrachia, Reptilia and Aves of North America, Trans. Amer. Philos. Soc., vol. 14,1871 , pp. 100-122.

On the Skull of the Dinosaurian Laelaps incrassatus Cope. Proc. Amer. Philos. Soc., vol. 30,1892, p. 241.

On the homologies of the posterior cranial arches in the Reptilia. Trans. Amer. Philos. Soc., vol. 17,1892, p. 18.

Gilmore, Chartes W. A New Rhynchocephalian Reptile from the Jurassic of Wyoming, with Notes on the Fauna of "Quarry 9." Proc. U. S. Nat. Mus., vol. 37, 1910, pp. 39, 40, fig. 3.

Osteology of the Armored Dinosauria in the United States Museum, with Special Reference to the Genus Stegosaurus, Bull. 89, U. S. Nat. Mus., 1914, p. 25.

- On the Fore Limb of Allosaurus fragilis. Proc. U. S. Nat. Mus., vol. 49, 1915, pp. 501-513.

$\mathrm{H}_{\mathrm{AY}}$, O. P. Bibliography and Catalogue of the Fossil Vertebrata of North America. Bull, 179, U. S. Geol. Surv. 1901, pp. 487-494.

- On Certain General and Species of Carnivorous Dinosaurs, with special Reference to Ceratosaurus nasicornis Marsh. Proc. U. S. Nat. Mus., vol. 35, 1908, pp. 351-366, text figs. 1-4.

Huene, F. von. Die Dinosaurier der Europaischen Triasformation, Geologische und paleoniologishe abhandlungen Supplement, vol. 1, 1907-1908. Jena.

Hutchrnson, H. N. Extinct Monsters. Ed. 2, 1893, pp. 83-85, figs. 16, 17, 18.

- Extinct Monsters and Creatures of other days. 1911, new edition, pp. 132-145, text figs. 42, 44, 45,46, pls. 14,15 .

Huxley, T. H. On the classification of the Dinosaurus, with Observations on the Dinosauria of the Trias. Quart. Jour. Geol. Soc. London, vol. 26, 1870, pp. 32 (with one plate).

JAEKel, Oтto. Die Wirbeltiere, 1911, p. 160, fig. 176.

Lambe, L.M. On Dryptosaurus incrassatus (Cope), from the Edmonton Series of the Northwest Territory. Contr. Canadian Palaeont., vol. 3, pt. 3, 1904, pp. 5-27, pls. 1-8.

- On the Fore Limb of a Carnivorous Dinosaur from the Belly River Formation of Alberta, and a new genus of Ceratopsia from the same Horizon, with Remarks on the Integument of Some Cretaceous Herbi vorous Dinosaurs. Ottawa Naturalist, vol. 27, 1914, pp. 129-131, pl. 13.

- On a New Genus and Species of Carnivorous Dinosaur from the Belly River formation of Alberta, with a Description of the Skull of Stephanosaurus marginatus from the same Horizon. Ottawa Naturalist, vol. 28, 1914, pp. 13-17.

The Cretaceous Theropodous Dinosaur Gorgosaurus. Memoir 100, Geol. Surv. Canada, 1917, p1). 1-84, 49 text figures.

Lucas, F. A. Animals of the Past. 1901, pp. 106, figs. 23, 25.

- Animals Before Man in North America. 1902, pp. 164, figs.

Lult, R. S. Dinosaurian Distribution. Amer. Journ. Sci., vol. 29, 1910, pp. 13-16, 19-21, figs, 1, 4, 8.

The Reptilia of the Arundel formation. Maryland Geological Survey, Lower Cretaceons. 1911, pp. 183-188.

—_Cretaceous Dinosaurs. Bull. Geol. Soc. Amer., vol. 23, 1912, pp. 208, 209. 
LydekKer, R. Catalogue of Fossil Reptilia and Amphibia in the British Museum, pt. 1. 1888, pp. 154173 , figs. $25,26$. Some Recent Restorations of Dinosaurs. Nature, July 27, 1893, pp. 302-304, fig. 2.

Marsh, O. C. Principal Characters of American Jurassic Dinosaurs. Amer. Journ. Sci., vol. 17, pt. 2 , 1879, pp. 89-92, pls. 8-10.

Notice of New Jurassic Reptiles. Amer. Journ. Sci., vol. 18, 1879, pp. 504-505.

Principal Characters of American Jurassic Dinosaurs. Amer. Journ. Sci., vol. 21, pt. 5, 188], p. 423.

- A New Order of Extinct Jurassic Reptiles (Coeluria). Amer. Journ. Sci., vol. 21, 1881, pp. 339430 , pl. 10.

Classification of the Dinosauria. Amer. Journ. Sci., ser. 3, vol. 23, 1882, pp. 81-86.

- Principal Characters of American Jurassic Dinosaurs, pt. 8. The order Theropoda. Amer. Journ. Sci., vol. 27, 1884, pp. 329-340, pls. 8-14.

- On the United Metatarsal Bones of Ceratosaurus. Amer. Journ. Sci., vol. 28, 1884, pp. 161-162, text figs. 1-2.

Notice of a New Genus of Sauropoda and other New Dinosaurs from the Potomac formation. Amer. Journ. Sci., vol. 35, 1888, pp. 93-94. 451-452.

Restorations of Clasosaurus and Ceratosaurus. Amer. Journ. Sci., vol. 44, 1892, pp. 347-349, pl. 7.

Geological Magazine, London, vol. 10, 1893, p. 153, pl. 6.

On the Affinities and Classification of the Dinosaurian Reptiles. Amer. Journ. Sci., vol. 50, 1895, pp. 483-498, text figs. 1-11, pl. 10.

- Dinosaurs of North America. Sixteenth Annual Report U. S. Geological Survey for 1894-5, pt. 1, 1896, pp. 153-163, 203-206, 239-240, pls. $2,3,4,6,7,8,9,10,11,12,13,14,58$, 77, figs. $2,82$.

- Monograph U. S. Geological Survey, vol. 27, 1897, p. 503, pl. 25, text fig. 60 .

Menzbier, M.

Bull. Soc. Imp. Nat. Moscou, new ser., vol. 2, 1887, p. 553.

Mix, Jennie Irene, Mighty Animals. 1912, Frontispiece.

Nopcsa, F. B. A Foldtani Kozlong, Budapest, vol. 31, 1901, pp. 195-203, pl. 1.

British Dinosaurs: Streptospondylus. Geological Magazine, vol. 2, 1905, pp. 289-293.

Osbons, H. F. Fore and Hind Limbs of Carnivorous and Herbivorous Dinosaurs from the Jurassic of Wyoming. Dinosaur Contribution No. 3. Bull. Amer. Nat. Hist., vol. 12, 1899, pp. 161-164, figs. 1, 2, 3, 4, 4a.

The skull of Creosaurus. Bull. Amer. Mus. Nat Hist., vol. 19, 1903, pp. 697-701, figs. 1, 2.

Ornitholestes hermanni, A New Compsoguathoid Dinosaur from the Upper Jurassic. Bull.

Amer. Mus. Nat. Hist., vol. 19, Art. 12, 1903, pp. 459-464, figs. 1, 2, 3.

Fossil Wonders of the West. The Century Magazine, vol. 68, 1904, pp. 680-694.

Crania of Tyrannosaurus and Allosaurus. Mem. Amer. Mus. Nat. Hist., vol. 1, new. ser., pt. 1,

1912, pp. 3-30, text figs. 1-27, pls. 1-4.

Tyrannosaurus, Upper Cretaceous Dinosaur (Second Communication.) Bull. Amer. Mus. Nat.

Hist., vol. 22, 1906, pp. 281-296, figs. 2, 6 .

Skeletal Adaptations of Ornitholestes, Struthiomimus, Tyrannosaurus. Bull. Amer. Mus. Nat.

Hist., vol. 35 , art. 43,1917 , pp. $733-771$, pls. 24 to 37 , text figs. 1-19.

WALcotT, C. D. Correspondence Science, ser. 2, vol. 11, 1900, p. 23.

Woodward, A. S. Outlines of Vertebrate Paleontology, 1898.

ZitTel, K. A. Handbuch der Palaeontologie, vol. 3, 1890.

Text-book of Paleontology, Eng. Edition, vol. 2, 1902, pp. 227-230, figs. 328, 329, 330.

Grundzuge der Palaentologie, vol. 2, 1911, pp. 278-283, figs. 424, 425, 427. 


\section{EXPLANATION OF PLATES.}

\section{Plate 1.}

Type of Antrodemus valens Leidy, compared. Anterior half of an anterior caudal centrum. No. 218, U.S.N.M.

Figs. 1, 2, and 3. Posterior, lateral and sectional views of the type of Antrodemus valens Leidy.

4, 5, and 6. Same views of No. 8367, U.S.N.M. Sixth caudal vertebra of Antrodemus valens Leidy, previously identified as Allosaurus fragilis Marsh to show the close resemblances of these bones in two differentindividuals. All figures slightly more than two-thirds nat. size.

Plate 2.

(See p. 3.)

Type of Allosaurus fragilis Marsh.

Fig. 1. Proximal phalanx of digit III, right-hind foot. No. 1930, Yale University Museum, superior view.

2. Posterior dorsal centrum, same specimen. Inferior view.

3. Posterior sacral? centrum, same specimen. Inferior view. Reproduced from photographs of casts of the type specimen. All figures about three-quarters nat. size.

(See p. 4.)

Plate 3.

Skull of Antrodemus Leidy.

FIG. 1. Top view of the skull of Antrodemus valens Leidy. No. 4734, U.S.N.M.

(See p. 14.)

2. Skull and lower jaws Antrodemns valens Leidy. Viewed from the right side. No.4734, U.S.N.M. Both figures about one-quarter nat. size. Reproduced from photographs. The light-colored portions represent the restored bones.

(See p. 7.)

Plate 4.

Skull of Antrodemus.

Fig. 1. Top view of the skull of Antrodemus valens Leidy. No. 4734, U.S.N.M.

(See p. 14.)

2. Skull of Antrodemus valens Leidy. Viewed from the right side. No. 4734, U.S.N.M., alsp., alisphenoid; an., angular; ar., articular; $d$. , dentary; ec.pt., ectopterygoid; ex.mf., external mandibular foramen; $f$., frontal; $f^{\prime}$., first antiorbital fenestra; $f . "$, second antiorbital fenestra; $j$. , jugal; la., lachrymal; lat.t. fen., lateral temporal fenestra; $m x$. , maxillary; $n_{.}$, nasal; o., orbit; $p$. , parietal; par., prearticular; $p f$. , prefrontal; $p m x$. , premaxillary; p.oc., paraoccipital; po.f., postfrontal; pt., pterygoid; q., quadrate; $q j$. , quadratojugal; sa., surangular, $s q .$, squamosal; s.t.f., supratemporal fossa. Both figures, one-quarter nat. size.

(See p. 7.)

\section{Plate 5.}

Scapulae of Antrodemus.

FIG. 1. Left scapula and coracoid of Antrodemus valens Leidy. No. 4734, U.S.N.M. The blade of this scapula has suffered injury in life, as evidenced by the bifurcated and greatly widened end, as compared with the opposite normal bone of the same individual, see fig. 2. (See p.57.)

2. Right scapula and coracoid of same. Both figures about one-third nat. size. (See p. 58.)

\section{Plate 6.}

\section{Humerus of Antrodemus.}

FIGS. 1-7. Left humerus of Antrodemus valens Leidy. Yale University Museum. a, anterior side; $d$. , deltoid ridge; i. c., internal condyle; o. c., outer condyle; $p$. , posterior side. Fig. 1, internal view; 2 , posterior view; 3 , anterior view; 4 , external view; 5 , proximal view; 6 , distal view; 7 crosssection of shaft. All of the figures are one-half natural size. Drawn under the direction of Prof. O. C. Marsh.

(See p. 58.) $144035^{\circ}-20-11$ 


\section{Plate 7.}

Fore and hind feet of Antrodemus.

FIG. 1. Right hind foot of Antrodemus valens Leidy. No.324, A.M.N.H. A bout one-sixth natural size. Viewed from the front. (After Osborn.)

2. Same foot. Oblique internal view to show the complete hallux. (After Osborn.) (See p. 73.)

3. Right fore foot of Antrodemus valens Leidy, No. 4734, U.S.N.M. Less than one-half natural size. Shows the radius, ulna, and complete foot just as it was found in the sandstone.

Plate 8.

(See p. 60.)

\section{Sacrum of Antrodemus.}

IIG. 1. Sacrum of Antrodemus valens Leidy. No. 4734, U.S.N.M. Viewed from the left side; onefourth natural size. $a c$. , acetabulum; $d$., diapophyses of sacral vertebrae; $i l$. , right ilium; $i . p$., ischiac peduncle; $p . p$., pubic peduncle; $s r$., sacral ribs; $s_{1} s_{5}$, sacral vertebrae one and five, respectively. The contour of the anterior border of the ilium is missing and is here incorrectly restored; compare with fig. 2, pl. 10. Drawn under the direction of Prof. O. C. Marsh.

\section{Plate 9.}

(See p. 43.)

Sacrum and ilia of Antrodemus.

Figs. 1 and 2. Sacrum with attached ilia of Antrodemus valens Leidy. No. 4734, U.S.N.M. ac., acetabulum; il., ilium; i.p., ischiac peduncle; p.p., pubic peduncle; s., spinous processes; $S_{1} S_{5}$, sacral vertebrae one and five, respectively; $z^{\prime}$, posterior zygapophyses. 1 . Posterior view of sacrum with articulated ilia. 2. Ventral view of same. Both figures onefourth natural size. Drawn under the direction of Prof. O. C. Marsh.

(See p. 53.)

\section{Plate 10.}

\section{Sacrum and ilia of Antrodemus.}

FIgS. 1 and 2. Sacrum and ilia of Antrodeums valens Leidy. No. 4734, U.S.N.M. p. p., pubic peduncle; $s$., spinous processes; $S_{1}$, first sacral vertebra; $z$., anterior zygapophyses. 1 . Anterior view of sacrum with articulated ilia. 2. Lateral view of detached left ilium of same. Both figures are about one-fourth natural size. Fig. 1. drawn under the direction of Prof. o. C. Marsh. (See p. 43.)

\section{Plate 11.}

\section{Pubes of Antrodemus.}

Figs. 1-3. Pubes of Antrodemus valens Marsh. In Yale University Museum. Young individual. d., distal end of foot; $i l$., surface for articulation with pubic peduncle of ilium; is., process for articulation with pubis; su., sutural surface for union with opposite pubis on median line. 1, anterior view of articulated pubes; 2 , external view of right pubis; 3 , internal view of right pubis. All figures one-fourth natural size. Drawn under the direction of Prof. O. C. Marsh.

\section{Plate 12}

(See p. 67.)

\section{Ischia of Antrodemus.}

Figs. 1-8. Ischia of Antrodemus valens Leidy. In Yale University Museum. il., surface for articulation with ischiac peduncle of ilium; ob. $p r$., obturator process; $p$., process for articulation with the pubis; $s . s$., flattened sutural surface for union of the two ischia on the median line. 1 , posterior view of articulated ischia; 2 , anterior view of articulated ischia; 3 , external view of left ischium; 4 , internal view of left ischium; 5 , top view of articulated ischia; 6 , top view of left ischium; 7 , distal ends of articulated ischia; 8 , cross section of shafts of ischia. All of the figures one-fourth natural size. Drawn under the direction of Prof. O. C. Marsh. 


\section{Plate 13.}

Hind limbs, pelvis and sacrum of Antrodemus valens Leidy. No. 4734, U.S.N.M. About one-thirteenth nat. size. Viewed from the right side. Shown as mounted and exhibited in the U.S. National Museum. The anterior end of the ilium has been incorrectly restored as may be seen by comparing it with the left element shown in fig. 2, pl. 10, which is complete. (See p. 67.)

\section{Plate 14.}

Femur of Antrodemus.

Ficss. 1-7. Left femur of Antrodemus valens Leidy. In Yale University Museum. a., anterior trochanter; $b$., area for attachment of large muscle; $h$, head; $i c$. , internal condyle; m.c., medullary cavity; oc., outer or external condyle; $t r$., fourth trochanter. 1 , external view; 2, anterior view; 3 , posterior view; 4 , internal view; 5 , proximal view; 6 , cross section of shaft; 7 , distal view. All of the figures are one-fourth nat. size. Drawn under the direction of Prof. O. C. Marsh.

(See p. 68.)

\section{Plate 15.}

Abdominal ribs of Antrodemus valens Leidy. No. 4734, U.S.N.M. Viewed from the ventral side as found in the matrix. Less than one-half nat. size.

(See p. 53.)

Plate 16.

\section{Restorations of Antrodemus.}

Upper figure. Mounted skeleton of Antrodemus in the American Museum of Natural History, New York. No. 5753, about one-thirtieth natural size. This is the only mounterl skeleton of this animal.

(See p. 56. .)

Lower figure. Restoration of Antrodemus (Allosaurus) by Chas. R. Knight. Based on the mounted skeleton shown in figure above. Both figures after H. F. Osborn. Reproduced here through the courtesy of the American Museum of Natural History.

(See p. 56.)

\section{Plate 17.}

\section{Skull of Ceratosaurus.}

FIg. 1. Skull and lower jaws of Ceratosaurus nasicornis Marsh, viewed from the right side. Type. No. 4735, U.S.N.M. About one-fourth nat. size. 1, angular; 2, first antiorbital fenestra; 3, articular; 7, dentary; 10, hyoid? bone; 11, jugal; 13 maxillary; 14, maxillary depression; 15, external nares; 17, nasal horn; 19, orbit; 22, parietal; 24, postfrontal; 25 , lachrymal; 26, premaxillary; 27, postnarial foramen; 28 , pterygoid + portion of quadrate; 30 , quadrate; 31, quadratojugal; 33, squamosal; 34, surangular; (after Hay).

2. Left side of same skull and lower jaws. About one-fourth nat. size.

(See p. 78.)

(See p. 78.)

\section{Plate 18.}

\section{Restored skull of Ceratosaurus.}

FIG. 1. Top view of skull Ceratosaurus nasicornis Marsh. Type. Cat. No. 4735, U.S.N.M. (See p. 80.)

2. Skull and lower jaw of Ceratosaurus nusicornis Marsh. Type. Viewed from the right side. No. 4735, U.S.N.M. an., angular; ar., articular; bo., occipital condyle; $d$. , dentary; $e x$. $o c$., exoccipital; $f$., frontal $; f^{\prime}$., first antiorbital fenestra; $j$. , jugal; la., lachrymal; lat. $t$. fen., lateral temporal fenestra; $m x .$, maxillary; $n$. , nasal; $n . h$. , nasal honcore; $o$. , orbit: $p$. , parietal; p.ar., prearticular; $p f$. , prefrontal; $p m x .$, . premaxillary; p.oc., paroccipital; po.f., postfrontal+postorbital; pt., pterygoid; q., quadrate; $q j$. , quadratojugal; sa., surangular; sq.., squamosal; s.t.f., supratemporal fossa. Both figures one-fourth nat. size. (See p. 78.) 
Plate 19.

Atlas and axis of Ceratosaurus.

FIgs. 1-5. Atlas of Ceratosaurus nasicornis Marsh. Type. No. 4735, U.S.N.M. 1, inferior view; 2, top view; 3 , posterior view; 4 , lateral view; 5 , anterior view.

6-10. Axis of Ceratosaurus nasicornis Marsh. Type. No. 4735, U.S.N.M. 6, inferior view; 7, top view; 8 , posterior view; 9 , lateral view; 10 , anterior view. $d$. , diapophysis; in., intercentrum of atlas; n., neurapophysis; n. p., neurapophysial processes; o., odortoid; $p$., parapophysis; z., anterior zygapophyses; $z^{\prime}$., posterior zygapophyses. All the figures are one-half nat. size. All except figure 2 are after Marsh. All drawn under the direction of Prof. O. C. Marsh.

(See p. 95.)

\section{Plate 20.}

\section{Cervical vertebrae of Ceratosaurus.}

Figs. 1-4. Third cervical vertebra of Ceratosaurus nasicornis Marsh. Type. No. 4735, U.S.N.M. Fig. 1. Anterior view; 2, posterior view; 3, ventral view; 4, lateral view. All the figures are one-half nat. size. (After Marsh.)

(See p. 95.)

5. Sixth cervical vertebra of Ceratosaurus nasicornis Marsh. Type. No. 4735, U.S.N.M. Lateral view. One-half nat. size. $d$. , diapophysis; o.s., dermal ossifications; $p$., parapophysis; s., neural spine; z., anterior zygapophyses; $z^{\prime}$. , posterior zygapophyses; (After Marsh.) All drawn under direction of Prof. O. C. Marsh.

(See p.96.)

\section{Plate 21:}

Sacrum and pelvis of Ceratosaurus.

FIG. 1. Sacrum and pelvis of Ceratosaurus nasicornis Marsh. Type. Cat. No. 4735, U.S.N.M. Ventral view. 2. Same viewed from the front. ac., acetabulum; $c_{1} c_{2}$, caudal vertebrae 1 and 2 ; $i l$., ilium; i.p., ischiac peduncle; is., ischium; $p$. , pubes; $p . f$., pubic foramen; $p p$. , pubic peduncle; p.s. 21 , presacral $21 ;$ p.s. 23 , presacral $23 ; r_{.}$, posterior thoracic rib crushed backward out of position; s., spinous process of dorsal vertebra; $s_{1}, s_{5}$, sacrals one and five. Both figures drawn under the direction of Prof. O. C. Marsh but certain features as explained in the text are misleading. Both figures are one-four,th nat. size.

(See p. 97.)

\section{Plate 22.}

Caudal vertebrae of Ceratosaurus.

FIg. 1. Articulated caudal vertebrae 2 to 12, inclusive, of Ceratosaurus nasicornis Marsh. Type. No. 4735, U.S.N.M. Viewed from the left side. os., row of dermal ossifications as found in position in the matrix, $2,3,4,5,6,7,8,9,10,11 ; 12$; caudal vetebrae 2 to 12 .

(See p. 98.)

2. Ventral view of same; Both figures are one-fourth nat. size. Drawn under the direction of Prof. O. C. Marsh.

\section{Plate 23.}

(See p. 98.)

\section{Pelvis of Ceratosaurus.}

Pelvis and sacrum of Ceratosaurus nasicornis Marsh. Type. No. 4735, U.S.N.M. Viewed from the left side, ac., acetabulum; is., ischium; p., pubis; p.f., pubic foramen; p.s., 22, presacral vertebra $22 ; s$., suture between pubis and ischium; $s_{5}$, sacral five. One-fourth nat. size. Drawn under direction of Prof. O. C. Marsh.

(See p. 106.)

\section{Plate 24.}

\section{Metatarsals of Ceratosaurus.}

Figs. 1-4. Metatarsals of left hind foot of Ceratosaurus nasicornis Marsh. Type. No. 4735, U.S.N.M, 1, anterior view; 2, lateral view, external side; 3 , lateral view, internal side; 4, superior view. II, III, IV, metatarsals 2, 3, and 4. All the figures are one-half nat. size. Drawn under the direction of Prof. O. C. Marsh.

(See p. 112.) 
Plate 25.

Metatarsals of Ceratosaurus.

FIgs. 1-2. Metatarsals of left hind foot of Ceratosaurus nasicornis Marsh. Type. Cat. No. 4735, U.S.N.M. 1, posterior view; 2, distal view; I, roughened surface for articulation of hallux, II, III, IV, metatarsals 2,3, and 4. Both the figures are one-half size. Drawn under the direction of Prof. O. C. Marsh.

(See p. 112.)

Plate 26.

Left ramus and scapula of Ceratosaurus.

1. Left scapula of Ceratosaurus nasicornis Marsh. Type. No. 4735, U.S.N.M. External view. About one-third nat. size. Distal end missing.

2. Left ramus of Ceratosaurus nasicornis Marsh. 'Type. No. 4735, U.S.N.M. Internal view. About one-third nat. size.

(See p. 88.)

\section{Plate 27.}

Restorations of Ceratosaurus.

Upper figure. Restoration of Ceratosaurus nasicornis Marsh. 1892. One-thirtieth nat. size. There are five too many restored dorsal vertebrae in the middle of the back bone. (After Marsh.)

(See p. 115.)

Lower figure. Life restoration of Ceratosaurus nasicornis Marsh. By Frank Bond, 1889. Drawn under the direction of Professor W. C. Knight.

(See p. 115.)

\section{Plate 28.}

\section{Restorations of Ceratosaurus.}

Upper figure. Life restoration of Ceratosaurus nasicornis Marsh, by J. M. Gleeson, 1901. Drawn under the direction of Charles R. Knight. (After F. A. Lucas.)

(See p. 115.)

Lower figure. Life restoration of Ceratosaurus nasicornis Marsh. By J. Smit, 1911. (After Rev. H. N. Hutchinson.)

(See p. 116.)

Plate 29.

Skeleton of Ceratosaurus.

Mounted skeleton of Ceratosaurus nasicornis Marsh. No. 4733, U.S.N.M. About onethirtieth nat. size. Shown as exhibited in the U. S. National Museum.

(See p. 114.)

Plate 30.

\section{Restoration of Ceratosaurus.}

Drawing of the mounted skeleton of Ceratosaurus nasicornis Marsh, shown in the preceding plate. The original parts present in the skeleton are represented by line shading and the restored parts in outline. The ribs have been restored too heavy, their distal ends especially should be more slender and tapering. There is also one too many presacral vertebrae in the backbone. About one-fifteenth nat. size. 1, first caudal vertebra; 9, ninth cervical vertebra; 23 , twenty-third presacral or last dorsal vertebra.

(See p. 114.)

\section{Plate 31.}

\section{Restoration of Ceratosaurus.}

Model restoration of Ceratosaurus nasicornis Marsh. Modeled by Charles W. Gilmore, 1915. Based on the type and mounted skeleton shown in plate 29. In order to depict the flesh-eating habits of Ceratosaurus, it is shown here as completing the kill of Camptosaurus nanus, a small herbivorous contemporary. About one twenty-fourth nat.size. (See p. 116.) 


\section{Plate 32.}

Caudal vertebrae of Dryptosaurus and Antrodemus.

FIG. 1. Anterior caudal vertebra of Dryptosaurus? potens (Lull). Type No. 3049, U.S.N.M. Viewed from the left side. About two-thirds nat. size.

(See p. 117.)

2. Anterior caudal vertebra of Antrodemus valens Leidy, No. 8367 , U.S.N.M. Viewed from the left side. About two-thirds nat. size. Comparative views to show difference in outline, especially of the ventral borders.

(See p. 117.)

\section{Plate 33.}

Lower jaw of Labrosaurus.

Left dentary of Labrosaurus ferox Marsh. No. 2315, U.S.N.M. Type. One-half nat. size. (After Marsh.) ' 1, lateral view; 2, internal view; 3, superior view.

(See p. 124.)

\section{Plate 34.}

Bones of Dryptosaurus and Coelurus.

Fig. 1. Tooth of Dryptosaurus? medius (Marsh). No. 3121, Goucher College. Side and front views, nat. size. (After Lull.)

2. Tooth of Dryptosaurus? medius (Marsh). Type No. 4972, U.S.N.M. Twice nat. size.

(See p. 120.)
(3. Proximal phatanx of hind

3. Proximal phalanx of hind foot of Dryptosaurus? medius (Marsh). Superior view, three-eighths nat. size. (After Lull.) (See p. 121.)

4. Tooth of Coelurus? gracilis Marsh. No. 4973, U. S. N. M. Side view. Nat. size. (After Lull.)

(See. p. 126.)

Frgs. 5 and 6. Pubes of Coelurus agilis Marsh. Yale University Museum. 5, side view; 6, front view. One-fourth nat. size. $a$, proximal end; $b$, articular ends of pubes; $c$, distal ends. (After Marsh.)

(See p. 128.)

7 and 8. Dorsal vertebra of Coelurus fragilis Marsh. Type No. 1991, Yale Museum, nat. size. 7 , front view; 8 , side view. $a$, anterior end; $d$, diapophysis; $n c$, neural canal; $p$, posterior end; $s$, base of neural spine; $z$, anterior zygapophysis; $z^{\prime}$, posterior zygapophysis. (After Marsh.)

(See p. 127.)

\section{Plate 35.}

\section{Skeletons of Ornithomimus.}

FIG. 1. Articulated sacrum, caudal vertebrae and pelvis of Ornithomimus sedens Marsh. Type No. 4736, U.S.N.M. Viewed from right side. About one-sixth nat. size.

(See p. 133.)

2. Skeleton of Ornithomimus altus Lambe. No. 53339, Amer. Museum of Natural History. Shown in the attitude as found and as now exhibited. About one-fifth nat. size. (After Osborn.)

(See p. 130.)

\section{Plate 36.}

Bones of Coelurus and brain of Ceratosaurus.

Figs. 1-2. Cast of brain cavity of Ceratosaurus nasicornis Marsh. Made from skull shown in plate 17.

(1) Viewed from top; (2) View ed from left side. cer., cerebral hemispheres; med., medulla oblongata; olf., olfactory lobe; I, II, III, V, cranial nerves one, two, three and five. Both figures one-half nat. size. (After Marsh.)

(See p. 93.)

3. Ungual phalanx of an unidentified dinosaur from the Belly River formation (Upper Cretaceous), No. 5387, Amer. Mus. Nat. Hist. Lateral view. Twice nat. size. (See p. 127.)

4. Ungual phalanx of Coelurus? gracilis Marsh. Type. No. 4973, U.S. N. M. Lateral view. Twice nat. size. With the exception of size note the close resemblance of this bone to fig. 3 .

(See p. 127.) 

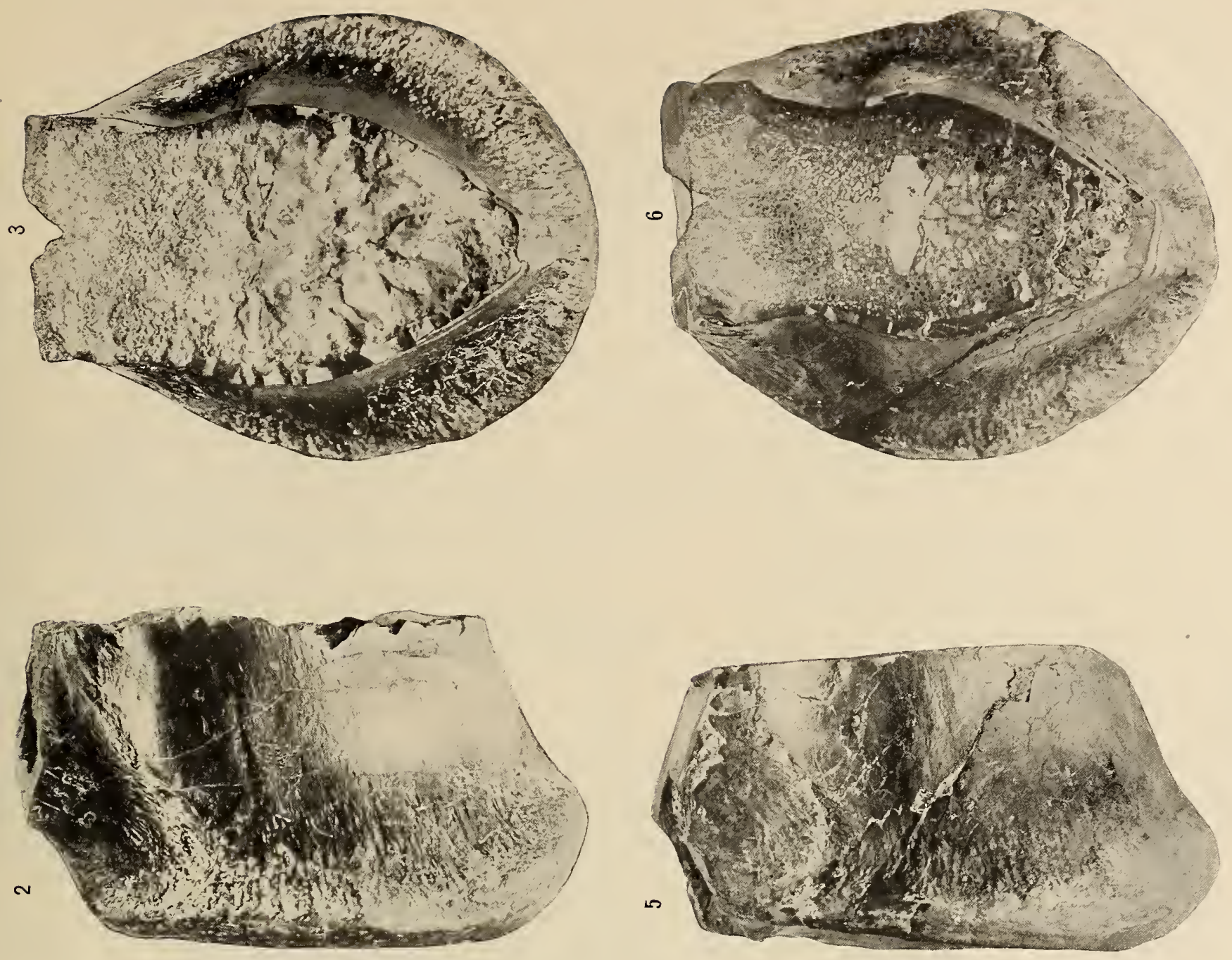

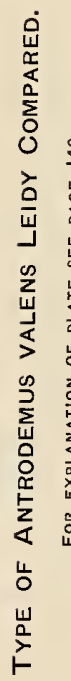
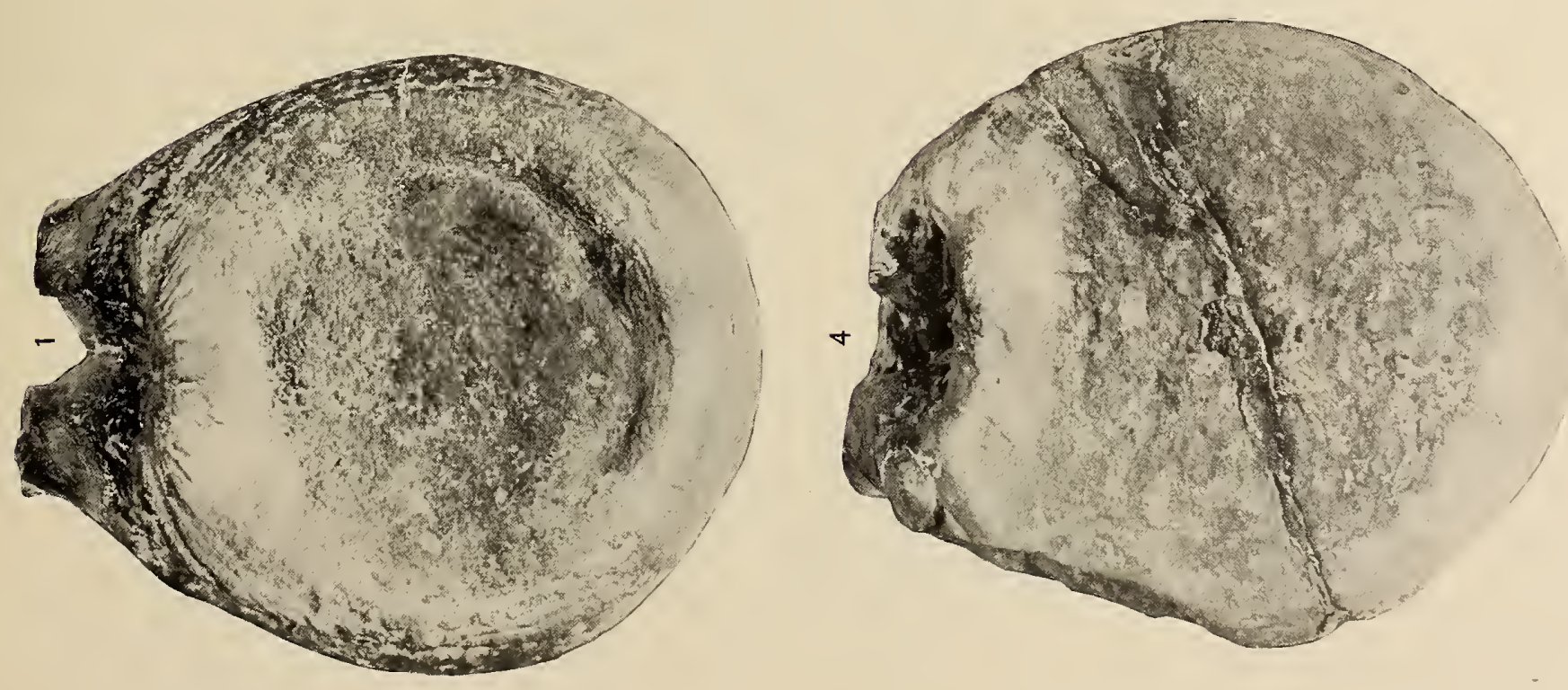
1

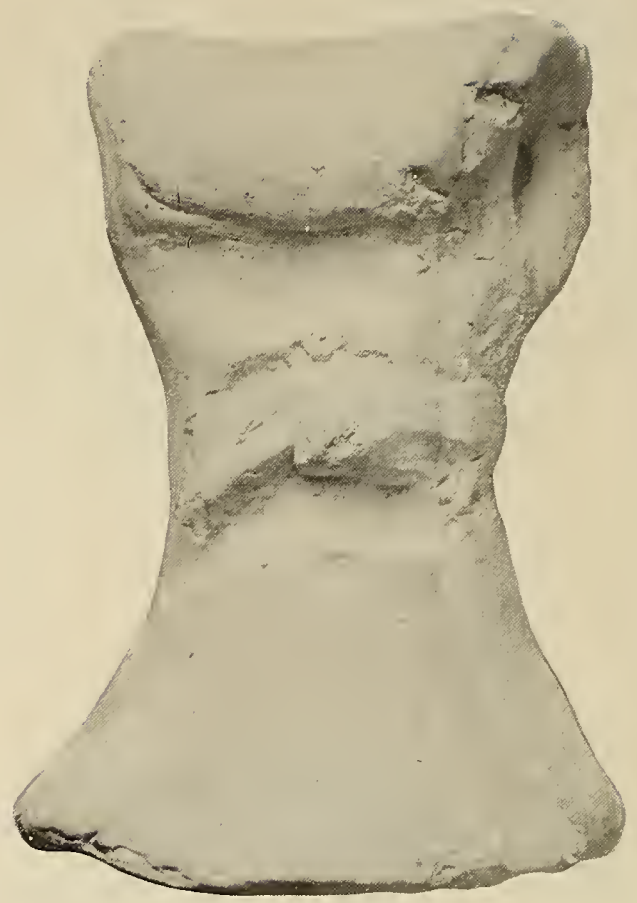

2

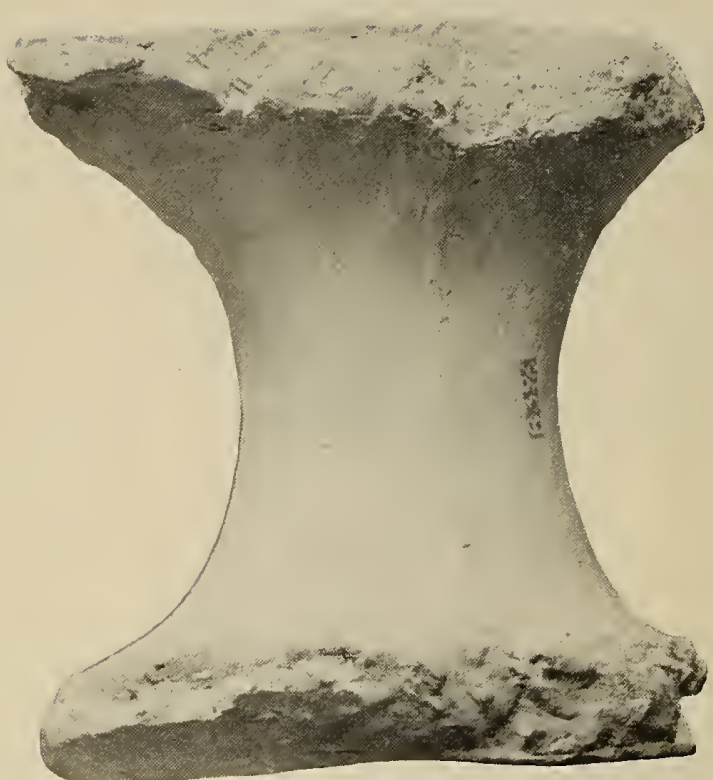

3

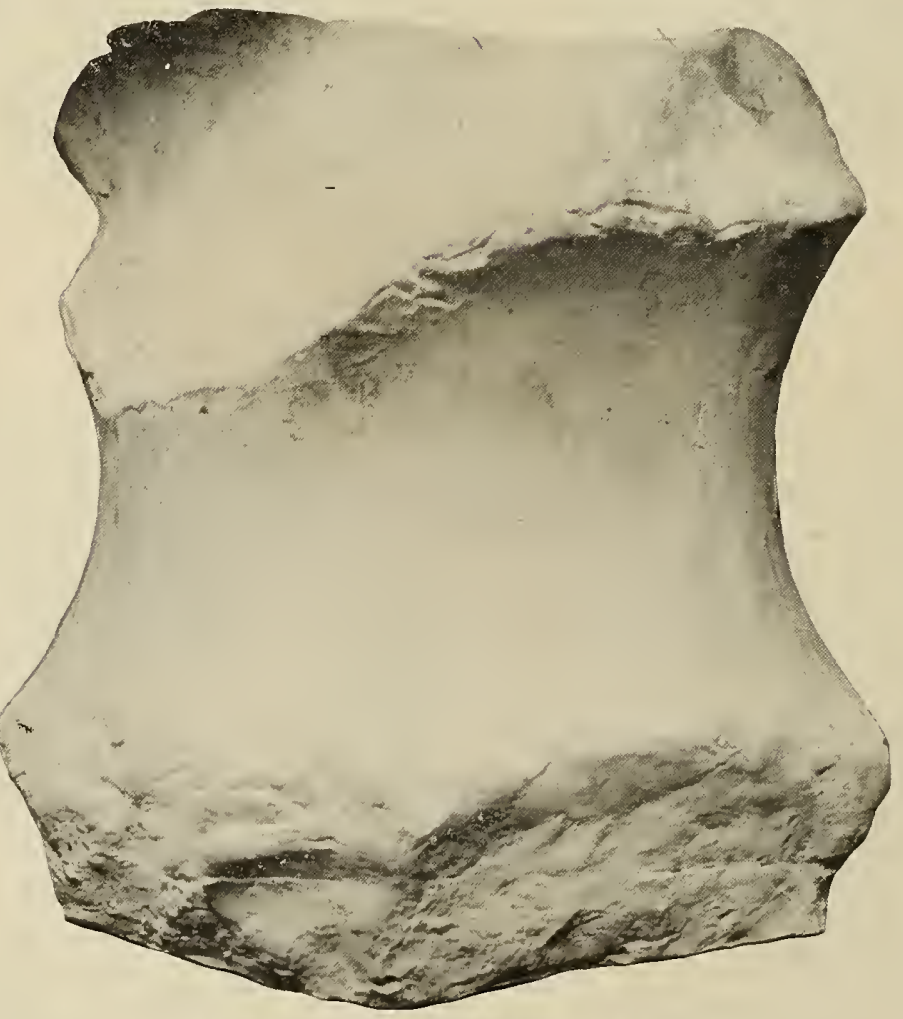

Type of allosaurus fragills Marsh

For explanation of Plate SeE Page 149. 

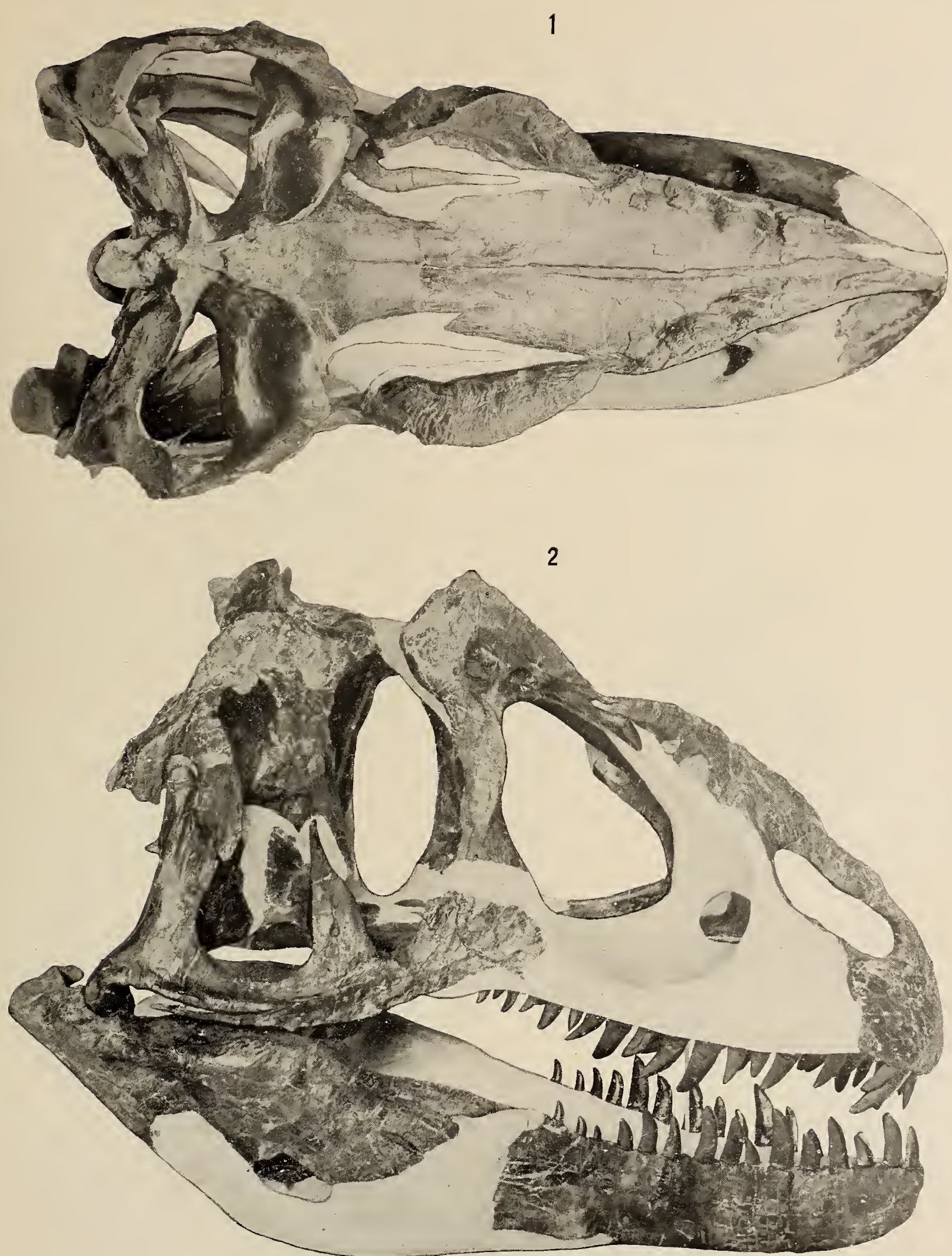

SKull of ANTROdemus VALENS LEIdy, Side AND TOP VIEWS.

For Explanation of Plate SEe Page 149. 

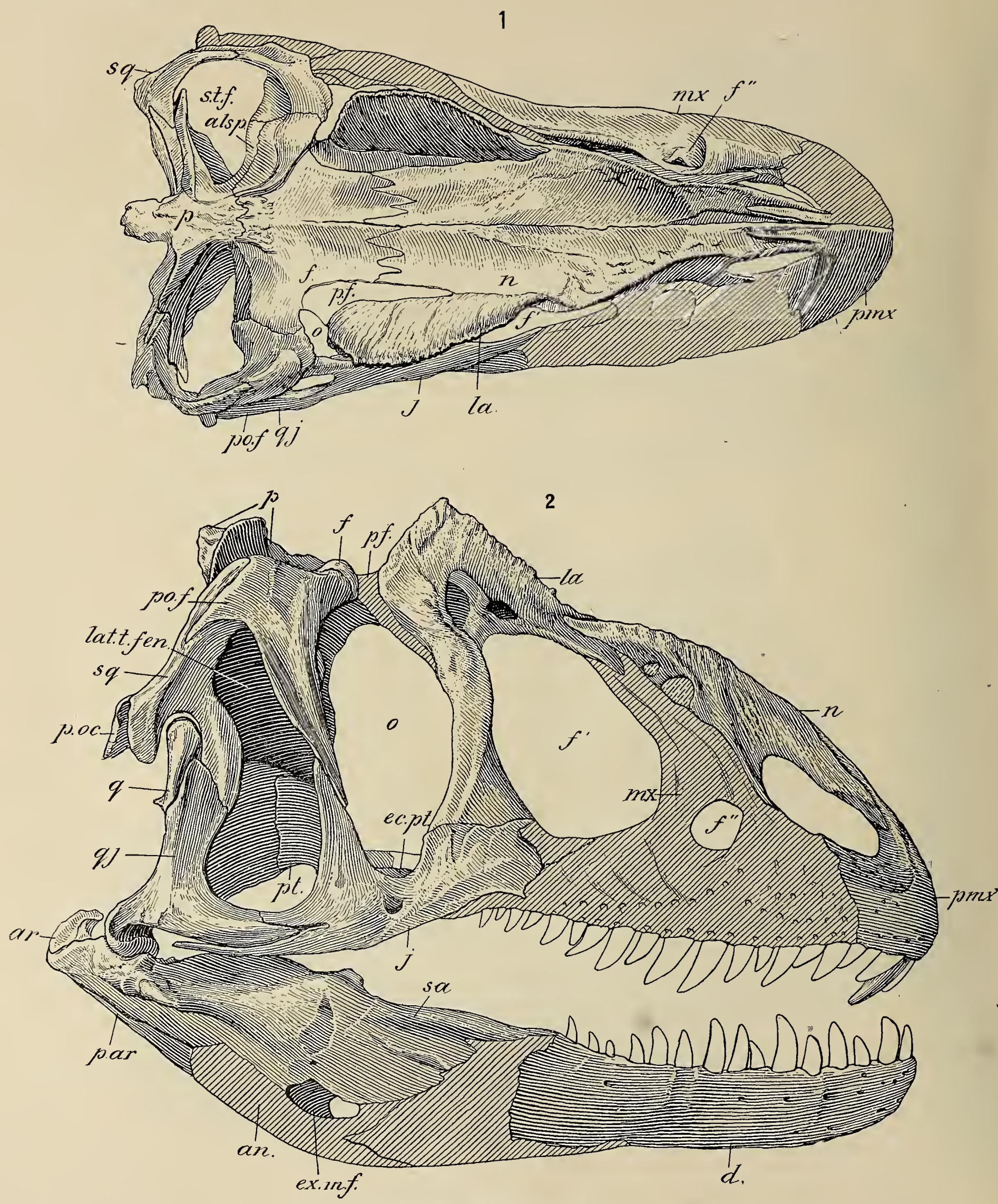

SKulL of ANTROdemus VALENS LeIdy, Side AND TOP VIEWs.

For Explanation of PLATE SEe PAGE 149. 

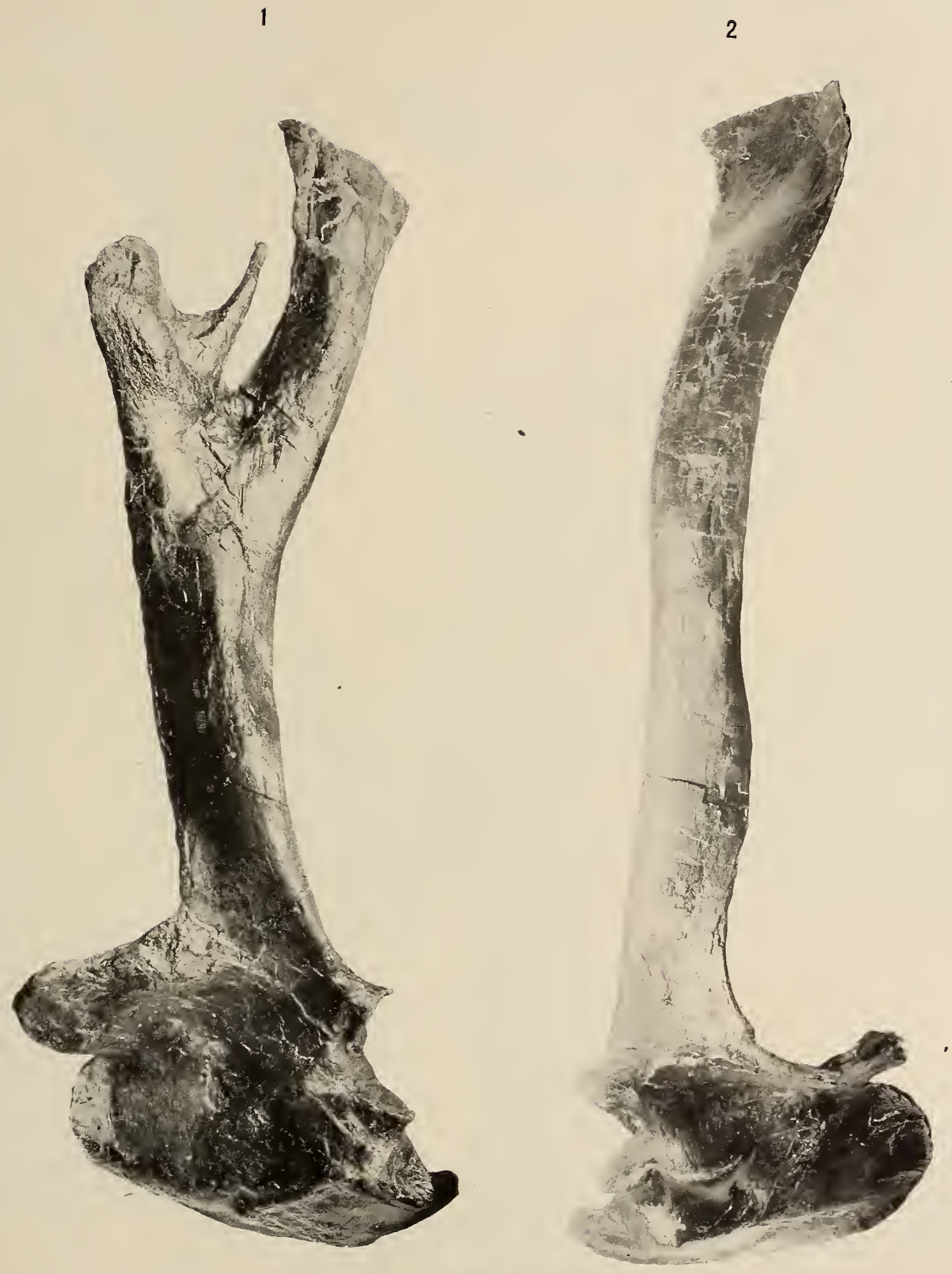

SCAPULAE of ANTROdemUS VALENS Leidy,

For explanation of PLate SEe PAge 149. 


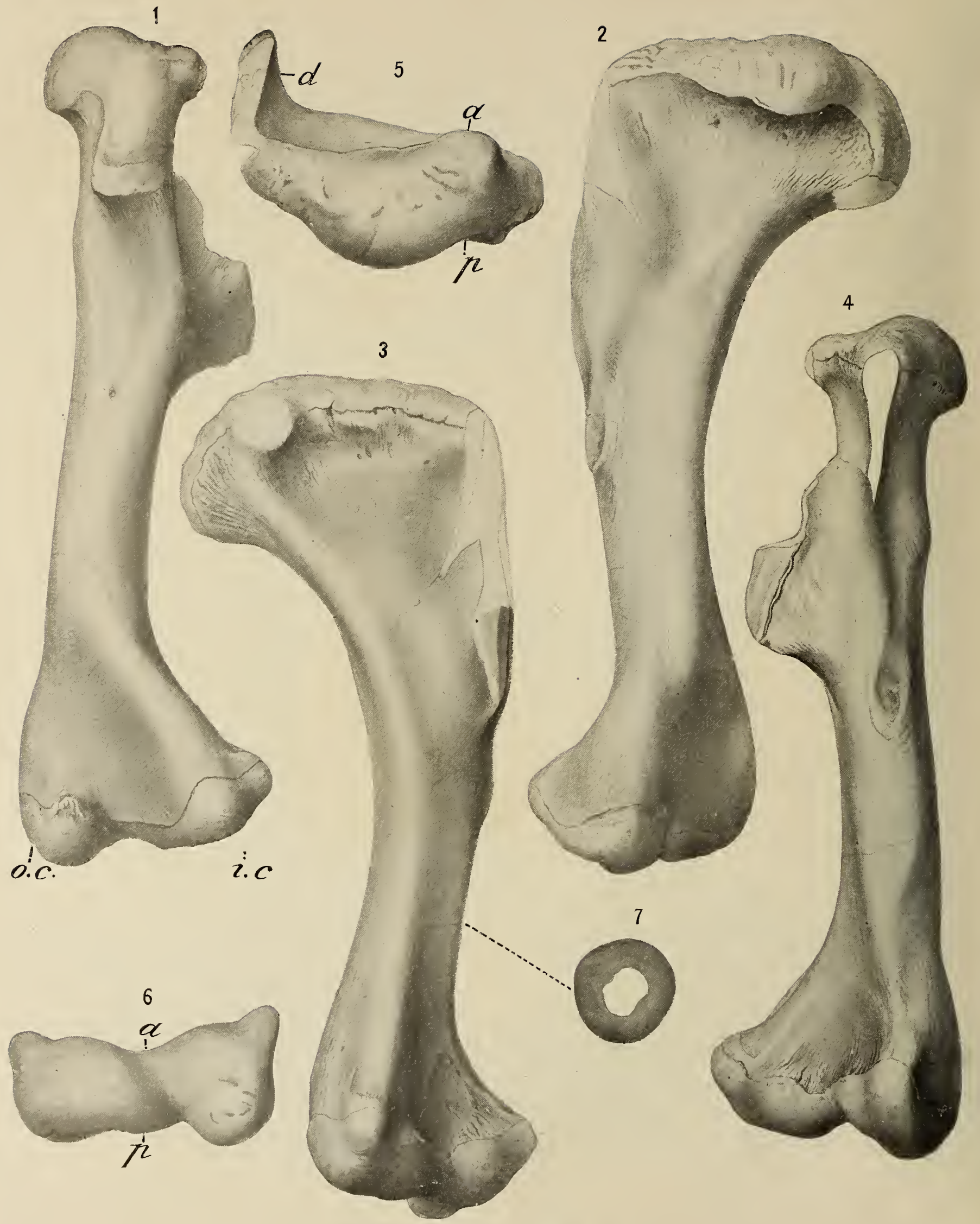

Humerus of ANTROdemus VALENS Leidy.

FOR EXPLANATION QF PLATE SEE PAGE 149 

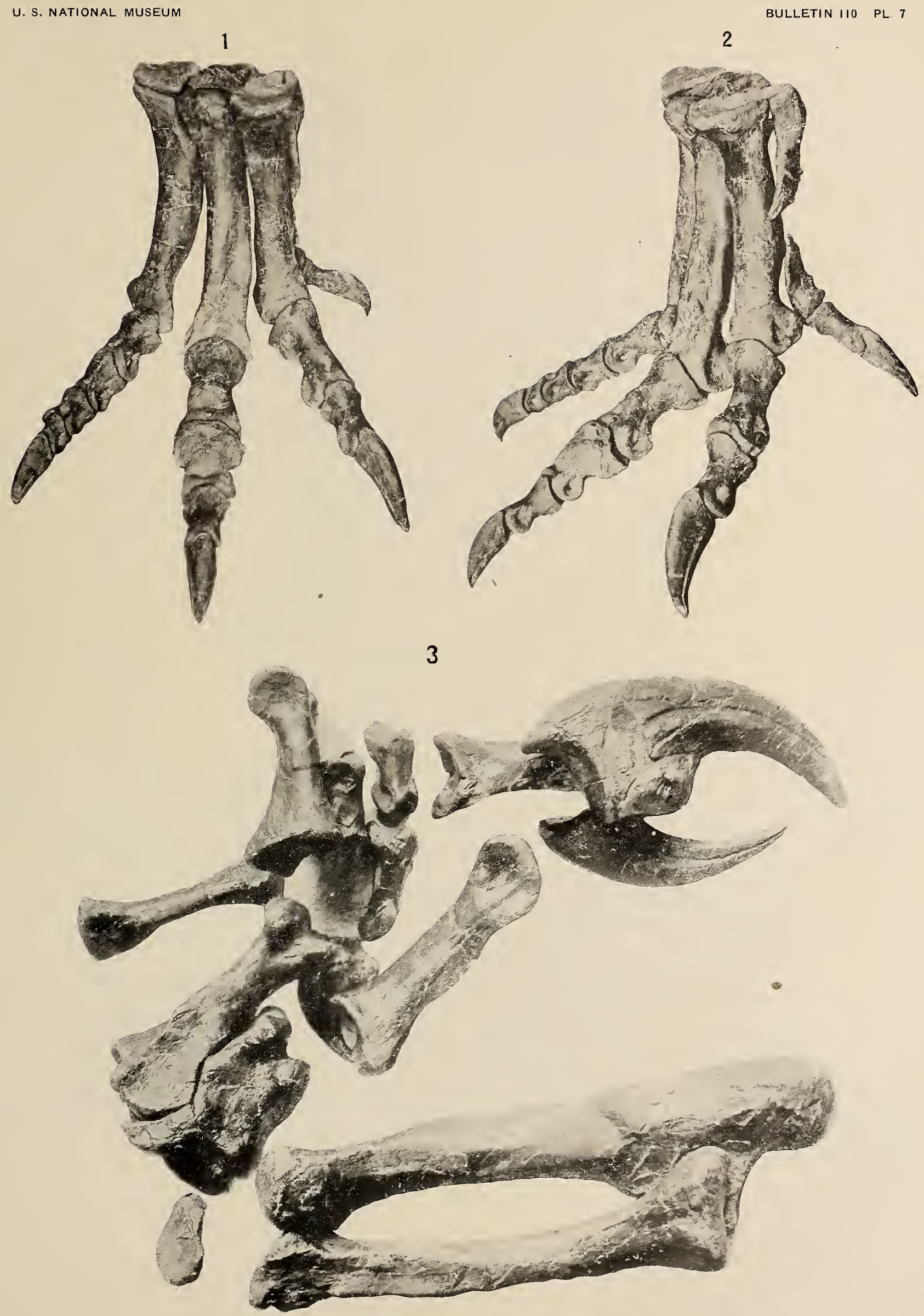

Radius, Ulna, fore and Hind Feet of antrodemus Valens Leidy.

For EXPLANATION OF PLATE SEE PAgE 150 


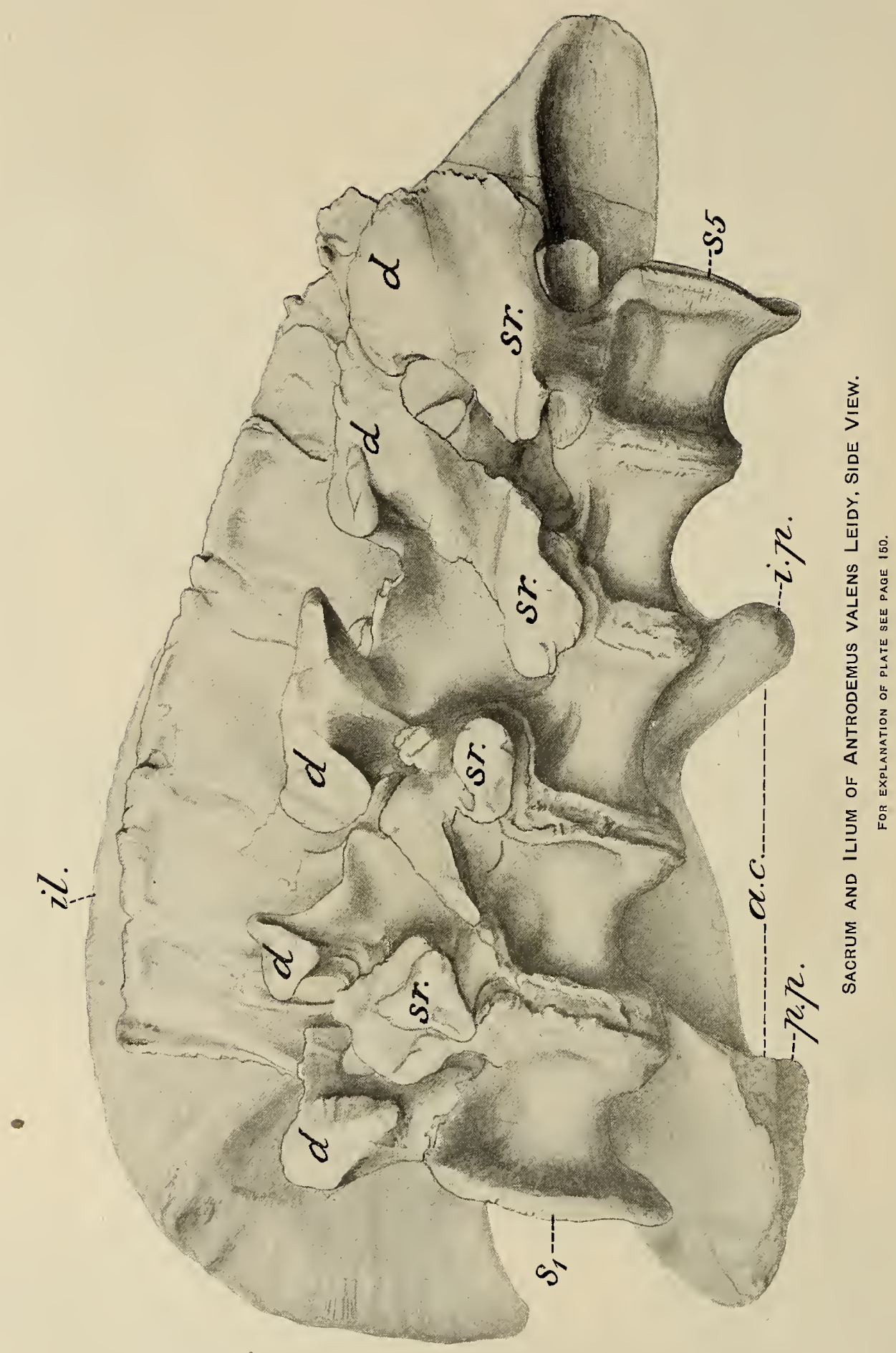



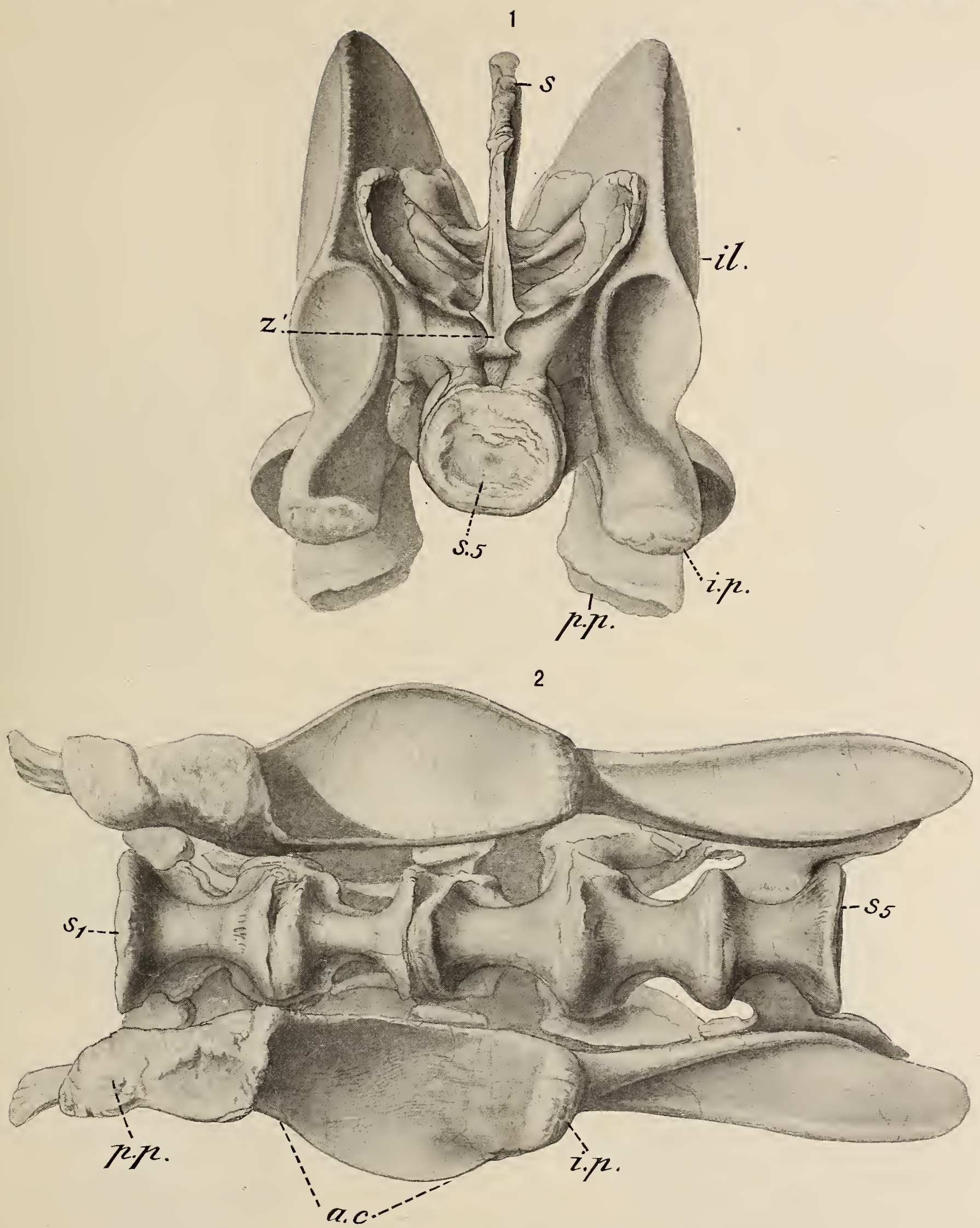

SACRUM AND ILIA OF ANTRODEMUS VALENS LEIDY, BACK AND LOWER VIEWS.

For EXPLANATION OF PLATE SEE PAGE 150. 


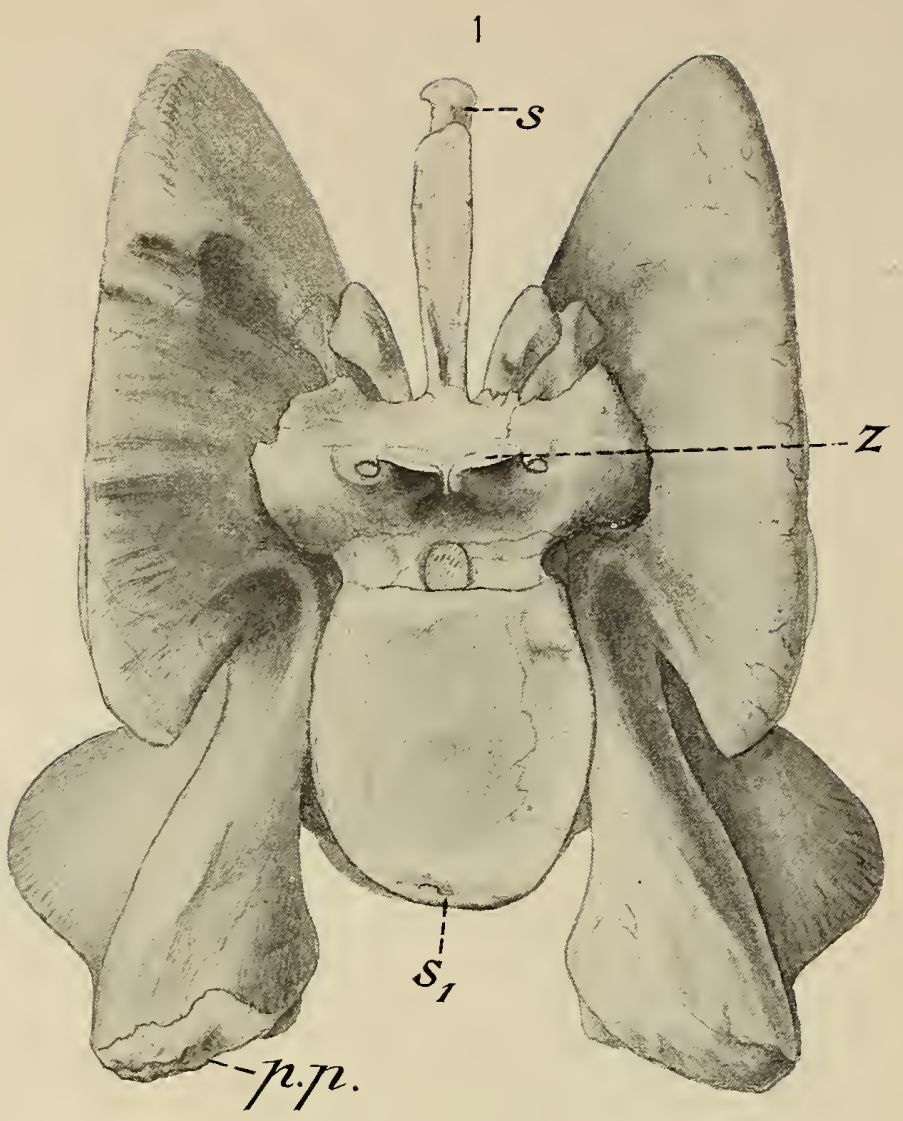

2

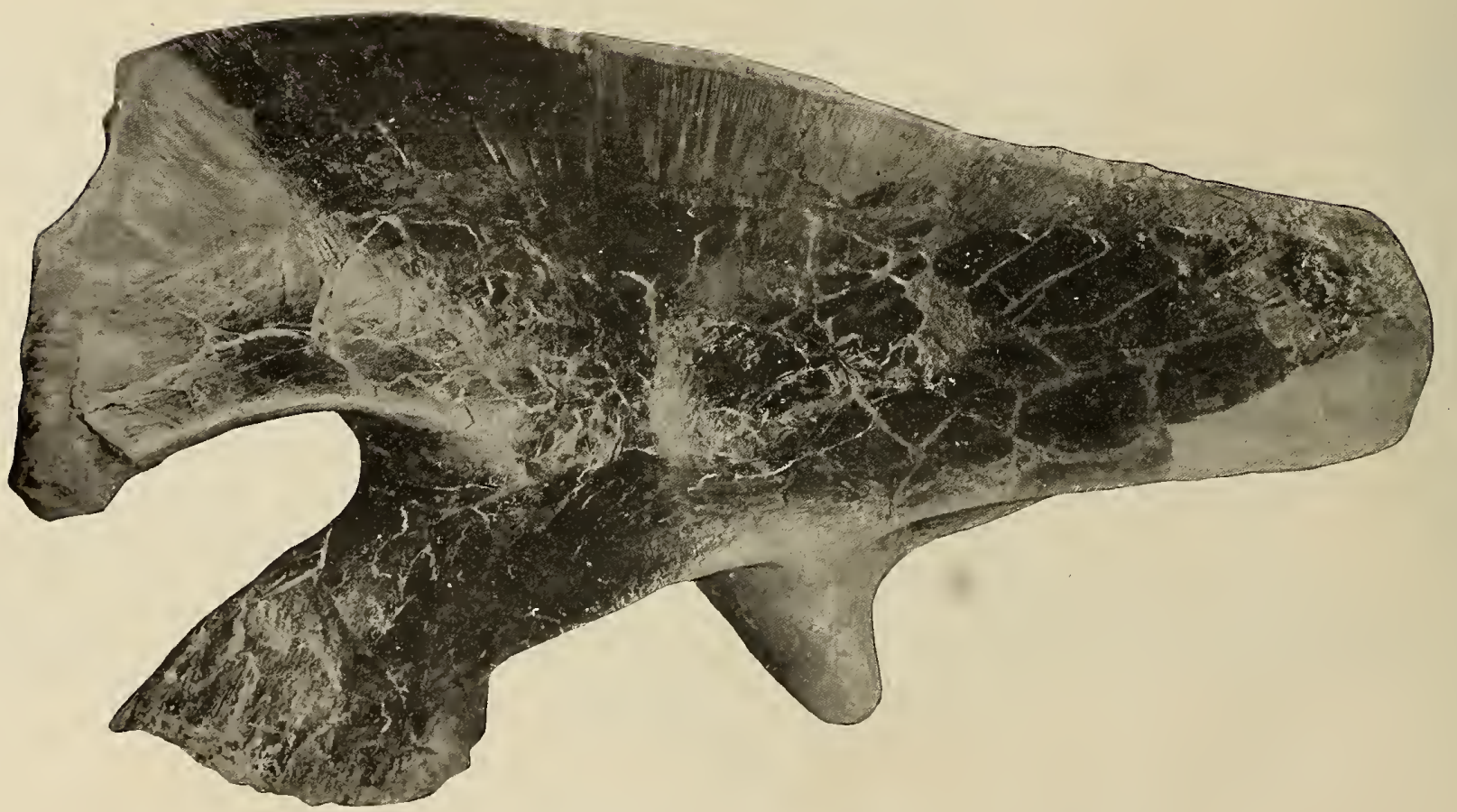

SACRUM AND ILIA OF ANTRODEMUS VALENS LEIDY, FRONT AND SIDE VIEWS.

for explanation of plate see page 150. 


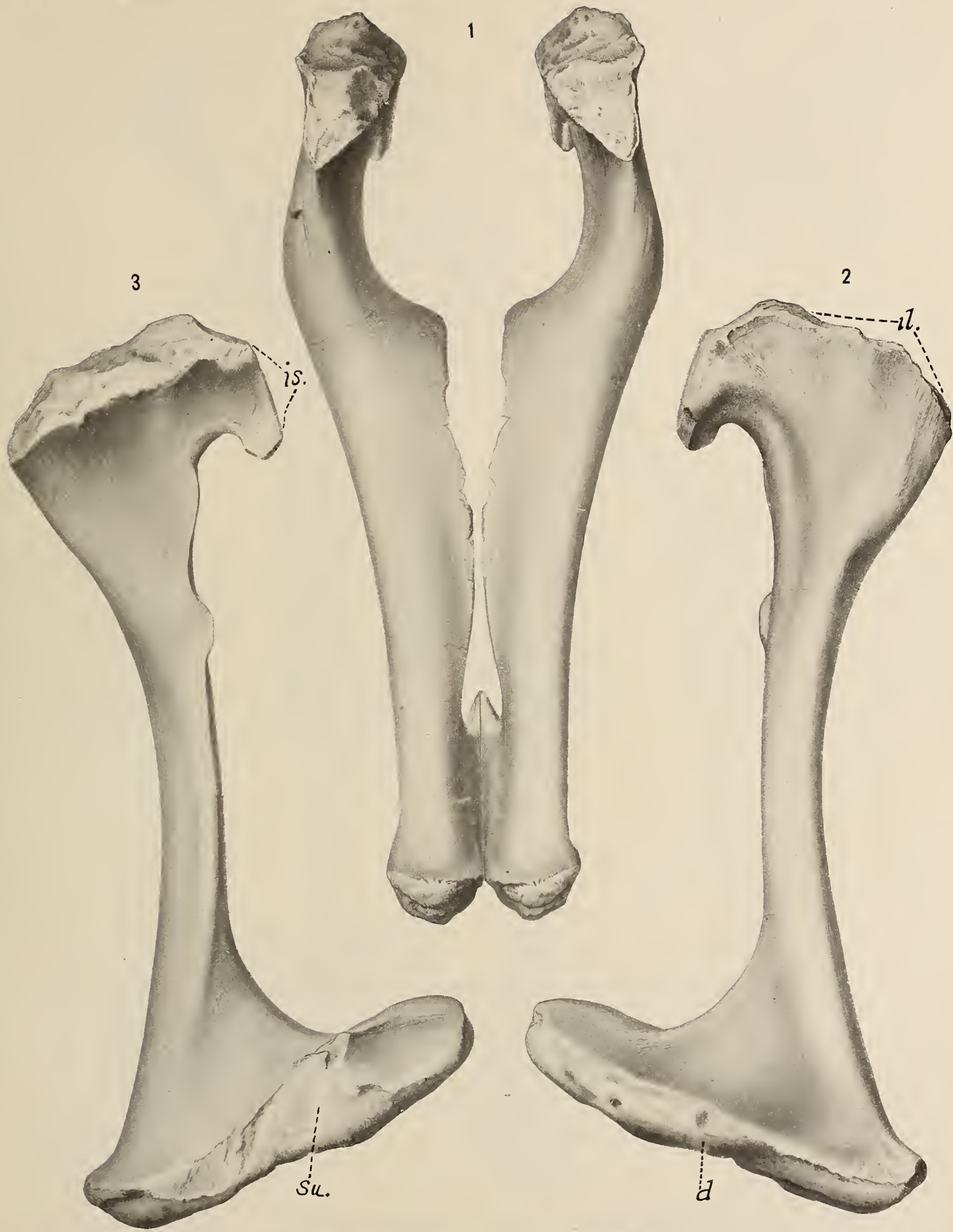

PUBES OF ANTRODEMUS, FRONT AND SIDE VIEWS.

For Explanation of plate see page 150 

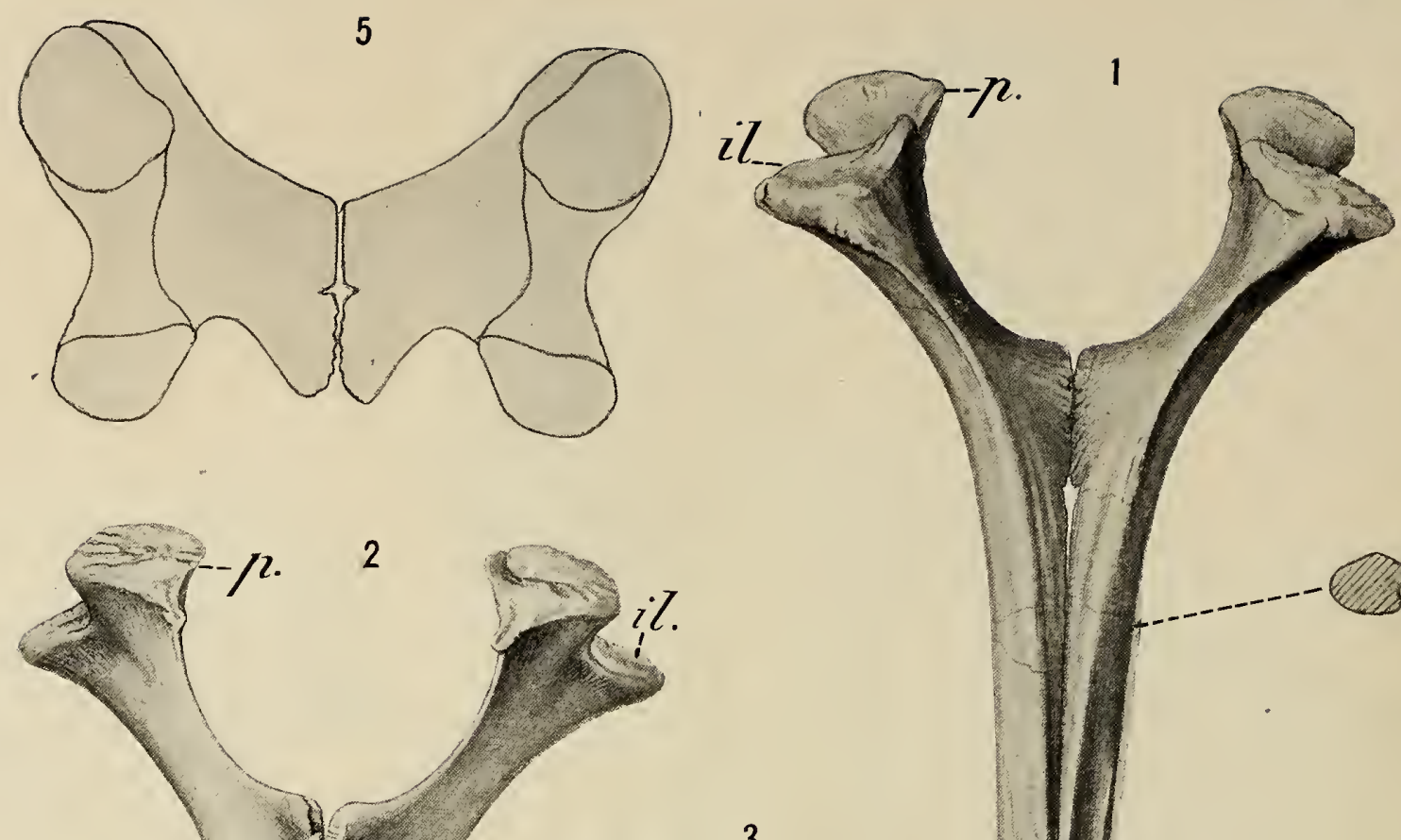

8
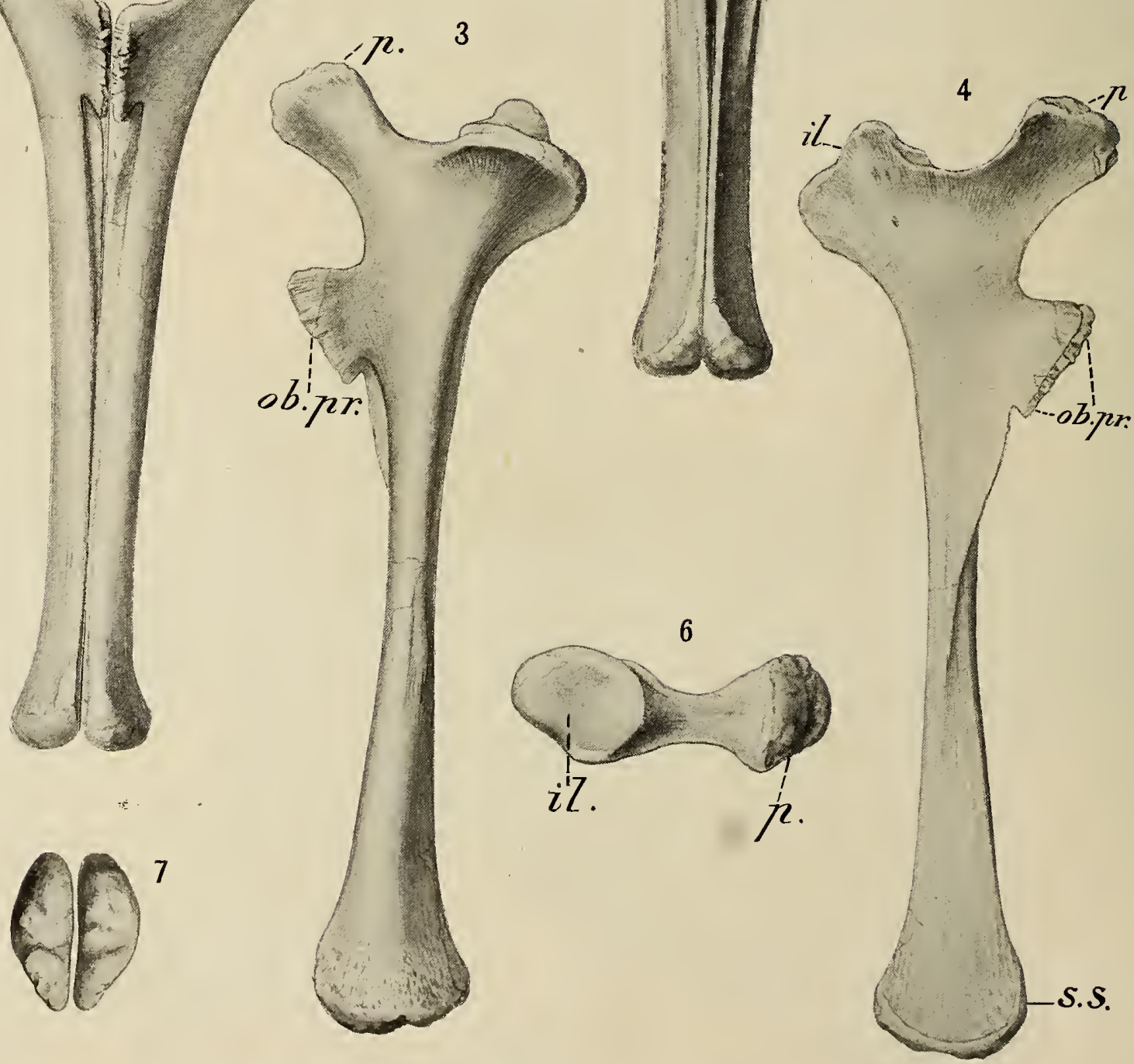

ISCHIA OF ANTRODEMUS VALENS LEIDY, ALL ASPECTS.

For explanation of PLATE SEe PAge 150 


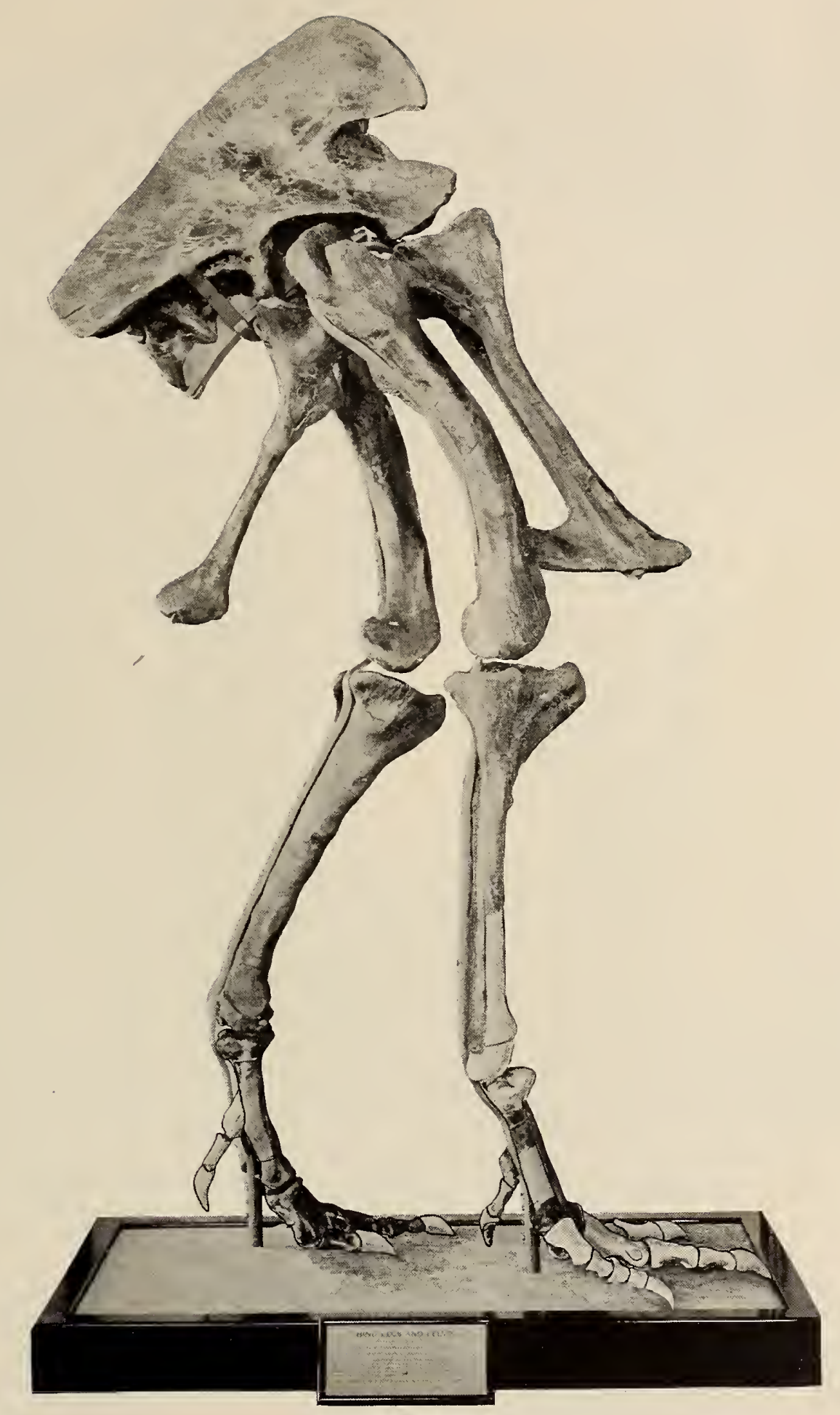

Hind Limbs, PelVis, and Sacrum of Antrodemus Valens Leidy, Lateral View. For EXPLANATION OF PLATE SEE PAGE 161. 

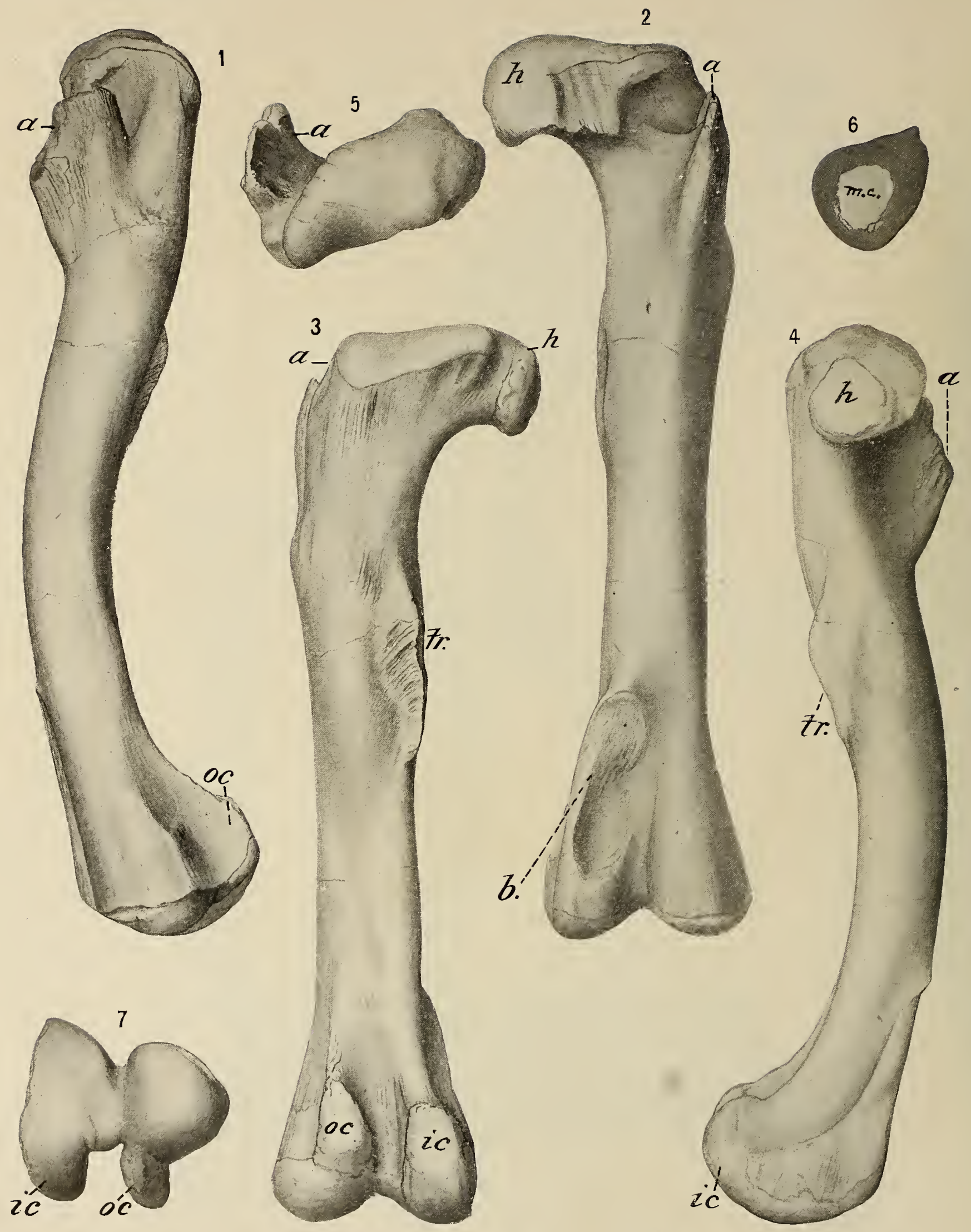

Femur of ANTrodemus Valens Leidy, all Aspects.

For explanation of Plate see page I5I. 


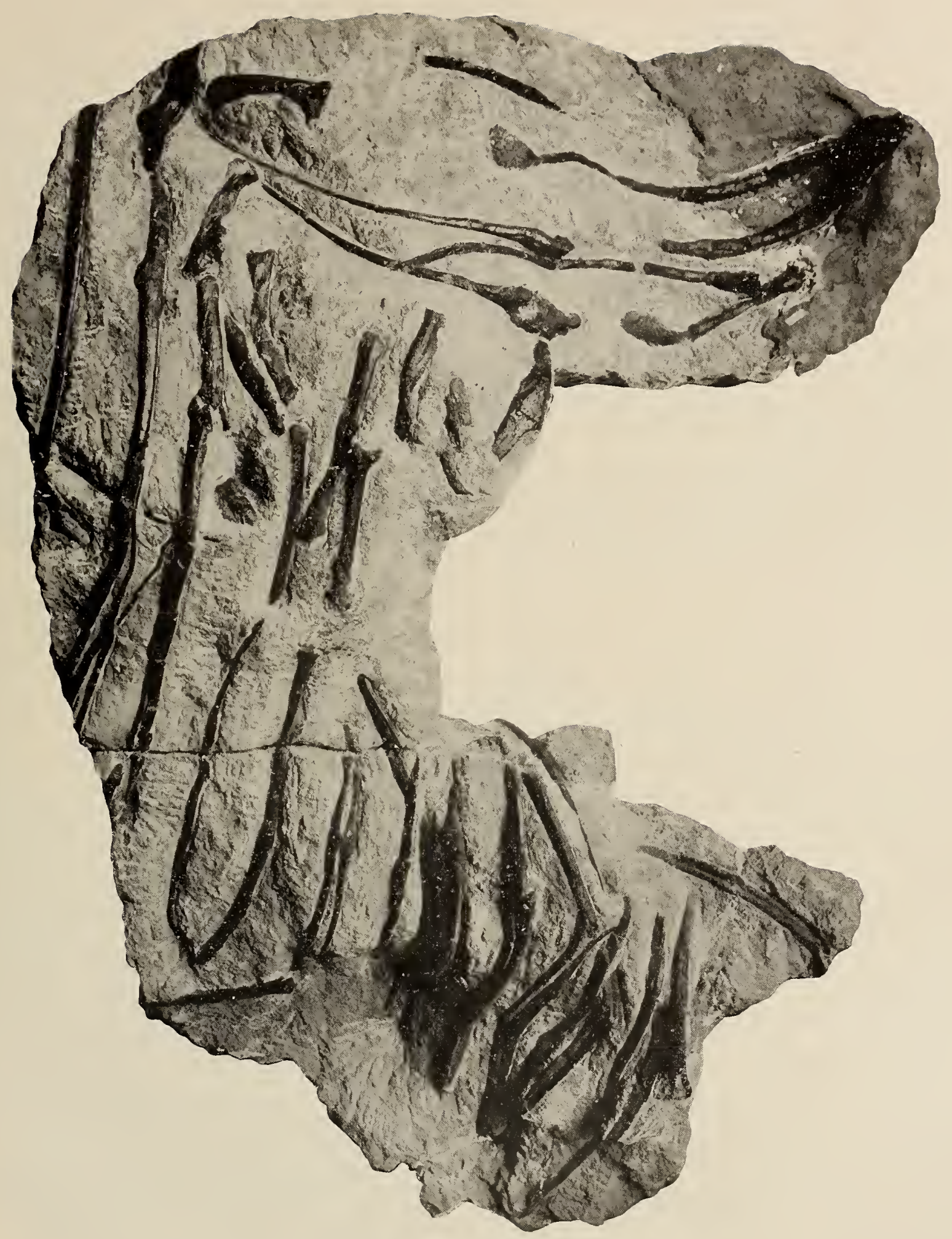

ABDominal RIBS of ANTRODEMUS VALENS LEIDY. 

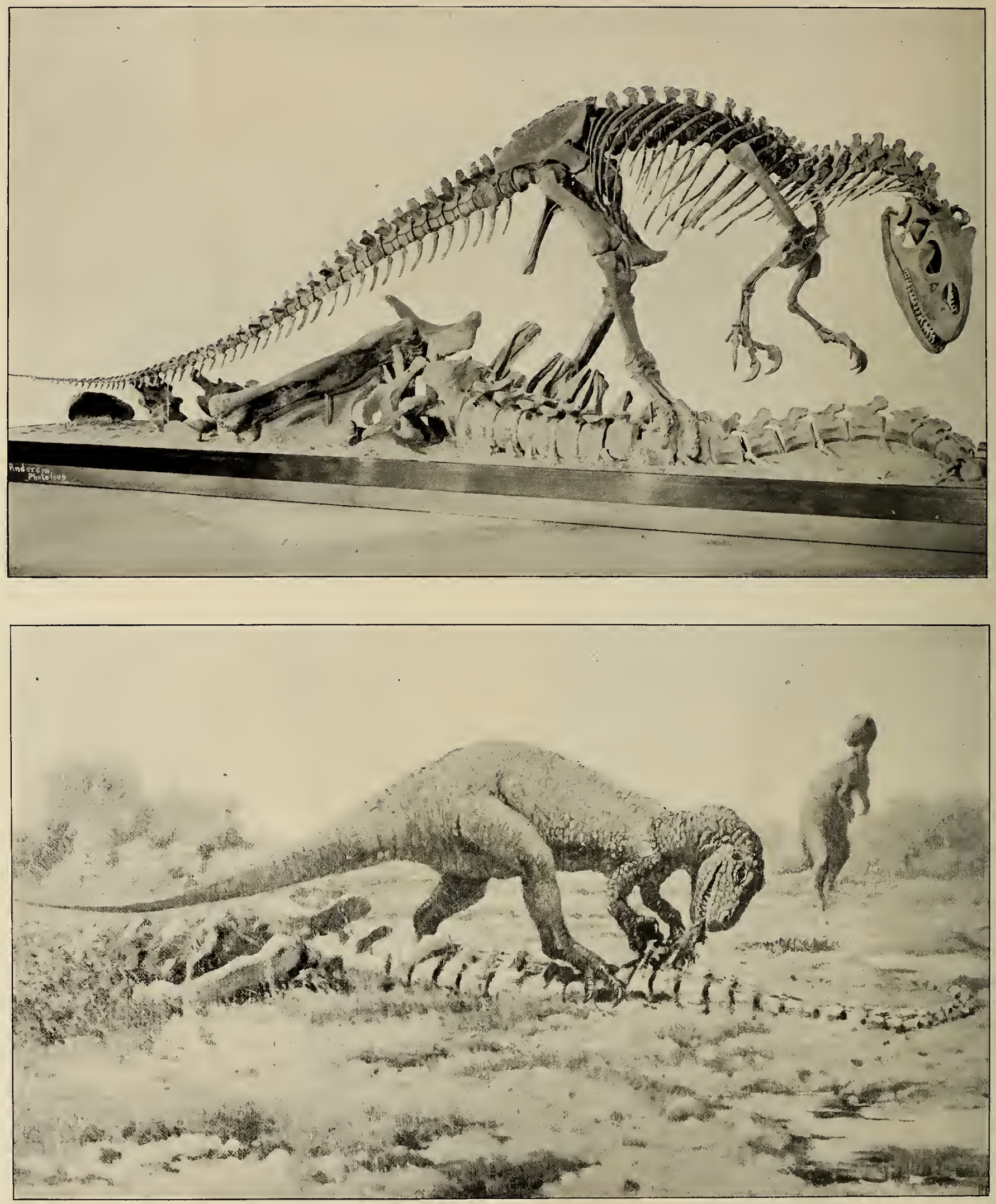

Articulated SkEleton and Restoration of Antrodemus Valens Leidy.

For explanation OF PLATE SEE PAgE 16 ! 

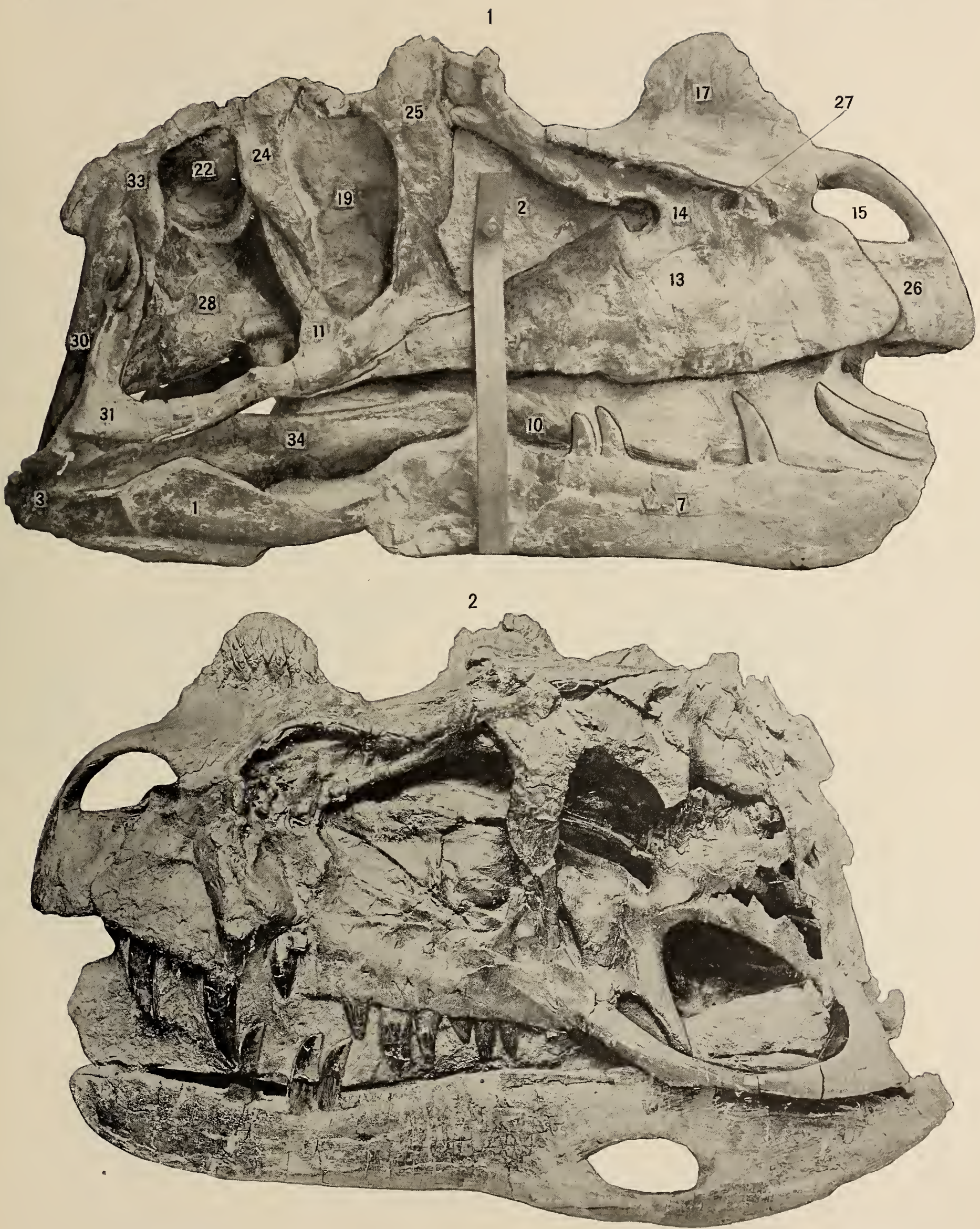

Skull of Ceratosaurus nasicornis Marsh, Side Views. 

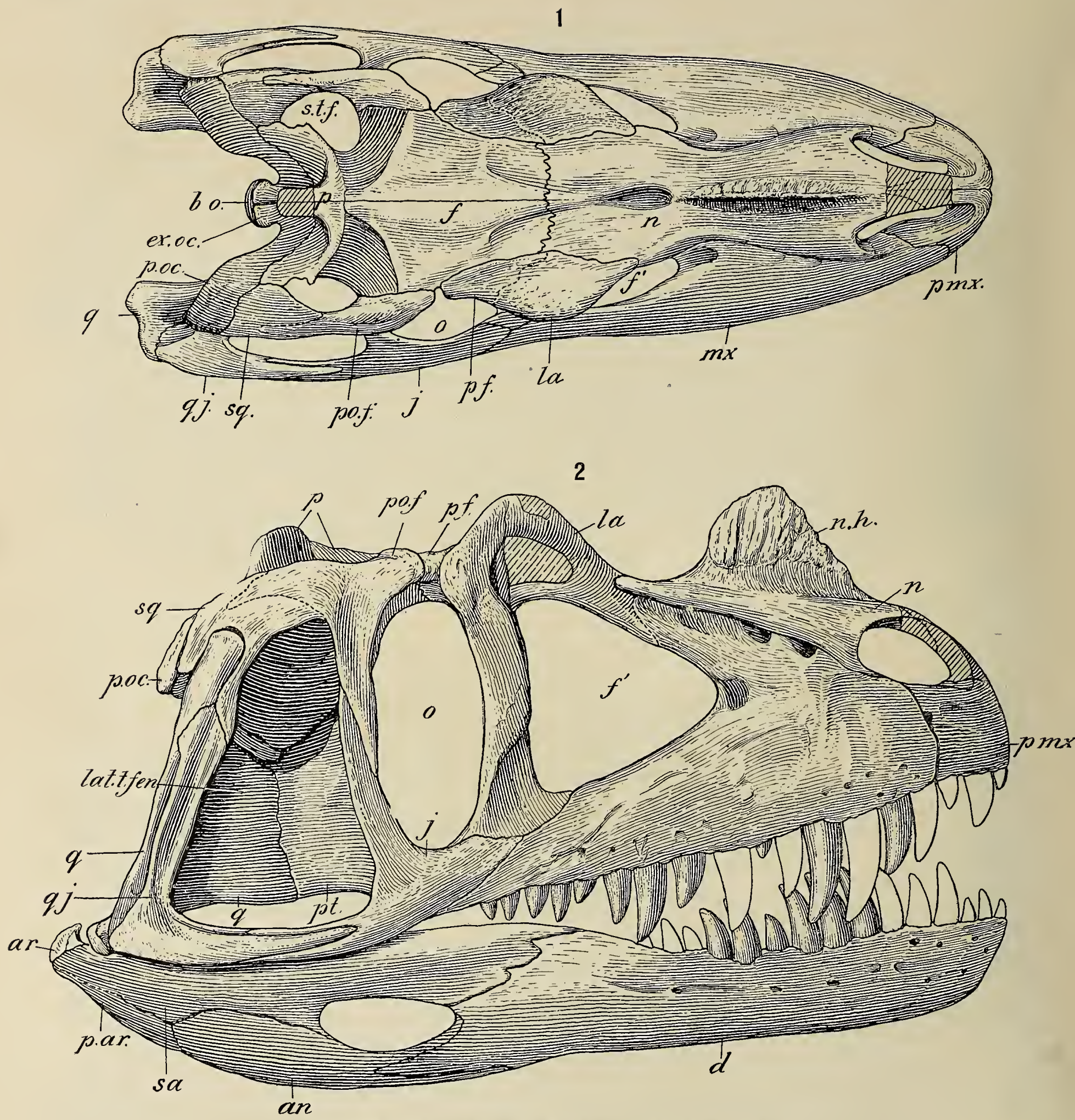

Skull of Ceratosaurus nasicornis Marsh, Side and Top Views.

For EXPLANATION OF PLATE SEE PAgE 151 

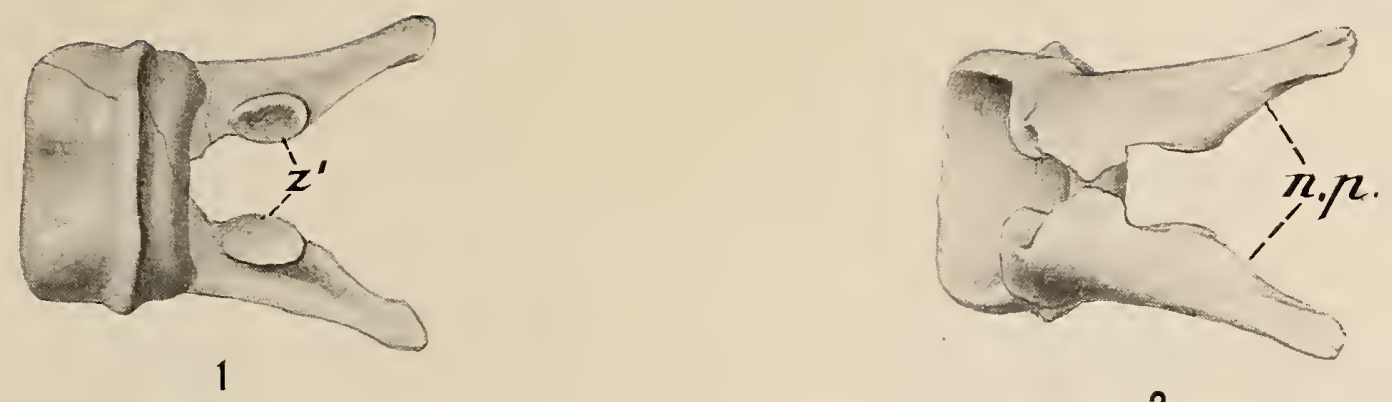

2

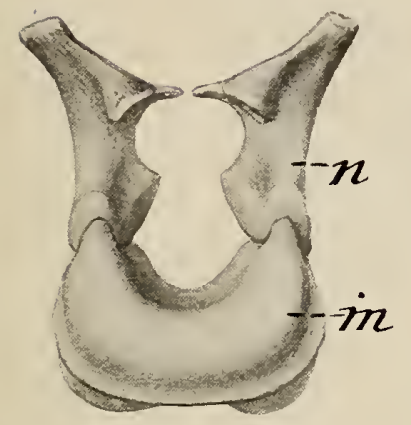

3

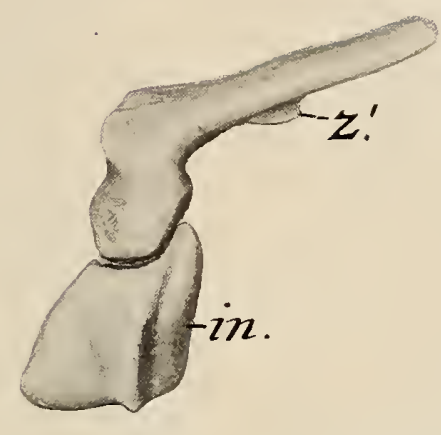

4

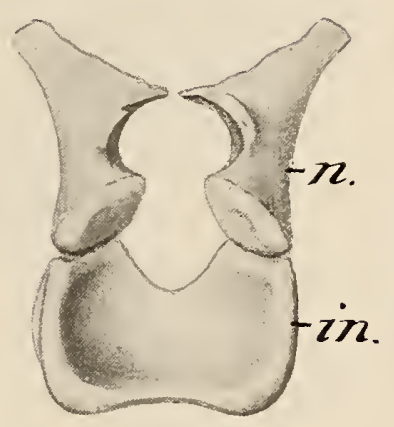

5
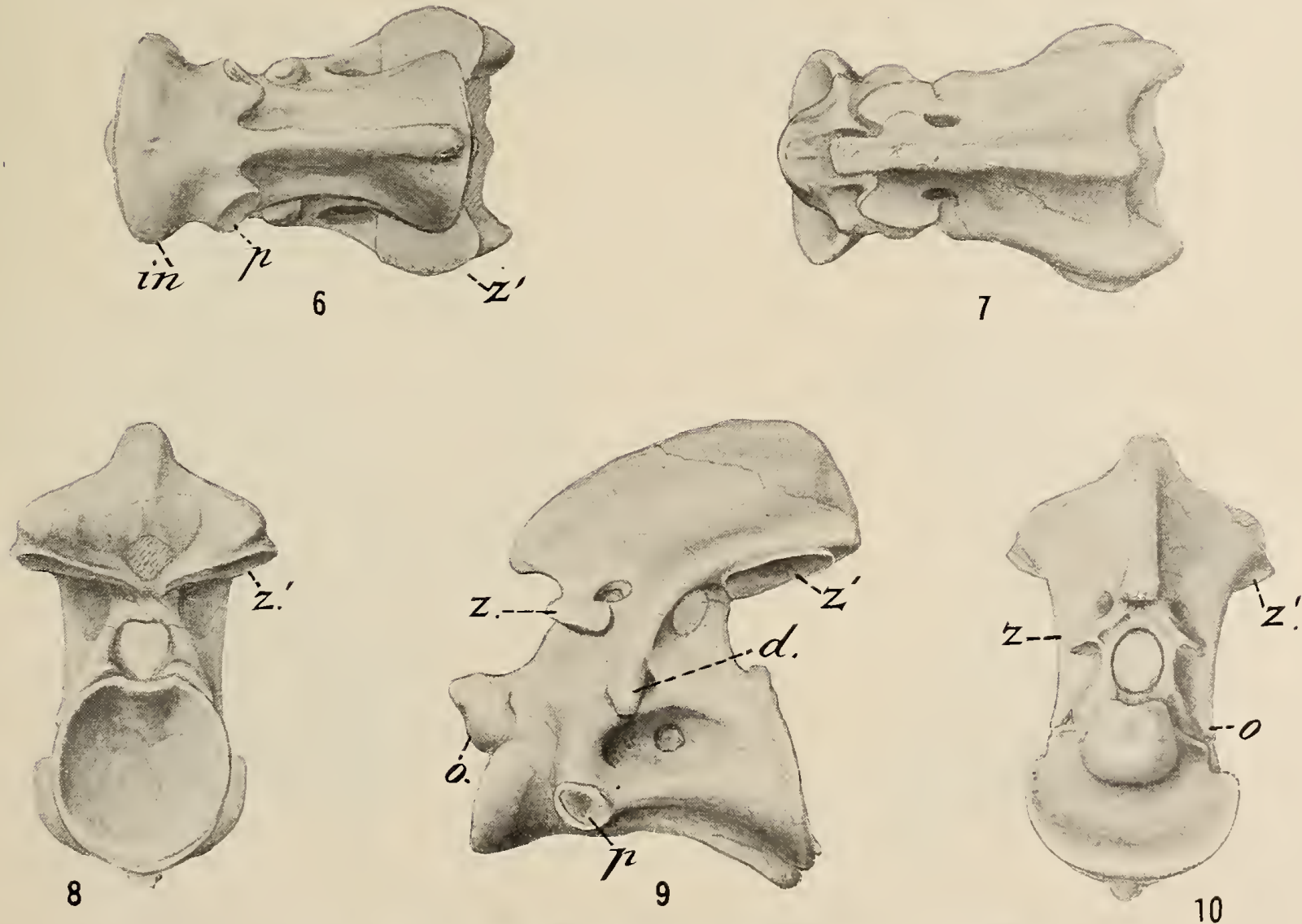

Atlas and Axis of Ceratosaurus nasicornis marsh, all aspects.

For EXPLANATION OF PLATE SEE PAgE 162. 

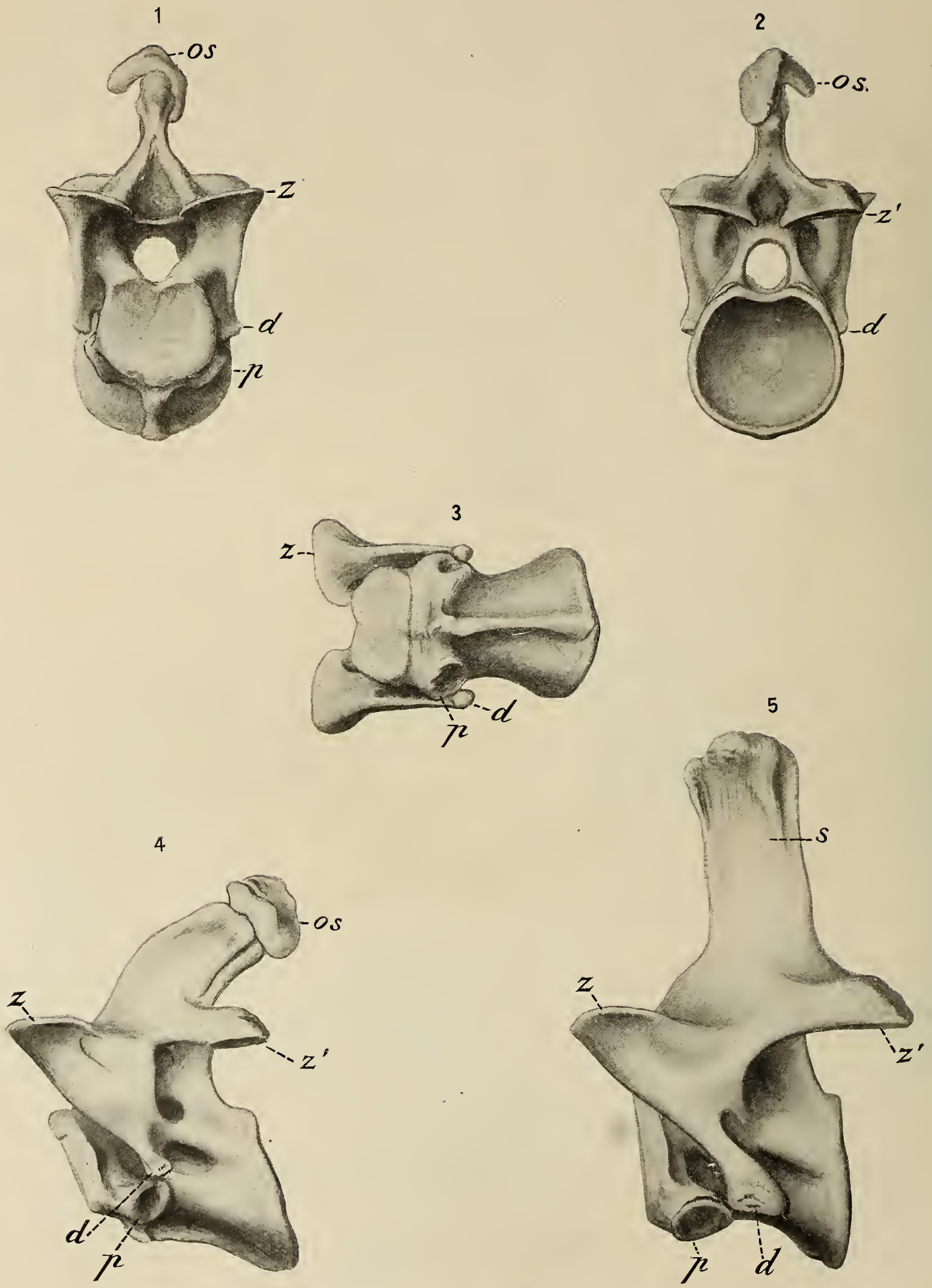

Cervical Vertebrae of Ceratosaurus nasicornis Marsh

For explanation of plate see page 162 


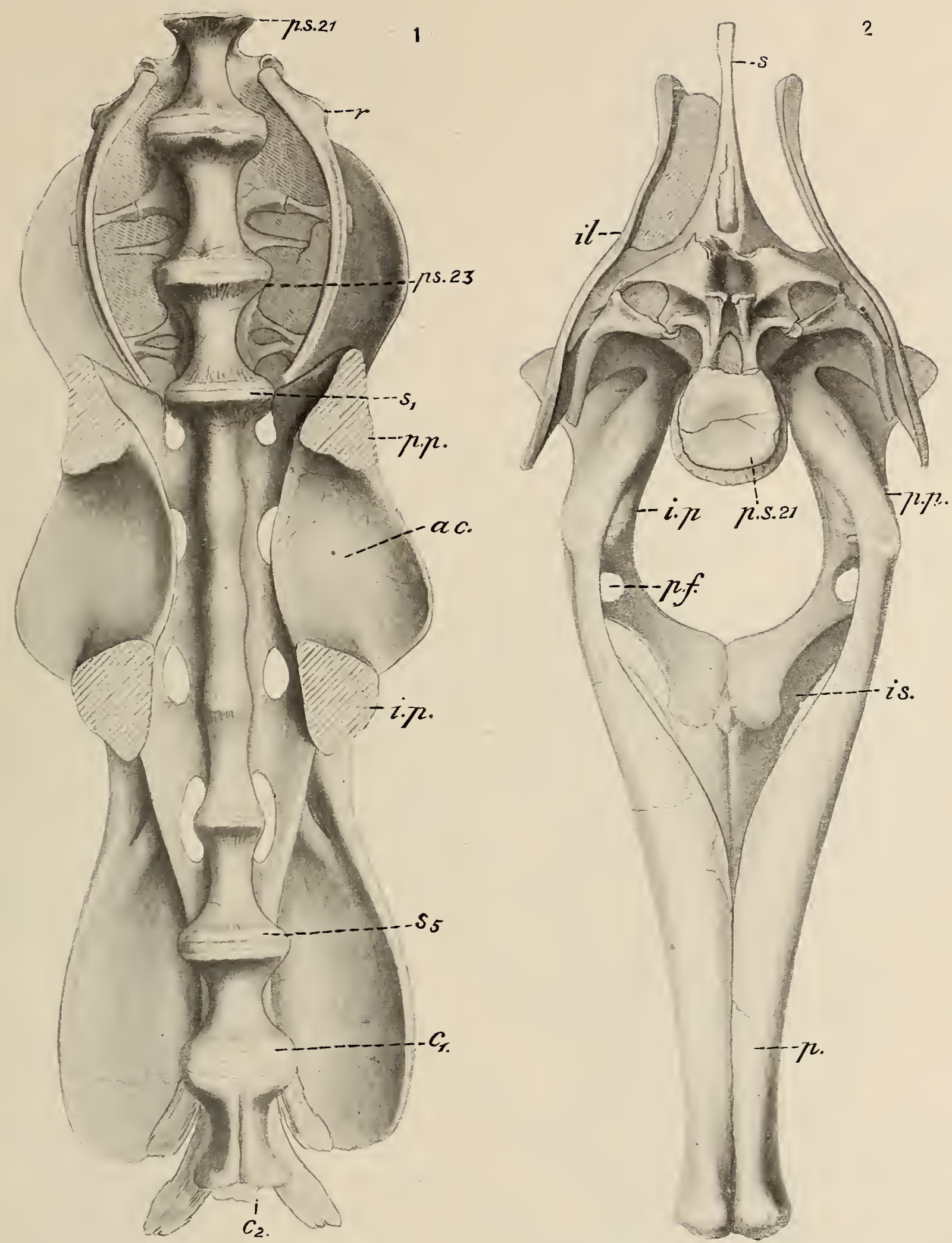

Sacrum and Pelvis of Ceratosaurus nasicornis Marsh, Ventral and front Views. 

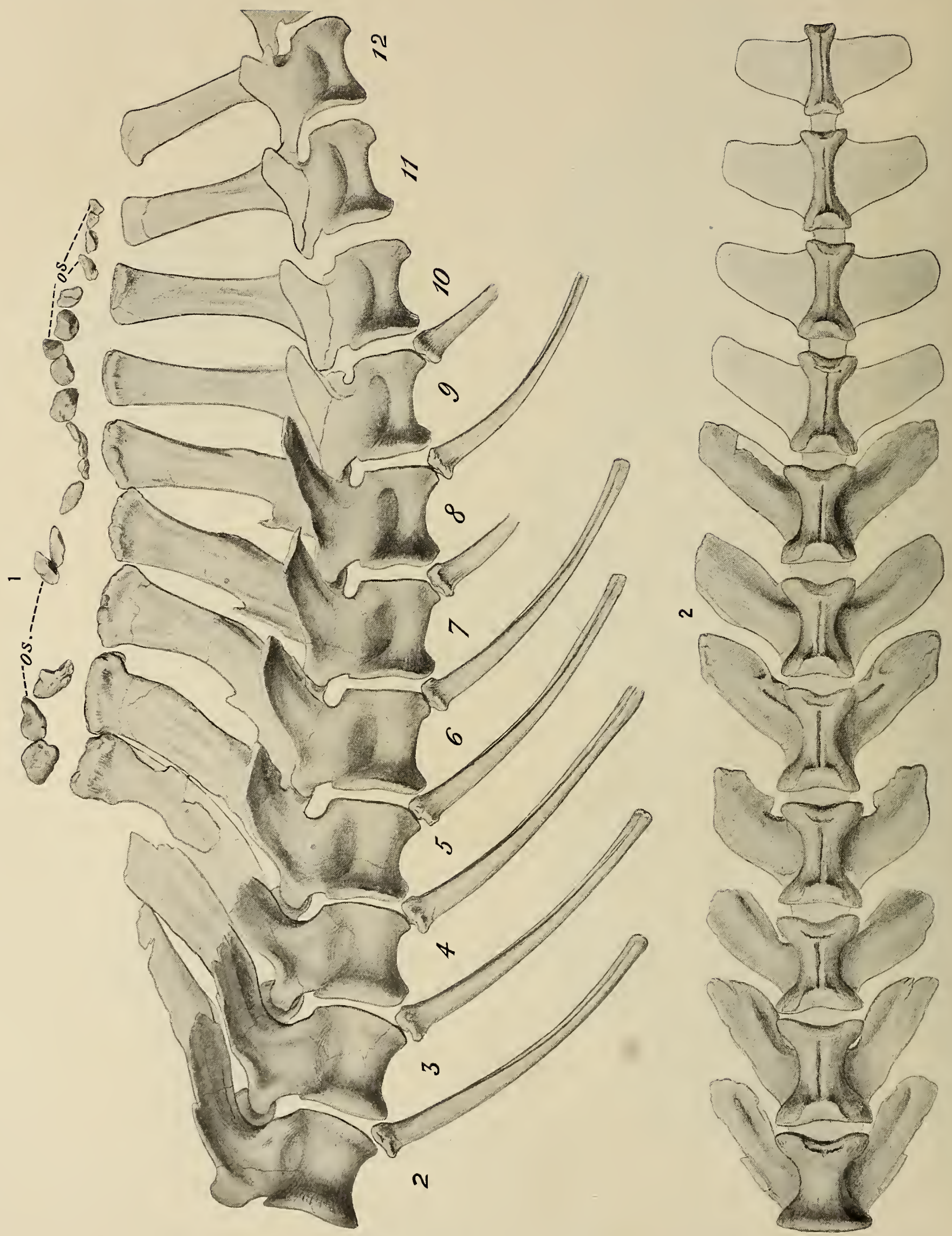

Caudal Vertebrae of Ceratosaurus nasicornis Marsh, Side and Ventral Views. For EXPLANATION OF PLATE SEE PAGE 152 . 
童

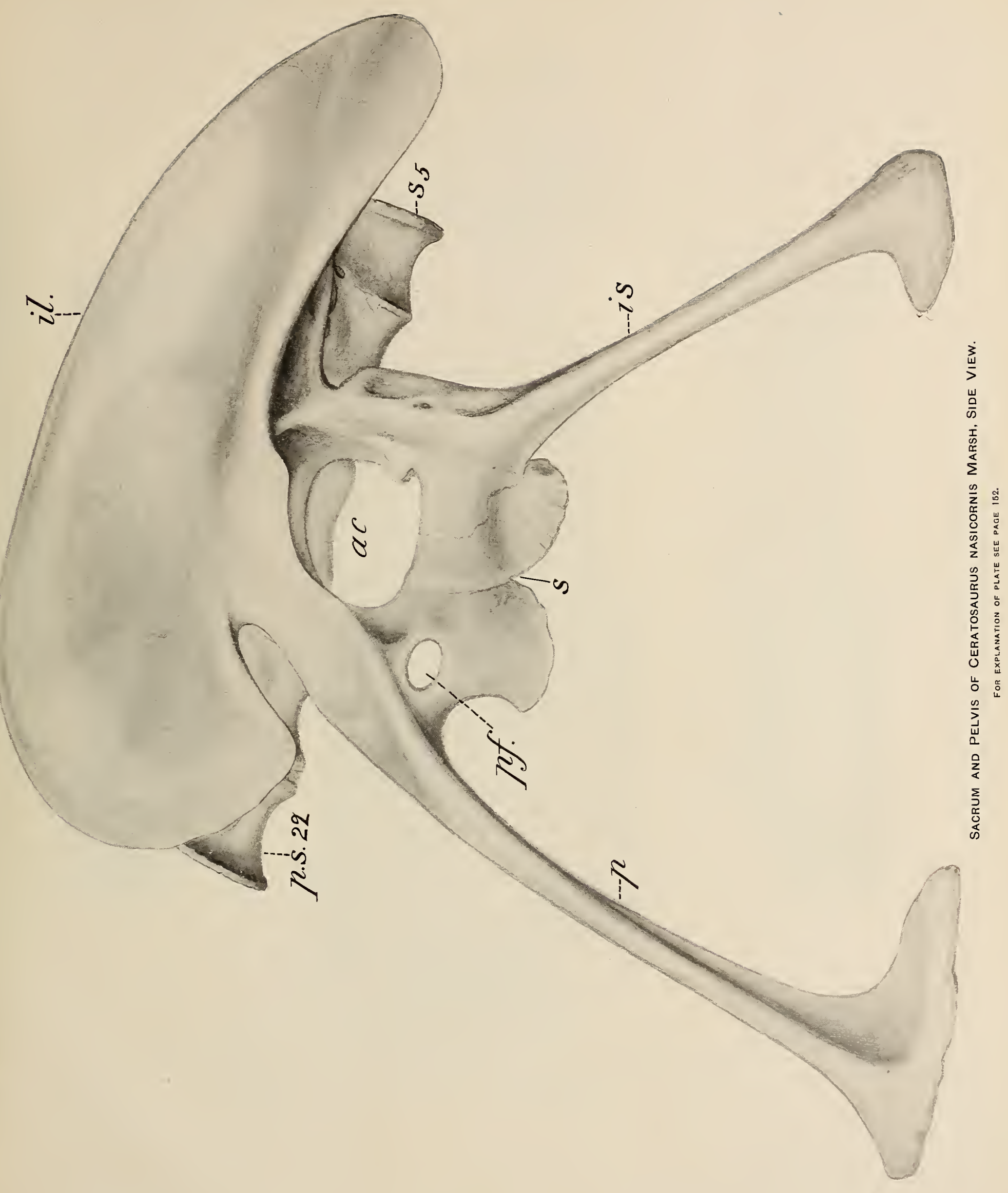



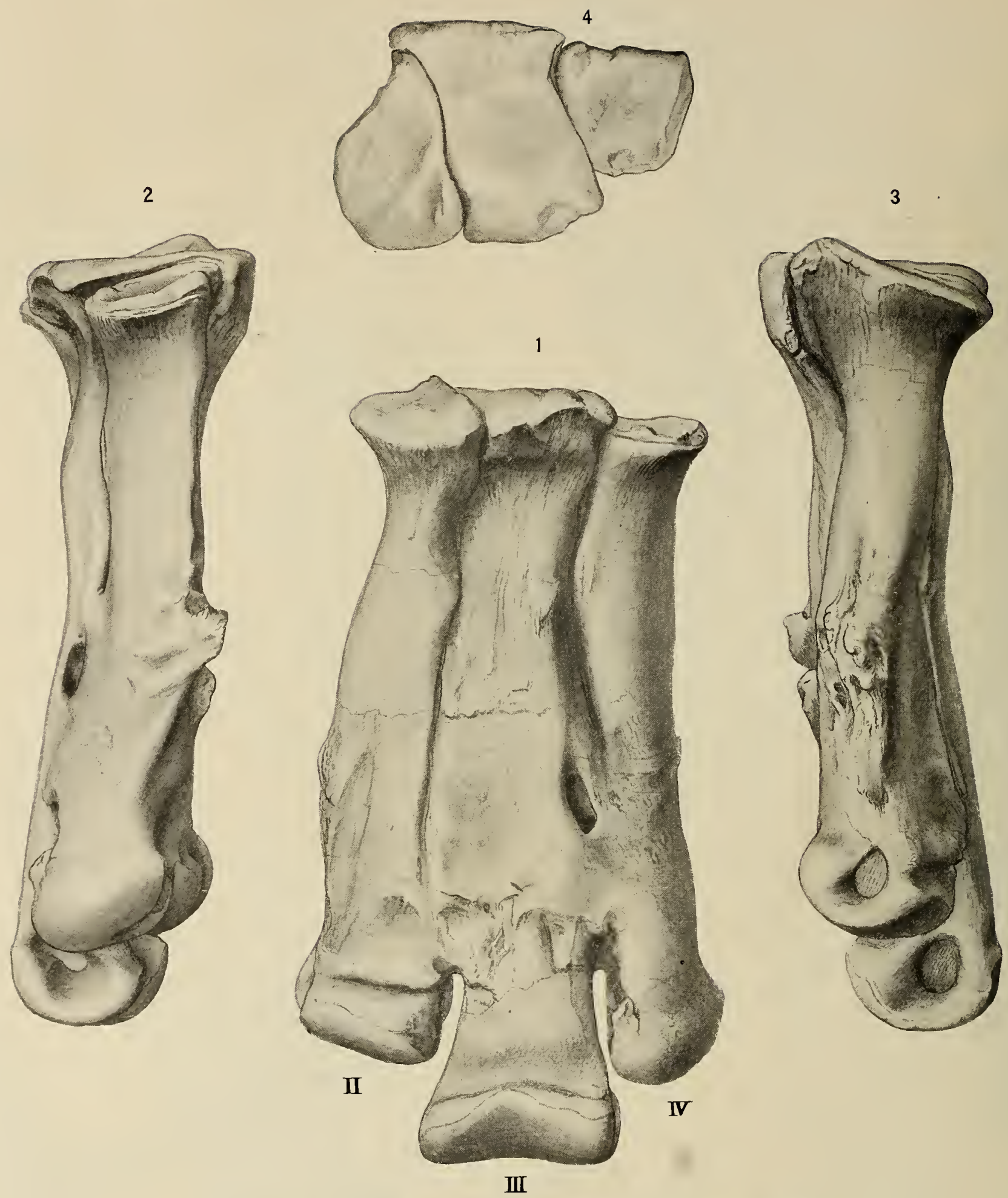

Metatarsals of Ceratosaurus nasicornis Marsh, Front, sides, and Top.

for explanation of Plate see page 152. 

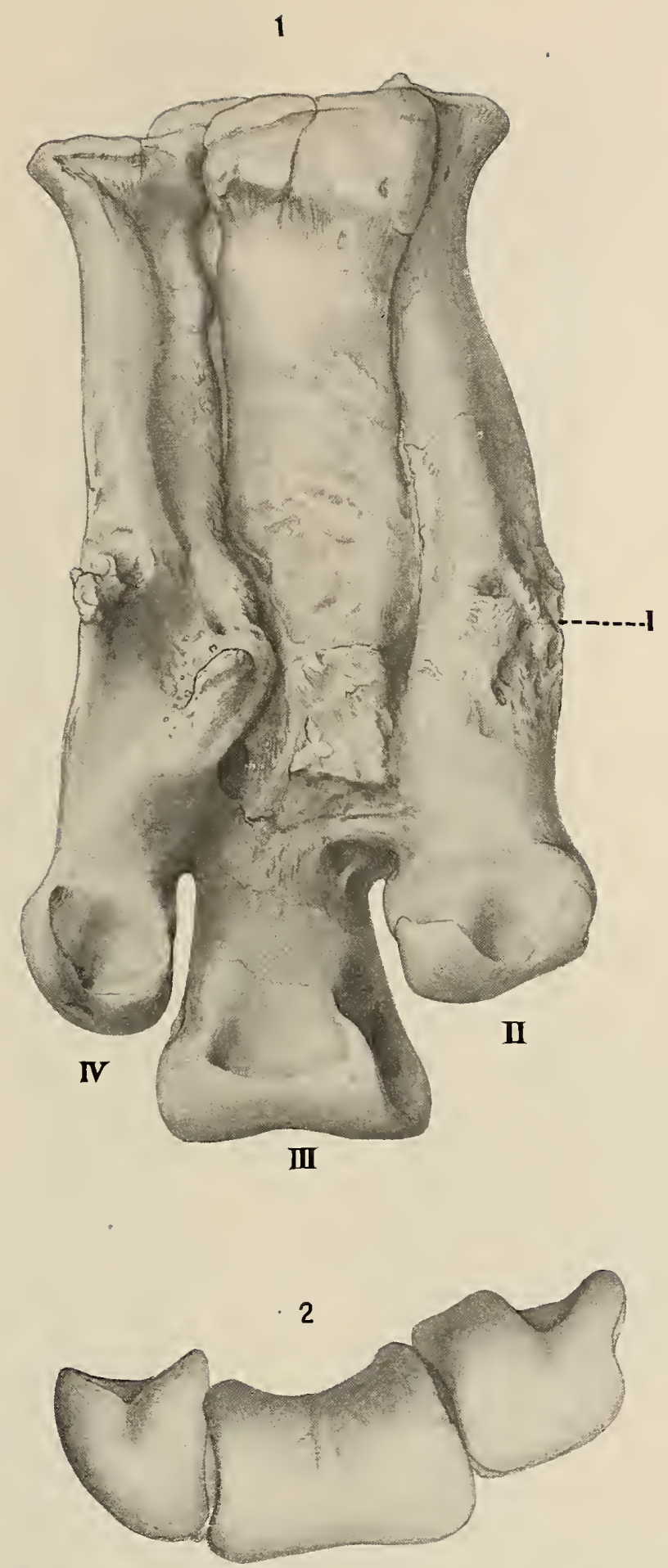

Metatarsals of Ceratosaurus nasicornis Marsh, Back and End Views.

For EXPlanation OF PLATE SEe PAge 153. 

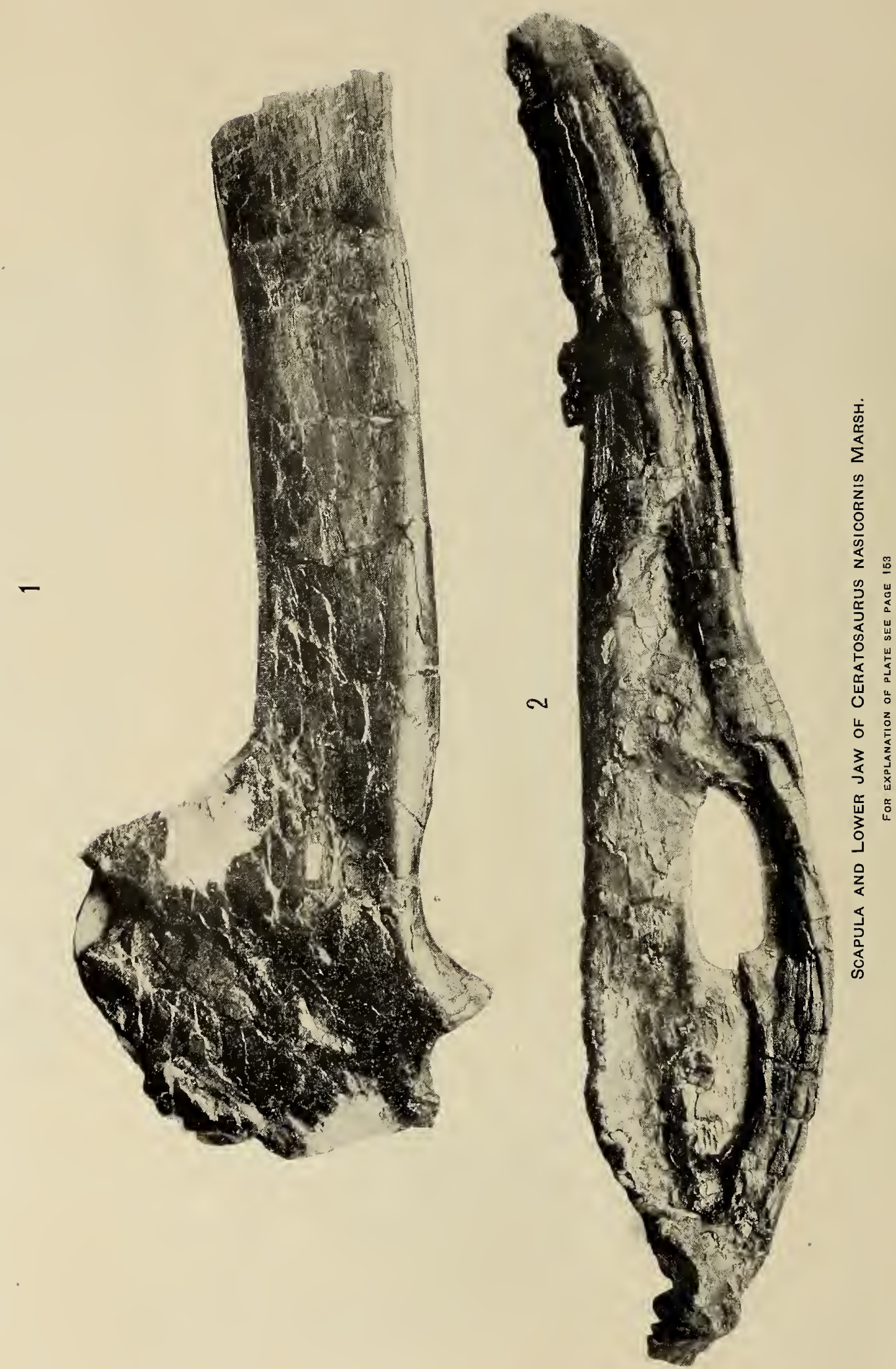

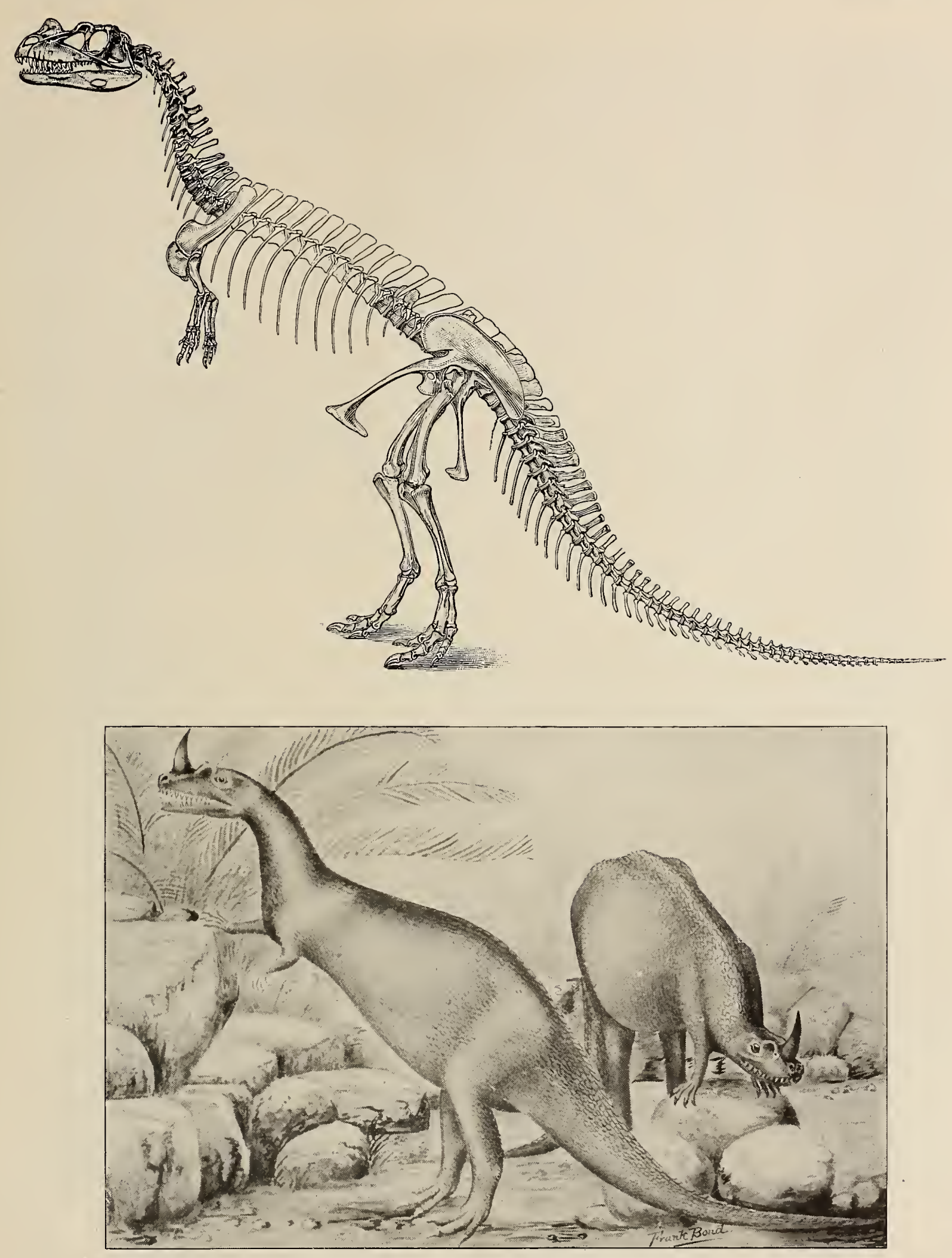

Restorations of Ceratosaurus nasicornis Marsh.

for explanation of PLate see Page 153. 

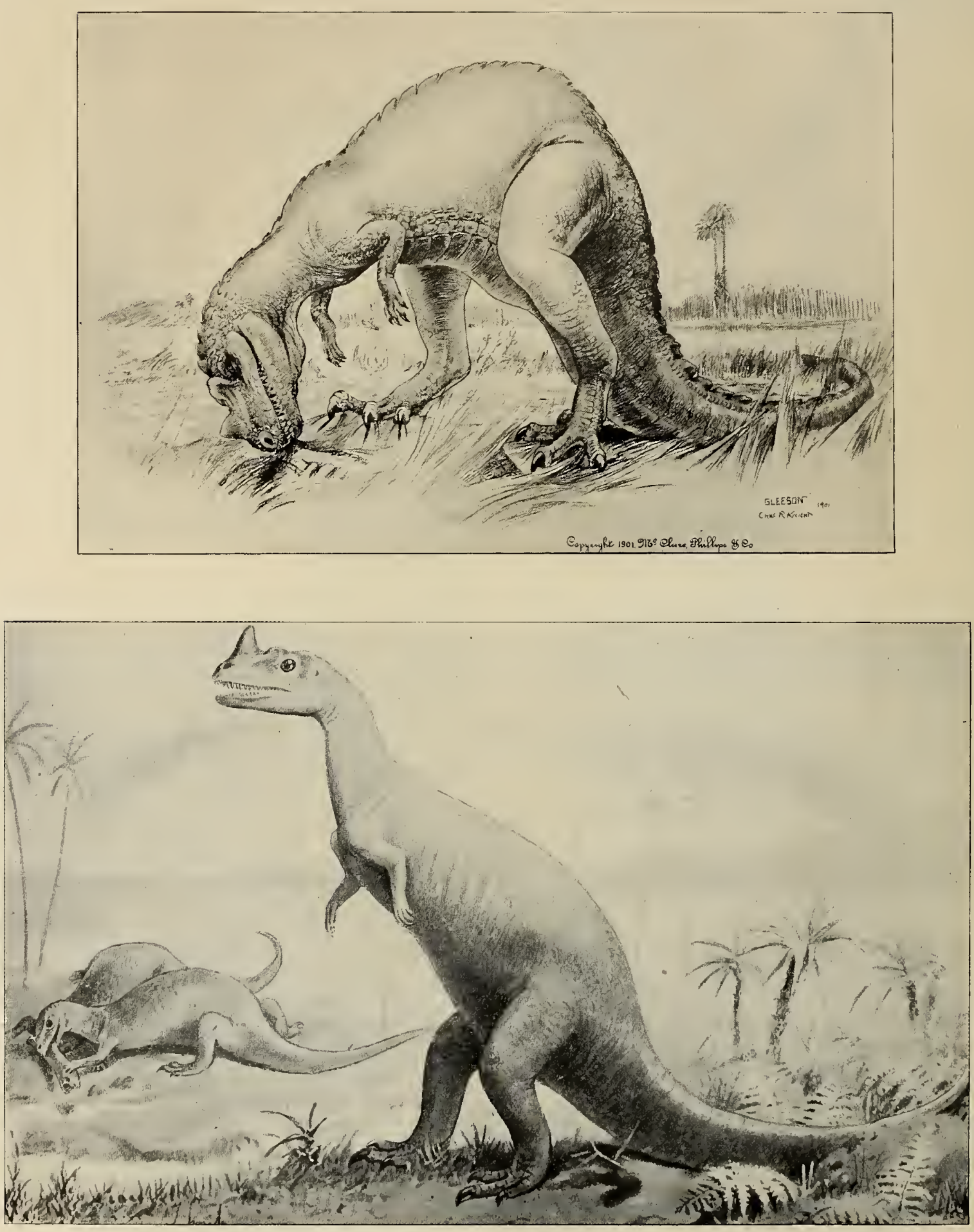

Restorations of Ceratosaurus nasicornis Marsh.

FOR EXPLANATION OF PLATE SEE PAGE 153 


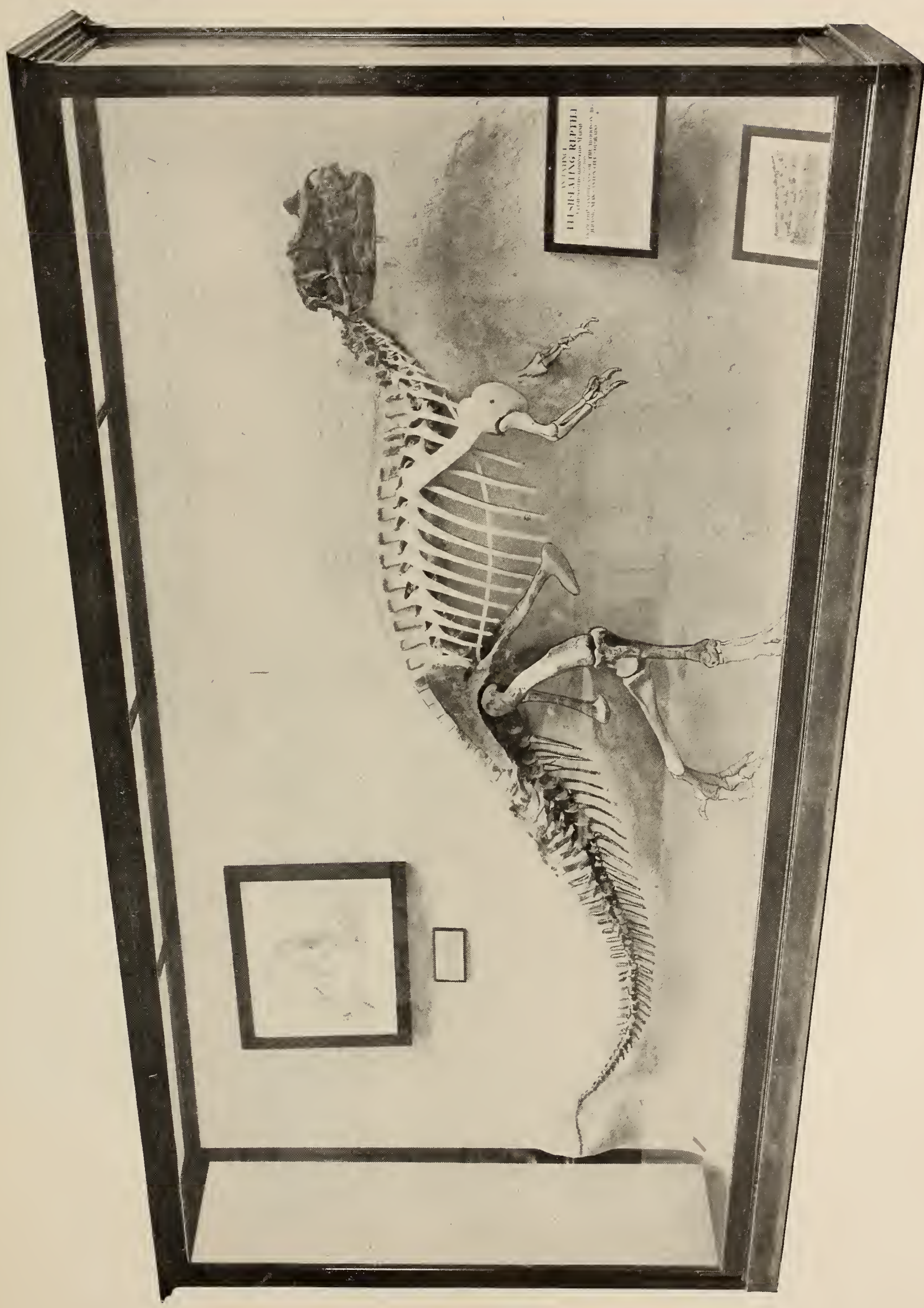




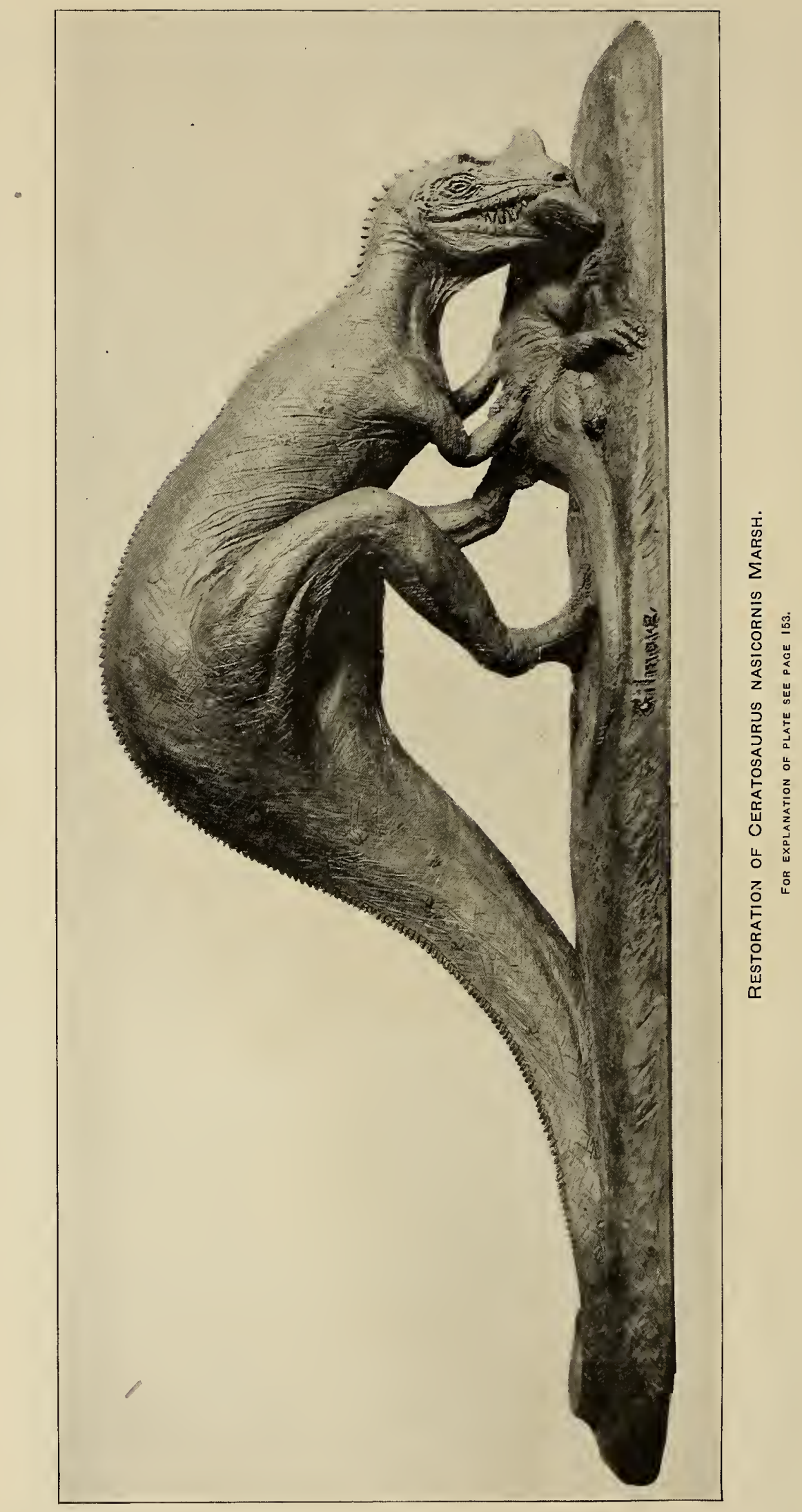






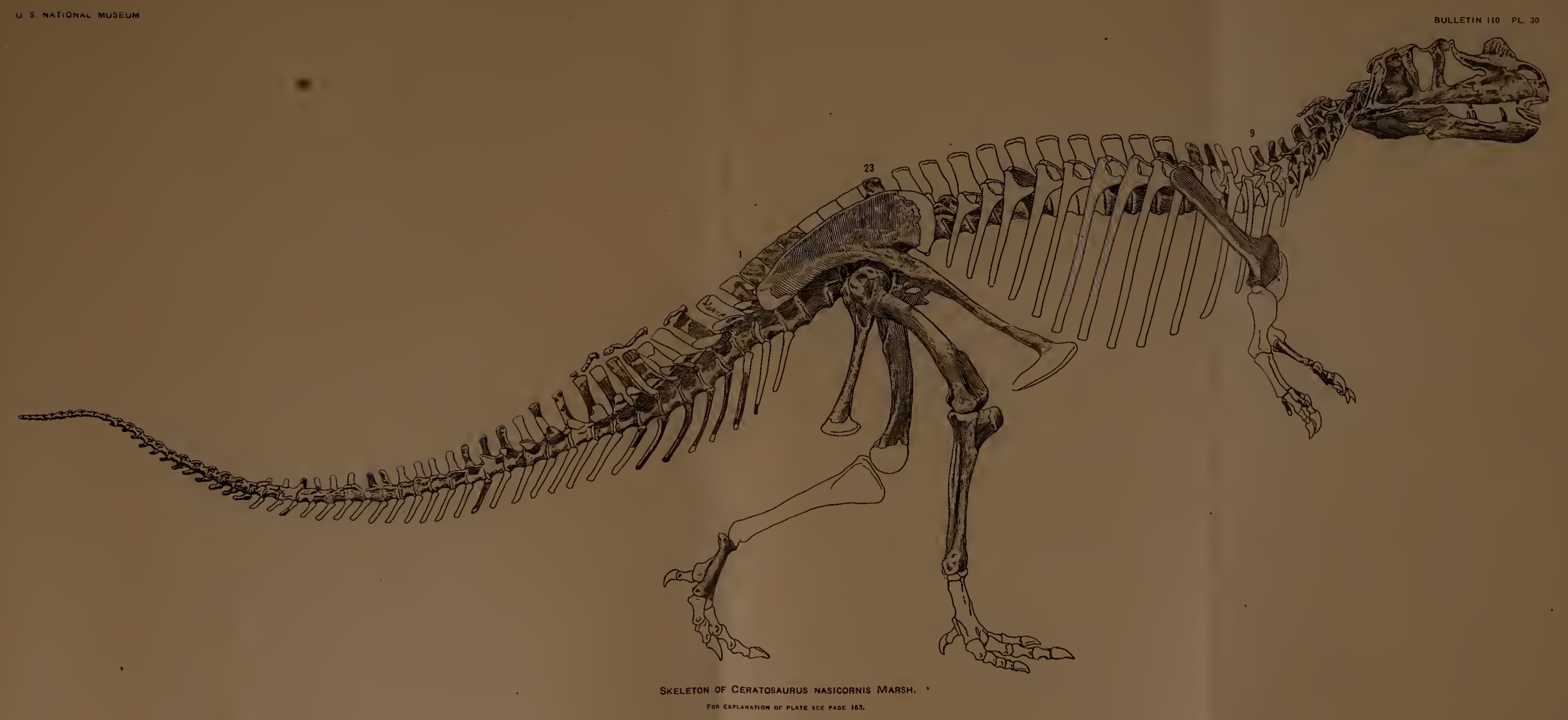





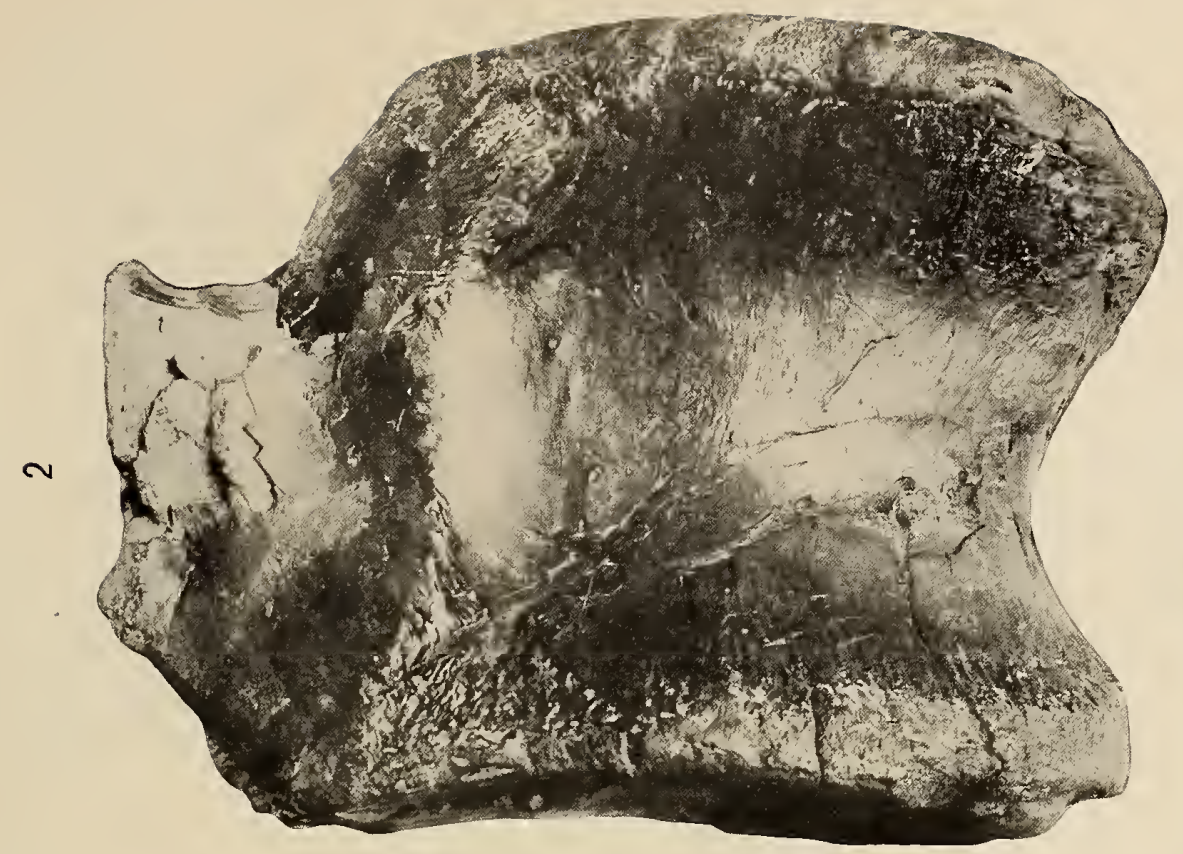




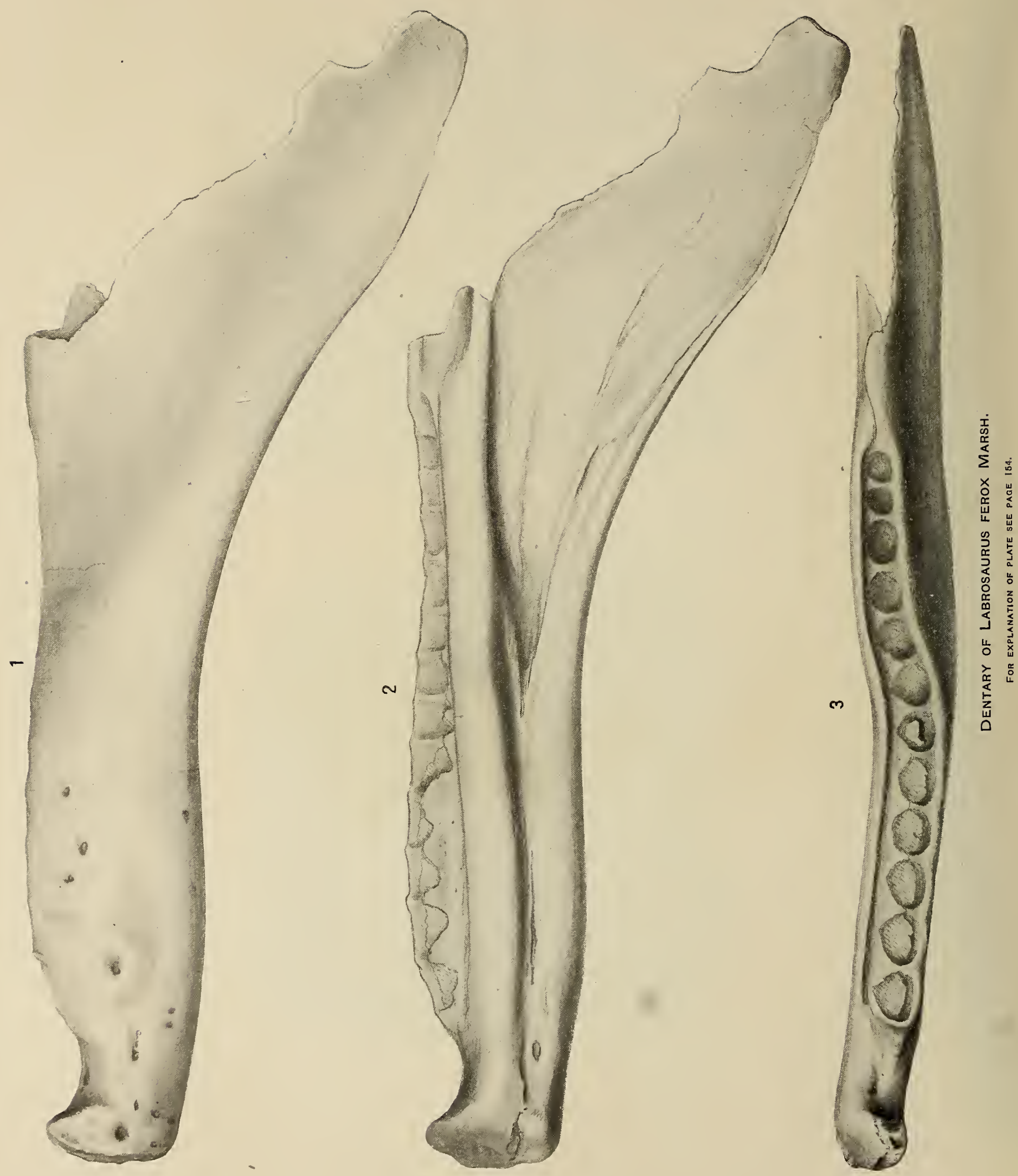



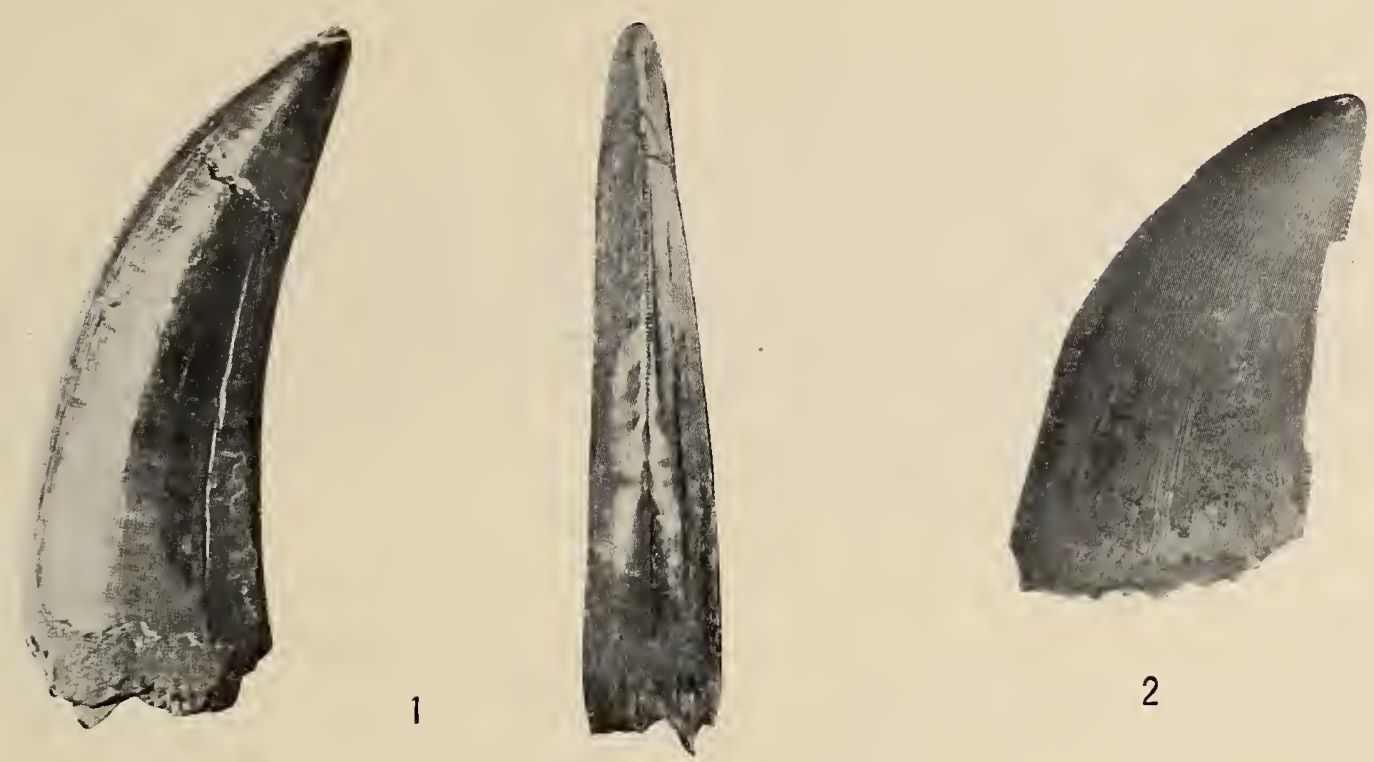

2
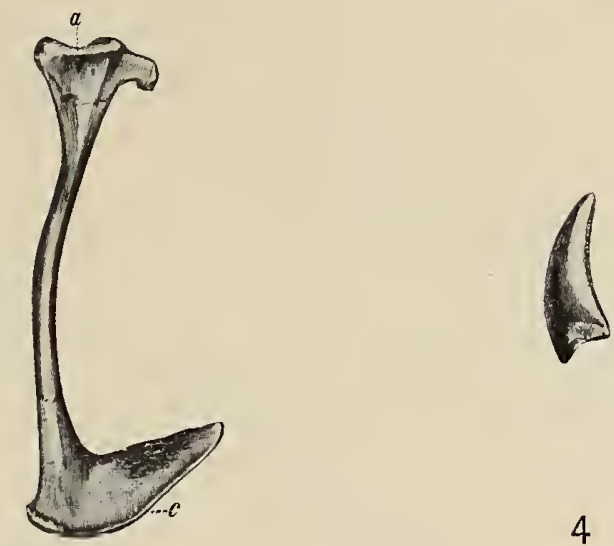

4

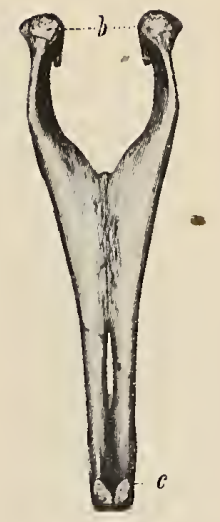

5

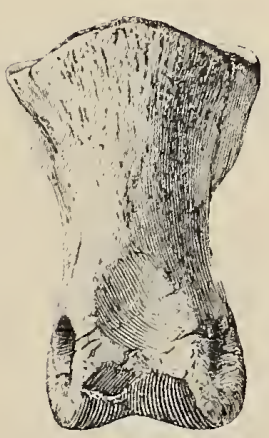

3

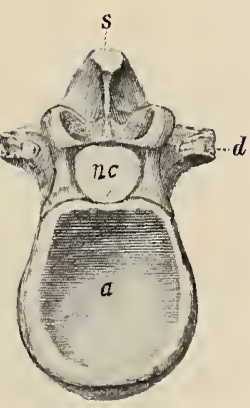

7

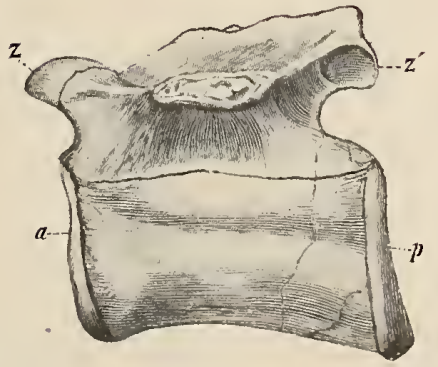

8

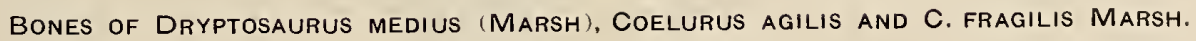
For explanation of Plate see Page 164. 


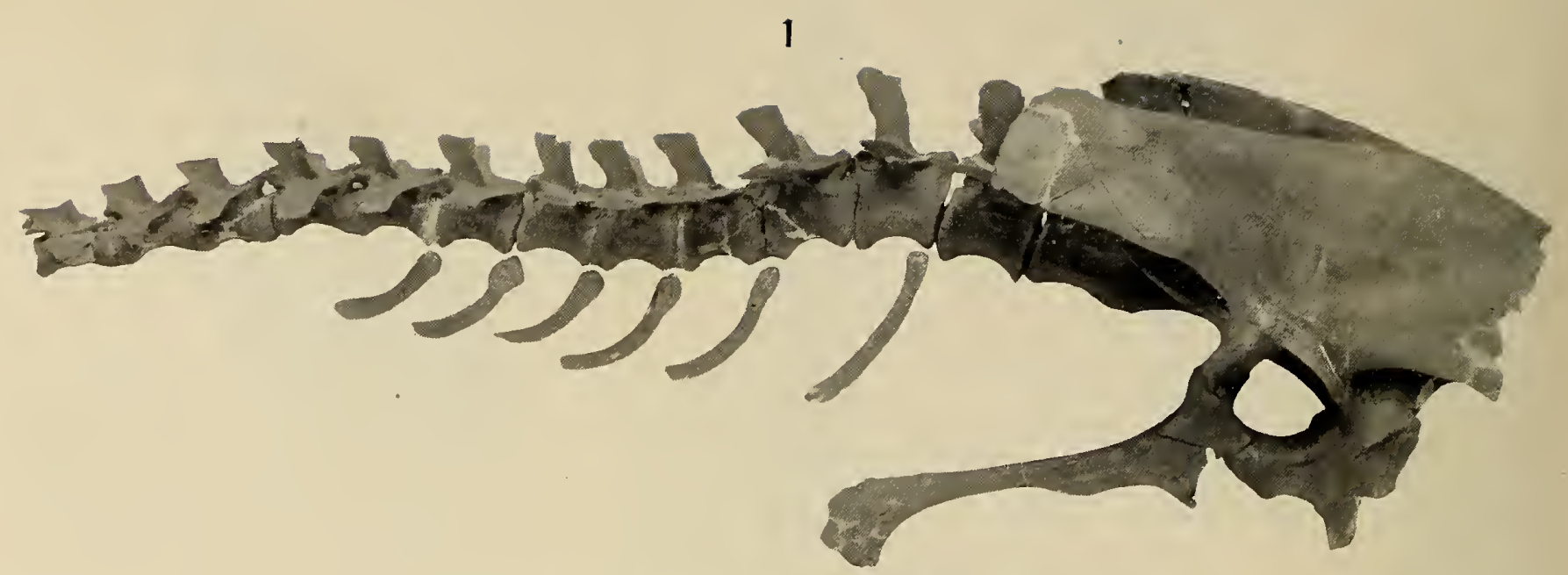

Pelvis and Caudals of ORNithomimus sedens Marsh.

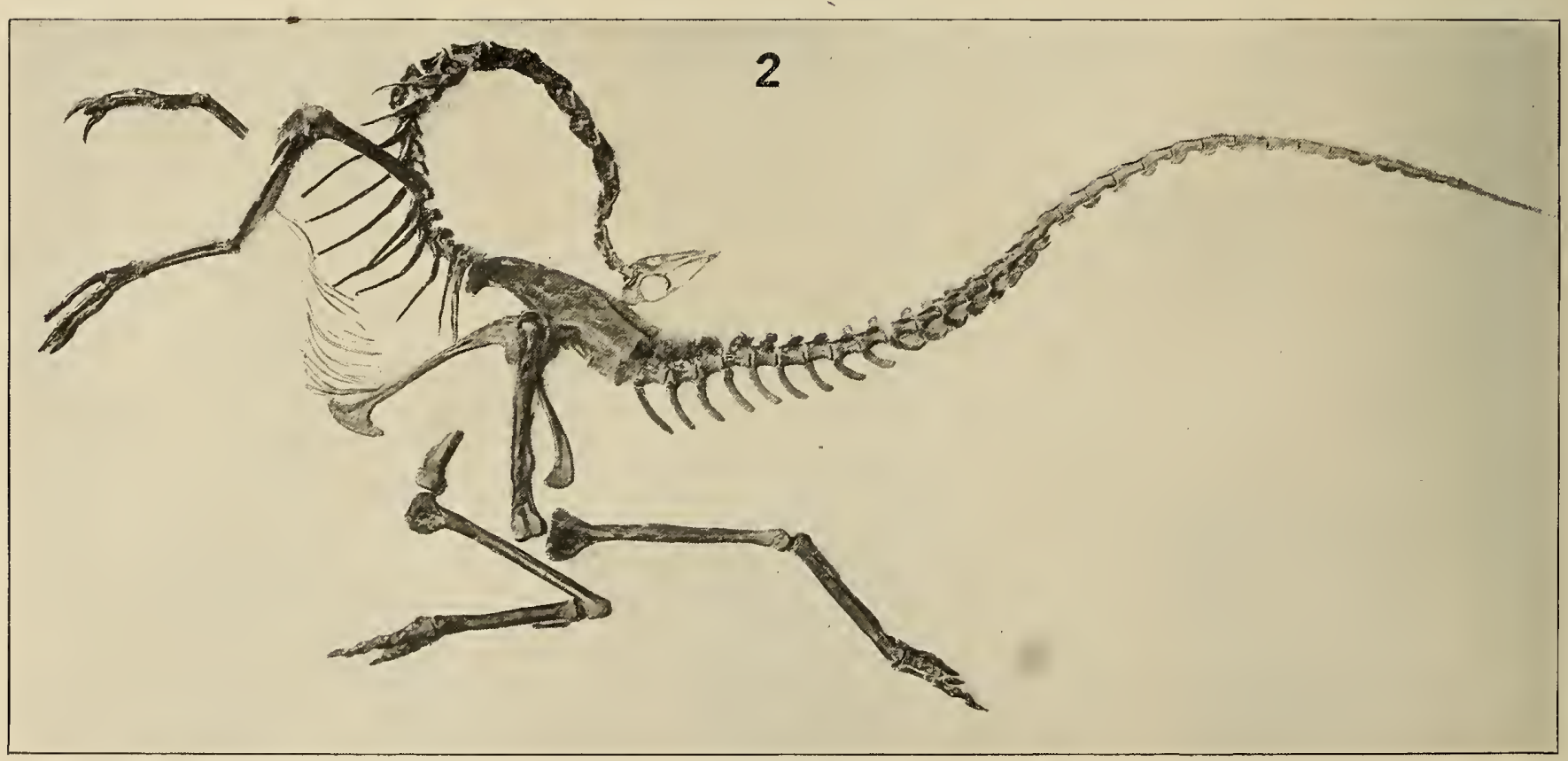

SKELETON OF ORNITHOMIMUS ALTUS LAMBE.

For EXPLANation OF PLATE SEe Page 154. 


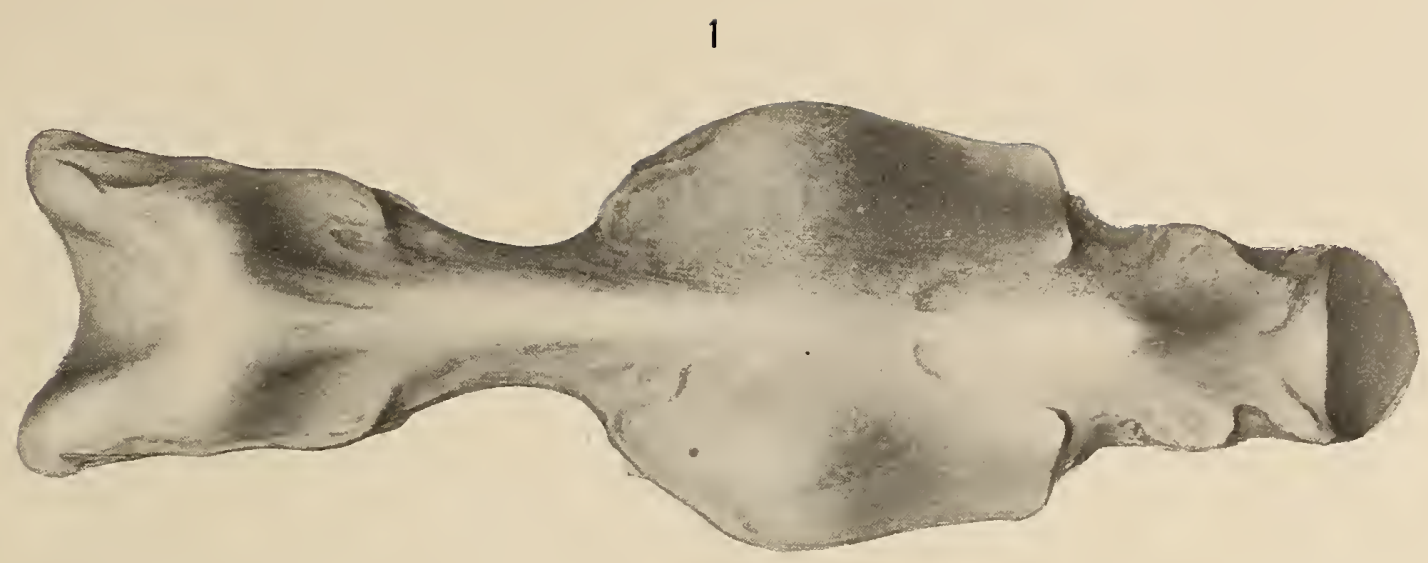

2
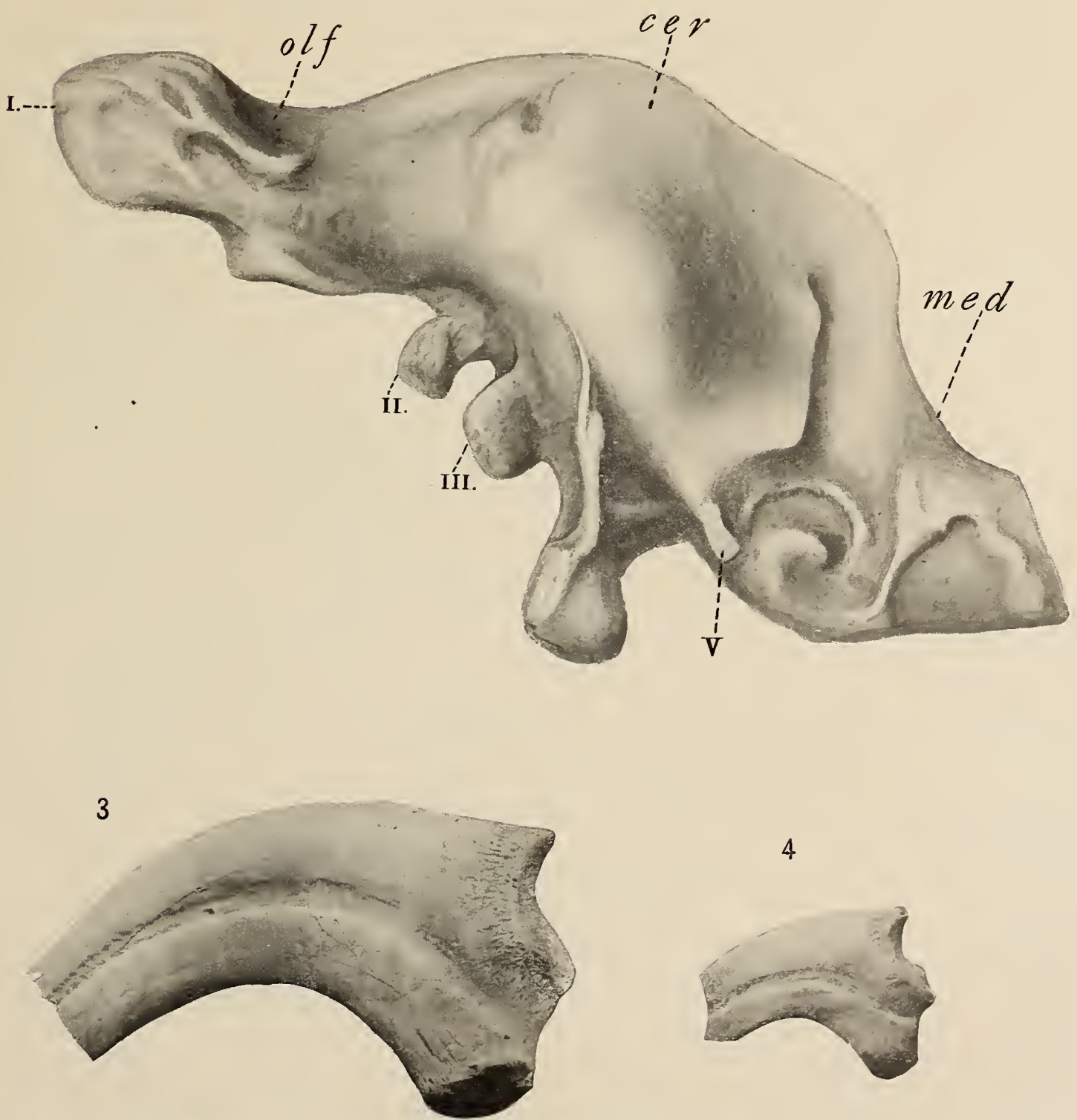

4

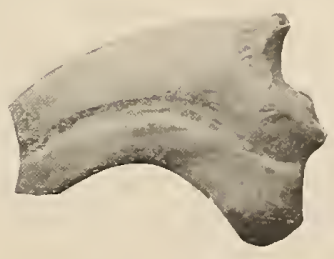

Brain of Ceratosaurus nasicornis; Unguals of Coelurus gracilis Marsh and Unidentified Dinosaur. for explanation of plate see page 154. 



\section{N DEX.}

[Figures in BLACK-FACE type indicate descriptions.]

\begin{tabular}{|c|c|}
\hline $\begin{array}{c}\text { A. } \\
\text { Acetabulum } \ldots \ldots \ldots \ldots \ldots \ldots \ldots \ldots \ldots \ldots\end{array}$ & 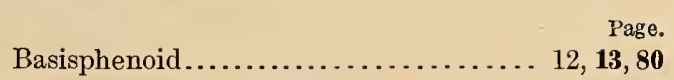 \\
\hline Albertosaurus. ...................... 90, 124 & Bauer, G., on quadrate foramen........... \\
\hline sarcophagus Osborn............... & Bavaria, fossils from...$\ldots \ldots \ldots \ldots \ldots$ \\
\hline isphenoid............ 12, 13, 14, 17, 29, 79 & Beeson, L. M., photographs by ........... \\
\hline kali Creek. ..................... 122, 131 & Belly River formation.............. \\
\hline Allosaurus. ... 4-7, $9,10,20,55-57,83,117,118,125$ & $64,82,127,130,131,137,145,146$ \\
\hline agilis. ....................... & Berger, Frederick, drawings by............ \\
\hline ferox $\ldots \ldots \ldots \ldots \ldots \ldots \ldots \ldots \ldots \ldots \ldots$ & Bibbins, Arthur, fossils collected by ..... 119, 137 \\
\hline fragilis............... 1, 3-5,55, 102, 120 & ns found near....... \\
\hline lucarius........................ 124, 125 & tion by. \\
\hline$\ldots \ldots 1,121,137,139,140$ & Boss, N. H., work of. ....... \\
\hline $\begin{array}{l}\text { eum of Natural History, speci- } \\
, 34,49,56,58,64,93,127,137,141,142\end{array}$ & 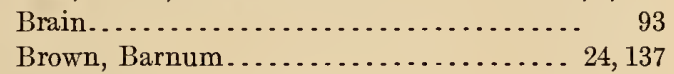 \\
\hline ias fragillissimus Cope........ 127 & Brown, Fred, specimens collected by...... \\
\hline 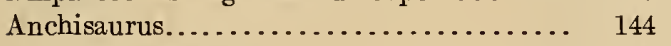 & \\
\hline $\operatorname{csh} \ldots \ldots \ldots . . .$. & C. \\
\hline ......... & Calcaneum. \\
\hline . $8,25, \mathbf{2 6 , 8 9 , 9 0}$ & Camptosaurus.. \\
\hline 29 & nanus........................... \\
\hline Antiorbital. & Canon City, Colorado, fossil specimens found \\
\hline $\begin{array}{l}\text { Antrodemus. } \\
\qquad \begin{array}{r}7,10,12,17,18,20,22,24-26,28 \\
32,37,43,45,46,48-50,53,55-58 \\
60,61,64-66,68-74,76,78-85,87 \\
88,92,93,95-98,102-105,107-114 \\
118,120,128,133,139,140,144-146\end{array}\end{array}$ & 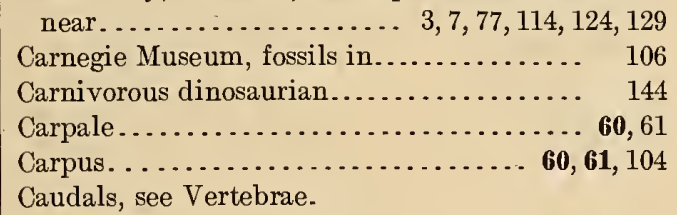 \\
\hline materials ............... 7 & 132 \\
\hline & ontanus.... \\
\hline $3-5,7,9,29,31,48,67$ & . \\
\hline $68,84,102,117,120,124$ & uridae, family characters....... \\
\hline rmula.................. & $\begin{array}{r}\text { Ceratosaurus......... } 14,15,20-26,28-32,35,41 \text {, } \\
43-46,49,53,55,56,58,64-66,68-70,76-\end{array}$ \\
\hline (n) & 108,110 \\
\hline pteryx.................... 112 & $128,132,133,145-6$ \\
\hline$\ldots \ldots \ldots \ldots \ldots 26,27, \mathbf{2 8}, \mathbf{9 0}, \mathbf{9 1}$ & leton. 114-115, 116 \\
\hline ion.... $1,116,117,11$ & orations.......... 115, 116 \\
\hline$\ldots \ldots \ldots \ldots 69-72,73,110,111,112$ & aracters... \\
\hline Atlas...................... 31, 32,94,95 & nasicornis Marsh .................... 1, 9 , \\
\hline Axis...................... 32, 33, 34,95 & $\begin{array}{l}14,20,26,29,31,48,56,59,64,66,76 \\
78,80,82-84,92-94,106,112,113,115\end{array}$ \\
\hline & $\begin{array}{l}4,100 \\
\ldots . . .\end{array}$ \\
\hline & Vertebrae. \\
\hline Basioccipital & $48,100,101$ \\
\hline
\end{tabular}




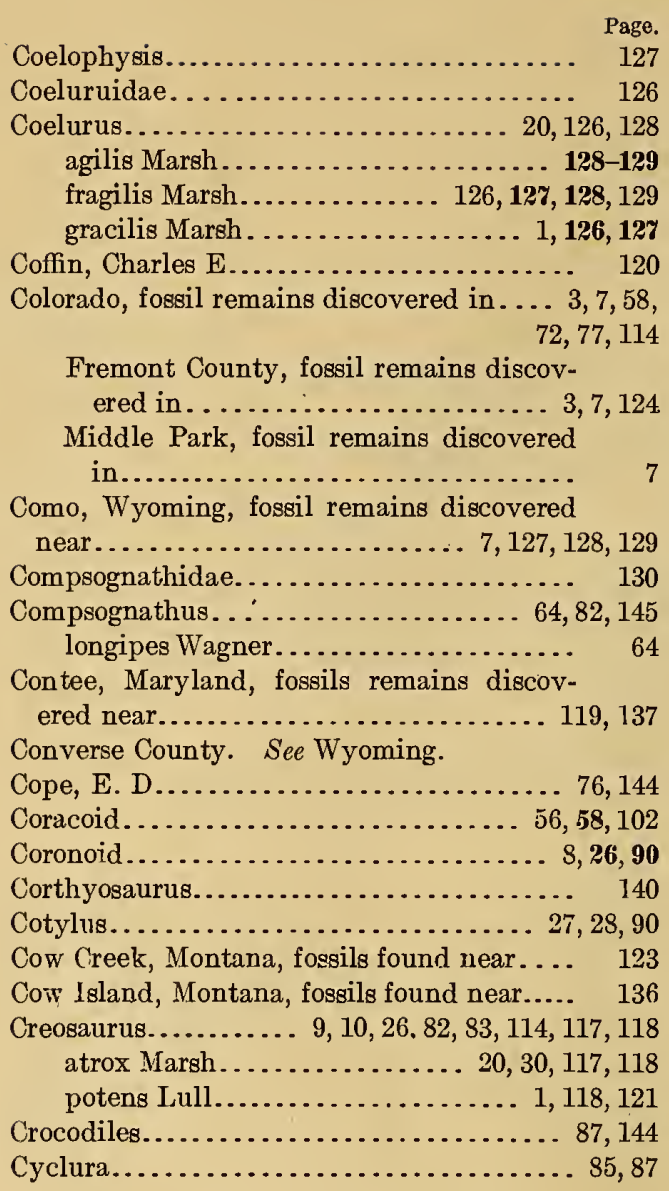

D.

Deinodon....................... 123, 124 grandis (Marsh)............... 1, 122, 131 horridus Leidy..................... 124

Deltoid ridge.................... $\quad \boldsymbol{6 9}$

Dental rugosae...................... $\quad 89$

Dentary.................... 25, 88, 89, 90

Denver formation................ 129-131, 137

Dermal armor...................... 113, 114

Diplodocus..................... 83, 87, 106

Dorsals. See Vertebrae.

Dryosaurus..................... 119, 137, 139 altus Marsh..................... 138

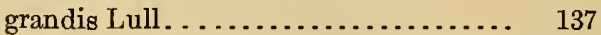

Dryptosaurus............ 70, 119, 120, 121, 124 acquinlungus Cope................. 119 incrassatus Cope.................. $\quad 36$ medius (Marsh) .................. 119-121 potens (Lull) ................ 116-119, 121

Dynamosaurus imperosus Osborn........ 123
E.

Page.

Eagle sandstone, fossils found in ....... 123, 131 Ectopterygoids..................... 8, 24

Edmonton formation, fossils from.......... 137

Epipterygoid...................... 85

Ethmoid........................ 14, 80

Eustachian canal...................... 13,80

Exoccipital. ................... 11, 12, 79

External mandibular foramen......... 88,89

F.

Farmington, New Mexico, fossils found near 124

Felch, Charles E., letter from........... $\quad 77$

Felch, M. P., fossil remains collected by ... 7,77 , $114,124,129$

Femur....................... 68, 108-110

Fergus County. See Montana.

Fibula..................... 70, 7 1, 73, 110

Foramen magnum................... 79

ovale............................. 12

Foramina for exit of cranial nerves:

second......................... 12, 14

third........................... 12, 14

fourth........................ 14

ninth......................... 12

tenth......................... 14

eleventh...................... 12

twelfth........................... 12

Fore limb and foot.............. 55-64, 103, 106

Four Mile Creek, Colorado, fossils found

near............................. $\quad 114$

Fremont County. See Coloradn.

Frontals.

$15,28,29,81$

G.

Gallinas Creek, New Mexico, fossils from... 144

Garden Park, Colorado, fossils from... 77, 114, 124

Gaupp, on adlachrymal.............. 17

Gidley, J. W., acknowledgment of assist-

ance.............................. 2

Giles, G. B., work of . . . . . . . . . . . . 2

Gleeson, J. M., restoration by ......... 113, 115

Goldberg, Louis, work of . . . . . . . . . . . . . 2

Gorgosaurus . . . . . . . . . . . . . . . . . . 30, $40,42,45,47,48,53,55,69,70,76,82$, $96,98,104,107,119,133,137,145,146$

libratus Lambe........... 26, 53,64, 99, 101

Goucher College, fossil specimens from ... 120, 121

Granger, Walter, data furnished......... 2, 24, 73

Gregory, W. K.:

on adlachrymal................... $\quad 17$

on orbitosphenoids............... 13

Gunther, on abdominal ribs............. 146 
H.

Hallopus victor Marsh.

Hatcher, J. B., fossils collected by ...... 114 $119,122,123,126,131,135,137$

Hay, O. P., acknowledgment of assistance given. . . . . . . . . . . . . . . . . . . . . . on Allosaurus fore limb............. 56 on Creosaurus................... 117, 118 on figures after.................. 86 on Lah,rosaurus ferox............... 124, 125 on lower jaw Ceratosaurus. . . . . . . . . . on palate of Ceratosaurus............ 81-88 on prearticular of Ceratosaurus........ on quadrate foramen of Ceratosaurus.. $\quad 84$ on second antiorbital fenestra......... 83 on splenial of Ceratosaurus. . . . . . . . . 89 on work of . ................... $78,80,81$ Hayden, F. V., fossil specimen collected by . $\quad 6,7$ Hell Creek, Montana................... 130 Hind $\operatorname{limb}$ and foot. . . . . . . . . . . 65-75, 108-113 Humerus . . . . . . . . . . . . . . . . . . . . . 58, 59

Hutchinson, H. N................. 116 Hyoid............................. 92 Hypocentrum ...................... $\quad 33$

Hypsilophodon..................... 140

I.

Iguanodon......................... 140 Ilinm. .................. 43, 65, 66, 106, 108 Intercentrum..................... 31, 94 Intermedium...................... 60-62 Ischium 67, 68,108

J.

Jurlith River formation. .. 130, 131, 136, 137 Jugal. $8,18,21,22,81,83,84$

K.

Kansas University, fossil specimens in..... 56 Kennedy, Ed., fossils collected by........ 7 Kirtland formation, fossils from.......... 1.23 Knight, Charles R., restoration by ..... . . 113, 115 Knight, W. C., restoration under direction of 115

I.

Labrosaurus...................... 34, 124 ferox Marsh.................. 1, 124-126 fragilis Marsh................... 125 sulcatus Marsh.................... 125 Lachrymal........... 15, 17, 19, 22, 81, 82, 85 Laelaps........................ 144 Lakes, Arthur, fossils collected by......... 114 $144035^{\circ}-20-12$
I

Lambe, L. M. Page.

on abdominal ribs. .................

oll frorgosaurus.................... 64

on Ornithomimus.............. 130, 142

Lance Creek, Wyoming. .............. 122, 127

Lance formation. 82, 122, 123, 130-132, 137, 143, 145

Laosaurus consors Marsh................ $\quad 140$

Lateral, temporal fossa................ 22, 28

Leidy, Joseph, on Antrodemus valens... 2, 5, 6, $\mathbf{7}$

Lower jaw........................ 88

Iucas, F. A......................... 115

Lull, R. $\$$...................... 4, 118 on Allosaurus medius Marsh. 119, 129, 121, 111 on Coelurus agilis Marsh. . ......... 129 on Coelurus fragilis Marsh.......... 127, 128 on Coelurus gracilis Marsh........... $\quad \mathbf{1 2 6}$ on Creosaurus potens Lull.......... 116, 117 on Dryosaurus grandis Lull...... 138, 139, 140 on occurrence of fossils.............. 3 on Ornithomimus minutus Marsh..... 143

Lydekker, R...................... $\quad 76$

M.

Mandibular foramen................... 26, 27 Marsh, O. C., drawings under direction

of...................... 2, 97, 100, 115 figures by ........ 20,65, 75, 96, 99, 107, 137 fossil collections of................ 2 on Allosaurus medius Marsh.......... 119 on Ceratosauridae.................. 76 on cervical vertebrae................ 95 on fore $\operatorname{limb} . \ldots \ldots \ldots \ldots . . . \ldots . . .56-58$ on hyoid....................... 92 on Labrosaurus ferox Marsh........... 124 on metatarsals.................... 76,112 on Onithomimus grandis Marsh ..... 122, 123 on Ornithomimus minutus Marsh.... 142, 143 on Ornithomimus sedens .Marsh...... 131, 132 on pubis........................ 67 on quadrate..................... 84 work of. $78,83,85,94,96,106,108,129,130,136$ Maryland, occurrence of fossils.......... 1 Matthew, W. D., on vertebral formula of Allosaurus...................... 93 Maxillary........ 8, 20-22, 29, 81, 83, 85, 87, 92 Megalosauridie.................. 116, 130, 144

Megalosaurus................. 6, 76, 82, 146 nasicornis (Marsh) ................. $\quad 77$

Merrill, G.P., acknowledgement of assistance given.......................... 2 Metacarpals............................. 61 measurements of................ 63 Metacarpus................ 61, 92, 104, 105 
Page,

Metatarsus

nieasurements of............ 75, 106, 113 iddle Park, Colorado, fossil specimens from.

Montana, Ferguis County, fossil specimens

from.......................... 123

orrison formation. . . . . . . . . . . . . . . . 64

udge, B. F., fossils collected by ..... . 3, 77, 114

Muirkirk, Maryland, fossils found near.119, 120, 126

Murphy, J. K., fossils collected by ....... 116

\section{N.}

Nasal hor

$15,18,19,8$

Nasals

Neuropophyses..................... 31, 32,94

Niobrara County, fossils from. See Wyoming.

O.

Obturator process. . . . . . . . . . . . . . 68

Occipital condyle. . . . . . . . . . . . . . . . 10, 11

Odontoid........................ 32,94

Oil Creek, Colorado, fossils from . ........ 114

Olecranon process..................... 59, 103

Orbital opening.................... $\quad 28$

Orbitosphenoid................... 12, 13, 14

Ornithomimid . . . . . . . . . . . 1, 121, 137, 140, 141

Ornithomimidae. . . . . . . . . . . . . . 129, 132, 137

Ornitholestes. ..... 20 20, 55, 61, 64, 82, 128, 136, 145

hermanni................ 59, 61, 64, 126

Ornithomimus...................... . . 47,

$59,61,107,123,129-132,135,137,138,142,145$

affinis Gilmore. . . . . . . . . 1, 121, 131, 137-142

altus Lambe. . . . 64, 130-132, 134, 135, 137-14?

grandis Marsh..... . . . . . . . . 1, 121, 122, 129, 131

minutus Marsh.... . . . . . . . . 1, 129, 131, 142-144

sedens Marsh. . . . . 1, 129, 130, 131-135, 141, 142

tenuis Marsh... . . . . . . . . . 1, 129, 131, 13j-137

velox Marsh . . . . . . . . . . 129-131, 136, 137, 143

Ornithopoda...................... 129

Osborn, H. F...................... 40. 40.

on abdominal ribs............... . 53

on Deinodon.......................... 123

on dentary .......................

on hallux....................... $\quad 73$

on lachrymal. . . . . . . . . . . . . . . . . . 17

on maxillary ................... 20,22

on Ornitholestes................... 128

on Ornithomimus. ........... 130, 132, 135

on postfrontal, postorbital complex... 16,81

on prearticular................. 28

on presplenial.................... 26, 89

on Theropod skull..................... 144

on Tyrannosaurus. . . . . . . . . . . . . . . . 112

work of.................. 9, 10, 12, 14
Page.

Ossicles......................... 113

Osteology of Antrodemus............. 7-75

Osteology of Ceratosaurus..... . . . . . . . . . 78-114

Ottawa Museum, fossils in.............. 131

\section{P.}

Palate................................ 84-87

Palatine........................... 85, 86

Para.occipital. ............... 11, 12,79

Parasphenoid..................... 13,80

Parietal................ 12, 14, 15, 17, 29, 80,81

Peabody Museum, fossil specimens in ... 3, 56, 64

Pelvis. ......................... 65, 106 of Ornithomimus sedens Marsh....... 135

Phalanges, fore foot. . . . . . . . . 6. 62, 63, 105, 106 measurements of .................... 63

Phalanges, hind foot................. 74-75

measurements of. .................. $\quad 75$

Phytosauridae............................. 144

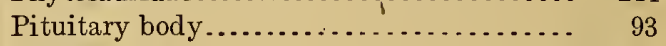

Plateosaurus........................... 144

Pleurocoelus........................ 141

Poicilopleuron................... 2,6 bucklandi...................... 6 valens Leidy ................... 2, $5, \mathbf{6}, \mathbf{7}$

Postfrontal....................... 16, 81,85

Postorbital.................... 16, 29, 80, 81

Postpalatine vacuity ................ . 85,87

Prearticular.................. 26, 28,90,91

Prefrontal ....................... 8, 15, 16, $8 \mathbf{1}$

Premaxillary.......... 8, 18, 19, $\mathbf{2 0}, 29, \mathbf{8 2}, \mathbf{8 3}, 92$

Presphenoids....................... 13

Priconodon........................ 141, 142 crassus Marsh...................... 141

Prince Georges County, Maryland, fossils from $119,121,126,137$

Proötics.................. 11, 12, 13, 16, 17, 19

Pterygoids.................. . 8, 13, 23, 24, 84-87

Pubis......................66, 67, 107, 108 of Ornithomimus sedens Marsh........ 135

Q.

Quadrate................... 8, 22, 23, 78, 84, 87

Quadrate foramen..................... 23, 28

Quadratojugal.................. 8, $22, \mathbf{2 3}, \mathbf{8 3}$

Quarry No. 1, fossils from. 7, 58, 72, 77, 114, 124, 129

Quarry No. 9, fossils from.............. 7,127

Quarry No. 13, fossils from............... 129

Quarry C, fossils from.................... 7 map of............................ 38

Quarry D, fossils from $\ldots . . . \ldots \ldots \ldots \ldots \ldots . .7$

Quarry "Bone Cabin," fossils from...... 9, 93, 128

Quarry Peterson's, fossils from........... 143 
R.

\section{Radiale}

Radius........... 56,60, 103, 104

Red Deer River, Canada, fossils found near. $\quad 130$

Reed, W. H., fossils found by........... 128, 129

Reeside, J. B., jr., fossils found by ........ 123

Ribs............................ 48, 101

abdominal.................... 53-55, 10?

cervical........................48-50

thoracic................50-53, 101, 102

s.

Sacral ribs........................... 44

Sacral vertebrae............... 43-45, 97, 98 measurements of................... 45

Sacrum ........................... 65 of Ornithornimus sedens Marsh..... 132, 133

San Juan River, New Mexico, fossils found

on.............................. 123

Sauropoda................ 44, 65, 66, 82, 106

Scapula........................ 57, 58, 102

Scelidosaurus.......................... 140

Second antiorbital fenestra............. 29

Shoulder girdle....................... 102

Slcull of Antrodemus..................... 7

of Ceratosaurus..................... 78

Sinit, T., restoration by .................. 116

Sphenodon................... 24, 85, 87, 146 punctatum....................... 146

Splenial. . . . . . . . . . . . . . . . . . . . 8, 25, 26, 89, 90

Squamosil.................. 11, 23, 24, 29, 84

Stegosaurus...................... 140, 141, 1.42

ungulatus Marsh................... 14]

Struthiomimus..........61, 64, 82, 130, 135, 136 tenuis (Marsh)................... 135

Sullins, A. E., fossils collected by........ 122, 131

Supradentary .................... 25, 89,90

Supraoccipital.................... 12, 79

Supratemporal fossa............... 14, 29, 80

Surangular............. 25, 26, $27,28,89,91$

T.

Tarsalia

Tarsiss.
Page.

Teeth....................... 29-31,92, $\mathbf{9 3}$

Theropoda. 1, 2, 24, 76, 79, 82, 83, 106, 112, 129, 144 .

Thescelosaurus..................... 139, 140

Tibia...................... . 69-71, 72,110

Torosaurus zone..................... 130

Trachodon..................... 130, 139, 140

Transverse bone.................... 85, 87

Triassic.................. 64, 66, 76, 144

Triceratops zone.................. 130, 140

Trigeminal nerve.................... ${ }_{12}$

Tyrannosaurus.................... 12-17, $20,22,23,25,26,28-30,37,40,42,43,45$, $53,65,66,69,76,78-84,87-91,95,96,98,101$, $107,112,117,119,121-123,133,136,144,145$ rex Osborn................. 9, 26,93,121

U.

Ulna . . . . . . . . . . . . . . . . 56, 59, 60, 103

Ulnare..........................

Utterback, W. H., fossils collected by...... 114

V.

Vertebral column................... 31, 93 caudals ............45-47, 98-100, 133-135

cervicals .................. 34-36,95,96

dorsals................. 36-43,96, 97

formula....................... 31

Vomer...................... $85,86,87$

W.

Weber, Rudolph, drawings by........... 2

Williston, S. W., on Creosaurus......... 118 on fore $\operatorname{limb} \ldots \ldots \ldots \ldots \ldots \ldots 57,58,117,118$ work done..................... 114

Wyoming, Albany County, fossils from... . 7, 129 Converse County ................ 131 Niobrara County ......... 122, 123, 131, 143

Y.

Yale Museum, specimens in... . . 4, 131, 136, 143

$\mathrm{Z}$.

Zittel, K. A., on Megalosauridae.......... 2 on Ornithomimidae............. 129, 130 






SMITHSONIAN INSTITUTION LIBRARIES

|||||||||||||||||||||||||||||||||||||||||||||||||||||||||||||

$\begin{array}{llll}3 & 9088 & 00733 & 9526\end{array}$ 